\title{
PLUVIUS: A Generalized One-Dimensional Model of Reactive Pollutant Behavior, Including Dry Deposition, Precipitation Formation, and Wet Removal
}

Second Edition

R. C. Easter

J. M. Hales

November 1984

Prepared for the U.S. Enviornmental Protection Agency under a Related Services Agreement with the U.S. Department of Energy Contract DE-AC06-76RLO 1830

Pacific Northwest Laboratory Operated for the U.S. Department of Energy by Battelle Memorial Institute 


\title{
DISCLAIMER
}

This report was prepared as an account of work sponsored by an agency of the United States Government. Neither the United States Government nor any agency thereof, nor any of their employees, makes any warranty, express or implied, or assumes any legal liability or responsibility for the accuracy, completeness, or usefulness of any information, apparatus, product, or process disclosed, or represents that its use would not infringe privately owned rights. Reference herein to any specific commercial product, process, or service by trade name, trademark, manufacturer, or otherwise, does not necessarily constitute or imply its endorsement, recommendation, or favoring by the United States Government or any agency thereof. The views and opinions of authors expressed herein do not necessarily state or reflect those of the United States Government or any agency thereof.

\author{
PACIFIC NORTHWEST LABORATORY \\ operated by \\ BATTELLE \\ for the \\ UNITED STATES DEPARTMENT OF ENERGY \\ under Contract DE-AC06-76RLO 1830
}

Printed in the United States of America Available from

National Technical Information Service United States Department of Commerce 5285 Port Royal Road

Springfield, Virginia 22161

NTIS Price Codes

Microfiche A01

\begin{tabular}{cr} 
Printed Copy & \multicolumn{1}{c}{$\begin{array}{c}\text { Price } \\
\text { Codes }\end{array}$} \\
$001-025$ & A02 \\
$026-050$ & A03 \\
$051-075$ & A04 \\
$076-100$ & A05 \\
$101-125$ & A06 \\
$126-150$ & A07 \\
$151-175$ & A08 \\
$176-200$ & A09 \\
$201-225$ & A010 \\
$226-250$ & A011 \\
$251-275$ & A012 \\
$276-300$ & A013
\end{tabular}


PLUVIUS: A GENERALIZED

ONE-DIMENSIONAL MODEL OF

REACTIVE POLLUTANT BEHAVIOR, INCLUDING DRY DEPOSITION,

PRECIPITATION FORMATION, AND

WET REMOVAL

Second Edition

R. C. Easter

J. M. Hales

November 1984

This research has been funded as part of the National Acid Precipitation Assessment Program by the U.S. Environmental Protection Agency under a Related Services Agreement with the U.S. Department of Energy Contract DE-AC06-76RLO 1830

Interagency Agreement EPA-DW930059

Pacific Northwest Laboratory

Richland, Washington 99352 
Although the research described in this article has been funded wholly or in part by the United States Environmental Protection Agency (EPA), it has not been subjected to EPA review and therefore does not necessarily reflect the views of EPA and no official endorsement should be inferred. 


\section{PREFACE}

This second-edition user's manual describes Mod 5.0, the most recent version of the one-dimensional "PLUVIUS" reactive-storm simulation code. Mod 3.1 , a predecessor, was documented in the original PLUVIUS manual (Hales, 1981) approximately two years prior to this writing, and has been used rather extensively since that time. Our operating experience with Mod 3.1 during this period has led to a progressive series of improvements which have been collectively implemented in Mod 5.0, and it is appropriate at this point to document these advances for the general user community. The most important of these changes are itemized as follows:

- The numerical integration scheme has been changed to utilize cubicspline spatial differencing. This differs from Mod 3.1, which employs a generalized Crank-Nicholson technique. Temporal differencing in Mod 5.0 continues to apply a conventional Crank-Nicholson approach. This modification has substantially improved the accuracy and computational efficiency of the code. More importantly, however, it has removed an instability problem which was frequently observed with Mod 3.1 under high precipitation conditions. Termed a "static" instability by Roach (1972), this is a potential problem whenever advection terms are represented by space-centered differences. The fourth-order spline technique employed by Mod 5.0 avoids this type of differencing and thus eliminates this particular source of instability.

- An operator-splitting technique is employed with Mod 5.0, which segregates transport and reaction terms. The primary advantage of this modification lies in Mod 5.0's enhanced ability to deal with rapidly-reacting and near-equilibrium systems. Integration of reaction terms is performed using a standard/stiff code for ordinary differential equations.

- Although we refer to PLUVIUS as a one-dimensional model, it may also be used for some two-dimensional, steady-state applications. For the case where the horizontal wind speed is independent of height, the difference between the one-dimensional time-dependent problem and 
two-dimensional steady-state problem is merely a change in the frame of reference. An enhancement in Mod 5.0 allows the modeling of two-dimensional steady-state situations with wind shear--a case that cannot be treated in the one-dimensional mode.

- Some basic improvements have been made in the code's energy-balance formulation, and in the numerical procedure with which the energy balance is computed.

- A more convenient bookkeeping procedure has been implemented for problem set-up and for dealing with multiple reactive species.

In addition to the above modifications to the code itself, we have provided a refined example problem, which includes more elegant characterizations of cloud-physical processes than those given in its Mod 3.1 counterpart. The chemistry in this example is also somewhat more detailed, but has been kept sufficiently simple to avoid obscuration of salient points of the code. The user can, of course, modify and extend this example at will, depending upon his individual needs.

Mod 5.0 is a substantial improvement over its predecessor, in the sense that it is more versatile, more efficient, more accurate, and easier to use. Although this strongly implies the obsolescence of Mod 3.1, it should not be taken to suggest immediate replacement of this older code in all cases. For current, limited applications where Mod 3.1 is performing satisfactorily, the user may be well-advised to continue with his on-line code. For new or anticipated extensive uses, however, one definitely should select this later and significantly improved version.

We expect that this second-edition manual will be the last user's guide published for the one-dimensional PLUVIUS series. Our newer multi$(1,2$, or 3$)$ dimensional "PLUVIUS II" code has recently become operational, and we anticipate that this more versatile code will be documented in user's-manual form in the future, after more substantial operation experience has been obtained.

This research has been funded as part of the National Acid Precipitation Assessment Program by the U.S. Environmental Protection Agency. We sincerely thank the EPA and the American taxpayer, who have acted jointly to make this effort possible. 


\section{$\triangle B S T R A C T$}

This report is a second-edition user's manual for the PLUVIUS reactive-storm model. The PLUVIUS code simulates the formation of storm systems of a variety of types, and characterizes the behavior of air pollutants as they flow through, react, within, and are scavenged by the storms.

The computer code supplied with this report is known as PIIJVIUS MOD 5.0, and is a substantial improvement over the MOD 3.1 version given in the origina? user's manual. Example applications of MOD 5.0 are given in the report to facilitate rapid application of the code for a variety of specific uses. 


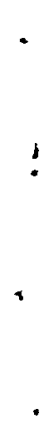




\section{CONTENTS}

PREFACE

ABSTRACT

1. INTRDDUCTION

2. FORMULATION OF GOVERNING EOIJATIONS AND BOUNDAPY CONDITIONS • 3

A. GRVERNING EQUATIONS DESCRIBING

MATFRIAL-BALANCE RELATTONSHIPS • $\quad . \quad . \quad . \quad . \quad 3$

B. INJTIAL ANM ROUNDARY CONDITIONS FOR

MATERIAL-BALANCE RELATIONSHIPS $\quad . \quad \cdot \quad . \quad . \quad . \quad . \quad 66$

C. GOVERNING EQUATION DESCRJPING ENERGY-BALANCE RELATIONSHIF $\&$

D. INITIAL AND BOUNDARY CONDITIONS FOR

THE ENERGY-RALANCE EQUATION

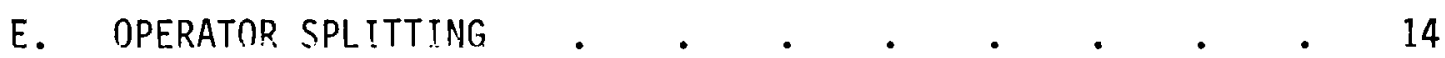

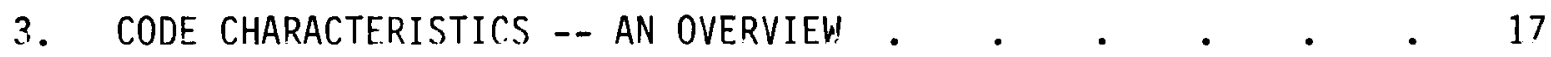

A. INITIAL RULES AND CONVENTIONS $\quad . \quad \ldots \quad . \quad . \quad . \quad$. 17

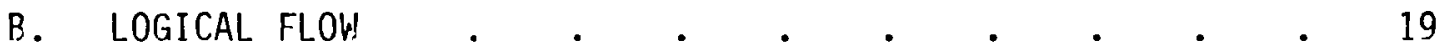

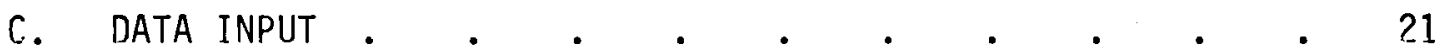

D. MODULAR CONSTRIJCTION

1. Class I Subroutines . . . . . . . . . $\quad$. 26

2. Class II Subroutines . . . . . . . . . . 33

E. "ZERO-DIMENSIONAL" TESTING FACILITY . . . . . . 33

4. EXAMPLE APPLICATION 1: SIMPLE AIR CHEMISTRY AND DRY DEPOSITION 37

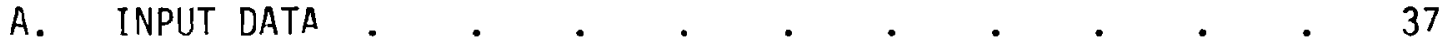

B. CLASS I SIJBPOITINE DESCRIPTIONS • • • • • • $\quad$ • 40

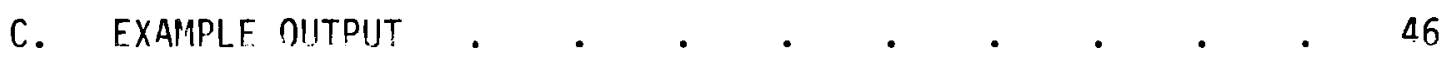


5. EXAMPLE APPLICATION ?: REACTIVE SCAVENGING

IN AN ORDGRAPHIC STORM . . . . . . . . . . 55

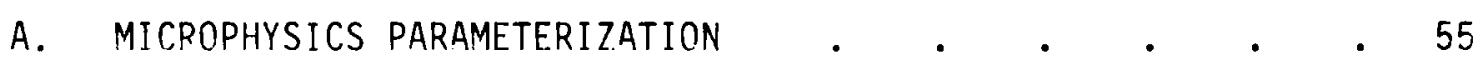

1. Water Species Classification Scheme . . . 55

2. Precipitation Formation Mechanisms . . . . 59

3. Precipitation Fallspeeds . . . . . 63

B. CHEMISTRY PARAMETERIZATION

1. Aerosol Scavenging . . . . . . . 68

2. Nonreactive Gas Scavenging . . . . . . 68

3. Aqueous Phase Chemical Transformation . . . 71

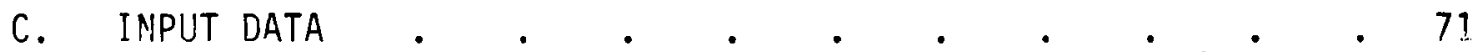

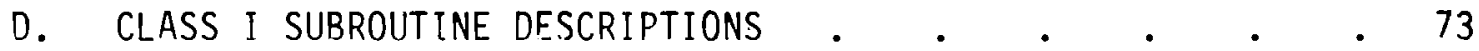

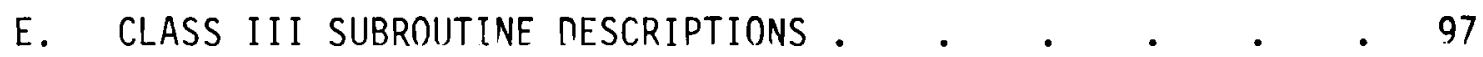

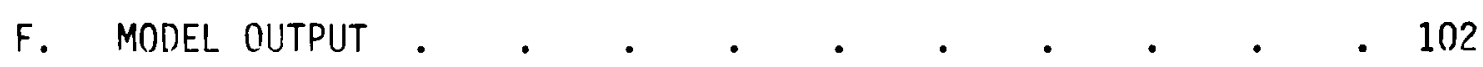

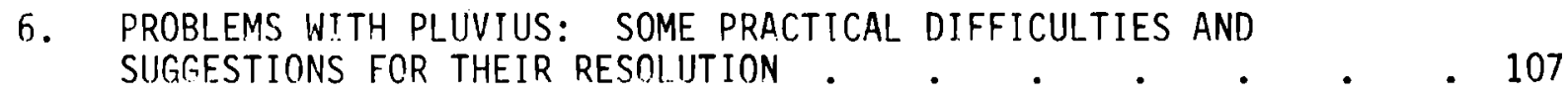

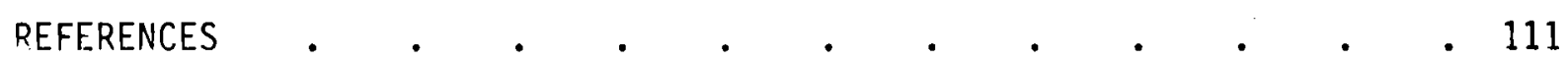

APPENDIX A - FINITE DIFFERENCE APPROXIMATION FOR TRANSPORT TERMS - A-1

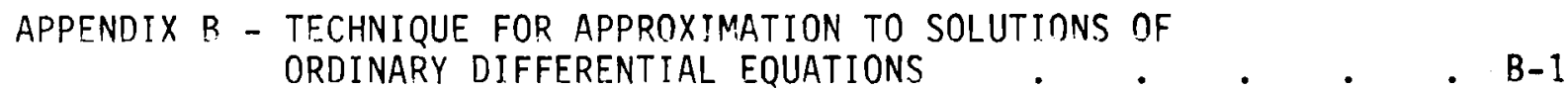

APPENDIX C - PLUVIUS MAIN PROGRAM AND CLASS II SUBROUTTNE LISTINGS • C-1

APPENDIX D - EXAMPLE APPLICATION 2 MODEL OIJTPIJT LISTINGS • • • D-1 


\section{FIGURES}

4-1 Results of Example 1 Computations at TCLOCK $=3500$ Seconds . . 53

5-1 Illustration of the Orographic Storm in Example Application 2 . 56

5-2 Interaction Diagram for Water Categories . . . . . 60

5-3 Interaction Diagram for Sulfur Species . . . . . . 67

5-4 Distributions of Cloud Water, Rain and Snow in . . . . . 103
Example Application

5-5 Distributions of Total $\mathrm{SO}_{2}$, Total $\mathrm{SO}_{4}$, and Total $\mathrm{H}_{2} \mathrm{O}_{2}$ Mixing
Ratios in Example Application 2

5-6 Rain Rate Concentrations of Rainborne Pollutants and Deposition Rates of Rainborne Pollutants at the Surface in Example Application 2 .

\section{TABLES}

3-1 Significances of Bypass Control Variables . . . . . 24

3-2 Listing of PLUVIUS Common Blocks for Example Application 1 . $\quad 27$

3-3 Summary of Class I Subroutines . . . . . . . 28

3-4 Summary of Class II Subroutines . . . . . . . . 34

4-1 Summary of Properties of Species in Example Application 1 . . 38

4-2 Input Data for Example Application 1 . . . . . . 39

4-3 Listing of Subroutine SETUP for Example Application 1 . . . 42

4-4 Listing of Subroutine ADJUST for Example Application 1 . . 43

4-5 Listing of Subroutine BOUND for Example Application 1 . . . 43

4-6 Listing of Subroutine DIFF for Example Application 1 . . . 43

4-7 Listing of Subroutine GEN for Example Application 1 . . . 45

4-8 Listing of Subroutine GRDSET for Example Application 1 . . 45 


\section{TABLES Continued}

4-9 Listing of Subroutine SETTL for Example Application 1 . . . 47

4-10 Listing of Subroutine TIMESP for Example Application 1 . $\quad 47$

4-11 Listing of Subroutine USHEAR for Example Application 1 . $\quad 47$

4-12 Listing of Subroutine VERT for Example Application 1 . . . 48

4-13 Output Heading Page from Example Application 1 . . . . 49

4-14 Model Output at TCLOCK=500 Seconds From Example Application 1 . 50

4-15 Model Outpout at TCLOCK=3500 Seconds From Example Application 1 . 51

5-1 Dependent Variables for Example Application 2 . . . . 65

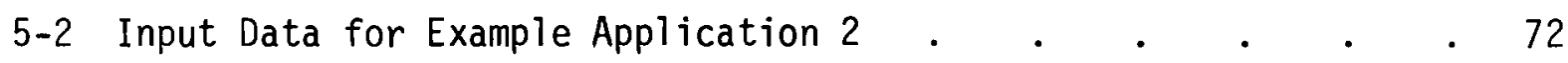

5-3 Listing of Subroutine SETUP for Example Application 2 . . . 75

5-4 Example Listing of PLUVIUS Common Blocks for Example Application 277

5-5 Listing of Subroutine ADJUST for Example Application 2 • $\quad 79$

5-6 Listing of Subroutine BOUND for Example Application 2 . • . 81

5-7 Listing of Subroutine DIFF for Example Application 2 - . 82

5-8 Listing of Subroutine GEN for Example Application 2 . . $\quad$. 84

5-9 Listing of Subroutine SETTL for Example Application 2 . . . 93

5-10 Listing of Subroutine TIMESP for Example Application 2 . 95

5-11 Listing of Subroutine USHEAR for Example Application 2 . 96

5-12 Listing of Subroutine VERT for Example Application 2 . . 98

5-13 Listing of Subroutine HENRY for Example Application 2 . . . 99

5-14 Listing of Function SSAT for Example Application 2 . . 101

C-1 Listing of PLUVIUS Main Program Unit . . . . . . C-2

$\mathrm{C}-2$ Listing of Subroutine ADVINT . . . . . . . . C -7

$\mathrm{C}-3$ Listing of Subroutine CHMINT . . . . . . . . C-12 


\section{TABLES Continued}

C-4 Listing of Subroutine DERIV . . . . . . . . . . C-13

C-5 Listing of Subroutine FILTER . . . . . . . . . . . C-15

C-6 Listing of Subroutine FIRSTD . . . . . . . . . . . C-19

C-7 Listing of Subroutine ODEINT . . . . . . . . . . . . . C-20

C-8 Listing of Subroutine SETVEC . . . . . . . . . . . . C-28

C-9 Listing of Subroutine TEMPF . . . . . . . . . . . . C-29

- C-10 Listing of Subroutine TRIDG2 . . . . . . . . . . . C-32

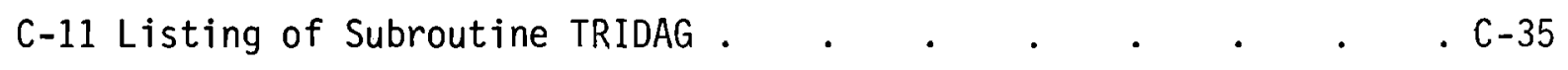

C-12 Listing of Subroutine ZERODM . $\quad . \quad$. . . . . . . . . . C-36

C-13 Listing of Subroutine PRESSF . . . . . . . . . . . C-38

C-14 Listing of Function RHOAIR . . . . . . . . . C-39

C-15 Listing of Function RLAPSE . . . . . . . . . . . C -39

C-16 Listing of Function SAT . . . . . . . . . . . . C-40

C-17 Listing of Subroutine COLLECT $\quad . \quad$. . . . . . . . C C-41

C-18 Listing of Subroutine PRINT . . . . . . . . . . . . . C-44

C-19 Description of PLUVIUS Variables and Parameters . . . . . C-47

D-1 Output Heading Page From Example Application 2 . . . . . . D-2

D-2 Example Application 2 Model Output at TCLOCK $=0$ Hours . . D-3

D-3 Example Application 2 Model Output at TCLOCK = 1 Hours . . D-6

D-4 Example Application 2 Model Output at TCLOCK $=2$ Hours . . D-9

D-5 Example Application 2 Model Output at TCLOCK $=3$ Hours . . D-12

D-6 Example Application 2 Model Output at TCLOCK $=4$ Hours . . D-15 


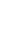


-Man is not capable of thought in any high degree, and even the most spiritual and highly cultivated of men habitually sees the world and himself through the lenses of delusive formulas and artiess simplifications.

Hermann Hesse, Steppenwolf

\section{INTRODUCTION}

During recent years numerous investigations of atmospheric behavior have been performed using one-dimensional simplifications of the continuity equations for mass, energy, and momentum. Such methods necessarily sacrifice some aspects of reality in the context of our three-dimensional atmosphere; but quite often they lead to valuable insights which could not be obtained otherwise within the constraints of computational capabilities and human perception. In the context of the Steppenwolf's rather pessimistic observation, one-dimensional models (and indeed a 11 other types of atmospheric interpretive models) create a type of lens through which atmospheric processes can be observed. They are imperfect lenses; but frequently they are capable of creating insights and concepts which would be largely impossible in their absence.

This statement is certainly a valid one with reference to air-pollutant transformation and removal processes. The chemistry and physics of these phenomena tend to be both poorly understood and mathematically complex, and the computational simplicity of one-dimensional modeling is thus a highly attractive feature. One example of such an application is the analysis of Omstedt and Rodhe (1978), who performed computations for the three-component system $\mathrm{H}_{2} \mathrm{~S}-\mathrm{SO}_{2}-\mathrm{SO}_{4}=$ using various assumptions with regard to chemical reaction, deposition and vertical transport.

Previous computer codes applied for these purposes tend to be rather specific to the immediate requirements at hand, and it seems desirable to possess a generalized code which would provide a flexible framework for numerous types of calculations. Specifically, there is a need for a code which would allow for: 
- variable diffusion in height and time

- generalized boundary conditions at both the top and bottom of the computational grid, allowing a versatile characterization of the deposition/resuspension process

- flexible vertical grid spacing

- the capability to describe cloud and precipitation formation phenomena

- the versatile incorporation of aqueous-phase and gaseous-phase chemical conversion for multiple-component systems, and

- the capability to describe wet removal processes.

The present report describes a code which has been developed for this purpose, and the following chapters provide a user's manual for its practical application. This manual begins by formulating the one-dimensional conservation equations to be used by the code. It then gives an overview of the code, which is intended to facilitate its use for example calculations, which constitute the final portion of the main body of the report. More detailed description of the code, along with a discussion of its numerical procedures, is given in the Appendices. 


\section{FORMULATION OF GOVERNING EQUATIONS \\ AND BOUNDARY CONDITIONS $(a)$}

\section{A. GOVERNING EQUATIONS DESCRIBING MATERIAL-BALANCE RELATIONSHIPS}

The starting point for this derivation is the conventional continuity equation for pollutant species k (cf. Bird, Stewart, and Lightfoot, 1960):

$$
\begin{aligned}
& \frac{\partial c_{k}}{\partial t}=-\nabla \cdot\left(c_{k} v_{k}\right)+G_{k} \\
& k=1,2,3, \ldots m
\end{aligned}
$$

where $c$ denotes molar concentration, $\chi$ is the pollutant velocity vector and $G$ is a volumetric generation term. Dropping the subscript $k$ for convenience, applying conventional $\mathrm{K}$-theory treatment, and expanding the divergence term yields the form

$$
\frac{\partial c}{\partial t}=-\frac{\partial}{\partial x}(c u)-\frac{\partial}{\partial y}(c v)-\frac{\partial}{\partial z}(c w)+\nabla \cdot f+G .
$$

$u, v$, and $w$ are the nondiffusive $x, y$, and $z$ components of the individual pollutant velocities, and $E$ is the pollutant flux arising from turbulent transport.

Let the corresponding components of air velocity be $u_{A}, v_{A}$, and $w_{A}$, and assume that

$$
u=u_{A}
$$

and

$$
v=v_{A}
$$

(a)The mathematics of this section are somewhat involved, and it is suggested that the reader skim this material initially and proceed rapidly to later sections describing code use. This section can be re-studied as necessary after the user has had initial experience executing the code. 
Also let $\quad w=w_{A}+w_{r}$

where $w_{r}$ represents the "settling" velocity of the pollutant species.

The following approximations are now applied:

- Because only one-dimensional or two-dimensional systems will be considered, neglect al1 variation with $y$.

Let $c^{*}$ represent the molar concentration of a ir, and neglect horizontal and temporal variations in $c^{*}$, so that the continuity equation for air becomes

$$
c^{\star}\left(\frac{\partial u_{A}}{\partial x}+\frac{\partial w_{A}}{\partial z}\right)+w_{A} \frac{\partial c^{\star}}{\partial z}=0
$$

- Ignore the horizontal component of the turbulent transport and apply the gradient-transport approximation, so that

$$
\nabla \cdot \underset{\sim}{F}=\frac{\partial}{\partial z}\left[c^{*} D_{m} \frac{\partial}{\partial z}\left(c / c^{*}\right)\right]
$$

where $D_{m}$ is the eddy diffusion coefficient.

The species continuity equation [Equation (2)] now becomes:

$$
\begin{aligned}
\frac{\partial c}{\partial t} & =-u_{A} \frac{\partial c}{\partial x}-w_{A} \frac{\partial c}{\partial z}-\frac{\partial}{\partial z}\left(w_{r} c\right) \\
& +\frac{c}{c^{\star}} w_{A} \frac{\partial c^{\star}}{\partial z}+\frac{\partial}{\partial z}\left[c^{\star} D_{m} \frac{\partial}{\partial z}\left(c / c^{\star}\right)\right]+G .
\end{aligned}
$$

At this point the development separates for the one-dimensional, time-dependent, and two-dimensional, steady-state cases. In the one-dimensional case one assumes that the horizontal air speed is constant with height, and proceeds to express the vertical air velocity as the sum of the change rate of terrain elevation $W_{A 0}$ and some additional component $w_{A}^{\prime}$; i.e.,

$$
w_{A}=w_{A o}+w_{A}^{\prime} \text {. }
$$

Defining in addition a "terrain-following" derivative 


$$
\frac{\hat{D} C}{\hat{D} t}=\frac{\partial C}{\partial t}+w_{A_{0}} \frac{\partial C}{\partial z}+u_{A} \frac{\partial C}{\partial x}
$$

Equation (7) can be expressed by the form

$$
\begin{aligned}
\frac{\hat{D C}}{\hat{D} t} & =-\frac{\partial}{\partial z}\left[\left(w_{r}+w_{A}^{\prime}\right) c\right]+\frac{\partial}{\partial z}\left[c^{*} D_{m} \frac{\partial}{\partial z}\left(c / c^{*}\right)\right]+c \frac{\partial w_{A}^{\prime}}{\partial z} \\
& +c \frac{w_{A}}{c^{\star}} \frac{\partial C^{\star}}{\partial z}+G
\end{aligned}
$$

Here the total derivative $\hat{D} c / \hat{D} t$ can be visualized as the time rate of change of material in a vertical column of air moving with the velocity $u_{A}$, $v_{A}, w_{A O} \cdot G$ is a catch-all term, providing for the combined effects of reaction and interphase transport.

For the two-dimensional, steady-state case one assigns the term $u_{A 0}$ to describe $u_{A}$ at the surface (the bottom level of the model domain), and defines $u^{*}$ as the horizontal velocity at some chosen reference level. Partitioning the vertical velocity by

$$
w_{A}=w_{A 0}\left(u_{A} / u_{A O}\right)+w_{A}^{\prime \prime},
$$

and defining a new derivative

$$
\frac{D^{\star} C}{D t^{\star}}=u^{\star} \frac{\partial C}{\partial x}+\left(u^{\star} / u_{A o}\right) w_{A o} \frac{\partial C}{\partial z},
$$

Equation (7) becomes

$$
\begin{aligned}
\frac{D^{\star} C}{D t^{\star}} & =\frac{u^{\star}}{u_{A}}\left\{-\frac{\partial}{\partial z}\left[\left(w_{r}+w_{A}^{\prime \prime}\right) c\right]+\frac{\partial}{\partial z}\left[c^{\star} D_{m} \frac{\partial}{\partial z}\left(c / c^{\star}\right)\right]\right. \\
& \left.+c \frac{\partial w_{A}^{\prime \prime}}{\partial z}+c \frac{w_{A}}{c^{\star}} \frac{\partial c^{\star}}{\partial z}+G\right\}
\end{aligned}
$$


Under conditions when $u_{A}$ is constant with height, $u_{A}=u^{*}$ and Equation (13) is identical to Equation (10). When $u_{A}$ is not constant, the physical interpretations of Equations (10) and (13) differ. In Equation (10), $\hat{\mathrm{D}} \mathrm{C} / \hat{\mathrm{D}} \mathrm{t}$ represents the rate of change in a vertical column moving with the horizontal velocity of the air. Thus the column maintains a physical integrity. In Equation (13), $D^{*} C / D t^{\star}$ also represents the rate of change in a vertical column, but in this case the column is moving at the velocity $u^{*}$ and air is flowing horizontally through the column at all levels where $u_{A} \neq u^{\star}$. The column at some time $t^{\star}$ corresponds to a column at position $x$, where

$$
x=x_{0}+u^{*}\left(t^{*}-t_{0}^{*}\right)
$$

and air at different levels may take different physical times to move from $x_{0}$ to $x$. Conveniently, Equations (10) and (13) have similar mathematical forms, so the same code can be used to provide solutions for both situations. An important restriction on the use of Equation (13) is that $u_{A}$ must be either always positive or always negative. Physically, this means that situations with flow moving in opposite directions at different levels cannot be handled; this restriction is imposed by the "forwardmarching" technique used in PLUVIUS' numerical integration scheme.

It is important to note that PLUVIUS is not a dynamical model. Thus, the air velocity components $u_{A}$ and $w_{A}$ are not calculated internally, but must be provided by the user in the form of some sort of "driver." Input wind data can be derived from actual measurements, from some dynamical atmospheric model, or even from some hypothetical test simulation. In any case, it is the user's responsibility to provide physically realistic values, as the model accepts them rather blindly. In particular, the mass continuity equation [Equation (5)] should be satisfied.

\section{B. INITIAL AND BOUNDARY CONDITIONS FOR MATERIAL-BALANCE RELATIONSHIPS}

Equations (10) and (13) are second-order parabolic with two independent variables, and as such they require two boundary conditions and 
one initial condition for a complete formulation of the problem. The initial condition can be stated quite simply as

$$
c(0, z)=\hat{c}_{I}(z)
$$

where $\hat{c}_{I}$ is some specified initial concentration field.

Boundary conditions must be specified at the top $(z=h)$ and bottom $(z=0)$ of the model domain. Three forms chosen for the present application correspond to the so-called "inflow, "outflow," and "flux" conditions.

The inflow condition represents a situation where at the boundary, the species has a net velocity into the model domain. This net velocity is $w_{r}+w_{A}^{\prime}$, but we have placed the restriction that $w_{A}^{\prime}=0$ at the two boundaries (there is no flow of air through the boundaries), so the net velocity reduces to $w_{r}$. Physically, the inflow condition is appropriate at the top boundary for species with a significant settling velocity. The condition is implemented by specifying the concentration at the boundary. Thus, at the top,

$$
c(t, h)=\hat{c}_{T}(t)
$$

and at the bottom,

$$
c(t, 0)=\hat{c}_{B}(t)
$$

where $\hat{\mathrm{c}}_{\mathrm{T}}$ and $\hat{\mathrm{c}}_{\mathrm{B}}$ are specified concentrations.

The outflow condition is the opposite to the inflow condition. It is particularly appropriate at the bottom boundary for species having a significant settling velocity, such as precipitation particles, or pollutants in precipitation particles. The condition is actually a computational condition, representing the fact that the outflow concentration is generated "upstream" within the model domain. It is discussed more fully in Appendix A. It should be noted that the outflow boundary condition has only been implemented at the bottom boundary in PLUVIUS. 
The flux boundary condition represents a situation where the boundary acts as an impermeable or semipermeable barrier, and any transport occurring across the boundary is influenced by processes outside of the model's domain. Examples are dry deposition of gases and submicron particles, and moisture transfer from evaporation and condensation. Mathematically, the condition is expressed as

$$
\left.\left[w_{r} c-D_{m} c^{\star} \frac{\partial}{\partial z} \frac{c}{c^{\star}}\right]\right|_{t, h}=\hat{f}_{T}(t)
$$

and $\left.\quad\left[w_{r} c-D_{m} c^{\star} \frac{\partial}{\partial z} \frac{c}{c^{\star}}\right]\right|_{t, 0}=\hat{f}_{B}(0)$,

where $\hat{f}_{T}$ and $\hat{f}_{B}$ are the specified fluxes at the top and bottom boundaries, respectively (units $=m 0 l e s / \mathrm{cm}^{2} \mathrm{sec}$ ). As an example, an impermeable boundary is specified by $\hat{f}_{T}=0$ or $\hat{f}_{B}=0$. An example for dry deposition is given in Section 5 .

\section{GOVERNING EQUATION DESCRIBING ENERGY-BALANCE RELATIONSHIP}

It is important to note that energy-balance considerations are necessary to the current model only when one desires to compute temperature distributions within the atmosphere. In view of this the following formulation is unnecessary for many applications; and indeed the model's computer code allows the associated operations to be bypassed when appropriate.

The starting point for formulation of the appropriate energy-balance equation can be obtained from Equation (10.1-19) from Bird, Stewart, and Lightfoot (1960). Expressing this equation on a molar basis, neglecting viscous generation, and adding a latent-heat term one obtains the form

$$
c^{*} C_{v} \frac{D T}{D t}=-\nabla \cdot q-T\left(\frac{\partial p}{\partial T}\right)_{\hat{v}} \nabla \cdot v_{A}+\dot{H},
$$

where 


$$
\begin{aligned}
& C_{v}=\text { specific heat of air at constant volume (molar basis) } \\
& T=\text { air temperature } \\
& \frac{D T}{D t}=\frac{\partial T}{\partial t}+v_{A} \cdot \nabla T \\
& q=\text { sensible heat flux vector } \\
& p=\text { pressure } \\
& \hat{v}=\text { specific volume } \\
& v_{A}=\text { three-dimensional air-velocity vector }
\end{aligned}
$$

and $\dot{H}=$ energy generation rate per unit volume from latent heating effects.

The second term on the right of Equation (19) may be converted to a more tractable form using the ideal-gas law and the continuity equation. From the ideal-gas law,

$$
\left(\frac{\partial p}{\partial T}\right)_{\hat{v}}=R c^{*}
$$

where $R$ is the gas constant. In addition, one can combine the gas law with the continuity equation to obtain

$$
\nabla \cdot v_{A}=\frac{1}{T} \frac{D T}{D t}-\frac{1}{p} \frac{D p}{D t}
$$

Assuming that the substantial derivative of $p$ is dominated by the vertical advection term, and invoking the hydrostatic assumption one obtains

$$
\frac{1}{p} \frac{D p}{D t} \cong \frac{w_{A}}{p} \frac{\partial p}{\partial z} \cong-w_{A} \frac{g m_{a}}{R T},
$$

where $\mathrm{m}_{\mathrm{a}}$ is the mean molecular weight of air and $\mathrm{g}$ is the gravitational acceleration. Equations (20), (21), and (22) now can be combined to provide the useful form 


$$
T\left(\frac{\partial p}{\partial T}\right)_{\hat{v}} \nabla \cdot v_{A}=R c^{\star} \frac{D T}{D t}+w_{A} C^{\star} g m_{a}
$$

For the sensible heat flux, we apply gradient-transport theory, and aga in assume that the vertical component dominates, so that

$$
-\nabla \cdot q=\frac{\partial}{\partial z}\left[c^{\star} C_{p} D_{H}\left(\frac{\partial T}{\partial z}-\Gamma_{d}\right)\right]
$$

where $\Gamma_{d}$ is the dry adiabatic lapse rate,

$$
\Gamma_{d}=-g m_{a} / C_{p}
$$

and

$$
C_{p}=C_{v}+R
$$

Substitution of Equations (23), (24), (25) and (26) into Equation (19) yields

$$
\frac{D T}{D t}=w_{A} \Gamma_{d}+\frac{1}{c^{\star}} \frac{\partial}{\partial z}\left[c^{\star} D_{H}\left(\frac{\partial T}{\partial z}-\Gamma_{d}\right)\right]+\frac{\dot{H}}{c^{\star} C_{p}} .
$$

Equation (27) can be considered as the basic form of the energy balance to be applied in PLUVIUS, although the functional form of the latent-heating term $\dot{H}$ remains to be specified. Under conditions where cloud and precipitation particles are present, $\dot{H}$ can be of major importance in the equation. This term represents a variety of transfer processes between water vapor and liquid and solid particles of numerous shapes and sizes. In general one may write

$$
\dot{H}=L_{c} G_{v \ell}+L_{f} G_{\ell S}+\left(L_{c}+L_{f}\right) G_{v s}
$$

where

$$
\begin{aligned}
L_{c}= & \text { latent heat of condensation (ergs/mole) } \\
L_{f}= & \text { latent heat of fusion (ergs/mole) } \\
G_{v e}= & \text { net rate of transfer of water from vapor to liquid particles } \\
& \left(\text { moles } / \mathrm{cm}^{3} \mathrm{sec}\right)
\end{aligned}
$$


$G_{\ell S}=$ net rate of transfer of water from 1 iquid to solid particles

$G_{v s}=$ net rate of transfer of water from vapor to solid particles.

Under subsaturated conditions we shall apply variants of equation (27) directly in the model, incorporating latent-heating effects as an explicit add-on term (Equation 28) as indicated. Under saturated conditions, however, we shall assume that a near-equilibrium exists between cloud water and water vapor; and because of this assumption it is expedient to incorporate the associated heating terms implicitly within the calculation, rather than as explicit rate components. To produce this semi-implicit formulation we define the saturation mixing ratio for water vapor, $r_{v s}$, as

$$
r_{v s}=\frac{c_{v s}}{c^{\star}}=\frac{e_{s}}{p}
$$

where $c_{v s}$ is the saturation vapor density for water $\left(\right.$ mole $\left./ \mathrm{cm}^{3}\right)$ and $e_{s}$ is the saturation vapor pressure. A mass-balance equation can be written for $r_{v s}$, which combines Equation (7) for $c_{v s}$ and $c^{\star}$, as

$$
c^{\star} \frac{D r_{v s}}{D t}=\frac{\partial}{\partial z}\left[c^{\star} D_{z} \frac{\partial r_{v s}}{\partial z}\right]+G_{v \ell}+G_{v s}
$$

It is important to note that Equation (30) is valid only at conditions of saturation equilibrium, while a similar equation for $r_{v}$, the (not necessarily saturated) water-vapor mixing ratio, will always hold.

$e_{s}$ is strictly a function of $T$, and can be expressed in terms of the Clausius-Clapeyron equation as

$$
\frac{\mathrm{de}_{\mathrm{S}}}{\mathrm{dT}}=\frac{\mathrm{e}_{\mathrm{S}} \mathrm{L}_{\mathrm{c}}}{R T^{2}}
$$

so that

$$
\frac{\partial r_{v s}}{\partial \xi}=r_{v s}\left[\frac{L_{c}}{R T^{2}} \frac{\partial T}{\partial \xi}-\frac{1}{p} \frac{\partial p}{\partial \xi}\right]
$$


where $\xi$ is any of the independent variables $(x, y, z, t)$.

Equation (28) can be rearranged as follows:

$$
G_{v \ell}+G_{v s}=\frac{\dot{H}}{L_{c}}-\frac{L_{f}}{L_{c}} G_{\ell s}-\frac{L_{f}}{L_{c}} G_{v s} \text {. }
$$

Under the assumption that $D_{z}=D_{H}$, this can be combined with Equations (27) and (30) to yield

$$
\frac{D T}{D t}=w_{A} \Gamma_{W}+\frac{1}{c^{\star} x_{1}} \frac{\partial}{\partial z}\left[c^{\star} x_{1} D_{H}\left(\frac{\partial T}{\partial z}-\Gamma_{W}\right)\right]+\frac{\dot{H}_{W}}{C^{\star} x_{1} C_{p}}
$$

where

$$
\begin{aligned}
& \Gamma_{w}=\Gamma_{d} x_{2} / x_{1} \text { is the wet adiabatic lapse rate, } \\
& x_{2}=1+L_{c} r_{v s} / R T, \\
& x_{1}=1+L_{c}{ }^{2} r_{v s} / C_{p} R T^{2}, \\
& \dot{H}_{w}=L_{f}\left(G_{\ell s}+G_{v s}\right) .
\end{aligned}
$$

Noting the similar forms of Equations (27) and (33), we will write

$$
\frac{D T}{D t}=w_{A} \Gamma+\frac{1}{c^{\star} \chi} \frac{\partial}{\partial z}\left[c^{\star} x D_{H}\left(\frac{\partial T}{\partial z}-\Gamma\right)\right]+\frac{\dot{H}^{\star}}{c^{\star} \chi C_{p}}
$$

where for unsaturated conditions,

$$
\begin{aligned}
\Gamma & =\Gamma_{d} \\
X & =1 \\
\dot{H}^{*} & =\dot{H}
\end{aligned}
$$

and for saturated conditions, 


$$
\begin{aligned}
\Gamma & =\Gamma_{w} \\
x & =x_{1} \\
\dot{H}^{*} & =\dot{H}_{w}
\end{aligned}
$$

All that remains now is to put Equation (34) in a form suitable for our one-dimensional and two-dimensional steady-state conditions. For the one-dimensional case, Equation (34) becomes

$$
\begin{aligned}
\frac{\hat{D T}}{D \hat{t}} & =-\frac{\partial}{\partial z}\left(W_{A}^{\prime} T\right)+\frac{1}{c^{\star} \chi} \frac{\partial}{\partial z}\left[c^{\star} \chi D_{H} \frac{\partial T}{\partial z}\right] \\
& +T \frac{\partial W_{A}^{\prime}}{\partial z}+W_{A^{T}}-\frac{1}{c^{\star} \chi} \frac{\partial}{\partial z}\left(c^{\star} \chi D_{H} \Gamma\right)+\frac{\dot{H}^{\star}}{c^{\star} \chi C_{p}}
\end{aligned}
$$

For the two-dimensional, steady-state case, Equation (33) becomes

$$
\begin{aligned}
\frac{D^{\star} T}{D t^{\star}} & =\frac{u^{\star}}{u_{A}}\left\{-\frac{\partial}{\partial z}\left(w_{A}^{\prime \prime} T\right)+\frac{1}{c^{\star} \chi} \frac{\partial}{\partial z}\left[c^{\star} \chi D_{H} \frac{\partial T}{\partial z}\right]\right. \\
& \left.+T \frac{\partial w_{A}^{\prime \prime}}{\partial z}+w_{A} T-\frac{1}{c^{\star} \chi} \frac{\partial}{\partial z}\left(c^{\star} \chi D_{H^{T}} \Gamma\right)+\frac{\dot{H}^{\star}}{c^{\star} \chi C_{p}}\right\}
\end{aligned}
$$

These two equations are substantially similar in form to Equations (10) and (13), and basically the same solution technique is used for the energy and mass balance equations.

D. INITIAL AND BOUNDARY CONDITIONS FOR THE ENERGY-BALANCE EQUATION

The similarity of form between Equations (10) and (35) should be emphasized at this point. This similarity is evident as well in the initial and boundary conditions. The initial condition, for example, is simply 


$$
T(0, z)=\hat{T}_{I}(z)
$$

Flux-specified boundary conditions at the grid top and bottom are given respectively by

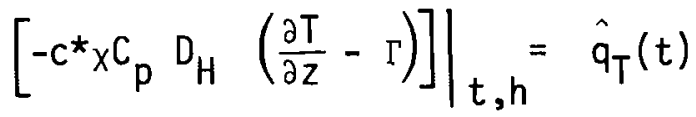

$$
\begin{aligned}
& {\left.\left[-c^{\star} \chi C_{p} D_{H}\left(\frac{\partial T}{\partial z}-\Gamma\right)\right]\right|_{t, 0}=\hat{q}_{B}(t),}
\end{aligned}
$$

where $\hat{q}_{T}$ and $\hat{q}_{B}$ are specified heat fluxes $\left(\mathrm{ergs} / \mathrm{cm}^{2} \cdot \mathrm{sec}\right.$ ). As the relative velocity for temperature is that of the air, and we have specified that $w_{A}^{\prime}=0$ at the boundaries, the inflow and outflow boundary conditions are not appropriate. We have, however, maintained the normal Dirichlet boundary condition.

These take the form

$$
T(t, h)=\hat{T}_{T}(t)
$$

and

$$
T(t, 0)=\hat{T}_{B}(t)
$$

at the top and bottom boundaries.

\section{E. OPERATOR SPLITTING}

Equations (10) and (35) are consolidated forms, in the sense that they contain terms describing transport and generation. For the purposes of numerical approximation it is advantageous to segregate these terms by a so-called "splitting" process. For the mass-balance equation [Equation (10)], this yields:

$$
\frac{\hat{D C}}{\hat{D} t}=\left.\frac{\hat{D C}}{\hat{D} t}\right|_{\text {transport }}+\left.\frac{\hat{D} C}{\hat{D} t}\right|_{\text {generation }}
$$


where

$$
\begin{aligned}
\left.\frac{\hat{D C}}{\hat{D t}}\right|_{\text {transport }} & =-\frac{\partial}{\partial z}\left[\left(w_{r}+w_{A}^{\prime}\right) c\right]+\frac{\partial}{\partial z}\left[c^{*} D_{m} \frac{\partial}{\partial z}\left(c / c^{*}\right)\right] \\
& +c \frac{\partial w_{A}^{\prime}}{\partial z}+c \frac{w_{A}}{c^{\star}} \frac{\partial c^{*}}{\partial z}
\end{aligned}
$$

and

$$
\left.\frac{\hat{D C}}{\mathrm{Dt}}\right|_{\text {generation }}=G
$$

A parallel form can be written for Equation (35):

$$
\begin{aligned}
\left.\frac{D T}{D t}\right|_{\text {transport }} & =-\frac{\partial}{\partial z}\left(w_{A}^{\prime} T\right)+\frac{1}{c^{\star} \chi} \frac{\partial}{\partial z}\left[c^{\star} X_{H} \frac{\partial T}{\partial z}\right] \\
& +T \frac{\partial w_{A}^{\prime}}{\partial z}+w_{A} \Gamma-\frac{1}{c^{\star} X} \frac{\partial}{\partial z}\left(c^{\star} X_{H} \Gamma\right)
\end{aligned}
$$

and

$$
\left.\frac{\mathrm{DT}}{\mathrm{Dt}}\right|_{\text {generation }}=\frac{\dot{H}^{\star}}{\mathrm{c}^{\star} \times \mathrm{C}_{\mathrm{p}}}
$$

Equations (42) - (45) are applicable for the one-dimensional, time-dependent case. The corresponding equations for the two-dimensional, steady-state case are developed similarly from Equations (13) and (36); they are identical to the above equations except for a factor of $\left(\frac{u^{*}}{u_{A}}\right)$ on
the right-hand side of each one. 


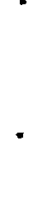

- 


\section{CODE CHARACTERISTICS -- AN OVERVIEW}

The objective of this section is to provide the reader with a fundamental exposure to the PLUVIUS, MOD 5.0 code, before the more detailed discussions of the example applications in the following sections. This preview can be segmented into the five separate areas of 1) initial rules and conventions, 2) logical flow, 3) data input, 4) modular construction, and 5) the zero-dimensional facility; these will be discussed individually in the following text. The successful user of PLUVIUS should have a moderate knowledge of the FORTRAN programming language. The text of this and the following sections is interspersed with many FORTRAN variable names and statements, which may be recognized by their appearance in upper-case.

\section{A. INITIAL RULES AND CONVENTIONS}

The computer code contains some important conventions, which are designed to maximize flexibility and computational efficiency. These conventions, which must be observed for successful code execution, are itemized in the following paragraphs.

- Dependent variables are stored in the two-dimensional array $C$. The array element $C(I, K)$ is the value of the Kth variable or "species" at vertical grid point $I$. The index variables $I$ and $K$ are used consistently throughout PLUVIUS for vertical grid point and species. Two dependent variables that are not stored in the array $C$ are air pressure and molar air density, which are held in the one-dimensional arrays PRESS and CS, respectively.

- Dependent variable values are temporarily held in the one-dimensional array CNN during the integration of the generation component of the mass balance equation at each grid point.

- The code contains two basic classes of dependent variables. The first is known as a "computed variable" and is calculated via the code's finite differencing procedure. The second is termed a "constrained variable." This class contains any variables that are not computed via the finite difference approximations, such as steady-state variables, variables 
which do not change with time, and variables which are force-fit to observations. The ordering of dependent variables is set so that constrained variables follow computed variables. NCOMP is the number of computed variables and NCNSTR is the number of constrained variables, so that

$C(I, 1) \ldots C(I, N C O M P)$ are computed variables, and $C(I, N C O M P+1) \ldots C(I, N C O M P+N C N S T R)$ are constrained variables.

It should be noted in this context that temperature, as well as pollutant and water species, can be treated as either a computed or constrained variable at the option of the user.

- Temperature and chemical species are identified within PLUVIUS, MOD 5.0 in the two following ways:

1) by a numerical value of the species index (eg. $C(I, 3)$ is the concentration at grid point I of the third species),

2) by an associated species location variable, which must be defined by the user.

As an example, suppose that gaseous-phase $\mathrm{SO}_{2}$ were designated as species number 3 , such that the vector

$$
C(I, 3), \quad I=1, \ldots, N
$$

defined the vertical column of $\mathrm{SO}_{2}$ concentrations. By defining the species location variable

$$
K S O 2 G=3
$$

the equivalence

$$
C(I, 3) \equiv C(I, K S O 2 G)
$$

exists.

The above bookkeeping technique, while seemingly trivial at this point, is of large utility when dealing with complex multicomponent systems. Species location variables are held in the LOCATN common block and should be initialized in the SETUP subroutine, as described in the next section. Temperature must use the location variable KTEMP. The species which is 
the sum of water vapor and cloud water must use the location variable KVAPCL when IFOG $\neq 0$ (see following discussion of bypass variables). other than this there is no restriction on the location variables, except that they be FORTRAN integers. The restriction in earlier versions of PLUVIUS that temperature be species 1 is not required in PLUVIUS, MOD 5.0 .

- Turbulent diffusivities $D(I, L)$ are grouped to allow the versatility of having different diffusion coefficients for different classes of computed variables, if desired. The index $L$ is known as the "diffusion regime." $L=1$ always pertains to the diffusivity of heat in the energy equation regardless of whether or not this equation is actually used in the current computation. $L=1$ cannot be used for any other species as it receives special treatment in the code appropriate only for temperature. The highest value of $L$ (total number of separate diffusion regimes) is given by the variable LTD. Normally a minimum of two sets of diffusivities are required, one for heat and one for pollutant, corresponding to $L T D=2$. The diffusion regime for each species is held in the array LDIF.

- Units employed consistently by the code are as follows:

$\begin{array}{ll}\text { material } & \text { gram-moles } / \mathrm{cm}^{3} \\ \text { length } & \mathrm{cm} \\ \text { temperature } & { }^{\circ} \mathrm{K} \\ \text { time } & \text { seconds } \\ \text { pressure } & \text { dynes } / \mathrm{cm}^{2} \\ \text { energy } & \text { ergs }\end{array}$

- Computations involving energy-balance calculations under saturated conditions ( IFOG $=1$ ) demand that one dependent variable be designated to describe the sum of cloud-water and water-vapor concentrations. As noted above, this variable is designated by the vector

C $(I, K V A P C L) \quad I=1, \ldots, N$.

B. LOGICAL FLOW

The primary logical flow in PLUVIUS, MOD 5.0 is demonstrated in the code's main program, as shown in Table $C-1$ in Appendix $C$. This program is 
divided into three segments, as follows:

- Data input

- Initialization

- Major computation loop .

The data input segment reads values for a number of primary program variables, as described later in this section. In a specific application, the user might wish to add additional input. The appropriate location for this is in SETUP or other Class I subroutines, rather than the main program.

The initialization segment sets up the vertical grid spacing (via GRDSET), sets initial concentrations for dependent variables (via SETUP), and initializes various computational variables via calls to other subroutines. The running model-time variable, TCLOCK, is initialized to the input value of TSTART. During the initialization segment, the flag INIT has a value of 1 , and several subroutines perform initialization code when INIT $=1$. Following initialization, the input data and initialized concentration arrays are printed, by executing the PRINT subroutine. The initialization flag INIT is then set equal to zero, and program flow proceeds to the major computation loop.

The major computation loop is executed repeatedly to integrate the massand energy-balance equations over the user specified time interval (TSTART to TSTOP). Each pass through the loop integrates the equations over a time step $2 \cdot D T$. As was noted in section 2-E, the transport and generation components of the governing equations have been "split." The basic 2-DT integration step has three parts:

1) integration of the transport component (Equations 42 and 44) for a time step DT, performed by subroutine ADVINT (see Table C-2),

2) integration of the generation component (Equations 43 and 45) for a time-step 2.DT, performed by subroutine CHMINT (see Table C-3),

3) a second integration of the transport component for a time-step DT.

For each transport integration, the dependent variable values are stored in the array COLD, then four subroutines which provide transport parameters 
are called (USHEAR, DIFF, VERT, SETTL). During the first transport integration, subroutine TIMESP is called, which supplies a new value for the integration time step DT. This time step is determined primarily by numerical convergence criteria for the transport integration. Next, subroutine ADVINT is called, which performs the actual integration.

Following the ADVINT and CHMINT calls, results are printed and/or output to mass storage as appropriate. A check is made to determine whether the model's time limit (TSTOP) has been exceeded, and if not the major computation cycle is repeated. Upon successfully advancing beyond TSTOP, the code

executes a normal Fortran stop.

C. DATA INPUT

Initial data are read in the main program by a simple sequence of READ statements, as shown in Table C-1. The first READ statement,

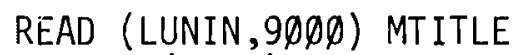

$9 \emptyset \emptyset \emptyset$ FORMAT (4ФA2)

reads a run title (up to 80 characters) which appears at the start of the model output.

The second READ statement,

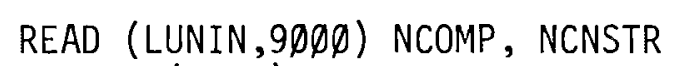

9000 FORMAT (10I5)

identifies the number of species to be considered in the computation, as indicated previously:

NCOMP = number of species that will be modeled via finite-difference . ("computed" approximation to Equations (10), (13), (35), or (36) and

species) their appropriate boundary conditions.

NCNSTR = number of species, whose concentrations may vary with space ("constrained" and time, but are computed by methods that do not involve the species) finite-difference approximations.

The third READ statement,

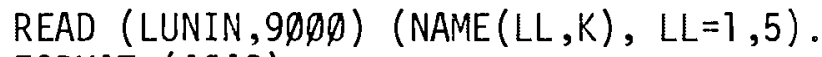

$99 \emptyset \emptyset$ FORMAT (4ФA2) 
provides for input of alphanumeric variable names (e.g., 0ZONE, S02). These alphanumeric names are for tabulated print-out only, and should not be confused with the "species location variables" described in Section $3 \mathrm{~A}$.

The fourth READ statement,

$$
\text { READ (LUNIN,9 92甲) N, LTD,DZ,GLEVL }
$$

$9 \emptyset 2 \emptyset$ FORMAT $(2 \mathrm{I} 5,2 \mathrm{E} 1 \emptyset .3)$

identifies the following variables:

$\mathrm{N}=$ number of grid points in vertical array,

LTD = total number of "diffusion regimes,"

$D Z \quad=$ the vertical grid spacing (when spacing is uniform),

GLEVL = elevation of grid bottom at computation's beginning.

The fifth READ statement,

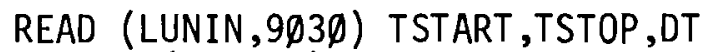

$9 \emptyset 3 \emptyset$ FORMAT (3E $\emptyset .3)$

informs the code of model start time, stop time, and initial time increment.

The sixth READ statement,

READ (LUNIN,9 $94 \emptyset)$
$14 \emptyset$ FORMAT (I5,2E $1 \emptyset .3)$

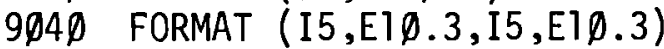

pertains to model output control. Model results may be printed either at regular model time intervals, or after a specified number of integration steps (which can have varying lengths). For regular time interval printout, set DTPRIN to the desired interval and NPRINT $=0$. If NPRINT is positive (and DTPRIN = 0), then print-out will occur after each set of NPRINT time steps. ITCOLL and DTCOLL control model output to disk file as follows:

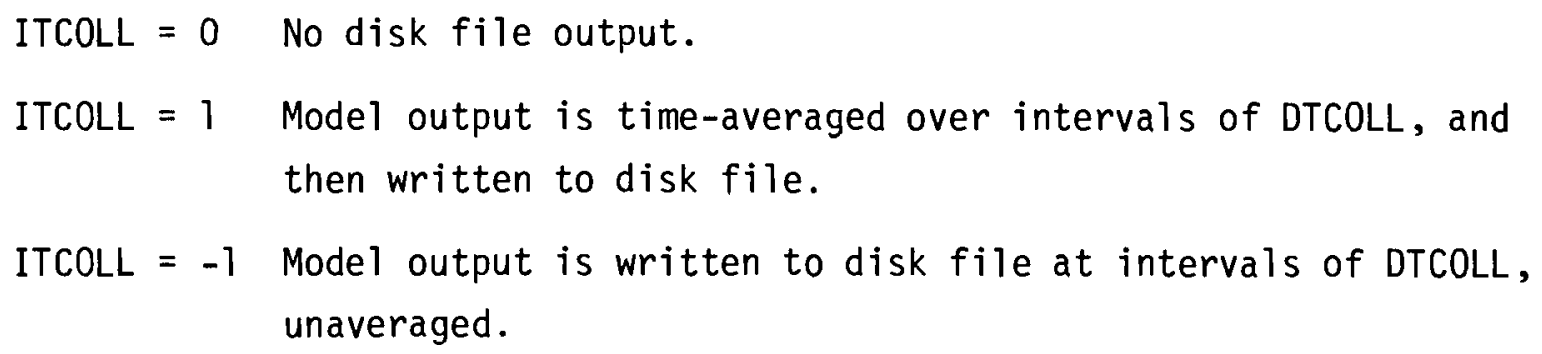
then written to disk file.

ITCOLL $=-1$ Model output is written to disk file at intervals of DTCOLL, unaveraged. 
The seventh READ statement,

\author{
READ (LUNIN, $9 \emptyset \emptyset \emptyset$ ) IGEN, IDIFF, ITEMP, I PRESS, ISETTL, IBOUND, IVERT, IFOG, \\ ISHEAR \\ $9 \emptyset \emptyset \emptyset$ FORMAT (1øI5)
}

provides for bypassing of a number of subroutines, if their corresponding physical relationships are either constant in time or else unimportant to the modeling problem at hand. If the value of a bypass variable is set positive, its corresponding physical phenomenon is subjected to detailed, repetitive calculation and the appropriate subroutines are interrogated at each time step. If the variable is set equal to zero or a negative value, the related routines are either called only once, during initialization stage of the program execution, or else bypassed completely as appropriate. Significances of the bypass variables and their corresponding subroutines are listed in Table 3-1.

The bypass variable IFOG, which relates to water condensation, has the following effect. If IFOG is positive, then a species "water vapor and cloud vapor" must be used (KVAPCL, see above). The code checks whether the air is saturated or unsaturated at each grid point, and treats Equation (34) appropriately. If IFOG is zero or negative, then the code does not treat latent heat effects implicitly, and the dry form of the energy balance equation [Equation (27)] is used. In this case, the KVAPCL species need not be present. When ITEMP is non-positive, IFOG has no effect.

The eighth READ statement,

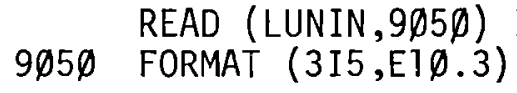

specifies boundary-condition types, diffusion regimes, and filtering for each computed variable or species. ITOP and IBOT specify the types of boundary conditions at the top and bottom of the vertical grid, respectively. Setting these to positive values imposes flux-specified conditions. If they are set equal to zero, the boundary conditions become concentration-specified (inflow), and if they are negative the boundary conditions are treated as outflow conditions. LDIF specifies the diffusion regime for the species. FILFAC pertains to the smoothing filter, which is discussed at the very end of Appendix A. If FILFAC is set equal to zero, no filtering will be applied to the associated species. 
TABLE 3-1: Significances of Bypass Control Variables

\begin{aligned}$\frac{\text { Variable }}{\text { IGEN }} & \multicolumn{1}{c}{$ Significance } \\ IDIFF & Physicochemical transformation \\ ITEMP & Atmospheric mixing \\ IPRESS & Temperature \\ ISETTL & Pressure \\ IBOUND & Terminal fall velocity \\ IVERT & Boundary conditions \\ IFOG & Vertical air velocity \end{aligned}

Corresponding Subroutine

GEN and

CHMINT

DIFF

TEMPF

PRESSF

SETTL

BOUND

VERT

No particular

subroutine;

bypasses at

several loca-

tions throughout code

ISHEAR

vertical shear in horizontal

wind field

USHEAR 
The ninth READ statement,

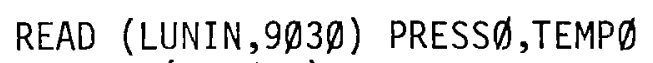

$9 \emptyset 3 \emptyset$ FORMAT (2E1Ø.3)

inputs the pressure (dynes $/ \mathrm{cm}^{2}$ ) and temperature (K) at grid position $Z(1)$ at the initial stage of computation.

These nine READ statements complete the necessary input requirements for - program execution. Examples of actual input and the corresponding computed output will be given in later sections of this report.

\section{MODULAR CONSTRUCTION}

As indicated in the previous text, the computer code is organized in a modular form, which is intended to provide the user with a large degree of versatility for specific applications. This subsection presents an overview of this structure by first discussing the modules on an individual basis, and then indicating how they operate as a composite whole. Examples of representative subroutines are given in the following sections.

Subroutines used by this code fall into three general classes:

1. Class I Subroutines - Those subroutines which are essential for basic operation of the code, and are intended for modular replacement by the user.

2. Class II Subroutines - Those subroutines which are essential for basic operation of the code and in general should be left unchanged by the user.

3. Class III Subroutines - Any additional subroutines, useful or necessary for a specific application, and supplied by the user. Often Class III subroutines are submodules of the major Class I subroutines.

Information exchange between the subroutines and the main program is conducted mainly with the use of blank and labeled COMMON. An example of these COMMON blocks, taken from the Example Application 1 of the next section, 
is given in Table 3-2. (a) The user will need to make the following modifications to these blocks for any particular application of PLUVIUS:

1) Set appropriate values, for the parameters NZMAX, NCMAX, and NCTMAX. These parameters specify the maximum number of vertical grid points, "computed" variables, and "computed" + "constrained" variables, respectively, and must be set to accommodate the size of the application.

2) Specify appropriate species location variables in the LOCATN COMMON block.

The variable INIT, often appearing by itself in the subroutine argument list, is used as a flag to inform the subroutine whether initialization or "normal execution" is occurring. If INIT $\neq 1$ the execution proceeds on the presumption that all initialization has been performed previously, with the result that several nonessential steps are bypassed. Setting of INIT to its appropriate value occurs automatically within the main program.

\section{Clases I subroutines}

To utilize PLUVIUS effectively, a user must have a good understanding of the Class I subroutines. It is through these Class I subroutines that the chemical, physical, and transport processes important to the user's application become part of the model. The ten Class I subroutines are summarized in Table 3-3, and are briefly described below. Examples of the routines provided in Sections 4 and 5 provide much additional information and insight about their usage.

SUBROUTINE ADJUST is applied to modify values of computed or constrained variables when these variables are limited by imposed constraints on the

(a)The reader will note that most of these COMMON blocks do not appear in the program and subroutine listings found in this manual. Rather, the statement "INCL'JDE "PLUVCMN" is found near the start of most listings. This is an enhancement of standard FORTRAN-77 provided in many FORTRAN implementations. During compilation of a program unit, an INCLUDE statement is replaced by the lines of code in the named file (PLUVCMN in this case). Thus the INCLUDE statement is mainly a programming convenience which removes the need to reproduce lines of code in several places. Users not having an INCLUDE facility in their FORTRAN implementation will have to perform this code replacement themselves. 
TABLE 3-2. Example Listing of PLUVIUS Common Blocks (held in the PLUVCMN INCLUDE file) for Example Application 1

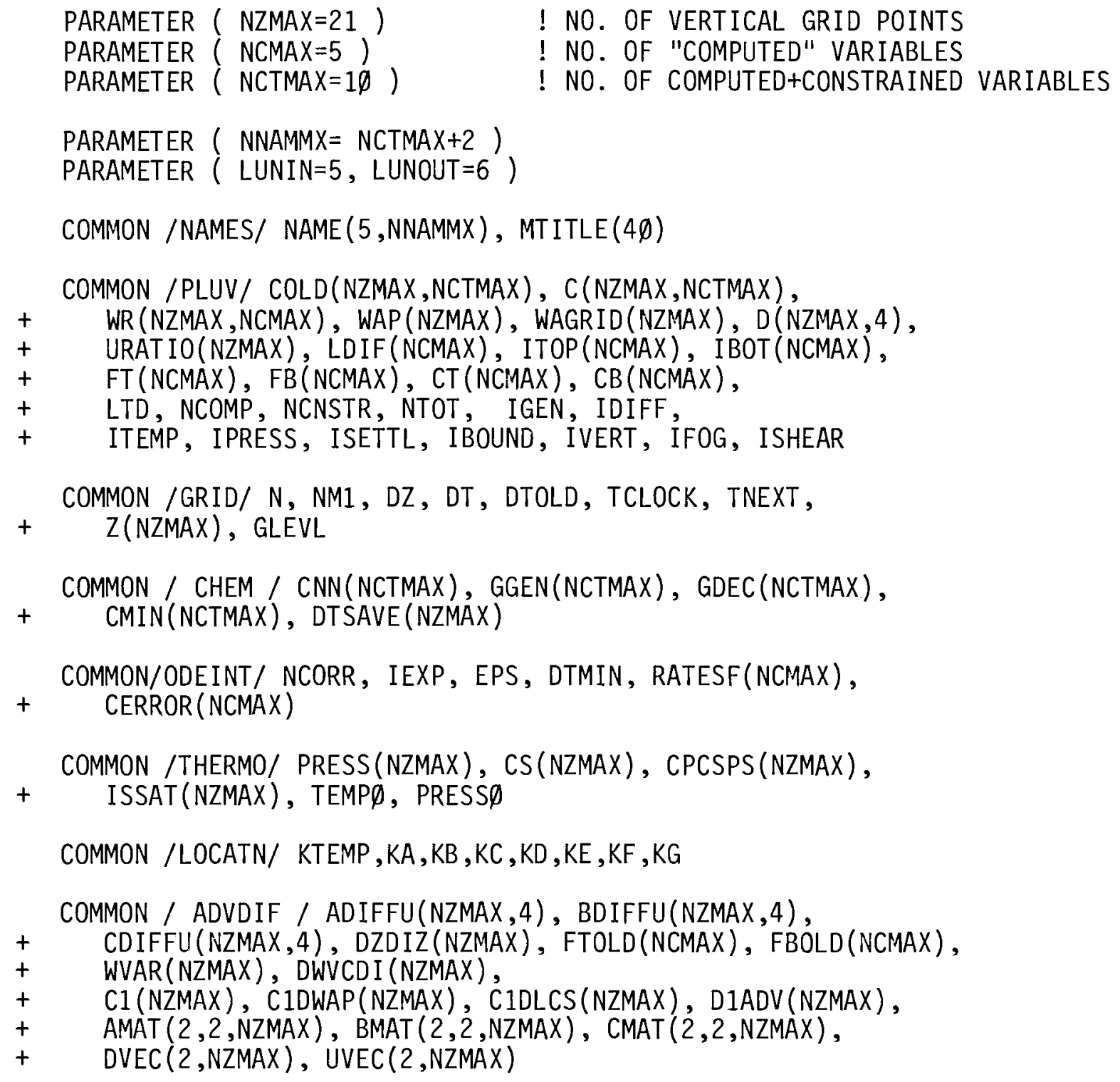


TABLE 3-3. Summary of Class I Subroutines

\begin{tabular}{|c|c|}
\hline Subroutinc & Purpose \\
\hline ADJUST & $\begin{array}{l}\text { Modifies species values after advec- } \\
\text { tion integration step to meet imposed } \\
\text { physical constraints. }\end{array}$ \\
\hline BOUND & $\begin{array}{l}\text { Sets boundary condition values for } \\
\text { flux and concentration specified } \\
\text { boundary conditions. }\end{array}$ \\
\hline DIFF & $\begin{array}{l}\text { Sets vertical eddy diffusivity } \\
\text { coefficients. }\end{array}$ \\
\hline GEN & $\begin{array}{l}\text { Sets source and sink terms (physico- } \\
\text { chemical generation and loss) for } \\
\text { computed species. Also computes } \\
\text { constrained species. }\end{array}$ \\
\hline GRDSET & Sets vertical grid spacing. \\
\hline SETTL & $\begin{array}{l}\text { Sets settling velocity, } w_{r} \text {, for computed } \\
\text { species. }\end{array}$ \\
\hline SETUP & $\begin{array}{l}\text { Sets initial values of computed and } \\
\text { constrained variables. }\end{array}$ \\
\hline T IMESP & Sets integration time step DT. \\
\hline USHEAR & $\begin{array}{l}\text { Sets horizontal air speed factor, } \\
u^{\star} / u_{A} \text {. }\end{array}$ \\
\hline VERT & $\begin{array}{l}\text { Sets the two components of the air vertical } \\
\text { velocity, } W_{A 0} \text { and } W_{A} \text { '. }\end{array}$ \\
\hline
\end{tabular}


system. ADJUST is applied after each advection integration step. The advection step may result in an "unphysical" relation between two closely linked species at a grid point, and an adjustment of these species is desirable. Also, some processes are more amenable to treatment by "adjustment" then by a rate law, such as nucleation scavenging of aerosols (see Section 5 ).

If there are no constraints of this type, then ADJUST should be supplied simply as a no operation stub. ADJUST does not have an associated bypass variable.

SUBROUTINE BOUND computes upper- and lower boundary conditions at each time step (if desired) for each of the computed species. If a boundary condition for species $K$ is flux specified, then the appropriate flux value must be assigned to $F B(K)$ and/or $F T(K)$, where $F B$ and $F T$ are the vertical pollutant fluxes at the bottom and top boundaries. Fluxes are positive upwards and units are gram-moles $/\left(\mathrm{cm}^{2} \mathrm{sec}\right)\left[\right.$ or ergs $/\left(\mathrm{cm}^{2} \mathrm{sec}\right)$ for temperature]. If a boundary condition is concentration-specified (inflow condition), then an appropriate concentration value is assigned to $C B(K)$ (bottom boundary) or CT(K) (top). Outflow-specified boundary conditions are handled computationally and require no treatment in BOUND. If all boundary conditions do not vary with time, then the bypass variable IBOUND should be set to zero, and BOUND will be called only once, during initialization.

SUBROUTINE DIFF establishes the vector of vertical diffusion coefficients for each diffusion regime, $D(I, L), I=1, \ldots, N, L=1, \ldots, L T D$. Units are $\mathrm{cm}^{2} / \mathrm{sec}$. Because of the finite-differencing procedure, $D(I, L)$ is defined as the diffusivity between grid points I and $I+1$. Remember that the diffusivity regime for temperature uses $L=1$ and cannot be used for any other - species. If diffusivities do not change with time, then repeated interrogations of this subroutine should be suppressed by setting IDIFF $=0$.

SUBROUTINE GEN is used to specify chemical transformation and interphase transfer rates for each species, and is one of the most important class I subroutines. These rates comprise the right-hand side of Equation (43), and are expressed as

$$
G_{K}=\operatorname{GGEN}(K)-\operatorname{GDEC}(K)
$$


where $\mathrm{GGEN}(\mathrm{K})$ is the generation rate (source terms) and GDEC is the decay rate (sink terms) for species $K$. For situations in which temperature is treated as a computed variable,

$$
\frac{\dot{H}^{\star}}{C^{\star} \times C_{p}}=\operatorname{GGEN}(\text { KTEMP) }-\operatorname{GDEC}(\text { KTEMP) }
$$

as indicated in Equation (47). [Note that $c^{\star} \times C_{p}$ is computed in SUBROUTINE TEMPF and stored in the array CPCSPS(I), I $=1, \ldots, N]$.

Segregation of $G$ into generation and decay terms is necessary because of requirements of the calling routine, ODEINT, which performs numerical integrations of the rate terms. It should be noted, however, that such segregation is mandatory only for stiff mathematical systems. If the species of interest reacts only slowly and does not approach equilibrium, then it is permissible to set GDEK $=0$, and consolidate both sources and sink terms into GGEN. Further discussion of this stiffness property and the ODEINT integrator are given in Appendix B.

GEN is also used for calculating constrained variables. These include variables that are computed on the basis of equilibrium assumptions, as well as those determined in a variety of possible alternative ways. These computations are performed in GEN because for many systems, the calculation of equilibrium or steady-state species is often intertwined with the calculation of rates of change for nonequilibrium species.

A minor inefficiency results from this organization because constrained species must be recomputed before output occurs. Thus the flag IGCALC is provided in calls to GEN. When IGCALC is positive, both constrained variables and generation and decay rates must be calculated. When IGCALC is zero, only constrained variables are needed. Some improvement in efficiency will result if the two calculations can be segregated, but the user should not try to force this segregation if it is unnatural for the problem at hand.

GEN is different from the other Class I subroutines in that GEN is called separately for each vertical grid point. The vertical index, $I$, is passed to 
GEN as a subroutine parameter. GEN uses the one-dimensional array CNN to hold current values of the dependent variables.

If the bypass variable IGEN is set nonpositive, then GEN is not called at al1, and the integration of the generation component (Equation 43 and 45) is skipped.

SUBROUTINE GRDSET establishes the vertical finite-difference grid by assigning values to the grid-height array, $Z(I)$. Grid spacing may be uniform $[Z(I)-Z(I-1)=$ constant $]$, or nonuniform, at the user's preference. For a uniform grid, the input variable $D Z$ can be used to specify the grid spacing $[Z(I)=(I-1) * D Z]$. GRDSET is called only once, during initialization, and the grid spacing remains fixed during a model run.

SUBROUTINE SETTL computes settling velocities, $w_{r}$, as defined in Equation (4). Settling velocities for each species (K) at each grid location (I) are assigned to array elements $W R(I, K)$. Units are $\mathrm{cm} / \mathrm{sec}$, and downward velocities are negative. Many species (gases, submicron aerosols, temperature) will have zero or negligible settling velocities, whereas precipitation-borne species will have significant fall velocities. If the bypass variable ISETTL is set nonpositive, then SETTL is called only once, during initialization.

SUBROUTINE SETUP sets the initial values of computed and constrained variables. Constrained variables may be set directly, or by calling GEN. After the initial temperature values are set, a call to PRESSF should be made to set pressure and air density. Other important tasks performed by SETUP are assigning values to species location variables, and initializing several parameters used by the ODEINT integrator. SETUP is called only once by PLUVIUS, during initialization.

SUBROUTINE TIMESP defines the basic integration time step, DT, for the next pass through the major computation 1oop. DT is completely variable from one time step to the next. It can be set to a constant value throughout the computation, or it may be adjusted to meet user demands. From an efficiency standpoint, it is desirable that DT be large. When vertical advection is significant, then computational constraints place limits on DT (see Example Application 2). 
SUBROUTINE USHEAR is necessary for two-dimensional, steady-state simulations involving wind shear. The subroutine sets the vector

$$
\operatorname{URATIO}(I)=\frac{U^{*}}{u_{A / Z}(I)} \quad, I=1, \ldots, N
$$

where the ratio on the right hand side is from Equation (13) and (36). For simulations with no shear (which includes all one-dimensional time-dependent simulations), URATIO should be set equal to 1 . When the bypass variable ISHEAR is set non-positive, USHEAR is called only once, during initialization.

SUBROUTINE VERT is used to set the vertical air velocity, $W_{A}$. In computations involving cloud and precipitation formation, $W_{A}$ is a very important parameter since the rate of moisture condensation is directly proportional to it. As indicated in Equations (8) and (11), the vertical air velocity is partitioned into two sub-components: the "grid vertical velocity", which is the rate of change of the vertical position of the computational grid, and the "relative vertical air velocity", which is the velocity of upward airflow through the computational grid. VERT simply assigns the grid vertical velocity values to the vector WAGRID(I), and the relative vertical air velocity values to the vector WAP(I). Units are $\mathrm{cm} / \mathrm{sec}$.

For one-dimensional time-dependent simulations [Equation (8)], the grid vertical velocity is given by $w_{A 0}$ and is thus constant with height. For the two-dimensional, steady-state simulations with horizontal wind shear, the vertical grid velocity is given by $w_{A 0} \cdot\left(u_{A} / u_{A 0}\right)$ [Equation (11)], and will vary with height. Using the variable URATIO, which is set in SUBROUTINE USHEAR, we can write

$$
\begin{aligned}
\text { WAGRID(I) } & \equiv \text { vertical grid velocity at grid I } \\
& \equiv w_{A O}\left(\frac{u_{A}}{u_{A 0}}\right)=w_{A o}\left(\frac{u^{\star}}{u_{A 0}}\right) /\left(\frac{u^{\star}}{u_{A}}\right) \\
& =\text { WAGRID(1)*URATIO(1)/URATIO(I). }
\end{aligned}
$$


Note that $w_{A O}$ is defined as the grid vertical velocity at the surface (bottom grid). VERT also has a bypass variable, IVERT, which, when set non-positive, causes VERT to be called only once, during initialization.

\section{Class II Subroutines}

As noted previously, Class II subroutines are not normally intended for user modification (modify at your own risk!), and thus will not be discussed in detail here. The subroutines group naturally into three subclasses: computational routines involved in the numerical integrations, thermodynamic routines, and output routines. The names and purposes of these subroutines

- are summarized in Table 3-4 for overview purposes. Complete listings of all Class II subroutines are presented in Appendix C, along with a description of many of the variables used throughout the code. The user may wish to tailor the two output routines to his specific needs, and this can generally be done without fear of side effects on the rest of the code.

\section{E. "ZERO-DIMENSIONAL" TESTING FACILITY}

When working with complex physicochemical systems, it is desirable to test the generation component of the model (SUBROUTINE GEN) with only 1 or 2 grid points, rather than 20 or 30 , simply to reduce computer usage. With a grid of this size (1 or 2), the advection and diffusion terms become meaningless. In PLUVIUS MOD 5.0, there is a facility which essentially bypasses the transport integration when the number of vertical grid points, $N$, is specified as 1 or 2 in the input data. Thus the user may switch back and forth between complete runs and generation component tests, simply by changing $N$ in the input data.

In actuality, SUBROUTINE ADVINT is not completely bypassed. However, when $N$ is 1 or 2, ADVINT skips its normally executed code and instead calls SUBROUTINE ZERODM. ZERODM simulates those physical effects that result if the grid is moving vertically with grid velocity WAGRID(1). If the grid is rising, then 1) pollutant concentrations decrease slowly because the air is expanding, and 2) the temperature cools adiabatically (if it is a "computed" 
TABLE 3-4. Summary of Class II Subroutines

\begin{tabular}{|c|c|c|}
\hline Sub-Class & Subroutine & Purpose \\
\hline \multirow[t]{11}{*}{$\begin{array}{l}\text { Computa- } \\
\text { tional }\end{array}$} & ADV INT & $\begin{array}{l}\text { Performs numerical integration of the } \\
\text { advection-diffusion component of the } \\
\text { governing equations. }\end{array}$ \\
\hline & CHMINT & $\begin{array}{l}\text { Controls the numerical integration of } \\
\text { the generation component of the govern- } \\
\text { ing equations. (Actual integration } \\
\text { performed by ODEINT.) }\end{array}$ \\
\hline & DERIV & $\begin{array}{l}\text { Provides species independent coefficients } \\
\text { for the mass balance equation to ADVINT. }\end{array}$ \\
\hline & FILTER & $\begin{array}{l}\text { Applies nonlinear filter after each } \\
\text { advection-diffusion integration step to } \\
\text { reduce "short-wave noise" (see Appendix A) }\end{array}$ \\
\hline & FIRSTD & $\begin{array}{l}\text { Calculates the first vertical derivative } \\
\text { of a vector. }\end{array}$ \\
\hline & ODEINT & $\begin{array}{l}\text { Performs actual numerical integration of } \\
\text { the generation component of the governing } \\
\text { equations (called by CHMINT). }\end{array}$ \\
\hline & SETVEC & $\begin{array}{l}\text { Provides species dependent coefficients } \\
\text { for the mass balance equation to ADVINT. }\end{array}$ \\
\hline & TEMPF & $\begin{array}{l}\text { Provides coefficients for the energy } \\
\text { balance equation to ADVINT. }\end{array}$ \\
\hline & TRIDG2 & $\begin{array}{l}\text { Solves simultaneous linear equations with } \\
\text { tridiagonal coefficient matrix, when } \\
\text { unknowns are two-element vectors. }\end{array}$ \\
\hline & TRIDAG & $\begin{array}{l}\text { Solves simultaneous } 1 \text { inear equations with } \\
\text { tridiagonal coefficient matrix, when } \\
\text { unknowns are scalars. }\end{array}$ \\
\hline & ZERODM & $\begin{array}{l}\text { Computes affects of vertical motions for } \\
\text { "zero-dimensional" mode. }\end{array}$ \\
\hline \multirow[t]{2}{*}{$\begin{array}{l}\text { Thermo- } \\
\text { dynamic }\end{array}$} & PRESSF & $\begin{array}{l}\text { Computes pressure by integrating the } \\
\text { hydrostatic equation and sets air } \\
\text { densities. }\end{array}$ \\
\hline & RHOAIR & $\begin{array}{l}\text { Function returns air density for specified } \\
\text { temperature and pressure. }\end{array}$ \\
\hline
\end{tabular}


TABLE 3-4 Continued

Sub-class

Output
Subroutine

RLAPSE

SAT

COLLECT

PRINT
Purpose

Function returns dry or moist adiabatic lapse rate for specified temperature and air density.

Function returns saturation vapor concentration over water for specified temperature.

Writes model results to mass storage for later plotting, etc.

Writes model results to 1 ine printer. 
variable). If WAGRID(1) is set to zero, then ZERODM has no effect whatever, and only the generation component of the code is exercised. The ability to specify a non-zero vertical velocity can be useful when the simulation includes cloud formation processes. 
4. EXAMPLE APPLICATION 1:

SIMPLE AIR CHEMISTRY AND DRY DEPOSITION

This section describes a very simplistic application of the PLUVIUS code. The purpose of this application is to provide an uncomplicated example of the use of the Class I subroutines and the input to and output from a PLUVIUS run. Because of this the physics and chemistry in the example have been purposely kept to a minimum.

The example simulates the evolution of a line-source plume. The plume is held in a 1-km-deep boundary layer which is capped by an impervious inversion, and the line source is at a height of $0.5 \mathrm{~km}$. The plume is advected downwind from the source by a horizontal wind which is constant in height, so the example is treated as one-dimensional, time-dependent. The simulation begins at a position corresponding to a travel time of 500 seconds from the source, and runs for an additional 3000 seconds.

There are eight dependent variables in the example: seven hypothetical species, labeled "A" through "G", and temperature. The physical and chemical properties of these variables are summarized in Table 4-1. Species $A, B, C$, and $D$ are "source" species in the plume. Species A and B are chemically inert, while $C$ and $D$ react to form the product species $E$. Species $F$ represents a constrained "background" variable which has a constant mixing ratio. Species $G$ is a constrained variable which is in equilibrium with $C$ and $F$. Temperature is treated as a constrained variable in this example, following a dry adiabatic lapse rate.

\section{A. INPUT DATA}

Input data for this example are given in Table 4-2, and they should be compared with the input statements described in Section 3 . The first input line is a run title which will appear on the printed output. The second input line specifies that there are five computed variables and three 
TABLE 4-1. Summary of Properties of Species in Example Application 1

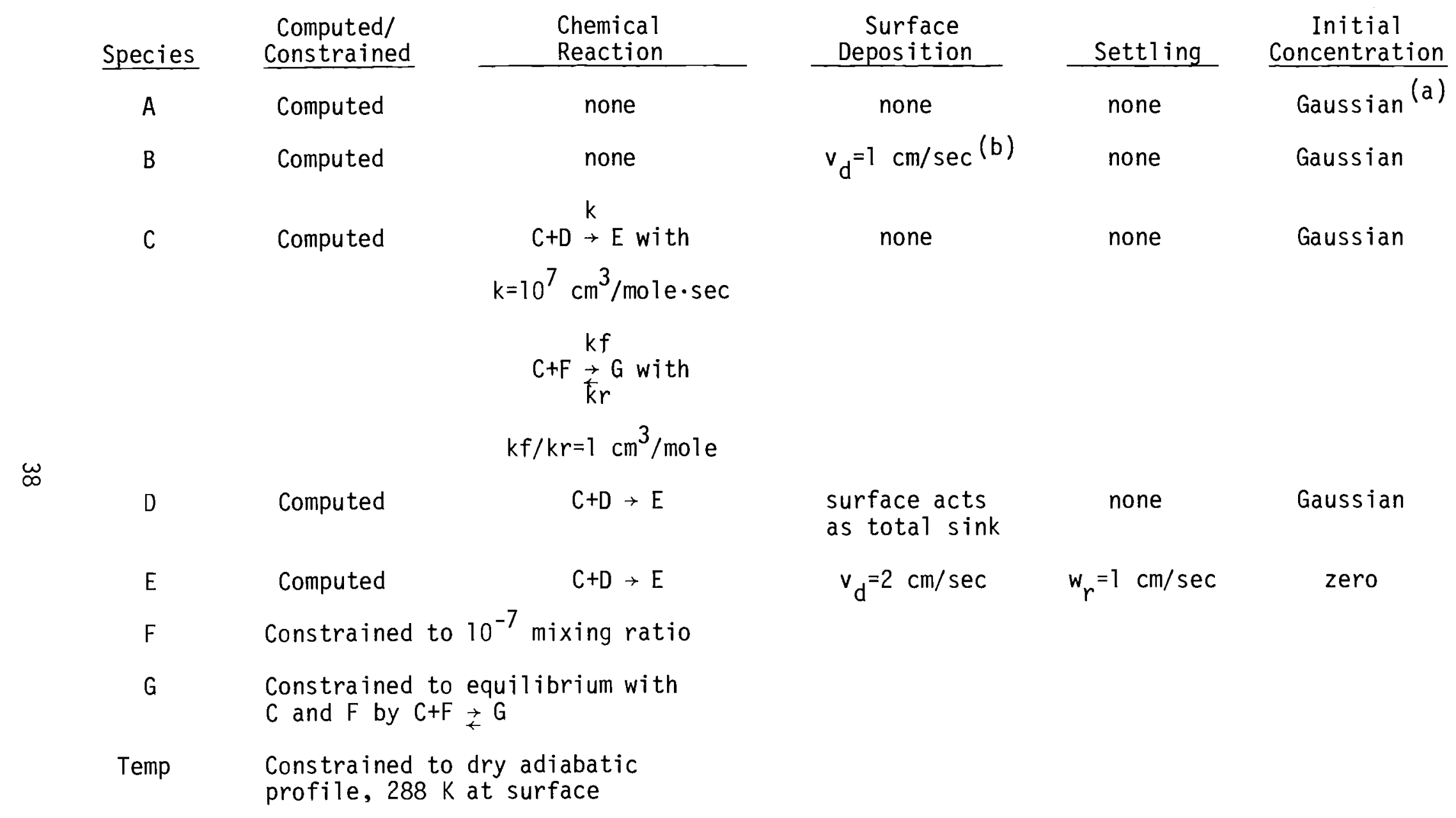

(a) Gaussian - see discussion in text.

(b) $v_{d}$ is deposition velocity. 
TABLE 4-2. Input Data For Example 1.

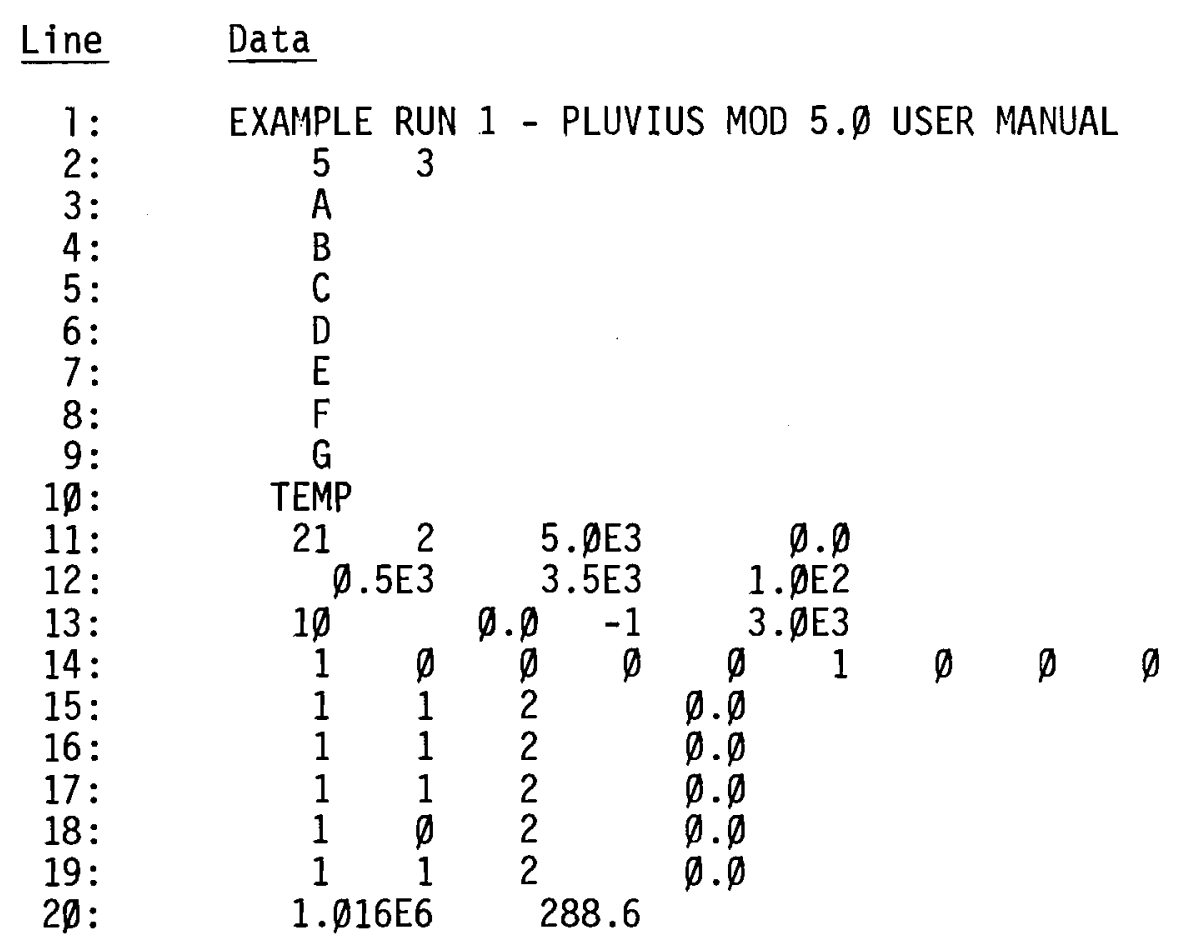


constrained variables in the example. The next eight input lines provide names for each variable, for use during program output.

Input 1 ine 11 specifies that the vertical grid consists of 21 grid points, that there are two "diffusion regimes", that the uniform grid spacing is $5000 \mathrm{~cm}$, and that the initial height of the bottom grid point (GLEVL) is at $0 \mathrm{~cm}$. Input 1 ine 12 specifies that the simulation begins at a time of 500 seconds, terminates at a time of 3500 seconds, and uses an initial integration time step of 100 seconds. Input 1 ine 13 specifies output control information. As NPRINT is specified positive (5), printed output will occur after every fifth integration cycle (remember that an integration cycle involves two advection-diffusion time steps). As ITCOLL is specified to be zero, no output to disk file will be made.

Input line 14 specifies the bypass variables. Only IGEN and IBOUND are positive, so only the CLASS I subroutines GEN and BOUND will be interrogated regularly. For this example, the information that is provided by the other CLASS I subroutines does not change with time, so the subroutines only need to be interrogated once at the start of the program.

Input lines 15 through 19 specify the boundary conditions, diffusion regimes, and filter factors for each of the five computed species. Each species uses diffusion regime 2 (remember that regime 1 is reserved for temperature). No filtering is applied (FILFAC =0.). All the species besides $D$ have flux-specified boundary conditions at both the top and bottom boundaries. Species $D$ has a concentration-specified bottom boundary condition. The final input line specifies initial surface pressure and temperatures of $1.016 \cdot 10^{6}$ dynes $/ \mathrm{cm}^{2}$ and $288.6 \mathrm{~K}$.

\section{B. CLASS I SUBROUTINE DESCRIPTIONS}

As discussed in Section 3, the ten Class I subroutines are the primary mechanism by which the physics and chemistry appropriate to a particular application are inserted into the PLUVIUS framework. Thus it is extremely important that the user have a good understanding of the function of each. The listings and discussions of these subroutines for our simple example 
which are given below should serve to clarify the initial subroutine descriptions of Section 3 .

SUBROUTINIE SETUP (Table 4-3)

SETiJP defines the initial concentration profiles for the dependent variables and state variables, and also defines the species location variables.

The species location variables are defined in the initial data statements; e.g., the variable $K A$ is used as a location index for species $A$ and rias a value 1 . Note that these values must correspond exactly to the oirdering of species given in the input data (e.g., A is first, and TEMP is las:.). The next data statements initialize parameters used by ODEINT.

The first executable statements compute the initial temperature profile, which follows a dry adiabatic lapse rate. Next, subroutine PRESSF is called whic'n computes the initial pressure and air density fields. Note that air density is used to initialize some of the other species in terms of mixing ratio, so the thermodynamic variables are computed first.

Next, the species A through G are initialized. The four "Gaussian" species are initialized so that their mixing ratios follow a Gaussian distribution, peaked at $0.5 \mathrm{~km}$ with a peak mixing ratio value of $10^{-6}$. The initial vertical plume-spread parameter, SIGMAZ, is $10^{4} \mathrm{~cm}$ and was chosen to correspond to 500 seconds of travel time from a line source at a specified diffusivity of $10^{5} \mathrm{~cm}^{2} / \mathrm{sec}$. Species $E$ is initialized to a zero concentration.

SUBROUTINE ADJUST (Table 4-4)

In this simple example, no "adjustment" is required. Thus the subroutine is provided as a do-nothing "stub."

SUBROUTINE BOUND (Table 4-5)

BOUND provides values for flux or concentration specified boundary conditions. For this example, the top boundary is an impervious inversion, so the flux at the top boundary (FT) is set to zero for each of the computed species. Species $A$ and $C$ are non-depositing (see Table 4-1), so their fluxes at the bottom boundary (FB) are also zero. 
TABLE 4-3. Listing of Subroutine SETUP for Example Application 1

SUBROUTINE SETUP

INCLUDE 'PLUVCMN'

C ESTABLISH SPECIES INDEX NAMES AND CONVERSION FACTORS

C

DATA KA, KB, KC, KD, KE, KF, KG $/ 1,2,3,4,5,6,7 /$

DATA KTEMP/8/

C

C

ESTABLISH PARAMETERS USED IN O.D.E. INTEGRATION ROUTINE (ODEINT)

DATA EPS/1.E-2/, DTMIN/1.E-15/, RATESF/NCMAX*1.E-2/

DATA NCORR/1/, IEXP/Ø/

DATA CMIN/NCTMAX $1 . E-25 /$

DATA CERROR/NCMAX $\star 1 . E-21 /$

$c$

C ESTABLISH INITIAL TEMPERATURE AS DRY ADIABATIC, THEN CALL

C PRESSF TO COMPUTE PRESSURE AND AIR DENSITY

C

$C(1, K T E M P)=$ TEMP $\emptyset$

TMPDUM = TEMP $\emptyset$

DO $I=2, N$

TMPDUM $=$ TMPDUM $-9.76 E-5^{\star}(Z(I)-Z(I-1))$

END DO

$C(I, K T E M P)=$ TMPDUM

CALL PRESSF (1)

C

C SET INITIAL VALUES OF SPECIES CONCENTRATIONS FOR COMPUTED SPECIES

C

DO $I=1, N$

$$
\begin{aligned}
& \mathrm{I}(\mathrm{I}, \mathrm{KA})=1 . \mathrm{E}-6 * \mathrm{CS}(\mathrm{I}) * \operatorname{EXP}(-(\mathrm{Z}(\mathrm{I})-50000 .) * * 2 / 2 . \mathrm{E} 8) \\
& C(\mathrm{I}, \mathrm{KB})=C(\mathrm{I}, \mathrm{KA}) \\
& C(\mathrm{I}, \mathrm{KC})=C(\mathrm{I}, \mathrm{KA}) \\
& C(\mathrm{I}, \mathrm{KD})=C(\mathrm{I}, \mathrm{KA}) \\
& C(\mathrm{I}, \mathrm{KE})=\emptyset . \\
& D O=\emptyset
\end{aligned}
$$

END DO

\section{RETURN}

END 
TABLE 4-4. Listing of Subroutine ADJUST for Example Application 1

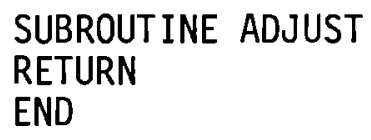

TABLE 4-5. Listing of Subroutine BOUND for Example Application 1

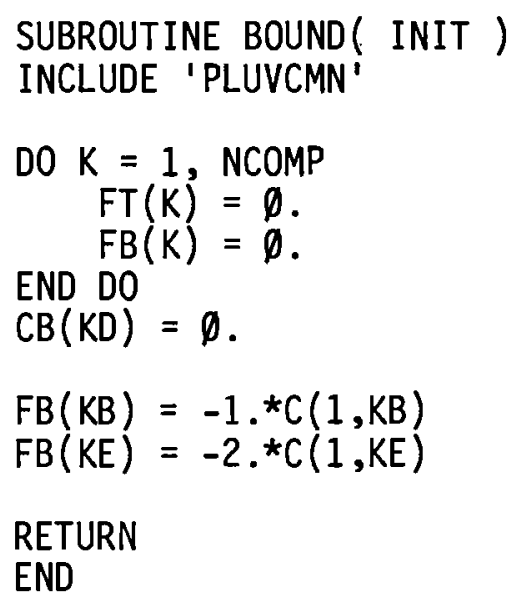

TABLE 4-6. Listing of Subroutine DIFF for Example Application 1

SUBROUTINE DIFF (INIT)

INCLUDE 'PLUVCMN'

DO I $=1, N$

END DO

$$
D(I, 2)=1000 \emptyset \emptyset \text {. }
$$

RETURN

END 
Species $B$ and $E$ dry deposit with deposition velocities of 1 and 2 $\mathrm{cm} / \mathrm{sec}$, respectively. For these species, the bottom flux is just the product of the current concentration and the deposition velocity (with negative sign). For species $D$, the surface acts as a total sink, so its concentration is always zero at the bottom boundary. This is accomplished by setting $C B(K D)$ equal to zero.

SUBROUTINE DIFF (Table 4-6)

DIFF sets the vertical eddy diffusivities for each diffusion regime. In this example, two diffusion regimes are required, but regime 1 is never used, since it is reserved for temperature and temperature is a constrained variable in this case. For regime 2, a constant eddy diffusivity of $10^{5} \mathrm{~cm}^{2} / \mathrm{sec}$ is used. Because the diffusivity is constant in time, the bypass variable IDIFF can be set to zero.

SUBROUTINE GEN (Table 4-7)

GEN computes generation and decay rates for the computed species, and also sets constrained species. The first part of the example routine sets the values for species $F$ and $G$. The reader may wonder why temperature is not set here also, since it too is a constrained species. For this example, temperature is constant in time, and was already initialized in SETUP. Thus there is no computational need to reset its value in GEN. Constrained species whose concentrations change with time should be set in GEN, but those that are constant in time may be established in SETUP, at the user's preference.

The second portion of GEN computes generation and decay rates. Of the two reactions shown in Table 4-1, only the first, which involves $C, D$, and $E$, need be treated here. The others simulate an equilibrium situation, and so produce no net gain or loss. Note that GEN works with the CNN array, rather than the $C$ array.

SUBROUTINE GRDSET (Table 4-8)

GRDSET establishes the vertical spacing of the computational grid. For this example, a uniform spacing is used, so the code is trivial. For uniform spacing, the input variable $D Z$ can be used to read in the grid spacing. 
TABLE 4-7. Listing of Subroutine GEN for Example Application 1

SUBROUT INE GEN( I, IGCALC, TGEN, DTAU, JPASSO )

INCLUDE 'PLUVCMN'

$c$
C

C SET CONSTRAINED VARIABLES

$\mathrm{CNN}(\mathrm{KF})=1 \cdot \mathrm{E}-7 * \mathrm{CS}(\mathrm{I})$

$\operatorname{CNN}(K G)=\operatorname{CNN}(K F) \star C N N(K C)$

IF (IGCALC .EQ. $\emptyset$ ) RETURN

$-\quad c$
0
0

$c$
$C$
$C$

SET GENERATION AND DECAY RATES

DO $K=1, N C O M P$

$\operatorname{GGEN}(K)=\emptyset$.

END DO $\operatorname{GDEC}(K)=\emptyset$.

$\operatorname{GDEC}(K C)=\operatorname{CNN}(K C) \star \operatorname{CNN}(K D) \star 1 . E 7$

$\operatorname{GDEC}(K D)=\operatorname{GDEC}(K C)$

$\operatorname{GGEN}(K E)=\operatorname{GDEC}(K C)$

RETURN

END

TABLE 4-8. Listing of Subroutine GRDSET for Example Application 1

SUBROUTINE GRDSET

INCLUDE 'PLUVCMN'

$Z(1)=\emptyset$.

DO I $=2, N$

END DO

$Z(I)=Z(I-1)+D Z$

RETURN

END 
SUBROUTINE SETTL (Table 4-9)

SETTL establishes the settling velocities of the computed variables. For this example, only species $E$ has a settling velocity, $1 \mathrm{~cm} / \mathrm{sec}$. This velocity is constant with time, so the bypass variable ISETTL can be set to zero. SUBROUTINE TIMESP (Table 4-10)

TIMESP sets the basic integration time step, DT. In this example, there are no serious computational limitations, and a fixed time step of 100 seconds is used. A fixed time step can be established when the initial value of DT is read in as part of the input, so TIMESP does nothing in this example.

SUBROUTINE USHEAR (Table 4-11)

USHEAR establishes the ratio URATIO $=u^{\star} / u_{A}$. For one-dimensional, time-dependant simulations, this ratio is always unity.

SUBROUTINE VERT (Table 4-12)

VERT establishes the two components of the air vertical velocity. In this example, the air vertical velocity is zero throughout the simulation, so the code is trivial.

\section{EXAMPLE OUTPUT}

Some of the output for this example application is shown in Tables 4-13 to 4-15. Table 4-13 shows a heading page which is produced at the start of each run. The page summarizes the dependent variables and other control data provided as input.

Table 4-14 shows the initial species concentrations at the start of the simulation, at time TCLOCK $=500$ seconds. Each column in the table shows a particular dependent variable. Pressure ("P") and air density ("CS") are also listed. Each row corresponds to a different vertical grid point. Heights are shown in kilometers to improve readability, although centimeters are used internally in the program. The four "Gaussian" species, A through $D$, have identical initial concentration profiles which maximize at $0.5 \mathrm{~km}$ above ground level. These distributions are slightly skewed with height 
TABLE 4-9. Listing of Subroutine SETTL for Example Application 1

SUBROUTINE SETTL(INIT)

INCLUDE 'PLUVCMN'

DO I $=1, N$

DO $K=1, N C O M P$

END DO $W R(I, K)=\emptyset$.

END DO

$\mathrm{WR}(\mathrm{I}, \mathrm{KE})=-1$.

RETURN

END

TABLE 4-10. Listing of Subroutine TIMESP for Example Application 1

SUBROUTINE TIMESP

INCLUDE 'PLUVCMN'

$\mathrm{DT}=190$.

RETURN

END

TABLE 4-11. Listing of Subroutine USHEAR for Example Application 1

$c$
$C$
$c$
$c$
$c$
$c$
$c$

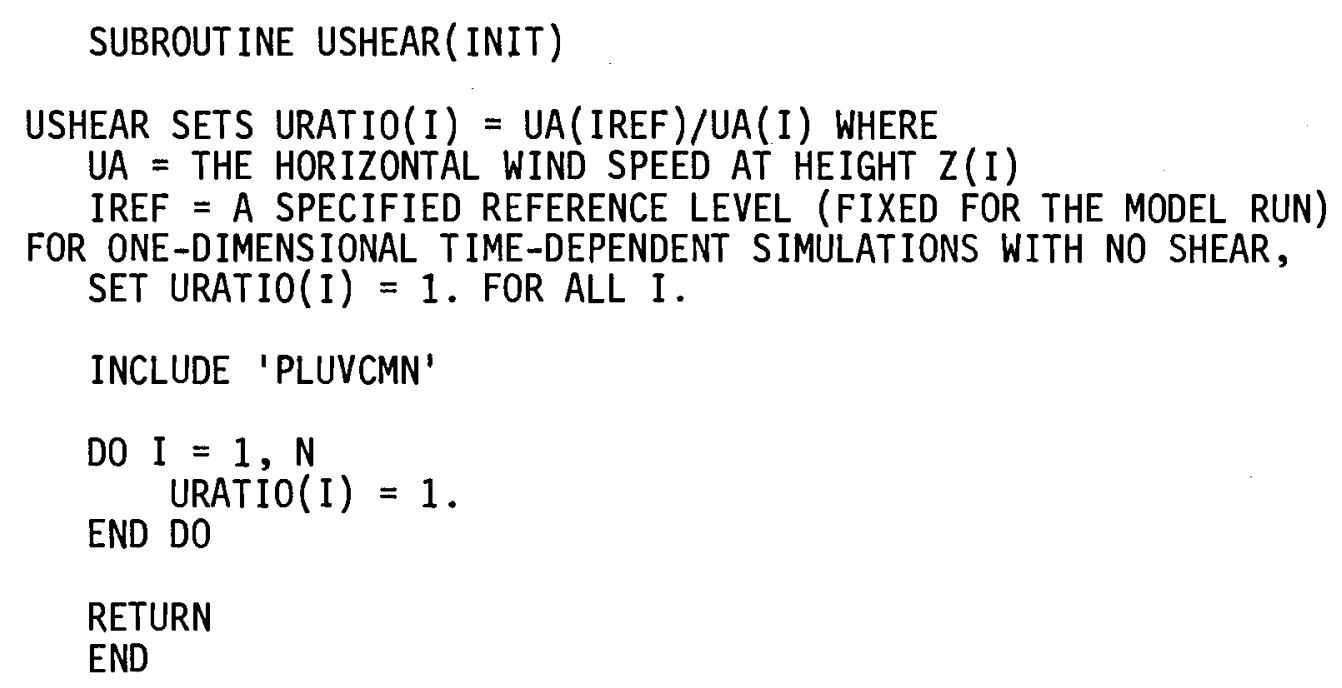

RETURN

END 
TABLE 4-12. Listing of Subroutine VERT for Example Application 1

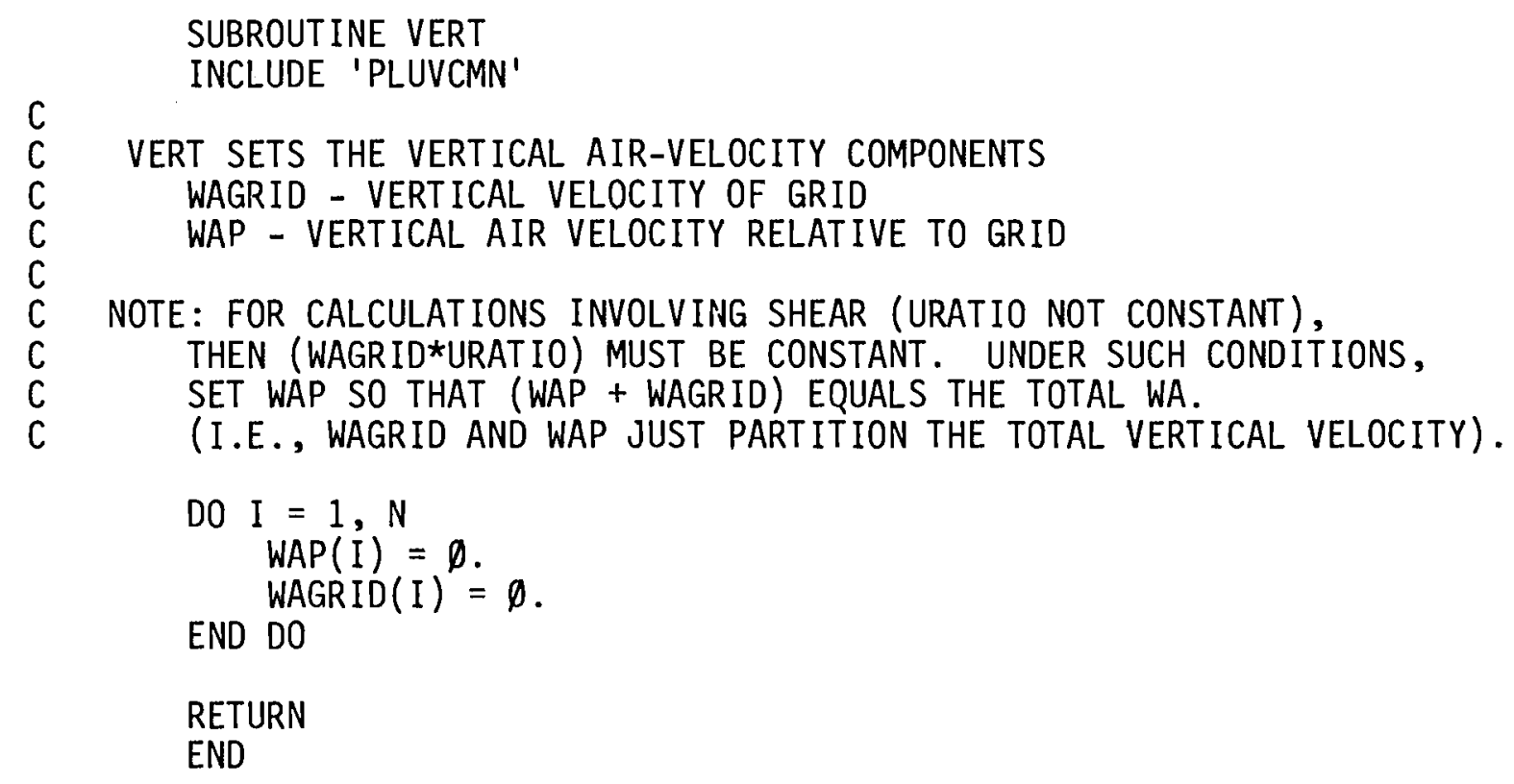


TABLE 4-13. Output Heading Page From Example Application 1

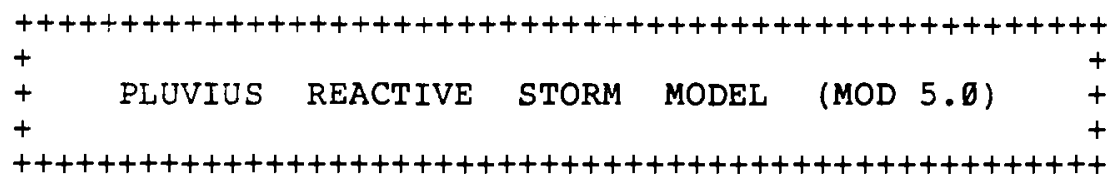

RUN ID: EXAMPLE RUN 1 - PLUVIUS MOD 5.0 USER MANUAL

COMPUTED SPECIES TOP B.C. BOTTOM B.C. DIFFUS. REGIME FILTER FACT.

\begin{tabular}{cc}
1 & A \\
2 & $\mathrm{~B}$ \\
3 & $\mathrm{C}$ \\
4 & $\mathrm{D}$ \\
5 & $\mathrm{E}$ \\
CONSTRAINED \\
\multicolumn{3}{c}{} \\
7 & $\mathrm{~F}$ \\
8 & $\mathrm{G}$ \\
8 & TEMP
\end{tabular}

CONTROL DATA

$\begin{array}{ll}\text { FLUX } & \text { FLUX } \\ \text { FLUX } & \text { FLUX } \\ \text { FLUX } & \text { FLUX } \\ \text { FLUX } & \text { CONC. } \\ \text { FLUX } & \text { FLUX }\end{array}$

$\begin{array}{ll}2 & 0.00 \\ 2 & 0.00 \\ 2 & 0.00 \\ 2 & 0.00 \\ 2 & 0.00\end{array}$

0.00

0.00

0.00

0.00

0.00

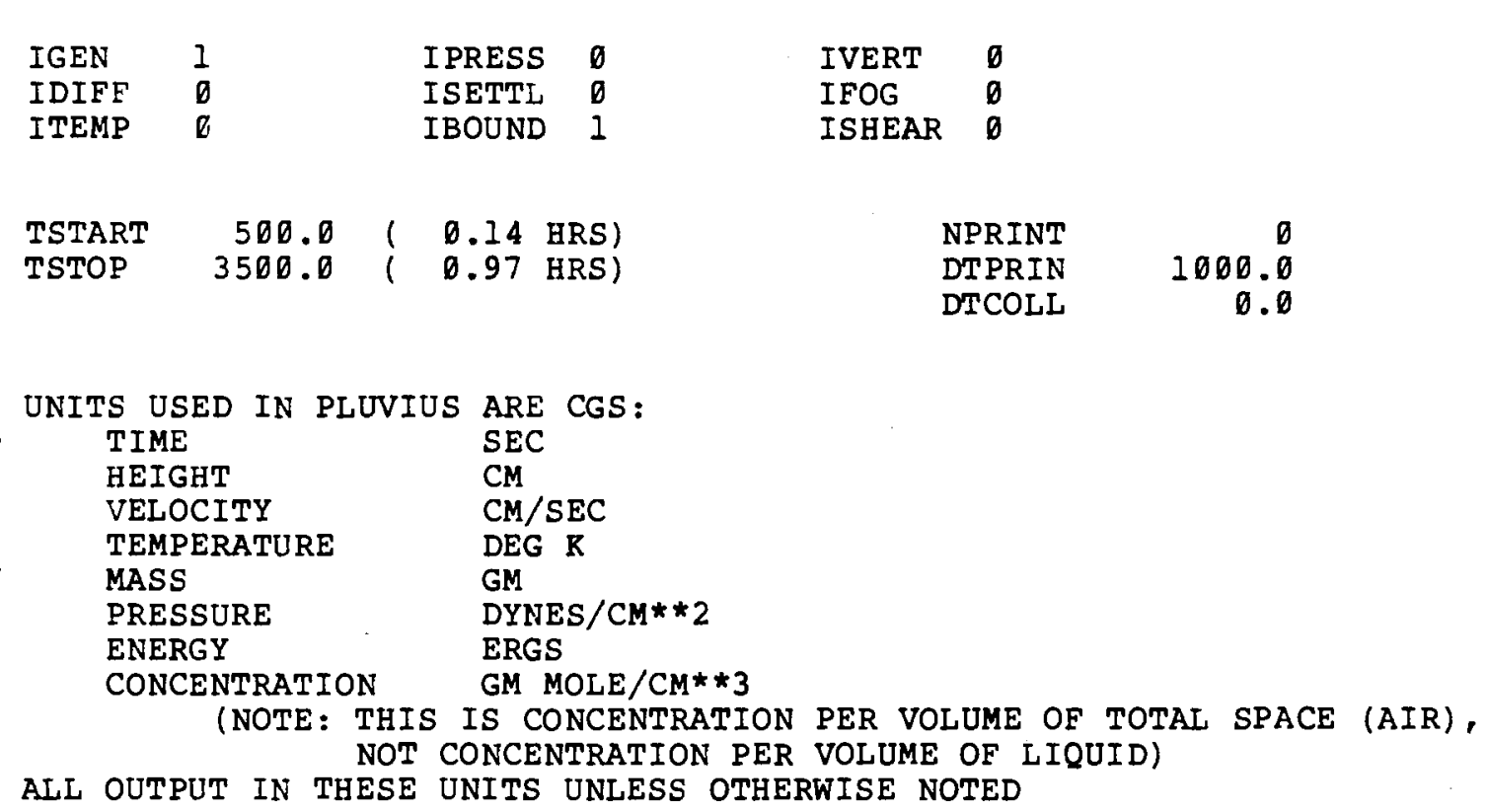

ALL OUTPUT IN THESE UNITS UNLESS OTHERWISE NOTED 
TABLE 4-14. Model Output at TCLOCK $=500$ Seconds From Example Application 1

\begin{tabular}{|c|c|c|c|c|c|c|c|c|c|}
\hline $\begin{array}{l}\text { TCLOCK } \\
\text { DT }\end{array}$ & $\begin{array}{l}500.00 \\
100.00\end{array}$ & ( & 0.139 HRS) & & $\begin{array}{l}\text { GLEVL (KM) } \\
\text { WAGRID(1) }\end{array}$ & $\begin{array}{r}0.000 \\
0.00\end{array}$ & & & \\
\hline$Z(\mathbf{K M})$ & A & B & C & D & E & F & G & TEMP & $\mathbf{P}$ \\
\hline
\end{tabular}

$1.000 \quad 0.1448 \mathrm{E}-15 \quad 0.1448 \mathrm{E}-15 \quad 0.1448 \mathrm{E}-15 \quad 0.1448 \mathrm{E}-15 \quad 0.1000 \mathrm{E}-24 \quad 0.3885 \mathrm{E}-11 \quad 0.5625 \mathrm{E}-27 \quad 0.2788 \mathrm{E}+\emptyset 3 \quad 0.9007 \mathrm{E}+06 \quad 0.3885 \mathrm{E}-04$

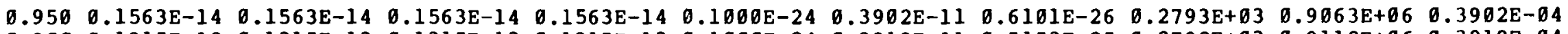

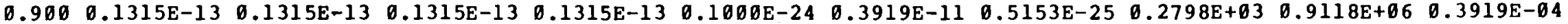

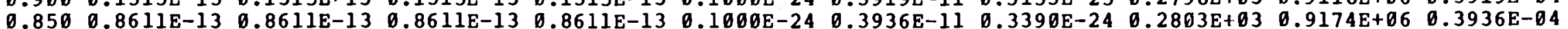

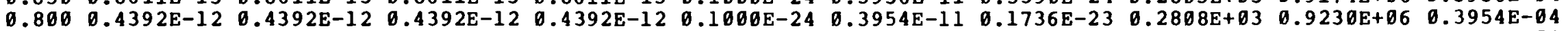

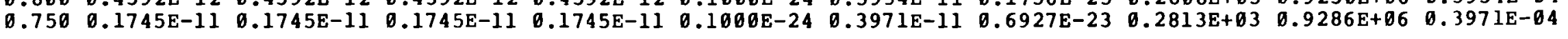

$\begin{array}{llllllllllll}0.700 & 0.5397 \mathrm{E}-11 & 0.5397 \mathrm{E}-11 & 0.5397 \mathrm{E}-11 & 0.5397 \mathrm{E}-11 & 0.1000 \mathrm{E}-24 & 0.3988 \mathrm{E}-11 & 0.2152 \mathrm{E}-22 \quad 0.2818 \mathrm{E}+03 \quad 0.9343 \mathrm{E}+06 \quad 0.3988 \mathrm{E}-04\end{array}$

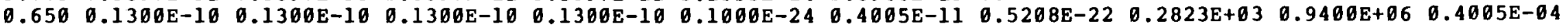
$0.6000 .2440 \mathrm{E}-100.2440 \mathrm{E}-100.2440 \mathrm{E}-100.2440 \mathrm{E}-100.1000 \mathrm{E}-240.4023 \mathrm{E}-110.9815 \mathrm{E}-220.2827 \mathrm{E}+030.9457 \mathrm{E}+060.4023 \mathrm{E}-04$

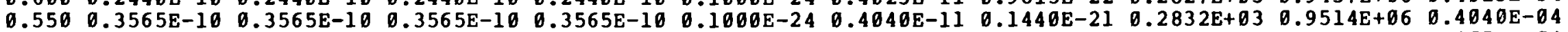

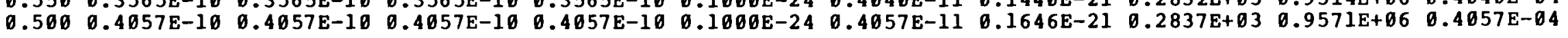

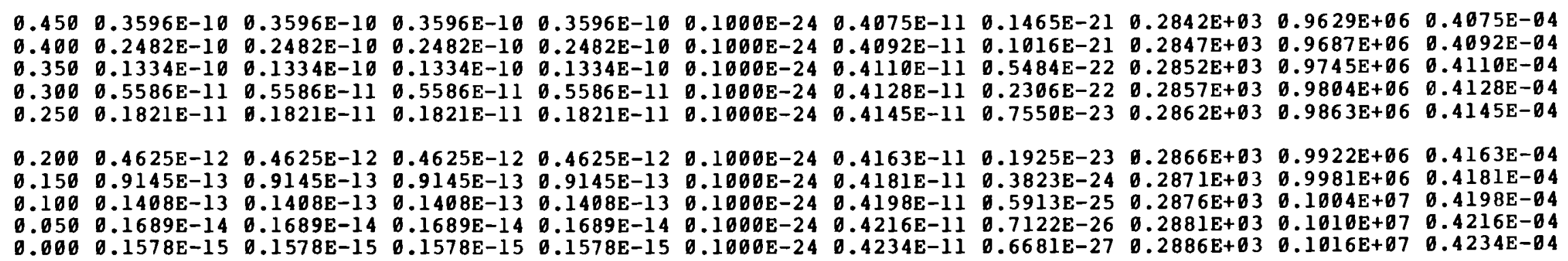


TABLE 4-15. Model Output at TCLOCK $=3500$ Seconds From Example Application 1

$\begin{array}{lrll}\text { TCLOCR } & 3500.00 & (0.972 \mathrm{HRS}) & \text { GLEVL (KM) } \\ \text { DT } & 100.00 & & \text { WAGRID(1) }\end{array}$
Z (KM)
A
B
C
E
F
TEMP
P
cs

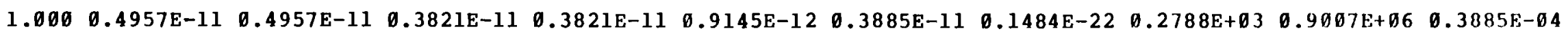

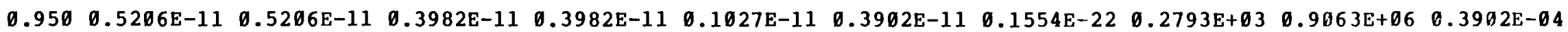

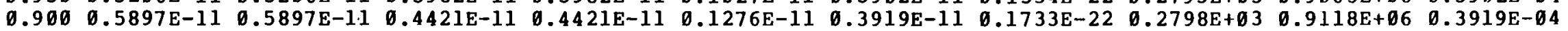

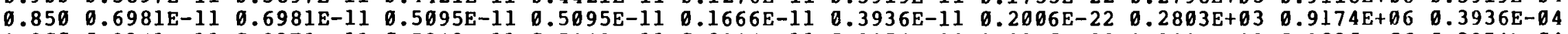
$\begin{array}{llllllllllll}0.800 & 0.8371 \mathrm{E}-11 & 0.8371 \mathrm{E}-11 & 0.5943 \mathrm{E}-11 & 0.5943 \mathrm{E}-11 & 0.2187 \mathrm{E}-11 & 0.3954 \mathrm{E}-11 & 0.2350 \mathrm{E}-22 & \emptyset .28 \emptyset 8 \mathrm{E}+\emptyset 3 & 0.9230 \mathrm{E}+06 & 0.3954 \mathrm{E}-\emptyset 4\end{array}$

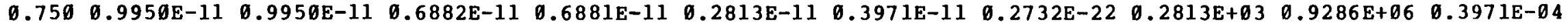

$\begin{array}{lllllllllllll}0.700 & 0.1157 \mathrm{E}-10 & 0.1157 \mathrm{E}-10 & 0.7821 \mathrm{E}-11 & 0.7819 \mathrm{E}-11 & 0.3497 \mathrm{E}-11 & 0.3988 \mathrm{E}-11 & 0.3119 \mathrm{E}-22 & 0.2818 \mathrm{E}+03 & 0.9343 \mathrm{E}+06 & 0.3988 \mathrm{E}-04\end{array}$

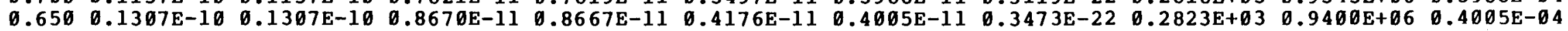

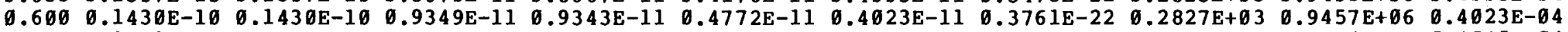

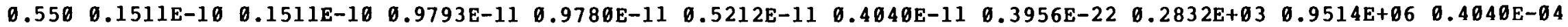

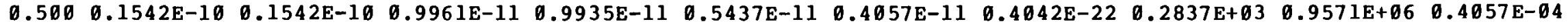

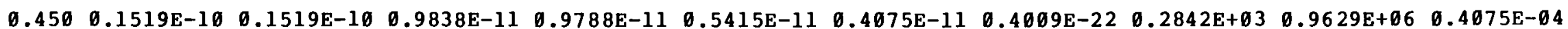

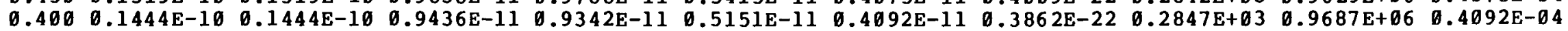

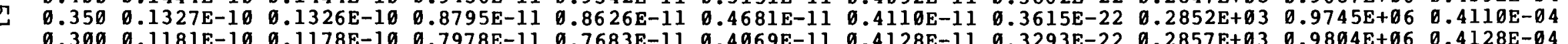

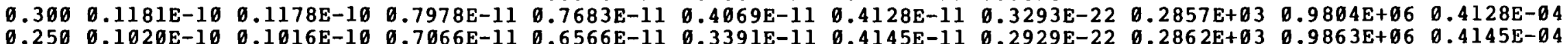

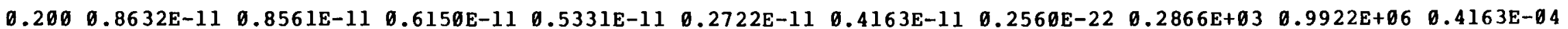

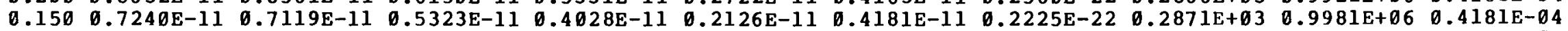

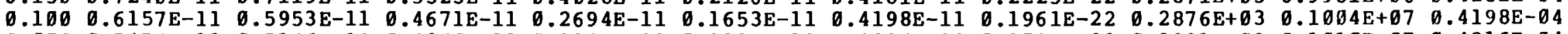

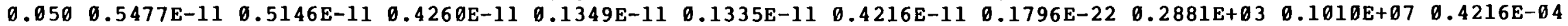
$\emptyset .000 \quad 0.5258 \mathrm{E}-11 \quad 0.4738 \mathrm{E}-11 \quad 0.4131 \mathrm{E}-11 \quad 0.1000 \mathrm{E}-24 \quad 0.1193 \mathrm{E}-11 \quad 0.4234 \mathrm{E}-11 \quad 0.1749 \mathrm{E}-22 \quad 0.2886 \mathrm{E}+\emptyset 3 \quad 0.1016 \mathrm{E}+07 \quad 0.4234 \mathrm{E}-04$ 
because the mixing ratios, rather than the concentrations, have symmetric Gaussian profiles. Species $\mathrm{F}$, held fixed at a $10^{-7}$ mixing ratio, shows a similar skewing. Species-G concentrations are established simply in terms of the noted equilibrium relationship.

Table 4-15 shows output at the end of the simulation, 3500 seconds downwind of the source, and a plot of these data is given in Figure 4-1. Species $A$ and $B$ differ only near the surface, because of the non-zero deposition of $B$. Species $C$ and $D$ have the same chemical reaction loss term, but the surface loss for $D$ causes it to have a significantly lower concentration than C. The circular points on the plot denote the analytical solution of Heines and Peters (1973) for an inert, non-depositing species (i.e., species $A$ in this example). 


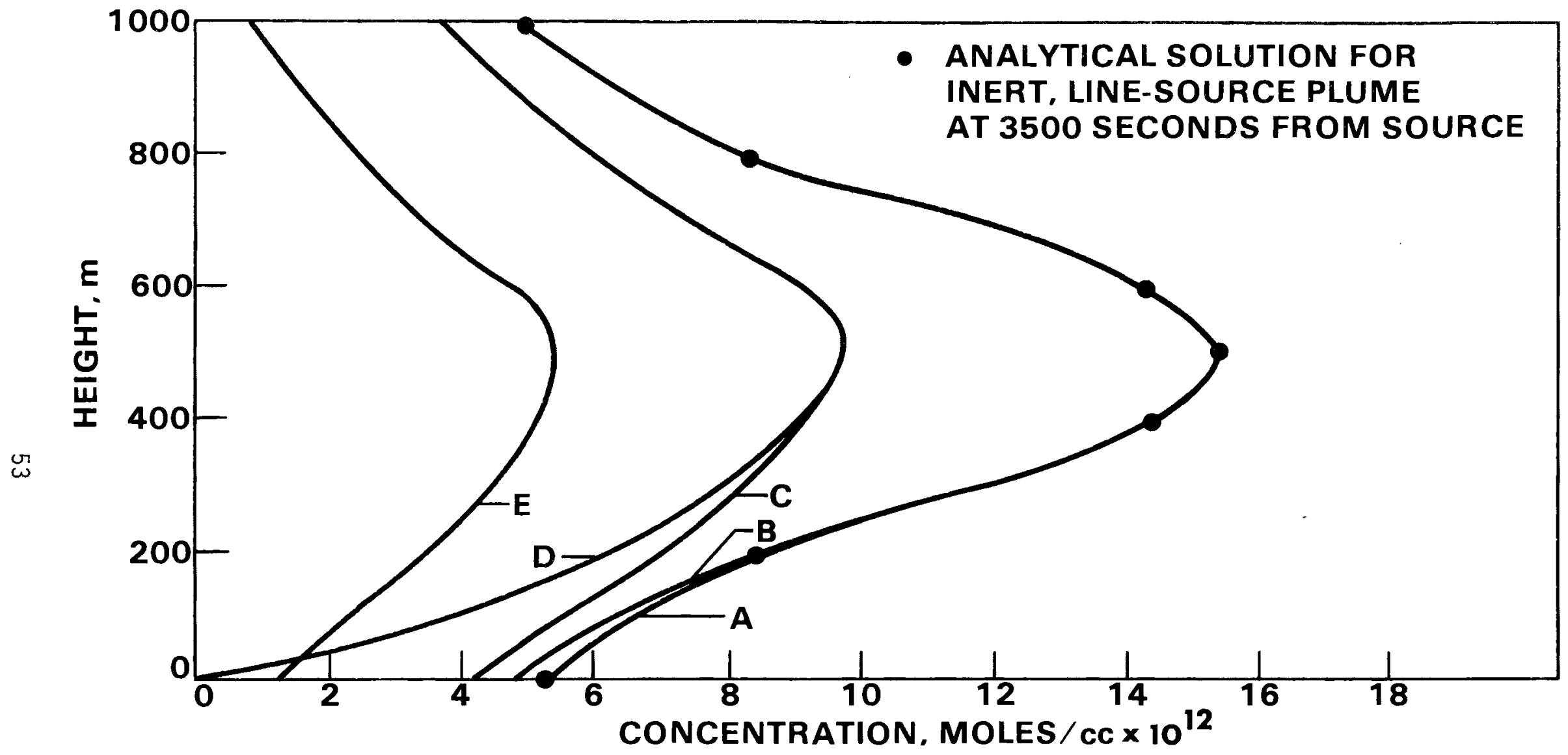

FIGURE 4-1. Results of Example 1 Computations at TCLOCK $=3500$ Seconds (Concentration profiles for species $A$ through $E$ are shown) 


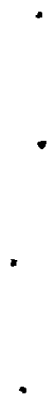


5. EXAMPLE APPLICATION 2:

REACTIVE SCAVENGING IN AN OROGRAPHIC STORM

This second example application of PLUVIUS simulates the precipitation scavenging of aerosols and reactive gas in an orographic storm. In this capacity, the code is also required to simulate the storm in which the scavenging processes occur. This in turn requires the additional considerations of

- multiphase systems and phase-transformation effects, and a moderately detailed description of the water balance.

The simulation is depicted schematically in Figure 5-1. In this figure, air is moving from left to right over a two-dimensional orographic barrier.

As the air moves over the barrier, it is lifted and cooled. As a result of this cooling, cloud forms and precipitation particles (rain and snow) grow.

- Four pollutant species are considered in the simulation: $\mathrm{SO}_{4}^{=}$aerosol and gaseous $\mathrm{SO}_{2}, \mathrm{H}_{2} \mathrm{O}_{2}$, and $\mathrm{O}_{3}$. The $\mathrm{SO}_{4}=$ aerosol attaches to cloud water via nucleation, resulting in water-bound "primary" $\mathrm{SO}_{4}^{=}$which may be scavenged subsequently by rain or snow. The gases dissolve in cloud and rain water, whereupon oxidation processes occur to generate additional "secondary" $\mathrm{SO}_{4}^{=}$. This also may be removed by precipitation, leading to an ultimate delivery of composite sulfate to the surface.

Treatment of both the precipitation-formation processes and reactive scavenging occurs in a highly parameterized fashion. These parameterizations are discussed in some detail in the first two subsections. Following that, the input data and Class I and Class III subroutines needed for the simulation are described. Finally, output from the simulation is presented.

\section{- A. MICROPHYSICS PARAMETERIZATION}

1. Water Species Classification Scheme

In real storm systems, precipitation-formation processes involve continuous spectra of liquid and solid (ice) cloud and precipitation particles ranging from micron to millimeter size and having, in the case of ice particles, complex and varying geometries and densities. Detailed treatment of the particle spectra in numerical models requires tremendous computing 


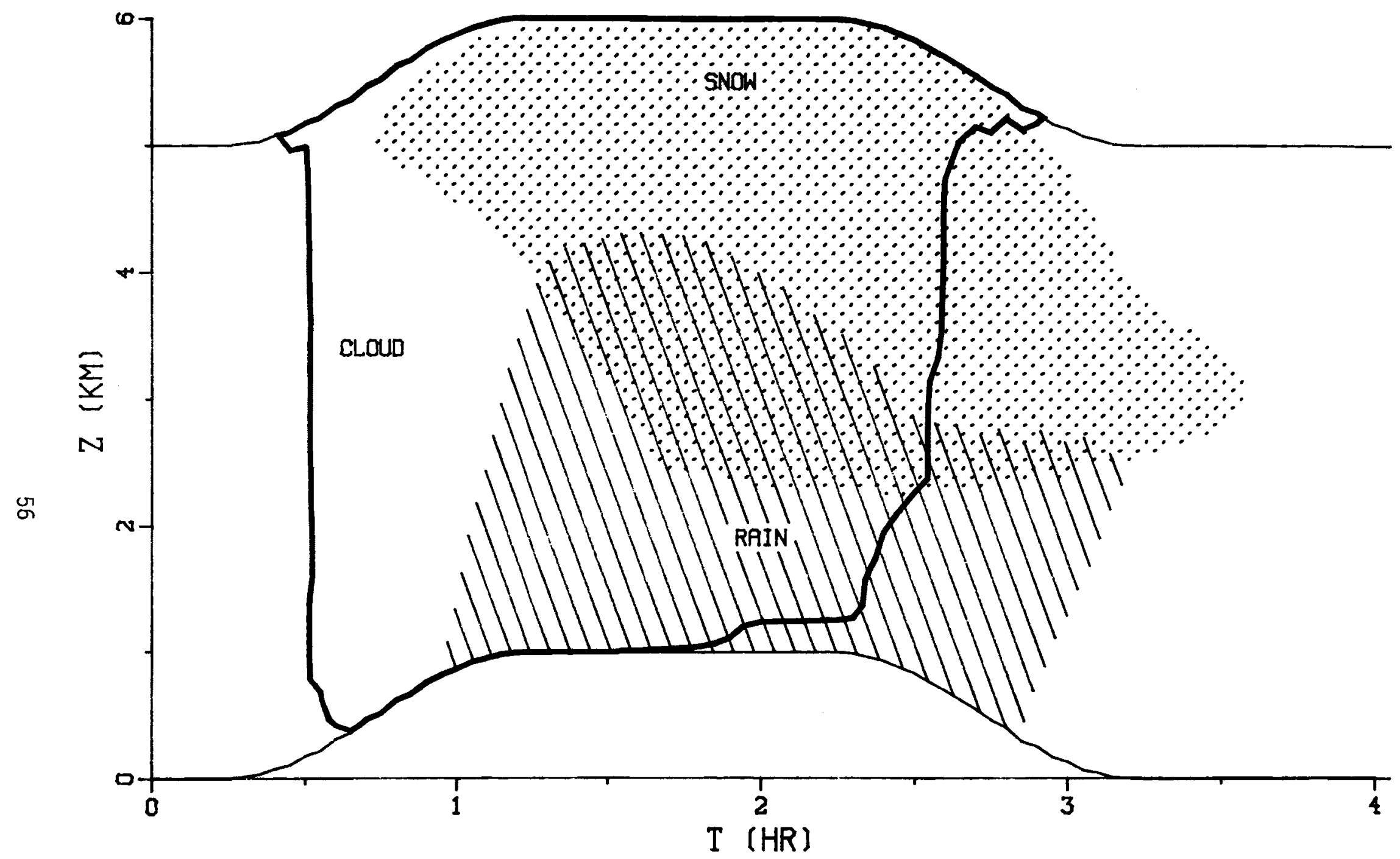

FIGURE 5-1. Illustration of the Orographic Storm in Example Application 2. The heavy solid line outlines the area of cloud (cloud water $>.01 \mathrm{gm} / \mathrm{m}^{3}$ ). The shaded and dotted areas show rain and snow regions (concentration $>.01 \mathrm{gm} / \mathrm{m}^{3}$ ). The outline of the orographic barrier is the lighter line along the bottom (reaching maximum height of $1 \mathrm{~km}$ ). The light line at the top shows the height of the grid top (the upper boundary of the computational domain). A time of 1 hour corresponds to a horizontal distance of $36 \mathrm{~km}$. 
resources, and this detail is not always justified when the cloud physics is not the main thrust of the model application. In the current application a microphysics parameterization scheme was employed which vastly reduces the complexity of simulating the precipitation processes.

The parameterization scheme follows closely the scheme initially developed by Kessler (1969) and used recently by Scott (1982a,b) in scavenging

- applications. Within the scheme, water substance is lumped into four categories: water vapor, cloud water, rain, and snow. The cloud water category consists of liquid particles with sizes up to several tens of microns. These cloud droplets have negligible settling velocities and

- essentially move with the air. The rain category consists of larger drops, with sizes in the 100- to 1,000-micron range. Both cloud water and rain are

- defined by single variables, their mass concentrations per volume of air denoted by $M_{c l o u d}$ and $M_{\text {rain }}$, respectively. Within the rain category, drops have a specified size distribution. In this work (as in Kessler and Scott), a Marshall-Palmer distribution is used,

$$
N_{r}(A) d A=N_{0, r} \cdot e^{-\lambda A} d A
$$

where $N_{r}(A) d A$ is the concentration of drops with sizes (diameters) between $A$ and $A+d A$. $N_{0, r}$ is determined empirically, and a value of $10^{7} \mathrm{~m}^{-4(a)}$ is used as per Scott (1982a). With this specification $\lambda$ becomes a function of $M_{\text {rain }}$, since

$$
M_{\text {rain }}=\int_{0}^{\infty} d A N(A) m(A)
$$

where $m(A)$ is the mass of a drop with diameter $A$. The size distribution is used to determine mean settling velocities and mean growth rates for the rain category.

(a)For consistency with other authors, gm-m-sec units are used in this subsection. The reader should be aware that within the PLUVIUS code, mole-cm-sec units are used. 
The snow category consists of all solid (ice) particles. The snow category is described by $i$ ts mass concentration, $M_{\text {snow }}$, and within this category particles are assumed to follow a Marshall-Palmer distribution,

$$
N_{S}(A) d A=N_{0, s} e^{-\lambda A} d A \text {. }
$$

$\mathrm{N}_{\mathrm{O}, \mathrm{S}}$ is determined empirically and is allowed to vary with temperature. Based on the data from Houze et a1. (1979) we employ

$$
\mathrm{N}_{0, \mathrm{~s}}=5.6 \cdot 10^{6} \cdot \mathrm{e}^{-.088 \mathrm{~T}}\left(\mathrm{~m}^{-4}\right)
$$

where $T$ is the temperature in degrees Celsius. With this specification, $\lambda$ in Equation (48) is determined by $M_{\text {snow }}$, as in Equation (47).

Our application of the Marshal1-Palmer distribution to describe ice-particle spectra is somewhat problematic, owing to the large range of particle sizes and the diversity of growth mechanisms involved. In mid-latitude storms ice formation in upper-storm regions is usually dominated by vapor deposition to small (one-to-several hundred micron) crystals, with riming and aggregation becoming much more important as particle growth continues. Accurate description of these processes over the extended particle-size range is difficult using a simple distribution expression; we have compensated for this shortcoming by applying the Marshall-Palmer distribution throughout the total particle-size range, but making some corrective adjustments to deposition calculations involving small crystals.

The reader should note that the above treatment of the ice-phase is somewhat unconventional, and that several different microphysics parameterizations have been developed in the cloud-modeling community (e.g., Bennetts and Rawlins, 1981; Lin et al., 1983). The parameterizations differ primarily in the treatment of ice-phase cloud and precipitation particles; the parameterization used in this example application should be viewed as a highly simplified form. 


\section{Precipitation Formation Mechanisms}

The interactions between the four water categories that eventually lead to precipitation formation are depicted in Figure 5-2. The driving force for precipitation formation is the vertical updraft, which produces adiabatic cooling and results in condensation of water vapor. Within the model, water vapor and cloud water exist at thermodynamic equilibrium. Water vapor is maintained at or below water saturation. Water vapor in excess of saturation condenses immediately to form cloud water, and cloud water evaporates immediately when water vapor falls below saturation.

Rain grows at the expense of cloud water through autoconversion and accretion. The autoconversion rate was obtained from Berry and Reinhardt (1974),

$$
\begin{aligned}
r_{\text {auto }} & =5.5 \cdot 10^{9}\left(M_{\text {cl oud }}\right)^{2} m_{c}^{5 / 3}\left[1-\left(\frac{2.35 \cdot 10^{-9}}{m_{c}}\right)^{4 / 3}\right] \\
& \cdot\left[1-\left(\frac{2.04 \cdot 10^{-9}}{m_{c}}\right)^{1 / 3}\right] .
\end{aligned}
$$

Here $r_{\text {auto }}$ is in $\left(\mathrm{gm} / \mathrm{m}^{3} / \mathrm{sec}\right), M_{c l o u d}$ is in $\mathrm{gm} / \mathrm{m}^{3}$ and $m_{c}=M_{c l o u d} / n_{c}$ is the average cloud-drop mass $\left(n_{c}\right.$ is the number of cloud drops per $\left.m^{3}\right)$. The rate of accretion of cloud drops by rain drops is taken from Scott (1982a)

$$
r_{\text {accr }}=5.2 \cdot 10^{-3} E_{\text {accr }} M_{\text {cloud }}\left(M_{\text {rain }}\right) \cdot 875
$$

- Here $E_{a c c r}$ is the collection efficiency for water-water collisions and is set to .65 as in Scott (1982a). Below cloud base, rain is allowed to evaporate.

- The evaporation rate is taken from Kessler (1969),

$$
r_{\text {evap }}=5.4 \cdot 10^{-4} \cdot\left(M_{\text {vapor, sat }}-M_{\text {vapor }}\right) \cdot\left(M_{\text {rain }}\right)^{.65} \text {. }
$$




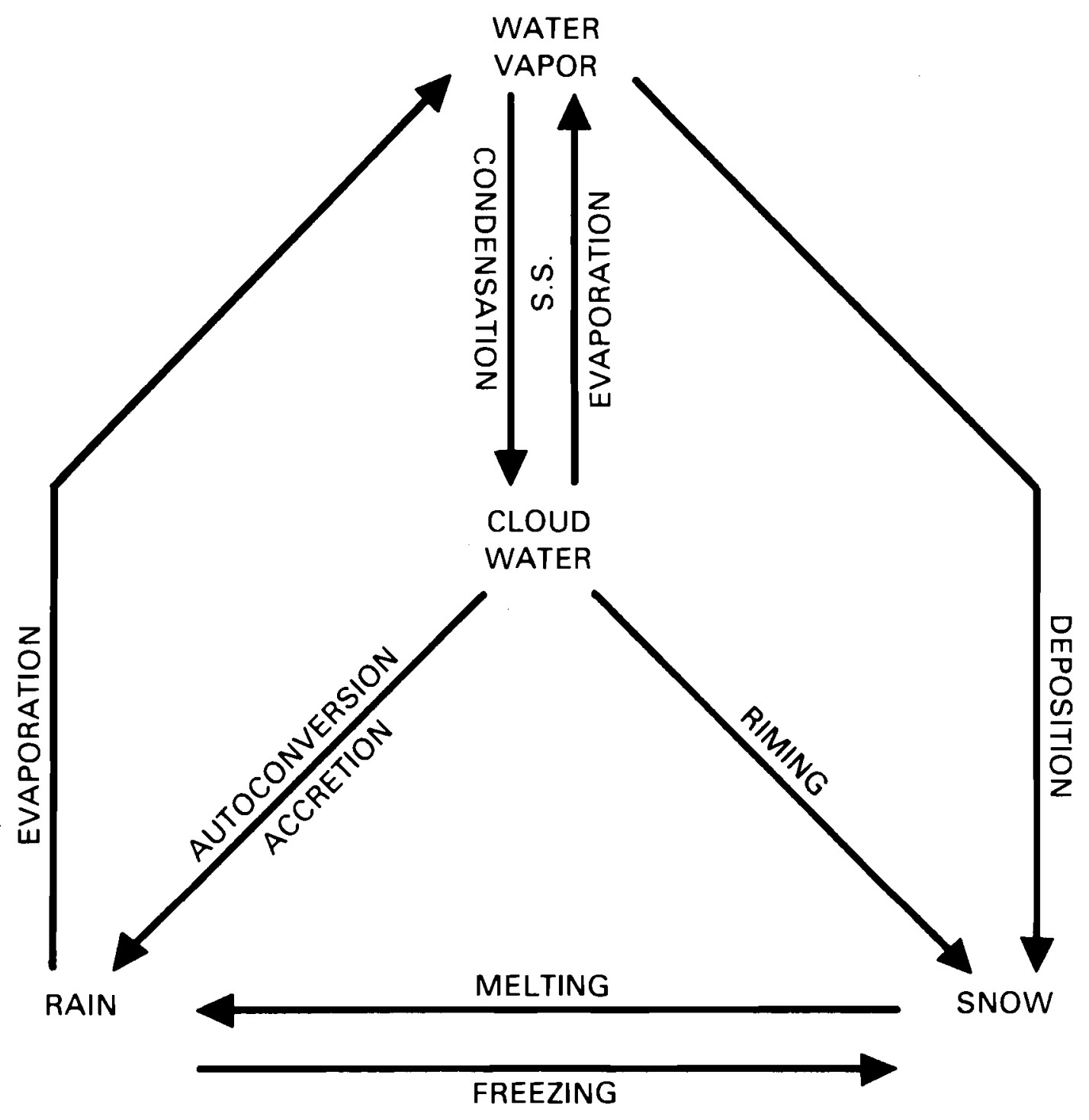

FIGURE 5-2. Interaction Diagram for Water Categories 
Here $M_{\text {vapor, sat }}$ is the saturation water-vapor density and $M_{\text {vapor }}$ is the actual water-vapor density. The rain and snow categories interact through melting and freezing. The freezing rate was obtained from Lin et al. (1983), and represents the freezing caused by collisions between raindrops and small ice crystals. The rate is

$$
r_{\text {freez }}=2.57 \cdot 10^{-5} N_{u} M_{R}^{1.63}
$$

where $N_{u}$ is the number concentration of ice crystals ( $m^{-3}$ units), taken from $\operatorname{scott}(1982 a)$ :

$$
\begin{aligned}
& N_{U}=400\left(-\frac{T_{C}}{16}\right)^{4} ; \\
& \left(T_{C} \text { is the temperature in degrees Celsius }\right) .
\end{aligned}
$$

The melting rate, $r_{\text {melt }}$, was also obtained from Lin et al. (their Equation (32), which we have chosen not to reproduce here).

The major formation mechanisms for the snow category are deposition and riming. The riming rate is evaluated, as per scott (1982a) by integrating the growth rate over the ice particle spectrum,

$$
r_{\text {rime }}=\int_{0}^{\infty} d A N(A) \dot{m}_{\text {rime }}(A),
$$

where $\dot{m}_{\text {rime }}(A)$ is the riming growth rate for an ice particle of size $A$. The derivation follows Scott (1982a). Scott suggests using a collection efficiency for ice-water collision of 0.1 when $A>300-400 \mu \mathrm{m}$ and zero for $A<300-400 \mu \mathrm{m}$. Using a riming cutoff of $A_{0}=350 \mu \mathrm{m}$, the resulting integration yields

$$
r_{\text {rime }}=0.32 \cdot \mathrm{N}_{0, \mathrm{~s}} \cdot \lambda^{-3.21} \cdot \mathrm{e}^{-\lambda \mathrm{A}_{0}} \cdot\left[2+2 \lambda A_{0}+\left(\lambda A_{0}\right)^{2}\right]
$$

where $\lambda$ and $\mathrm{N}_{\mathrm{O}, \mathrm{S}}$ are from Equation (48). 
The deposition growth rate also can be evaluated by integrating the individual crystal growth rates over the ice-particle spectrum using the Marshall-Palmer distribution. In the ice-formation zone near the cloud tops, however, this method seriously underestimates the growth rate. The reason is that the Marshall-Palmer distribution most accurately describes the spectrum of large ice particles, and it underestimates the number of ice particles when $M_{\text {snow }}$ is small. This in turn causes the depositional growth rate to be underestimated. To remedy this, the depositional growth rate was calculated using a second method. In this alternative procedure, the ice particles are assumed to be uniform in size, and have a number concentration given by Equation (54). The deposition growth is then

$$
r_{\text {dep }, u}=N_{u} \cdot \dot{m}_{\text {dep }}\left(A_{u}\right)
$$

where $\dot{m}_{\text {dep }}\left(A_{u}\right)$ is the deposition growth rate of an individual ice particle with size $A_{u}$ and mass $\left(M_{\text {snow }} / N_{u}\right)$. The individual crystal growth rates, $\dot{m}_{\text {dep }}$, were taken from Scott.

The Marshal1-Palmer deposition growth rate, $r_{\text {dep, mp }}$ was evaluated using the individual crystal growth rates from Scott (1982a) and

$$
r_{\text {dep }, m p}=\int_{0}^{\infty} d A N(A) \dot{m}_{d e p}(A)
$$

Because the individual crystal growth rate is roughly proportional to the crystal size $A$, we have

$$
r_{\text {dep,mp }}=N_{T} \cdot \dot{m}_{\text {dep }}(A)
$$

where $A$ is the average crystal size $(A=1 / \lambda)$ and $N_{T}$ is the total number of crystals given by the Marshall-Palmer distributions. However, Equation (59) presents the problem that when $M_{\star}$ snow is large it may predict $N_{T}>N_{u}$, which is unrealistic. We thus define $N_{T}{ }^{\star}$ as the smallest of $N_{T}$ and $N_{U}$ and define $A^{*}$ such that 


$$
N_{T}^{*}=\int_{A}^{\infty} * d A N(A)
$$

It should be noted here that $A^{*}$ is zero if $\mathrm{N}_{T}{ }^{*}=\mathrm{N}_{\mathrm{T}}$. We then define

$$
r_{\operatorname{dep}, m p^{\star}}=\int_{A}^{\infty} \mathrm{dAN} \mathrm{N}(\mathrm{A}) \dot{\mathrm{m}}_{\mathrm{dep}}(A) \text {, }
$$

which gives

$$
r_{\operatorname{dep}, m p^{*}}=\mathrm{N}_{\mathrm{T}}{ }^{*} \cdot \dot{\mathrm{m}}_{\mathrm{dep}} \overline{\left(\mathrm{A}^{\star}\right)} \text {, }
$$

where $\bar{A}^{\bar{*}}=\left(A^{*}+1 / \lambda\right)$. The value of $r_{\text {dep }}$ used in the model is now chosen to be the largest of $r_{\text {dep, } u}$ and $r_{\text {dep, mp* }}$ *

\section{Precipitation Fallspeeds}

The fallspeeds for rain and snow categories are simply the average mass-weighted fallspeed obtained using the Marshall-Palmer distribution, e.g.

$$
v_{\text {rain }}=\frac{\int_{0 d A N(A) m(A) v(A)}^{\infty}}{M_{\text {rain }}}
$$

Based on previous work by Kessler (1969) and by Pruppacher and Klett (1978) we have applied the following expressions for evaluation of Equation (63) in the case of rain:

$$
\begin{array}{ll}
v(A)=130 A^{1 / 2} & A>10^{-3} m \\
v(A)=4055 A & A<10^{-3} m
\end{array}
$$

Similarly, in evaluating $\mathrm{v}_{\text {snow }}$, we have used 


$$
\begin{array}{ll}
v(A)=3.33 A .206 & A>10^{-3} \mathrm{~m} \\
v(A)=473 A .927 & A<10^{-3} \mathrm{~m}
\end{array}
$$

where Equation (65a) is from Scott (1982a) and Equation (65b) is from Scott (1976).

\section{B. CHEMISTRY PARAMETERIZATION}

As noted earlier, the chemistry in this second example application is limited to four pollutant species: sulfate aerosol and gaseous $\mathrm{SO}_{2}, \mathrm{O}_{3}$, and $\mathrm{H}_{2} \mathrm{O}_{2}$. The intent is not to provide a rigorous simulation of reactive $\mathrm{SO}_{2}$ chemistry. Rather, this example was chosen to provide an instructive demonstration of reactive and non-reactive gas scavenging and aerosol scavenging using the PLUVIUS code. The extension of this example to a more elaborate chemical mechanism (both gas and aqueous phase) simply requires the inclusion of more species in the simulation; difficulties arise mainly from specifying reaction rates, solubilities, dissociation constants, and other physical parameters.

The treatment of chemistry is closely linked to the microphysical parameterization. For each pollutant species, one must consider that species associated with each water category. Thus, besides gaseous $\mathrm{SO}_{2}$, one must treat $\mathrm{SO}_{2}$ dissolved in cloud water, in rain, and in snow. The dependent variables needed for this example are summarized in Table 5-1. Several points should be noted concerning this table. First, for $\mathrm{SO}_{2}, \mathrm{H}_{2} \mathrm{O}_{2}$, and water itself, the sum of the gas-phase concentration and cloud water associated concentration is treated as a single computed variable (e.g., KS02GC, KH202GC, KVAPCL), while the concentrations are treated individually as constrained species ( $\mathrm{KSO} 2 \mathrm{G}$ and $\mathrm{KSO2C}$, etc.). This combination is possible because the two "phases" are in equilibrium, and also move with the same vertical velocities. A similar treatment is possible for $0_{3}$. However, the low solubility of $0_{3}$ makes it possible to treat both the $0_{3}$ in cloud and in rain by equilibrium solubility and simply compute these concentrations as temporary variables when needed.

The different phases for each pollutant species lead to a multitude of possible pathways which transfer mass between the different variables: mass 
TABLE 5-1. Dependent Variables for Example Application 2

\begin{tabular}{|c|c|c|}
\hline Variable & $\begin{array}{l}\text { Species } \\
\text { Location } \\
\text { Variable }\end{array}$ & Type \\
\hline $\begin{array}{l}\text { Temperature } \\
\text { Water Vapor and } \mathrm{Cloud} \text { Water } \\
\text { Rain } \\
\text { Snow } \\
\text { Cloud Water }\end{array}$ & $\begin{array}{l}\text { KTEMP } \\
\text { KVAPCL } \\
\text { KRAIN } \\
\text { KSNOW } \\
\text { KCLOUD }\end{array}$ & $\begin{array}{l}\text { Computed } \\
\text { Computed } \\
\text { Computed } \\
\text { Computed } \\
\text { Constrained by Saturation } \\
\text { Equilibrium }\end{array}$ \\
\hline $\begin{array}{l}\text { Sulfate Aerosol } \\
\text { Sulfate in Cloud Water } \\
\text { Sulfate in Rain } \\
\text { Sulfate in Snow }\end{array}$ & $\begin{array}{l}\text { KSO4A } \\
\text { KSO4C } \\
\text { KSO4R } \\
\text { KSO4S }\end{array}$ & $\begin{array}{l}\text { Computed } \\
\text { Computed } \\
\text { Computed } \\
\text { Computed }\end{array}$ \\
\hline $\begin{array}{l}\mathrm{SO}_{2} \text { in Gas Phase } \\
\text { and in Cloud Water } \\
\mathrm{SO}_{2} \text { in Rain } \\
\mathrm{SO}_{2} \text { in Snow } \\
\mathrm{SO}_{2} \text { in Cloud Water } \\
\mathrm{SO}_{2} \text { in Gas Phase }\end{array}$ & $\begin{array}{l}\text { KSO2GC } \\
\text { KS02R } \\
\text { KS02S } \\
\text { KS02C } \\
\text { KS02G }\end{array}$ & $\begin{array}{l}\text { Computed } \\
\text { Computed } \\
\text { Computed } \\
\text { Constrained by Solubility } \\
\text { Equilibrium } \\
\text { Constrained by Solubility } \\
\text { Equilibrium }\end{array}$ \\
\hline $\begin{array}{l}\mathrm{H}_{2} \mathrm{O}_{2} \text { in Gas Phase } \\
\mathrm{H}_{2} \mathrm{O}_{2} \text { in in } \mathrm{Ra} \text { in } \\
\mathrm{H}_{2} \mathrm{O}_{2} \text { in Snow } \\
\mathrm{H}_{2} \mathrm{O}_{2} \text { in Cloud Water } \\
\mathrm{H}_{2} \mathrm{O}_{2} \text { in Gas Phase }\end{array}$ & $\begin{array}{l}\text { KH202GC } \\
\text { KH202R } \\
\text { KH202S } \\
\text { KH202C } \\
\text { KH202G }\end{array}$ & $\begin{array}{l}\text { Computed } \\
\text { Computed } \\
\text { Computed } \\
\text { Constrained by Solubility } \\
\text { Equilibrium } \\
\text { Constrained by Solubility } \\
\text { Equilibrium }\end{array}$ \\
\hline Gas Phase $\mathrm{O}_{3}$ & K03G & Computed \\
\hline $\begin{array}{l}\mathrm{H}_{+}^{+} \text {in Cloud water } \\
\mathrm{H}^{+} \text {in Rain }\end{array}$ & $\begin{array}{l}\text { KHIONC } \\
\text { KHIONR }\end{array}$ & $\begin{array}{l}\text { Constrained by Empirical Relation } \\
\text { Constrained by Empirical Relation }\end{array}$ \\
\hline
\end{tabular}


transfer of gases and aerosol to liquid phases, transfer between phases by the precipitation-formation processes, and chemical reaction in each phase. These pathways are summarized for sulfur species in the interaction diagram shown in Figure 5-3. The paths between gaseous $\mathrm{SO}_{2}$ and cloud or rain $\mathrm{SO}_{2}$ represent mass transfer. The paths between aerosol $\mathrm{SO}_{4}$ and cloud or rain $\mathrm{SO}_{4}$ represent aerosol scavenging or evaporation. The paths between cloud, snow, and rain phases of each species represent precipitation processes. The paths between $\mathrm{SO}_{2}$ and $\mathrm{SO}_{4}$ represent aqueous chemical reactions.

The multiphase nature of the present example again should be stressed. Example Application 1 involved clear air and homogeneous chemistry; and pollutant concentrations were denoted by $c$, the moles of pollutant per cubiccentimeter space. In the present example, however, there are several different media to choose for volumetric bases. In 1 iquid-phase reaction-rate calculations, for example, one may desire to express concentration in terms of moles per cubic centimeter liquid, whereas gas-phase calculations normally are conducted on a gas-volume basis. To preserve consistency in PLUVIUS we shall always describe the dependent variable, $c$, in terms of moles per unit volume total space (volume of gas and liquid water and ice and . . .). Likewise, chemical reaction rates $\left[G_{k}\right.$ in Equation (1) and GGEN and GDEC in the code], shall always be expressed in units of moles per second per unit volume total space.

It is convenient in the following discussion to use other volumetric bases on occasion. When doing this we employ the following nomenclature:

c moles pollutant per cubic centimeter total space

$\hat{c} \quad$ moles pollutant per cubic centimeter of chosen condensed phase (1 iquid water, ice, ...)

$\tilde{c} \quad$ moles pollutant per liter of chosen condensed phase

$G_{k} \quad$ moles pollutant per second per cubic centimeter total space

$\hat{G}_{k} \quad$ moles pollutant per second per cubic centimeter condensed phase 


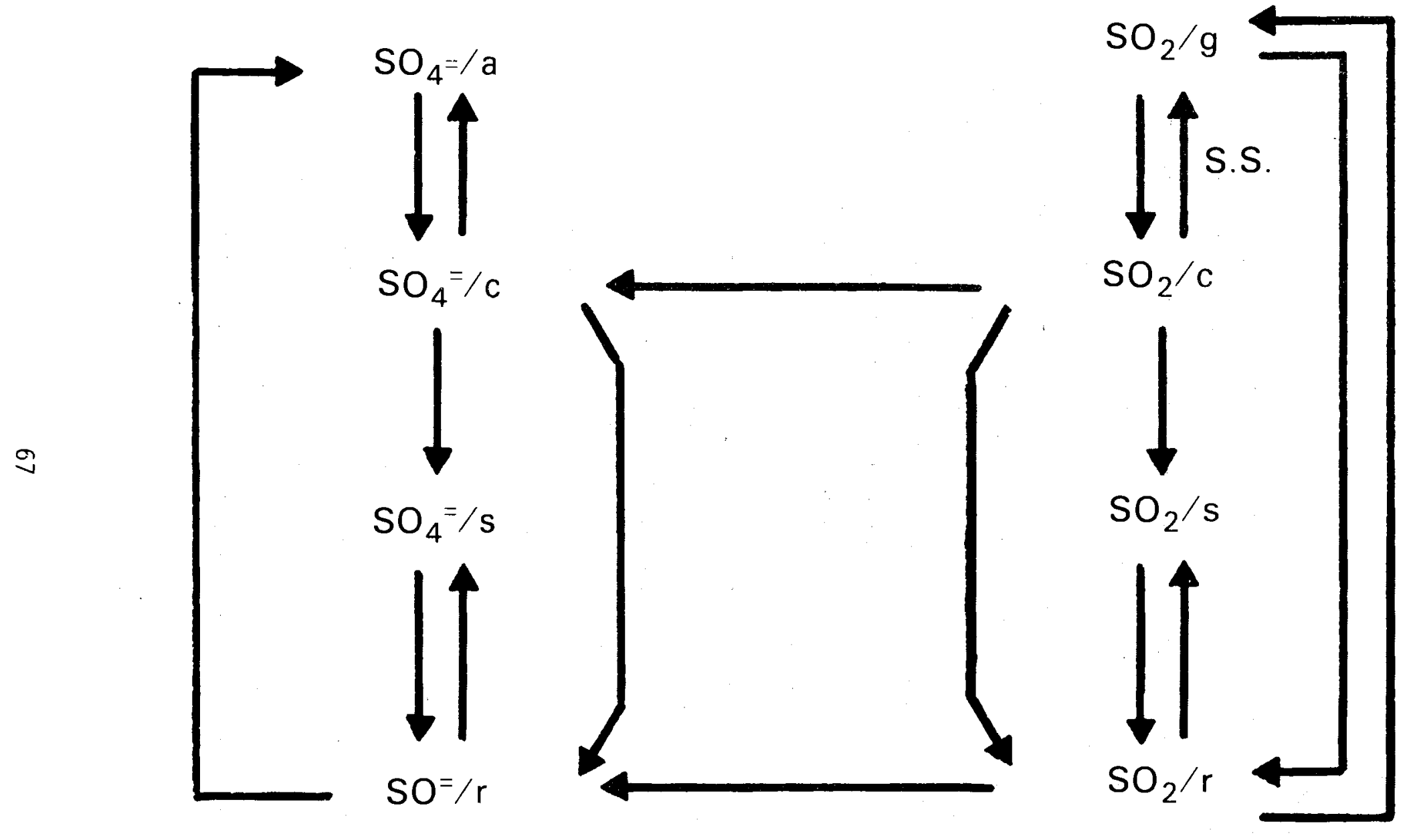

FIGURE 5-3. Interaction Diagram for Sulfur Species 
In making his own applications, the reader is well advised to exercise due care in distinguishing between these various definitions of concentration. It is relatively easy to mix definitions inadvertently in such endeavors; and once made, such errors often are highly difficult to detect and/or resolve.

\section{Aerosol Scavenging}

In the computations performed for this example, the in-cloud scavenging of sulfate aerosol is presumed to occur totally via a nucleation mechanism. This is expected to be an appropriate first approximation, owing to the secondary importance of competitive mechanisms, such as diffusional and phoretic processes, for particles in this size range. Cloud-droplet number density is set within PLUVIUS to a value typical of continental cloud systems (500 nuclei $/ \mathrm{cm}^{3}$ ) and, at the instant of cloud formation, this number of sulfate particles is incorporated into the droplet phase. New sulfate particles are allowed to nucleate within the modeled system as the sulfate-containing droplets are removed by conventional rain-formation processes. For the present application, the sulfate-aerosol size distribution is presumed to be monodisperse, with a particle diameter of $0.3 \mu \mathrm{m}$.

As can be noted from Figure 5-3, sulfate aerosol can be reinjected to the gaseous medium by evaporation of cloud droplets. Secondary sulfate (that is, that which has been formed by in-cloud conversion) is treated in a manner identical to "primary" sulfate once it has been reinjected in this fashion. For the present example, the size of the reinjected particles is taken to be the same as those of the original sulfate aerosol.

\section{Nonreactive Gas Scavenging}

In this example, the so-called "equilibrium scavenging" assumption for dissolved $\mathrm{SO}_{2}$ and $\mathrm{H}_{2} \mathrm{O}_{2}$ in cloud water and for dissolved $\mathrm{O}_{3}$ in cloud water and rain. This assumption has been demonstrated valid for cloud water (high surface to volume ratio), and for rain with gases at low solubility $\left(\mathrm{O}_{3}\right)$. For dissolved $\mathrm{SO}_{2}$ and $\mathrm{H}_{2} \mathrm{O}_{2}$ in rain, the mass transfer is calculated explicitly. 
$\mathrm{SO}_{2}$ and $\mathrm{H}_{2} \mathrm{O}_{2}$ in snow result only from the transfer of the cloud or rainborne species to snow; no direct gas-to-snow transfer is treated in this example.

For ozone and $\mathrm{H}_{2} \mathrm{O}_{2}$, equilibrium scavenging means that the aqueous concentrations are determined simply on the basis of solubility equilibrium. The solubility relation for $\mathrm{O}_{3}$ used here is from Kirk and Othmer (1947):

$$
\hat{c}_{0_{3 \mid \mathrm{aq}}}=.45 \mathrm{c}_{3 \mid \mathrm{g}} \text {. }
$$

The solubility relation for $\mathrm{H}_{2} \mathrm{O}_{2}$ is from Schumb et al. (1955):

$$
\tilde{\mathrm{c}}_{\mathrm{H}_{2} \mathrm{O}_{2 \mid \mathrm{aq}}}=6.763 \cdot 10^{-4} \mathrm{~T} \mathrm{e}^{6834.93 / \mathrm{T}} \mathrm{c}_{\mathrm{H}_{2} \mathrm{O}_{2} / \mathrm{g}} \cdot
$$

For $\mathrm{SO}_{2}$, the treatment is more involved, since the dissociation of aqueous $\mathrm{SO}_{2}$ must be considered. (a) The relation used here is given by Hales and Sutter (1973):

$$
\mathrm{y}_{\mathrm{SO}_{2}}=\mathrm{H}^{\prime} \hat{\mathrm{c}}_{\mathrm{SO}_{2 / \mathrm{e}}}
$$

$$
H^{\prime}=\frac{y_{\mathrm{SO}_{2}}}{\left(\mathrm{y}_{\mathrm{SO}_{2}} / \mathrm{H}_{\mathrm{O}}-\left(\tilde{\mathrm{c}}_{\mathrm{H}}+-\sqrt{\left.\tilde{\mathrm{c}}_{\mathrm{H}^{+}}{ }^{2}+4 \mathrm{y}_{\left.\mathrm{SO}_{2} \mathrm{~K}_{1} / \mathrm{H}_{\mathrm{O}}\right) / 2}\right)}\right.\right.},
$$

$$
\begin{aligned}
& H_{0}=\exp (10.21-3112 . / T) / P \text {, and } \\
& K_{1}=\exp (-10.96+1970 . / T)
\end{aligned}
$$

where $\mathrm{y}_{\mathrm{SO}_{2}}=$ mole fraction of $\mathrm{SO}_{2}$ in gas phase $\left(=\mathrm{c}_{\mathrm{SO}_{2}} / \mathrm{c}_{\mathrm{air}}\right)$

$$
\hat{\mathrm{c}}_{\mathrm{SO}_{2}}=\text { concentration of } \mathrm{S}^{\mathrm{IV}} \text { in aqueous phase, (moles } / \mathrm{cm}^{3} \text { water) }
$$

(a) "Dissolved $\mathrm{SO}_{2}$ " in this report will be taken to be the sum of all ionic and undissociated species existing in the +4 valence state. 


$$
\begin{aligned}
\tilde{\mathrm{C}}_{H^{+}}= & \begin{array}{l}
\text { aqueous-phase hydrogen-ion concentration contributed from } \\
\text { species other than dissolved } \mathrm{SO}_{2}, \text { molar }
\end{array} \\
T= & \text { temperature, } K \\
\mathrm{P}= & \text { pressure, atm. }
\end{aligned}
$$

It is important to note in the context of the above relationships that $\mathrm{H}_{\text {ex }}$ is important in determining the solubility of $\mathrm{SO}_{2}$, and thus its rate of nonreactive scavenging. If a more detailed treatment of aqueous chemistry were being used, then the hydrogen-ion concentration could be calculated directly using the electro-neutrality condition. For present purposes, hydrogen-ion concentrations in cloud water and rainwater are determined on the basis of concurrently-existing sulfate concentrations, using the empirical form

$$
\tilde{\mathrm{c}}_{\mathrm{H}^{+}}=1.03 \times 10^{-5}+1.184\left(\tilde{\mathrm{c}}_{\mathrm{SO}_{4}}=\right) \text {, molar }
$$

which has been derived from regional precipitation chemistry data (MAP3S/RAINE, 1982). With this treatment, cloud and rain acidity are treated as individual constrained variables in the code.

For the scavenging of $\mathrm{SO}_{2}$ and $\mathrm{H}_{2} \mathrm{O}_{2}$ by rain, the mass-transfer rates computed by Levine and Schwartz (1982) for Marshall-Palmer raindrop distributions have been used. This results in an expression of the form

$\frac{d}{d t}\left(c_{S_{2} O_{\text {rain }}}\right)=-\frac{d}{d t}\left(c_{S_{2} O_{2 \text { gas }}}\right)=\Lambda \cdot\left(c_{S_{2} O_{2 \mid \text { gas }}}-c_{S_{2} O_{2 \mid \text { equil ib }}}\right)$.

Here $\mathrm{c}_{\mathrm{SO}} \mathrm{F}_{\text {leguiljp }}$ is the gas-phase $\mathrm{SO}_{2}$ concentration that would be in equilibrium with the dissolved $\mathrm{SO}_{2}$ in the rain, and is calculated by applying Equation (68)-(69); $\Lambda$ is obtained from Levine and Schwartz. A similar rate expression results for $\mathrm{H}_{2} \mathrm{O}_{2}$. 


\section{Aqueous Phase Chemical Transformation}

Two chemical reactions involving dissolved $\mathrm{SO}_{2}$ and $\mathrm{H}_{2} \mathrm{O}_{2}$ or $\mathrm{O}_{3}$ are treated in the example. The reactions convert dissolved $\mathrm{SO}_{2}\left(\mathrm{~S}^{\mathrm{IV}}\right)$ to dissolved sulfate $\left(S^{V I}\right)$ both in the cloud water and in the rain water. No chemical reactions are considered in the gas or snow phases.

The rate expression for the $\mathrm{SO}_{2}-\mathrm{O}_{3}$ reaction is derived from the results of Penkett et a1. (1979):

$$
\begin{aligned}
& \text { rate of sulfate generation }=\frac{2.9 \mathrm{E} 6}{\sqrt{\hat{\mathrm{C}}_{\mathrm{H}}+}} \hat{\mathrm{c}} \mathrm{C}_{3} \hat{\mathrm{c}}_{\mathrm{SO}_{2}} \\
& \text { (units }=\text { moles } / \mathrm{cm}^{3} \text { water } \cdot \mathrm{sec} \text { ). }
\end{aligned}
$$

Here $\tilde{c}_{H^{+}}+$is the hydrogen-ion concentration (molar), which is approximated by Equation (72).

The rate expression for the $\mathrm{SO}_{2}-\mathrm{H}_{2} \mathrm{O}_{2}$ reaction is derived from Martin and Damschen (1981):

$$
\begin{aligned}
& \text { rate }=\frac{4.6 \mathrm{E} 7 \mathrm{C}_{\mathrm{H}_{2} \mathrm{O}_{2} \mid \mathrm{aq}}{ }^{\mathrm{c}_{\mathrm{SO}_{2}} \mathrm{aq}}}{\mathrm{c}_{\text {water }}\left[1+\frac{\mathrm{K}_{1}}{\tilde{\mathrm{c}}_{\mathrm{H}^{+}}}\left(1+\frac{\mathrm{K}_{2}}{\tilde{\mathrm{C}}_{\mathrm{H}^{+}}}\right)\right]} \\
& \text {(units } \left.=\text { moles } / \mathrm{cm}^{3} \text { water } \cdot \mathrm{sec}\right) .
\end{aligned}
$$

where $k_{1}$ and $k_{2}$ are the first and second dissociation constants for aqueous $\mathrm{SO}_{2}$, and $\mathrm{c}_{\text {water }}$ is either $\mathrm{c}_{\text {rain }}$ or $\mathrm{c}_{\text {cloud }}$ as appropriate.

\section{INPUT DATA}

Input data for this example are given in Table 5-2, and they should be compared with the input statements described in Section 3. The first input line is a run title which will appear on the printed output. The second input line specifies that there are 15 computed variables and 7 constrained variables in the example. The next 22 input lines provide names for each variable, for use during program output. 
TABLE 5-2. Input Data for Example Application 2

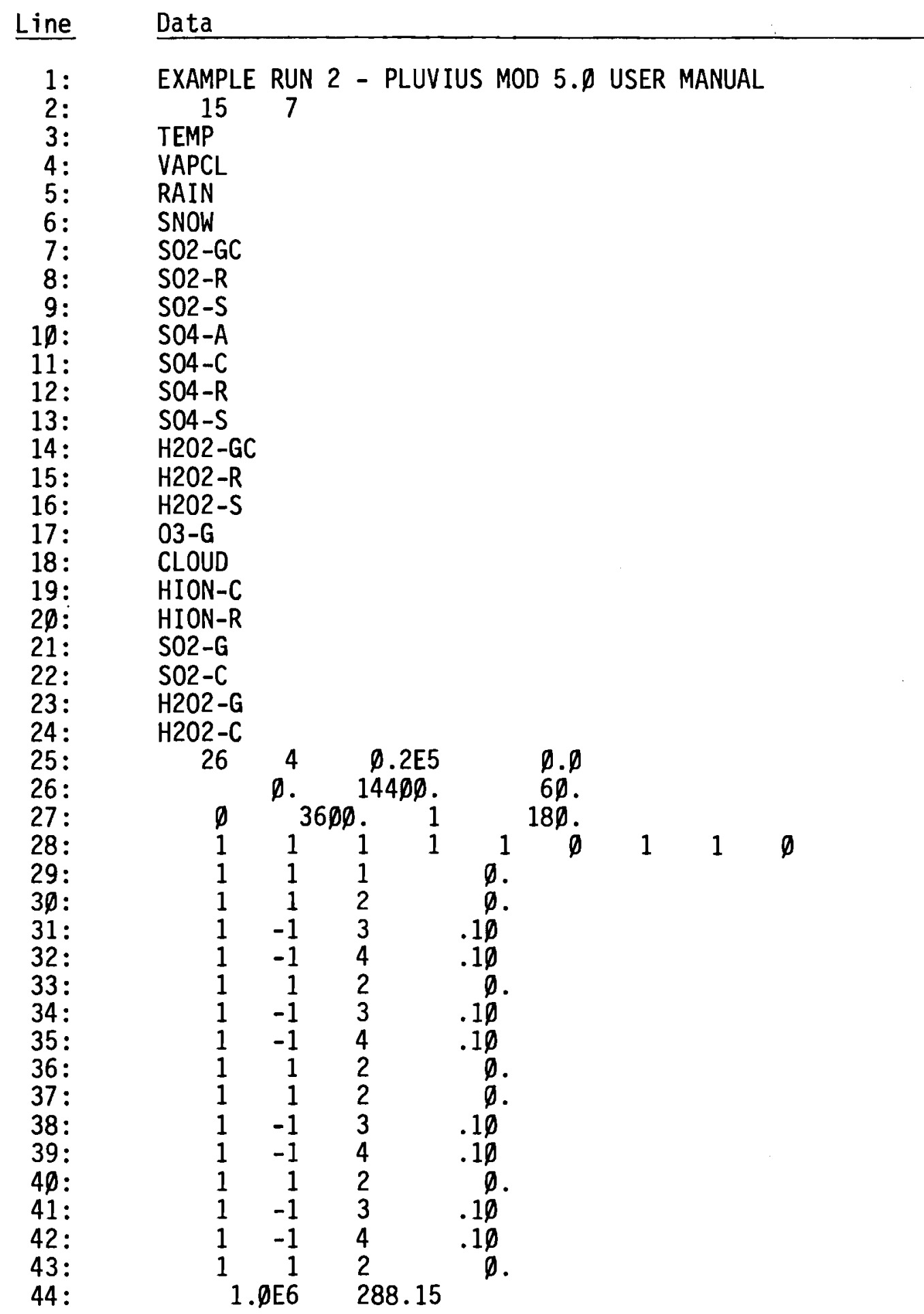


Input 1 ine 25 specifies that the vertical grid consists of 26 grid points, that there are four "diffusion regimes", that the uniform grid spacing is $2 \cdot 10^{4} \mathrm{~cm}(.2 \mathrm{~km})$, and that the initial height of the bottom grid point (GLEVL) is at $0 \mathrm{~cm}$. Input 1 ine 26 specifies that the simulation begins at a time of 0 seconds, terminates at a time of 14,400 seconds (4 hours), and uses an initial integration time step of 60 seconds. Input 1 ine 27 specifies output control information. As NPRINT is zero and DTPRIN is positive (3600), printed output will occur every 3600 seconds. The ITCOLL and DTCOLL values (1 and 180) specify that output to disk file will occur each 180 seconds, and this output will be time-averaged over the 180-second intervals.

Input 1 ine 28 specifies the bypass variables. A1 1 but IBOUND and ISHEAR are 1 . Thus the BOUND and USHEAR routines will only be called once during - initialization. The other Class I routines with bypass variables will be referenced throughout the simulation.

Input lines 29 through 43 specify the boundary conditions, diffusion regimes, and filter factors for each of the 15 computed species. A11 of the top boundary conditions are flux-specified (ITOP $=1$ ). The rain- and snowassociated species have outflow bottom-boundary conditions (IBOT $=-1$ ), and filter factors of 0.1 . These species have significant settling velocities, so the outflow boundary condition is appropriate; these settling velocities also result in the need to apply the smoothing filter after the advection-diffusion integration steps. The other species, which have zero settling velocities, have flux-specified bottom boundary conditions (IBOT $=1$ ) and do not require filtering $(F I L F A C=0)$. The rain- and snow-associated species use diffusion regimes 3 and 4 , respectively. Temperature uses regime 1 , and al1 remaining species use regime 2 . The final input 1 ine specifies initial surface pressure and temperature.

\section{CLASS I SUBROUTINE DESCRIPTIONS}

As discussed in Section 3, the ten Class I subroutines are the primary mechanism by which the physics and chemistry appropriate to a particular application are inserted into the PLUVIUS framework, and it is extremely important that the user have a good understanding of each. The listings and discussions of these subroutines for the second example application should provide additional insight about them. 
SUBROUTINE SETUP (Table 5-3)

SETUP defines the initial concentration profiles for the dependent variables and state variables, and also defines the species location variables. The species location variables for the 22 computed and constrained variables of this example are defined in the initial data statements. Note again that these values must correspond exactly to the ordering of species given in the input data (in this case, temperature is first and $\mathrm{H}_{2} \mathrm{O}_{2}$ in cloud water is last). The next statements specify values used in the ODEINT subroutine. Note that CMIN and CERROR are larger for temperature and water species than for pollutant species. Making these variables too small may impose unnecessary constraints on the integrator, while making them too large can result in an inaccurate solution. Values should be chosen which are small in comparison to significant values of each species, but not "too small."

The first executable statements compute the initial temperature and pressure profiles. For this example, we have arbitrarily chosen a moist-adiabatic temperature profile. A rough temperature profile (1apse rate $=7^{\circ} / \mathrm{km}$ ) is first computed, so that approximate pressure and density profiles can be set. Next, the moist adiabatic temperature profile is computed, using the Class II subroutine RLAPSE, and another PRESSF call recomputes the pressure and density profiles.

Next, the water vapor profile is established. It is arbitrarily set at $90 \%$ relative humidity for this example. Finally, the other variables are initialized. The only non-zero variables are aerosol sulfate and gaseous $\mathrm{SO}_{2}$, $\mathrm{H}_{2} \mathrm{O}_{2}$, and $\mathrm{O}_{3} . \mathrm{O}_{3}$ is set to $50 \mathrm{ppb}$. $\mathrm{SO}_{2}, \mathrm{H}_{2} \mathrm{O}_{2}$, and sulfate are set to $10 \mathrm{ppb}$, $1 \mathrm{ppb}$, and $1 \mathrm{ppb}$, respectively, below $1.5 \mathrm{~km}$ altitude, and $1 / 5$ these values above $1.5 \mathrm{~km}$.

Table 5-4 shows the common blocks in the INCLUDE file PLUVCMN for this example. The differences between this and example 1 are:

- The LOCATN common block holds the appropriate species location variables.

- Arrays are dimensioned to appropriate sizes (via the NZMAX, NCMAX, and NCTMAX parameters). 
TABLE 5-3. Listing of Subroutine SETUP for Example Application 2

SUBROUTINE SETUP

INCLUDE 'PLUVCMN'

C

C ESTABLISH SPECIES LOCATION VARIABLE VALUES

C

DATA KTEMP, KVAPCL, KRAIN, KSNOW, KCLOUD/1,2,3,4,16/

DATA KS02GC,KSO2R, KSO2S, KSO2G, KSO2C/5,6,7,19,2甲/

DATA KSO4A, KSO4C, KSO4R, KSO4S/8,9,10,11/

DATA KH202GC, KH2O2R, KH202S, KH2O2G, KH2O2C/12,13,14,21,22/

DATA K03G/15/

DATA KHIONC, KHIONR/17,18/

C ESTABLISH PARAMETERS USED IN O.D.E. INTEGRATION ROUTINE (ODEINT)

DATA EPS / . $.11 /$

DATA DTMIN / 1.E-10 /

DATA RATESF / NCMAX*1.E-2 /

DATA NCORR / 1 /

DATA IEXP / 1 /

DATA CMIN / NCTMAX*1.E-24 /

$\operatorname{CMIN}(K T E M P)=1 . E-8$

$\operatorname{CMIN}(\mathrm{KVAPCL})=1 \cdot \mathrm{E}-17$

$\operatorname{CMIN}($ KRAIN) $=1 . E-17$

$\operatorname{CMIN}($ KSNOW) $=1 . E-17$

$\operatorname{CMIN}($ KCLOUD $)=1 . E-17$

DO $K=1$, NCOMP

END DO

$$
\operatorname{CERROR}(K)=\operatorname{CMIN}(K) * 1 . E 4
$$

C

C ZERO OUT ALL CONCENTRATIONS

- C

DO I $=1, N$

DO $\mathrm{K}=1$, NTOT

END DO

$$
C(I, K)=\emptyset \text {. }
$$

END DO

C

C ESTABLISH TEMPERATURE, DENSITY, AND PRESSURE FIELDS

c FOR THIS EXAMPLE, TEMPERATURE FOLLOWS MOIST ADIABAT

C USE CONSTANT LAPSE RATE TO GET ROUGH PROFILE 
TABLE 5-3 Cont inued

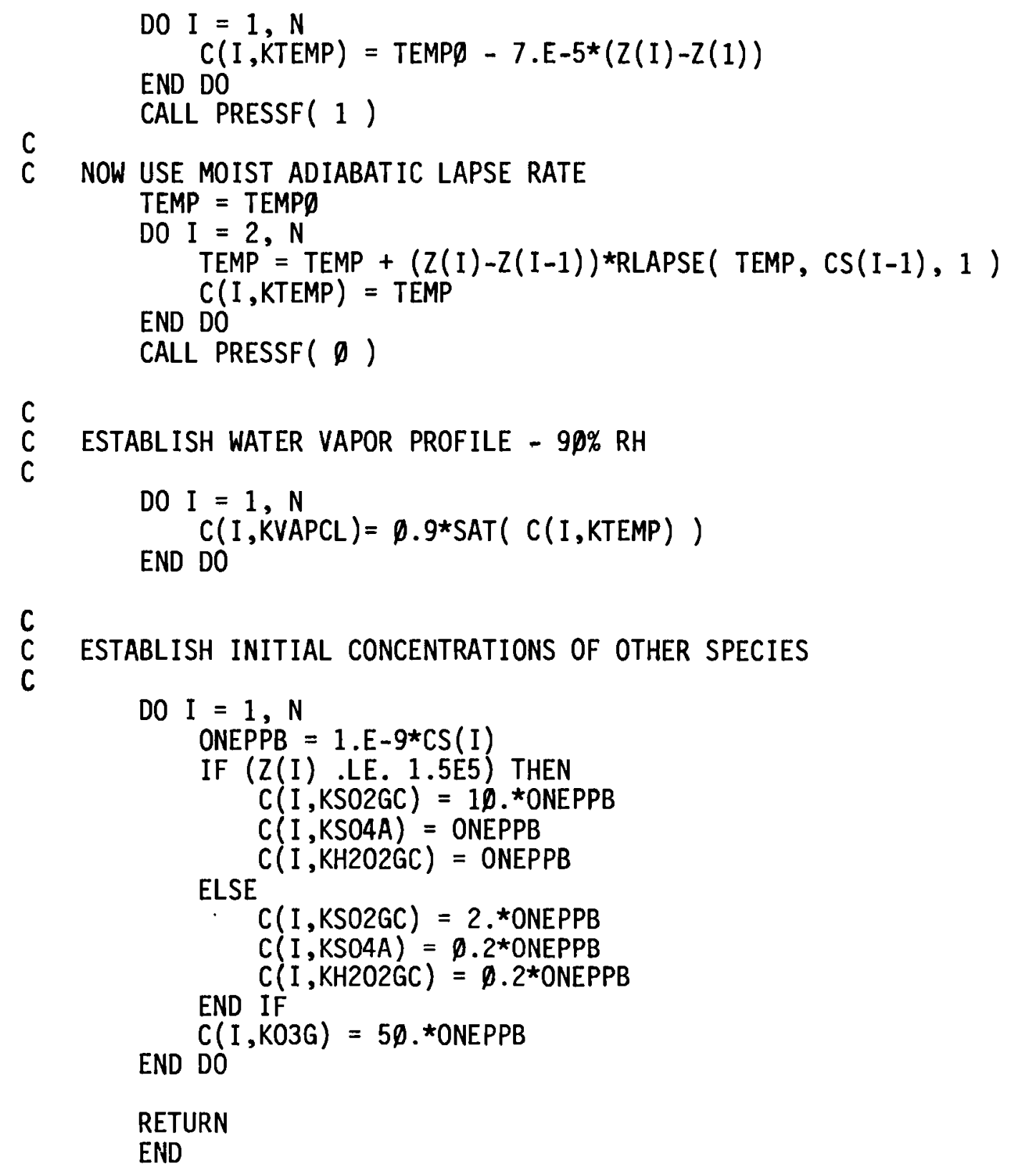




\section{TABLE 5-4. Example Listing of PLUVIUS Common Blocks (held in the PLUVCMN INCLUDE file) for Example Application 2}

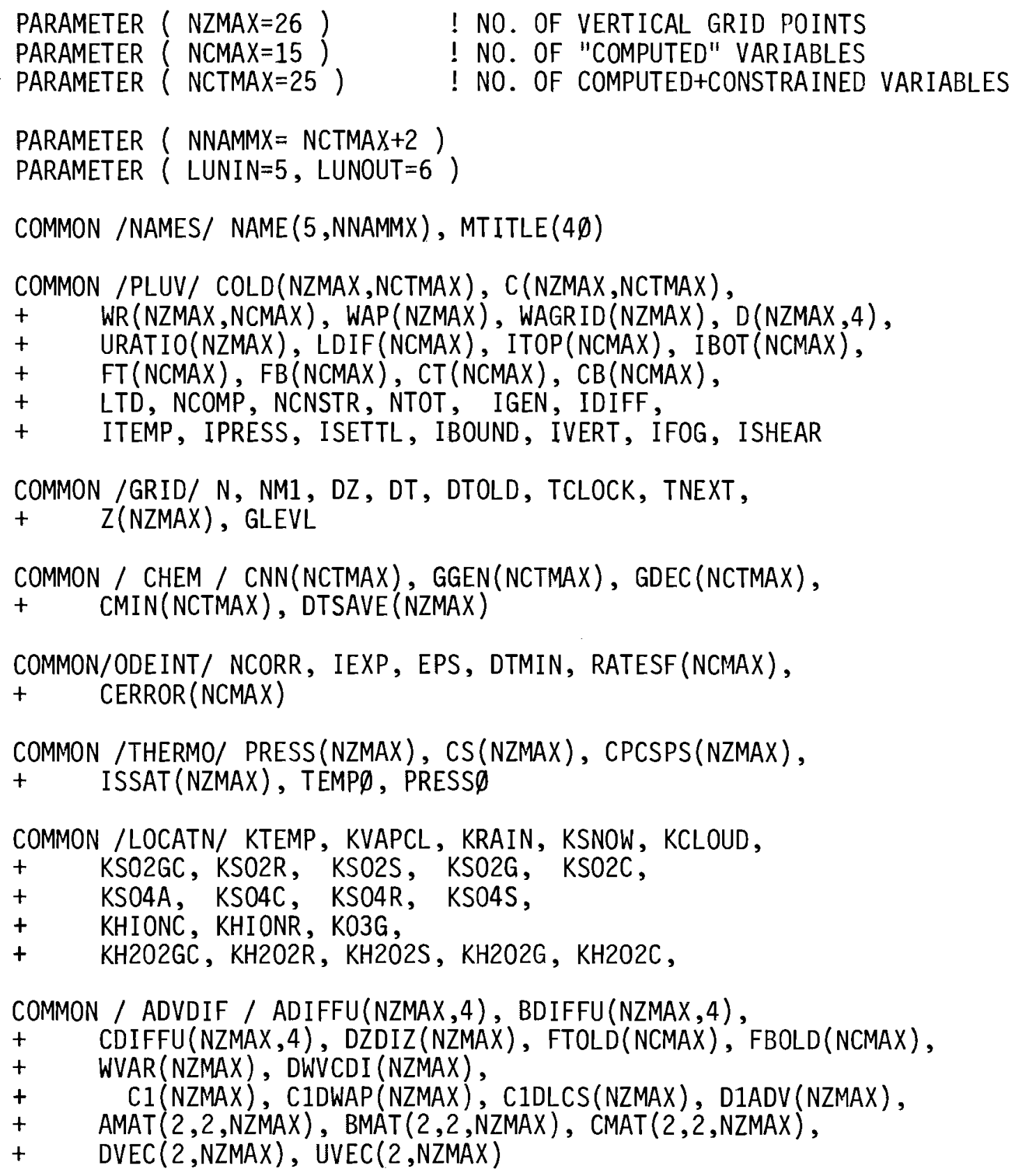


SUBROUTINE ADJUST (Table 5-5)

ADJUST performs three functions in the example. First, it treats nucleation scavenging of sulfate aerosol if cloud has just formed at a grid point. (To do this it must also compute the new cloud-water concentration, which it does initially). Second, if cloud has just evaporated, any remaining sulfate in cloud water is transferred to aerosol sulfate. Last, if the temperature is warmer than $5 \mathrm{C}$, it converts any snow or snowborne species to rain and rainborne species. This is done to "clean up" insignificantly small concentrations which are numerical artifacts of the advection scheme.

SUBROUTINE BOUND (Table 5-6)

BOUND provides values for flux or concentration specified boundary conditions. For this example, the top boundary is treated as impervious, and all the species have a flux boundary condition with zero flux at the top. At the bottom boundary, we are artificially using a zero flux condition for the gas, aerosol, and cloud type species. The rainborne and snowborne species have outflow bottom boundary conditions, because they have significant settling velocities. Note that the code zeroes $F B$, the bottom flux, for all variables: the $F B$ has no effect on the outflow boundary condition variables, so it is convenient to just zero all the FB's rather than doing it selectively.

Because the values of FT and FB are not time dependent, BOUND only needs to be called once, during initialization, so the bypass variable IBOUND is set to zero.

SUBROUTINE DIFF (Table 5-7)

DIFF sets the vertical eddy diffusivities for each diffusion regime. In this example, four regimes are used. Regime 1 is for temperature (i.e., heat), Regime 2 is for gases, aerosols, and cloudborne species. Regime 3 is for rain and rainborne species and Regime 4 is for snow and snowborne species.

The actual eddy diffusivity is $10^{5} \mathrm{~cm}^{2} / \mathrm{sec}$ for each regime in this example. For rain and snow, a "pseudo-diffusivity" is added on to parameterize the vertical dispersion of precipitation, which results from the variation of settling velocity with particle size. This pseudo-diffusivity is given by 
TABLE 5-5. Listing of Subroutine ADJUST for Example Application 2

SUBROUTINE ADJUST

INCLUDE 'PLUVCMN'

DATA XNC / 500. / ! CLOUD DROP CONC. (NO./CM**3)

DATA DPS $/ \emptyset .3 E-4 /$ ! AEROSOL DIAMETER (CM)

DO $19 \emptyset \emptyset \mathrm{I}=1, \mathrm{~N}$

$\mathrm{C}$
$\mathrm{C}$
$\mathrm{C}$

C CALC NEW CLOUD CONC

TEMP $=C(I, K T E M P)$

CLDOLD $=C(I, K C L O U D)$

CLOUD $=\operatorname{AMAXI}(\emptyset ., C(I, K V A P C L)-S A T(T E M P))$

$C(I, K C L O U D)=$ CLOUD

$c$
$C$
$C$
$C$

AEROSOL PICKUP BY NUCLEATION IF NEW CLOUD HAS FORMED

$X N S O 4 A=$ NO. OF SULFATE PARTICLES PER CM**3

IF ((CLOUD.GT.CMIN(KCLOUD)) .AND.

$+\quad$ (CLDOLD.LE.CMIN(KCLOUD))) THEN

CSO4A $=\operatorname{AMAX1}(\emptyset ., C(I, K S O 4 A))$

$X N S 04 A=\operatorname{CSO4A} /(.0053 *(D P S * * 3))$

IF (XNC .LT. XNSO4A) THEN

ELSE

FRACNU $=$ XNC $/$ XNSO4A

END IF

FRACNU $=1$.

CSNUC $=$ CSO4A*FRACNU

$C(\mathrm{I}, \mathrm{KSO4C})=\mathrm{C}(\mathrm{I}, \mathrm{KSO} 04 \mathrm{C})+\mathrm{CSNUC}$

$C(I, K S 04 A)=C(I, K S 04 A)-C S N U C$

- $\begin{aligned} & C \\ & C\end{aligned}$ AEROSOL RELEASE IF THERE IS NO CLOUD

ELSE IF (CLOUD .LE. CMIN(KCLOUD)) THEN

$C(I, K S 04 A)=C(I, K S 04 A)+C(I, K S 04 C)$

$C(I, K S O 4 C)=\emptyset$.

END IF

C 
TABLE 5-5 Continued

C FOR TEMP $>5$ C, MELT SNOW AND TRANSFER SNOWBORNE SPECIES TO RAIN

C

$$
\begin{aligned}
& \text { IF (TEMP .GE. 278.15) THEN } \\
& C(I, \text { KRAIN })=C(I, \text { KRAIN })+C(I, \text { KSNOW }) \\
& C(\mathrm{I}, \mathrm{KSNOW})=\emptyset \text {. } \\
& C(\mathrm{I}, \mathrm{KSO} R)=C(\mathrm{I}, \mathrm{KSO} 2 \mathrm{R})+\mathrm{C}(\mathrm{I}, \mathrm{KSO} \mathrm{S}) \\
& C(I, K S O 2 S)=\emptyset \text {. } \\
& C(I, K S 04 R)=C(I, K S 04 R)+C(I, K S 04 S) \\
& C(I, \mathrm{KSO4S})=\emptyset \text {. } \\
& C(I, K H 202 R)=C(I, K H 202 R)+C(I, K H 202 S) \\
& C(I, K H 202 S)=\emptyset \text {. }
\end{aligned}
$$

1900 CONTINUE

\section{RETURN}

END 
TABLE 5-6. Listing of Subroutine BOUND for Example Application 2

SUBROUTINE BOUND (INIT)

INCLUDE 'PLUVCMN'

C FOR FLUX B.C., PLACE APPROPRIATE FLUX IN FT(K) OR FB(K)

C FOR CONC. B.C., PLACE APPROPRIATE CONC. IN CT(K) OR CB(K)

C FOR OUTFLOW B.C., DO NOTHING HERE

DO $K=1$, NCOMP

$\mathrm{FT}(K)=\emptyset$.

$\mathrm{FB}(\mathrm{K})=\emptyset$.

END DO

RETURN

END 
TABLE 5-7. Listing of Subroutine DIFF for Example Application 2

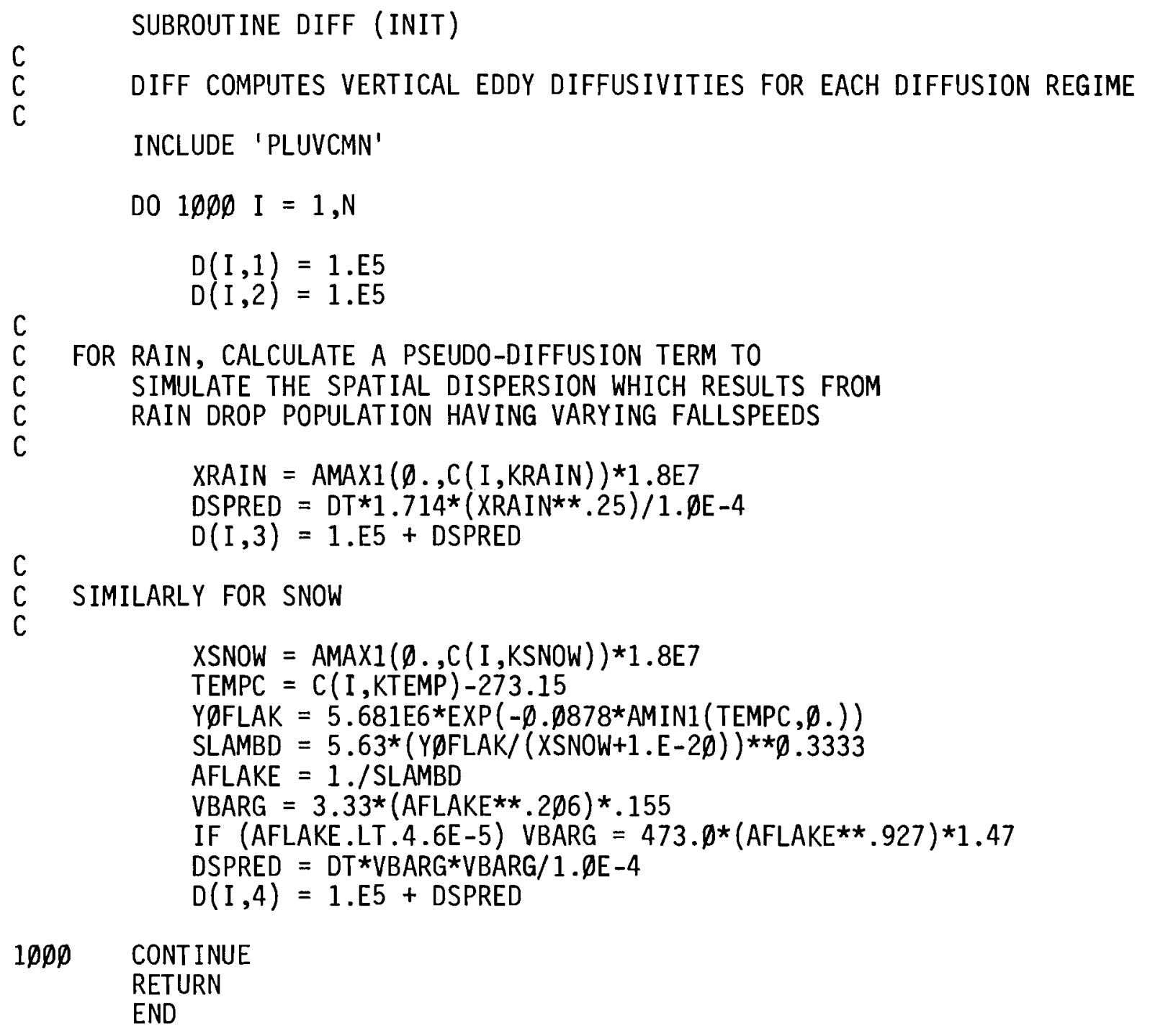




$$
D_{\text {pseudo }}=\Delta t \cdot\left(\overline{v^{2}}-\bar{v}^{2}\right)
$$

where $\Delta t$ is the integration time interval, $v^{2}$ is the mass-weighted average of the square of the settling velocity (over the Marshall-Palmer size distribution), and $\bar{v}$ is the mass-weighted average of the settling velocity. D pseudo is calculated using Equation (64) and (65), and the result is coded into DIFF in Table 5-6.

Because these pseudo-diffusivities are concentration dependent and change with time, IDIFF has been set equal to 1 .

SUBROUTINE GEN (Table 5-8)

GEN computes the generation and decay rates for the computed species, and also sets constrained species. In this example, GEN is the largest of the Class I subroutines because it implements most of the cloud physics and chemistry parameterizations discussed in the first two parts of this chapter.

At the start of the subroutine, several widely used species values are stored in local variables (temperature, rain, snow, cloud, water vapor), and the constrained variable cloud-water is calculated, using the water-vapor saturation constraint. This is followed by the section that computes cloud physics generation and decay rates. Note that many of these rates are expressed as pseudo first-order rates (e.g., ACCR, RIM, SMEL) with units of $\mathrm{sec}^{-1}$, so that they may also be used to compute generation and decay terms for the waterborne pollutant species resulting from the same cloud physics process. Several rates for decay processes (SMEL, FREEZ, EVAP, SUBLIM) have been arbitrarily limited to a maximum value of $1 \mathrm{sec}^{-1}$. This has been done to improve computational efficiency (reduce stiffness). (The limit of $1 \mathrm{sec}^{-1}$ does not significantly affect the solution, although a lower limit, say 0.01 $\sec ^{-1}$, could have significant effects.)

The next section computes constrained species (besides cloud water). This involves the equilibrium relations 
TABLE 5-8. Listing of Subroutine GEN for Example Application 2

SUBROUTINE GEN ( I, IGCALC, TGEN, DTAU, JPASSO )

C

C I = VERTICAL GRID INDEX AT WHICH GEN/DECAY RATES ARE TO BE COMPUTED

C IGCALC = IF $\emptyset$, ONLY CALCULATE CONSTRAINED VARIABLES

C TGEN = CURRENT MODEL TIME

C DTAU = CURRENT INTEGRATION TIME STEP IN O.D.E. INTEGRATOR

c JPASSO = FLAG SPECIFYING PREDICTOR (1) OR CORRECTOR $(2,3, \ldots)$ PASS

C IN O.D.E. INTEGRATOR

C

INCLUDE 'PLUVCMN'

DATA XNC /500./

DATA DPS $/ 0.3 \mathrm{E}-4 /$

DO $K=1$, NCOMP $\operatorname{GGEN}(K)=\emptyset$

END DO $\operatorname{GDEC}(K)=\emptyset$.

$\mathrm{C}$
$\mathrm{C}$
$\mathrm{C}$
$\mathrm{C}$
$\mathrm{C}$

DEF INE LOCAL WATER AND TEMPERATURE VARIABLES

CALCULATE NEW CLOUd AND WATER VAPOR

CALCULATE WATER VAPOR SATURATION CONCENTRATIONS

TEMP $=$ CNN (KTEMP)

TEMPC $=$ TEMP-273.15

VSATW $=$ SAT $($ TEMP $)$

VAPOR = AMIN1 $($ CNN $(K V A P C L)$, VSATW $)$

CLOUD $=$ CNN $(K V A P C L)-$ VAPOR

$\operatorname{CNN}(K C L O U D)=$ CLOUD

RAIN $=$ CNN $($ KRAIN $)$

SNOW $=$ CNN $($ KSNOW $)$

IF (TEMPC .LE. Ø.) THEN

ELSE VSATI $=$ SSAT (TEMP)

END IF

VSATI $=$ VSATW

C-

C

C

c $X$-..- VARIABLES ARE CONCENTRATIONS IN GM/M**3

C

CLOUD PHYSICS - CALCULATE GENERATION AND DECAY RATES FOR WATER SPECIES 

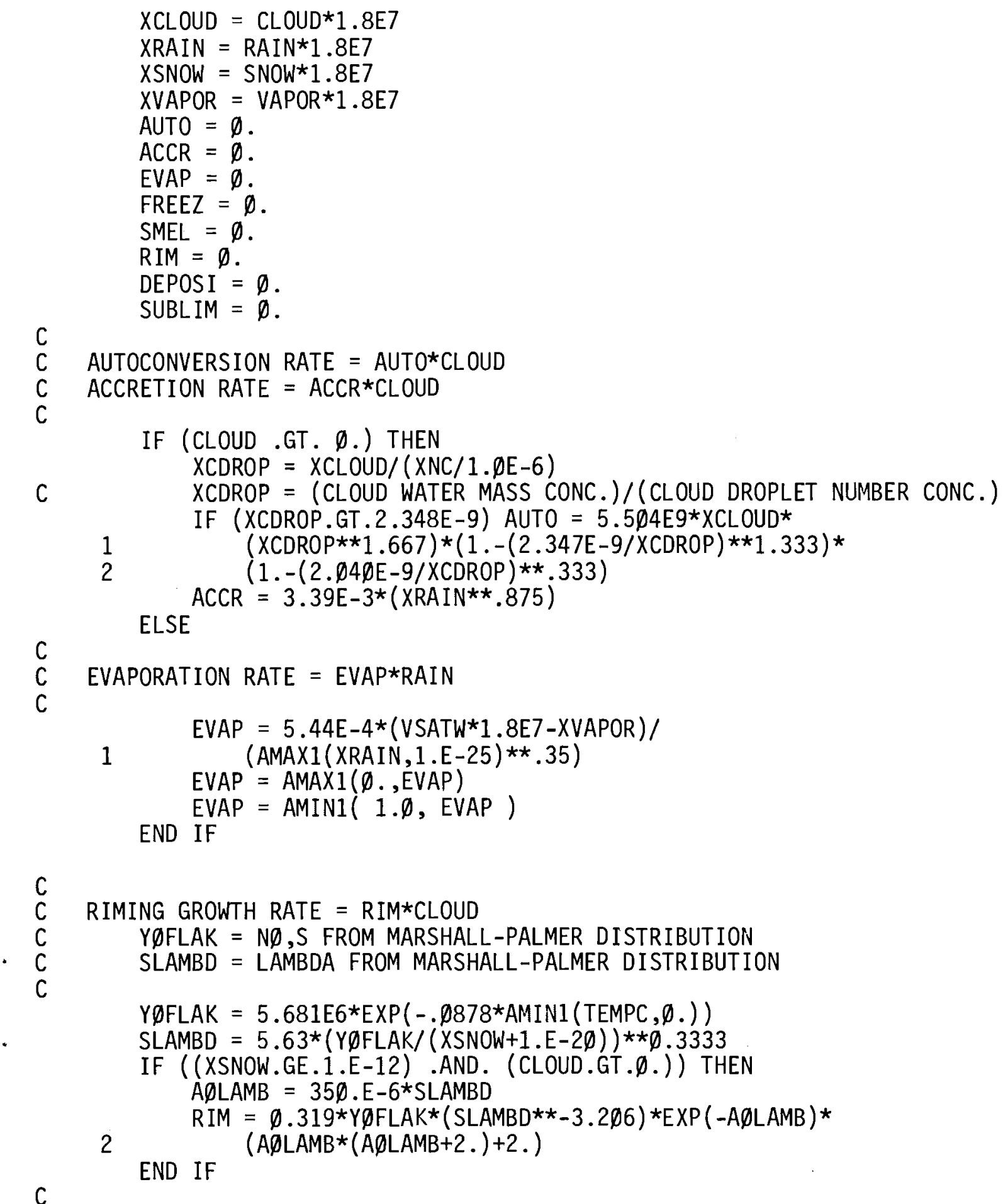
TABLE 5-8 Continued

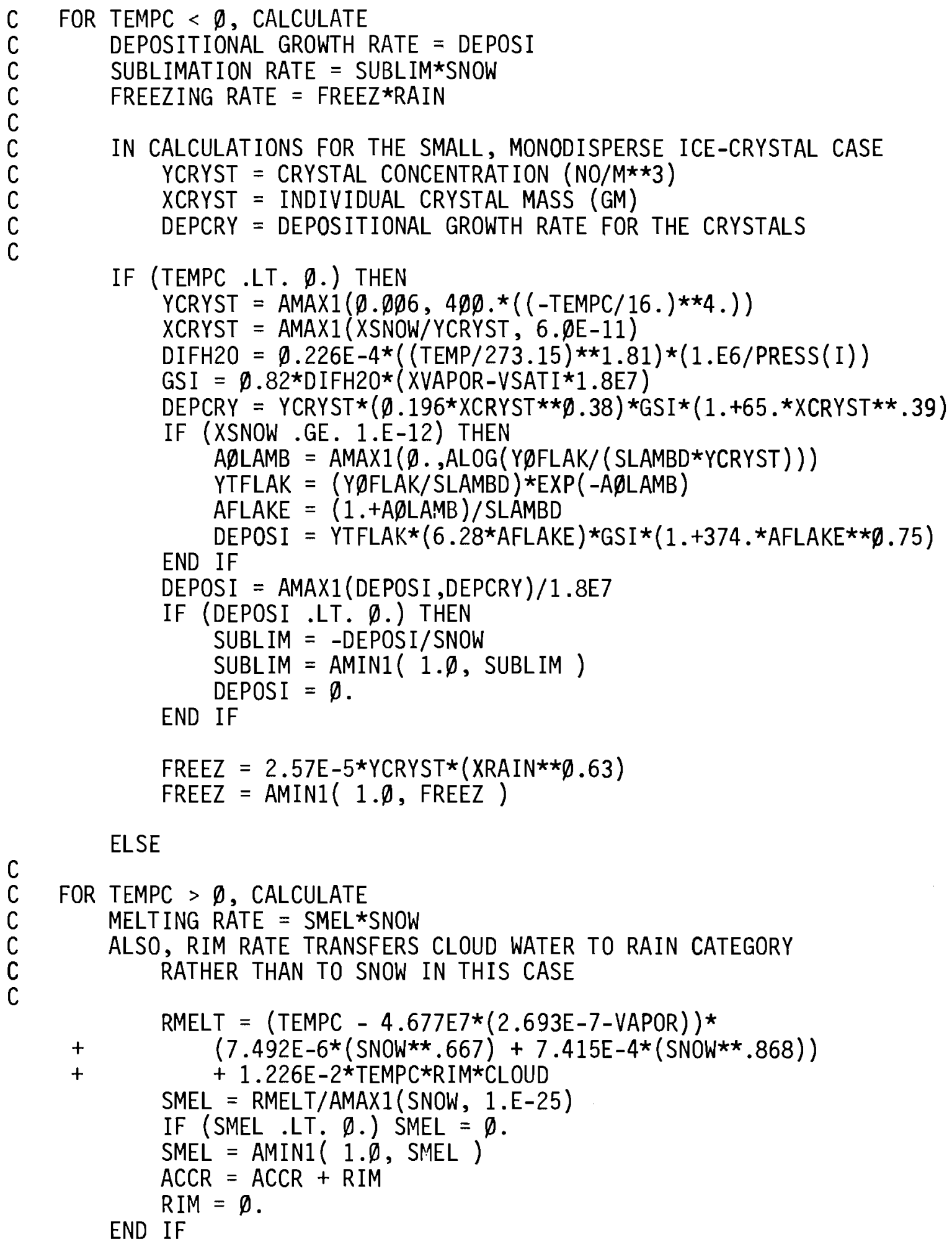


TABLE 5-8 Continued

CALC G TERMS FOR WATER SPECIES

C

$$
\begin{aligned}
& \text { GGEN }(\text { KRAIN })=(\text { AUTO+ACCR }) * C L O U D+S M E L * S N O W \\
& \text { GDEC }(\text { KRAIN })=(\text { EVAP+FREEZ }) * \text { RAIN } \\
& \text { GGEN }(K S N O W)=\text { DEPOSI + RIM*CLOUD + FREEZ*RAIN } \\
& \operatorname{GDEC}(K S N O W)=(\text { SMEL }+ \text { SUBLIM }) * S N O W \\
& \text { GGEN }(K V A P C L)=\text { EVAP*RAIN + SUBLIM*SNOW } \\
& \operatorname{GDEC}(K V A P C L)=(A U T O+A C C R+R I M) * C L O U D+D E P O S I
\end{aligned}
$$

LATENT HEATING TERMS

IF ISSAT(I) $=\emptyset$, THEN TEMPERATURE ADV-DIFF EQUATION WAS INTEGRATED UNSATURATED, SO CONSIDER ALL LATENT HEAT TERMS

OTHERWISE, TEMP. EQN. WAS INTEGRATED SATURATED, SO JUST CONSIDER

LATENT HEAT FROM WATER-ICE TRANSFORMATIONS, AND EVAPORATION

IF (ITEMP .EQ. $\emptyset$ ) GO TO $19 \emptyset \emptyset$

IF (ISSAT(I) .EQ. Ø) THEN

ELSE DMCOND = DEPOSI - SUBLIM*SNOW - EVAP*RAIN

END IF

DMCOND = -EVAP*RAIN

DMFREZ = DEPOSI - (SUBLIM+SMEL)*SNOW + RIM*CLOUD + FREEZ*RAIN

$\operatorname{GGEN}($ KTEMP $)=(4.5 \emptyset 3 E 11 *$ DMCOND $+5.2 \mathrm{E} 1 \emptyset *$ DMFREZ $) / C P C S P S(I)$

\section{$19 \emptyset \emptyset$ CONTINUE}

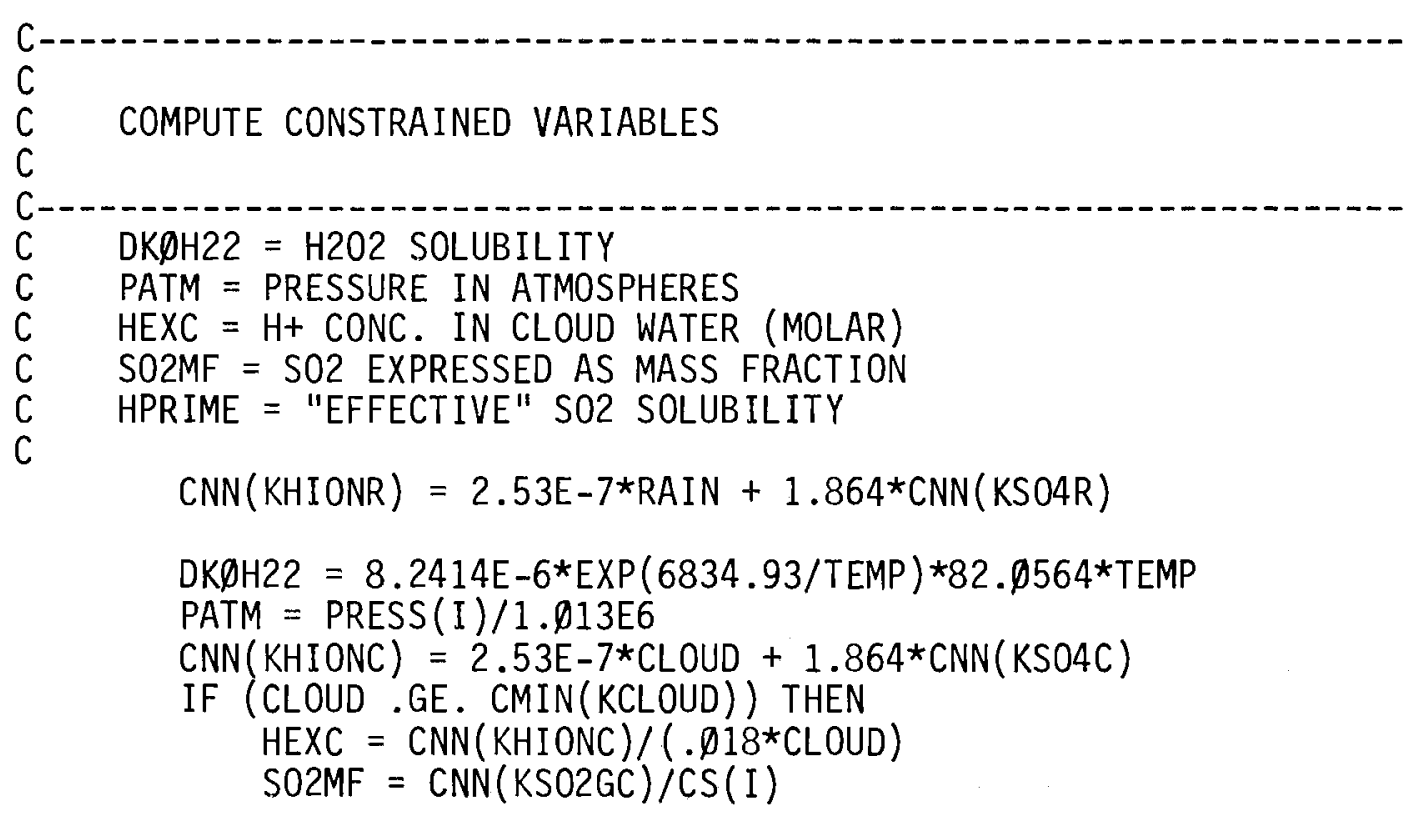




\section{TABLE 5-8 Continued}

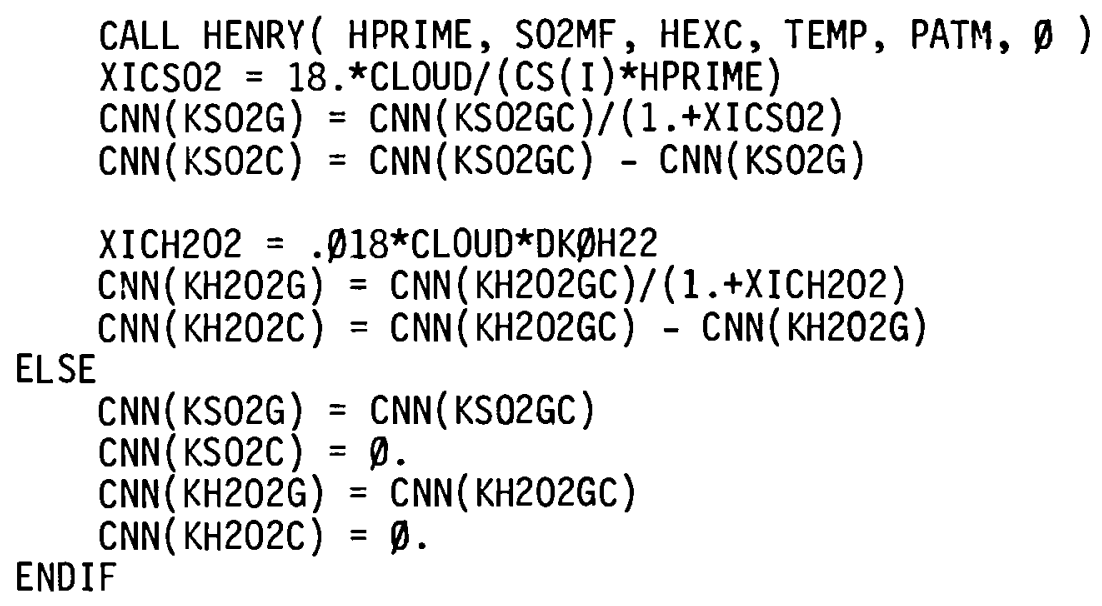

IF (IGCALC .LE. $\emptyset$ ) GOTO $8 \emptyset \emptyset \emptyset$

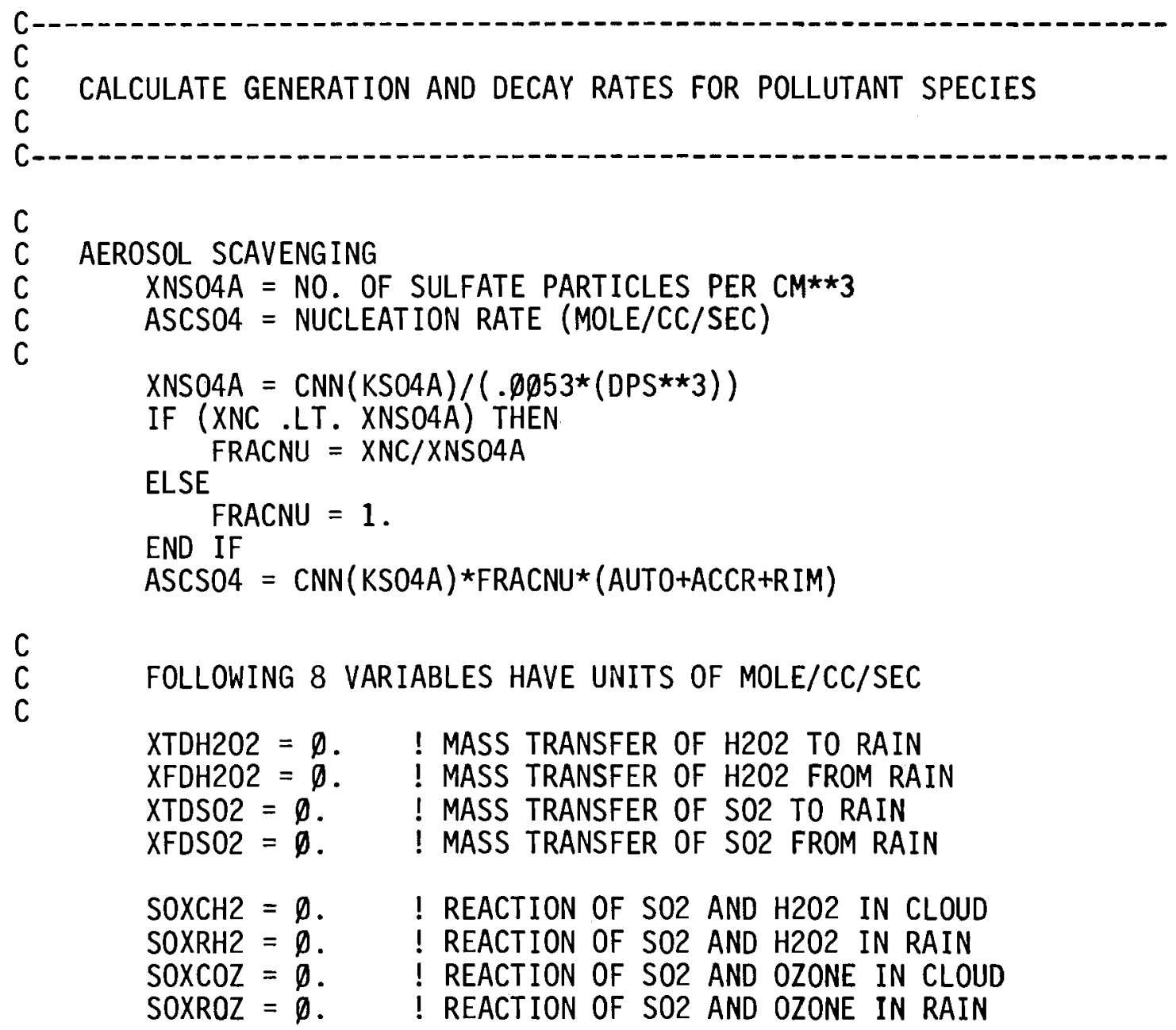


TABLE 5-8 Continued

$$
\text { DK1S }=\operatorname{EXP}(-10.96+1970 . / \text { TEMP })
$$

! FIRST DISSOC. CONSTANT FOR AQUEOUS SO2

$$
\text { C }
$$

C PROCESSES IN RAIN

C

IF (RAIN .GT . 1.E-6/1.8E7) THEN

C.......SOLUBILIT IES

$$
\text { HEXR }=\text { CNN }(K H I O N R) /\left(. \emptyset 18^{*} \text { RAIN }\right) \quad ! H+\text { CONC. IN RAIN (MOLAR) }
$$

SO2MF $=$ CNN $(K S O 2 G) / C S(I)$

CALL HENRY ( HPRIME, SOZMF, HEXR, TEMP, PATM, $\emptyset$ )

$\mathrm{XIRSO2}=18 . * \operatorname{RAIN} /(\mathrm{CS}(\mathrm{I}) * \mathrm{HPRIME})$

$\mathrm{XIRH202}=. \emptyset 18 *$ RAIN*DKØH22

C.......MASS TRANSFER

C XFRATE = MASS TRANSFER RATE FROM LEVINE AND SCHWARTZ

IF (JPASSO .EQ. 1) XFRATE $=31.2 *($ RAIN**.647)

$X$ TDSO2 $=$ XFRATE $*$ CNN $(K S 02 G)$

XFDSO2 $=$ XFRATE $*$ CNN $($ KSO2R $) / X I R S 02$

$X T D H 202=X$ FRATE $*$ CNN $($ KH2O2G $)$

XFDH202 $=$ XFRATE $* \mathrm{CNN}(\mathrm{KH} 202 \mathrm{R}) / \mathrm{XIRH} 202$

C........CHEMICAL REACTION

C SOZAQM = CONC. OF UNDISSOCIATED SO2 IN RAIN (MOLAR) SOXROZ $=2.9 \mathrm{E} 6 * \mathrm{CNN}(\mathrm{KSO} 2 \mathrm{R}) * \mathrm{CNN}(\mathrm{KO3G}) / \mathrm{SQRT}(\mathrm{HEXR})$

SO2AQM $=(\operatorname{CNN}(K S O 2 R) /(. \emptyset 18 *$ RAIN $)) /$

$+\quad(1 .+(D K 1 S / H E X R))$

SOXRH2 $=8.3 \mathrm{E} 5 * \mathrm{SO} 2 \mathrm{AQM}{ }^{\star} \mathrm{CNN}(\mathrm{KH} 202 \mathrm{R})$

ENDIF

C

C PROCESSES IN CLOUD WATER

C

IF (CNN(KCLOUD) .GT. CMIN(KCLOUD)) THEN

SOXCOZ $=2.9 \mathrm{E} 6 * \mathrm{CNN}(\mathrm{KSO} 2 \mathrm{C}) * \mathrm{CNN}(\mathrm{KO3G}) / \mathrm{SQRT}(\mathrm{HEXC})$

SO2AQM $=\left(\right.$ CNN $($ KSO2C $) /\left(. \emptyset 18^{*}\right.$ CLOUD $\left.)\right) /$
$+\quad(1 .+($ DKIS/HEXC $))$

SOXCH2 $=8.3 \mathrm{E} 5 * \mathrm{SO} 2 \mathrm{AQM} * \mathrm{CNN}(\mathrm{KH} 202 \mathrm{C})$

\footnotetext{
C ENDIF

COMPUTE GENERATION AND DECAY RATES

c

C...SO2

GGEN (KS02GC) $=$ XFDSO2 + SUBLIM*CNN (KS02S)

GDEC $(K S 02 G C)=(A U T 0+A C C R+R I M) * C N N(K S 02 C)$

$+\quad+\mathrm{SOXCH} 2+\mathrm{SOXCOZ}+\mathrm{XTDSO} 2$
} 


\section{TABLE 5-8 Continued}

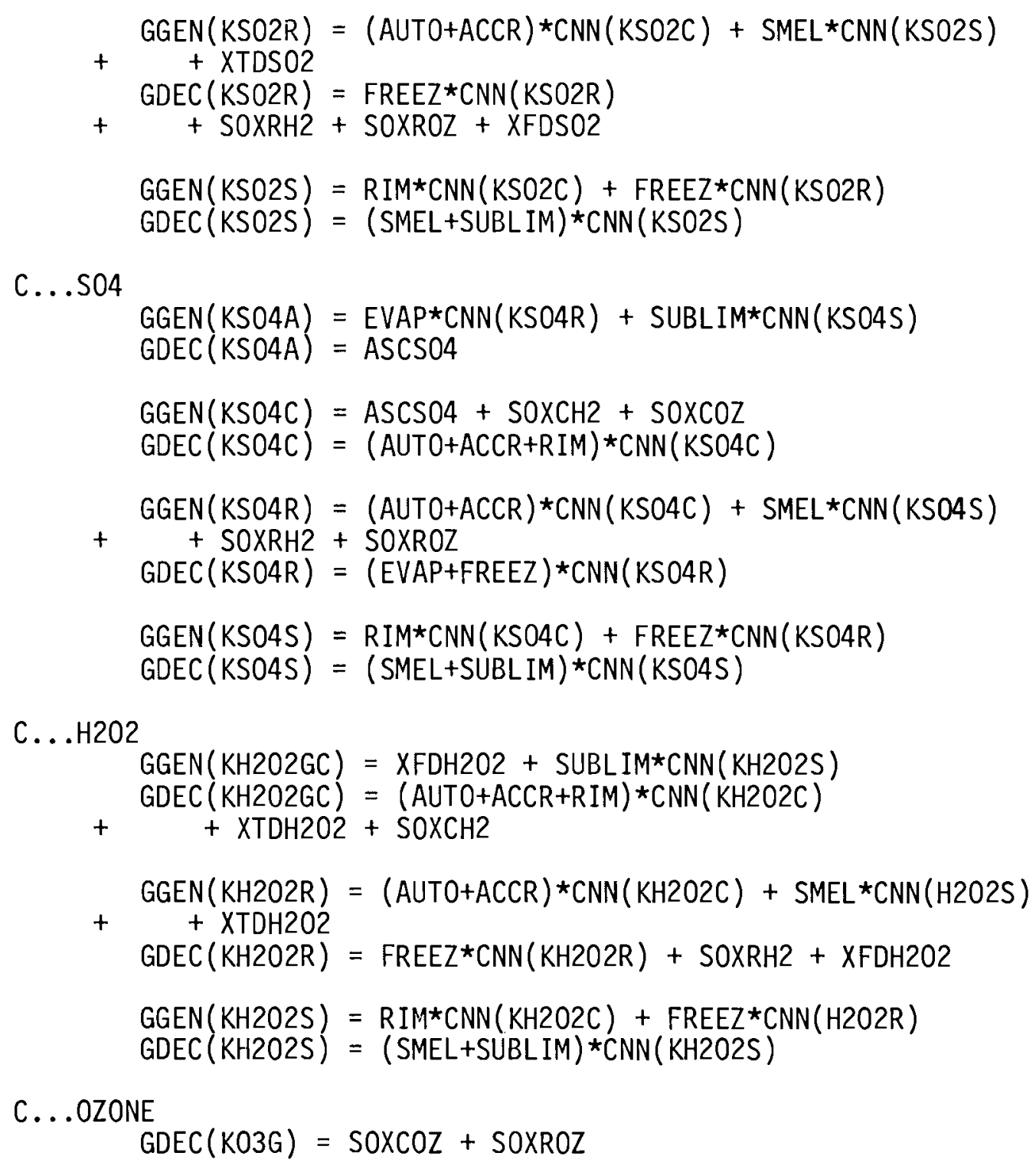

8000 CONTINUE

RETURN

END 


$$
\begin{aligned}
& \mathrm{SO}_{2 \text { |gas } \rightleftharpoons \mathrm{SO}_{2} \text { cloud }} \rightleftharpoons \mathrm{H}_{2} \mathrm{O}_{2 \mid \text { cloud }} \\
& \mathrm{H}_{2} \mathrm{O}_{2 \text { |gas } \rightleftharpoons} \rightleftharpoons
\end{aligned}
$$

discussed earlier in part B. The Class III subroutine HENRY is used to compute the $\mathrm{H}^{\prime}$ of Equation (69), which is needed for the $\mathrm{SO}_{2}$ equilibrium. The equilibria for aqueous $0_{3}$,

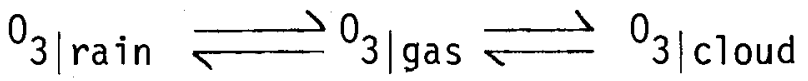

are computed later, since the aqueous $0_{3}$ concentrations are just used as temporary variables, unlike the aqueous $\mathrm{SO}_{2}$ and $\mathrm{H}_{2} \mathrm{O}_{2}$ variables. Again, this is possible because $0_{3}$ has a very low solubility; thus the aqueous $\mathrm{O}_{3}$ concentrations are very small compared to the corresponding gas concentrations.

The next section computes rates for the following processes: nucleation scavenging, mass transfer between gas and rainborne species, and chemical reaction of aqueous species. Note that the mass transfer to rain and the aqueous reactions in rain are "enabled" only when the rain concentration is above $10^{-6} \mathrm{gm} / \mathrm{m}^{3}$. This artificial cutoff has been inserted to improve computational efficiency. The justification is that the impact of these processes is negligible when the amount of rain is below the cutoff value. One should note also that in the mass-transfer section, the variable XFRATE which is $\Lambda$ in Equation (73) is only computed on the predictor pass (JPASSO = 1). This approximation has little effect when rain concentrations are - significant, but improves computational speed at low rain concentrations.

Finally, the net generation and decay rates are computed for each - species. It is worthwhile to work through this section of the code using Figures 5-2 and 5-3. Note that most terms occur in one species generation expression and in one species decay expression. The exceptions are chemical reaction terms which involve two reactants: these terms thus occur in two decay expressions. 
SUBROUTINE GRDSET (Table 4-8)

GRDSET establishes the vertical spacing of the computational grid. For this example, uniform spacing is again used, so GRDSET is the same as the Example 1 version.

SUBROUTINE SETTL (Table 5-9)

SETTL establishes the settling velocities of the computed species. In this example, rain, snow, and any precipitation-borne species have significant settling velocities. These velocities are the mass-weighted mean velocities for the rain and snow Marshall-Palmer size distributions, and are computed as described in the first part of this chapter. As these velocities are concentration dependent and change with time, we need ISETTL $=1$.

SUBROUTINE TIMESP (Table 5-10)

TIMESP sets the basic integration time step, DT. In this example, precipitation species can have significant settling velocities (approaching $10^{3} \mathrm{~cm} / \mathrm{sec}$ ), and computational constraints require that DT not be too large. In particular, it is important to keep the local Courant number near or below unity. This requires that

$$
\text { DT*URAT I0*W } \leqq D Z
$$

at all grids, where $W$ is the largest of the vertical velocities and $D Z$ is the local grid spacing. In this example, we have also set an upper limit for DT of 60 secs.

SUBROUTINE USHEAR (Table 5-11)

USHEAR establishes the ratio URATIO $=u^{*} / u_{A}$. This example is a two-dimensional time-dependent simulation, with $u_{A}$ varying in height. In particular, $u_{A}$ varies 1 inearly from $5 \mathrm{~m} / \mathrm{sec}$ at $z=0$ to $10 \mathrm{~m} / \mathrm{sec}$ at $z=1.5$ $\mathrm{km}$, and is constant at $10 \mathrm{~m} / \mathrm{sec}$ above this height. The reference level has been chosen as the grid top, so $u^{\star}=10 \mathrm{~m} / \mathrm{sec}$. The horizontal wind speed is constant in time for the example, so USHEAR only needs to be called initially and ISHEAR $=0$. 
TABLE 5-9. Listing of Subroutine SETTL for Example Application 2

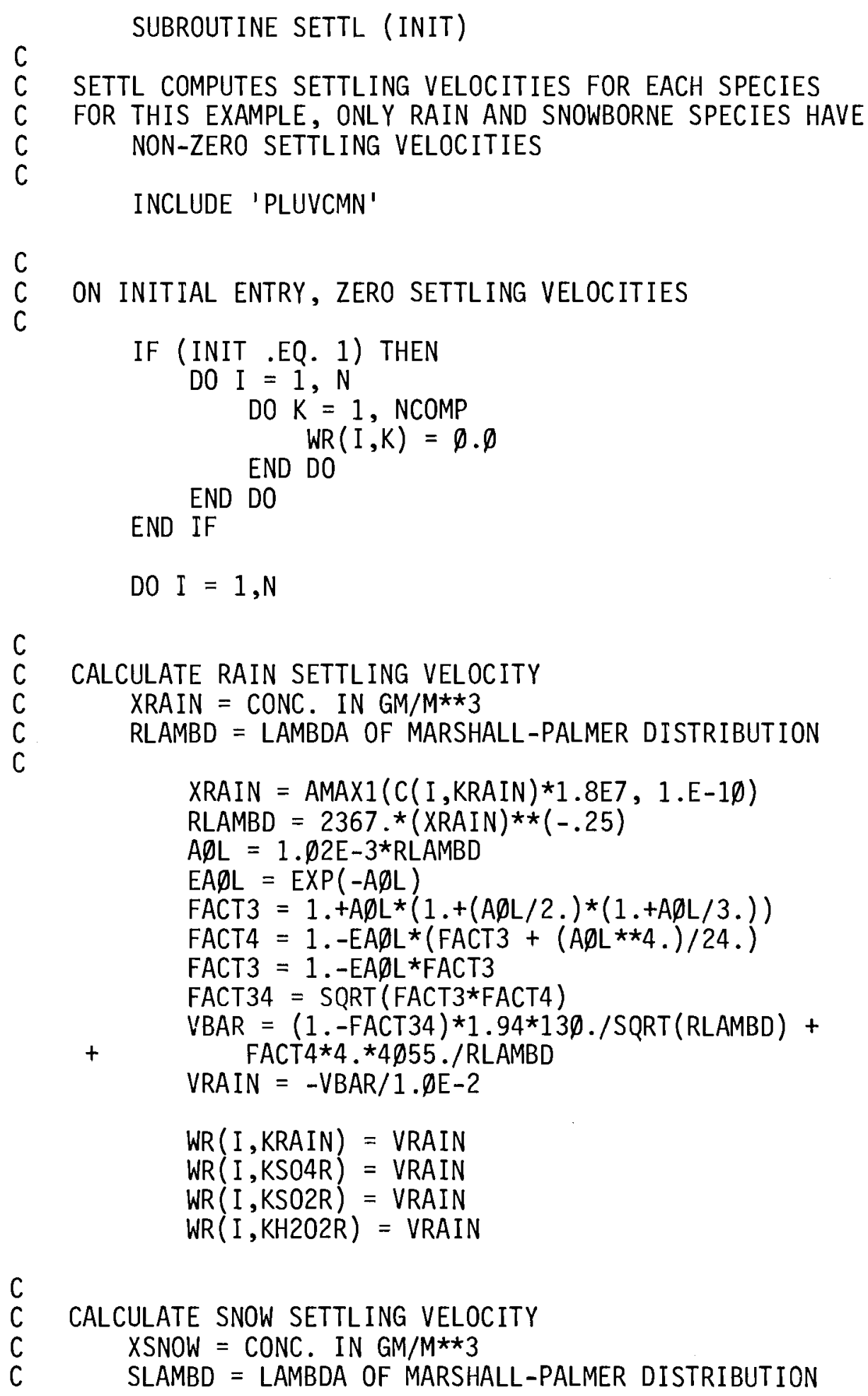




\section{TABLE 5-9 Continued}

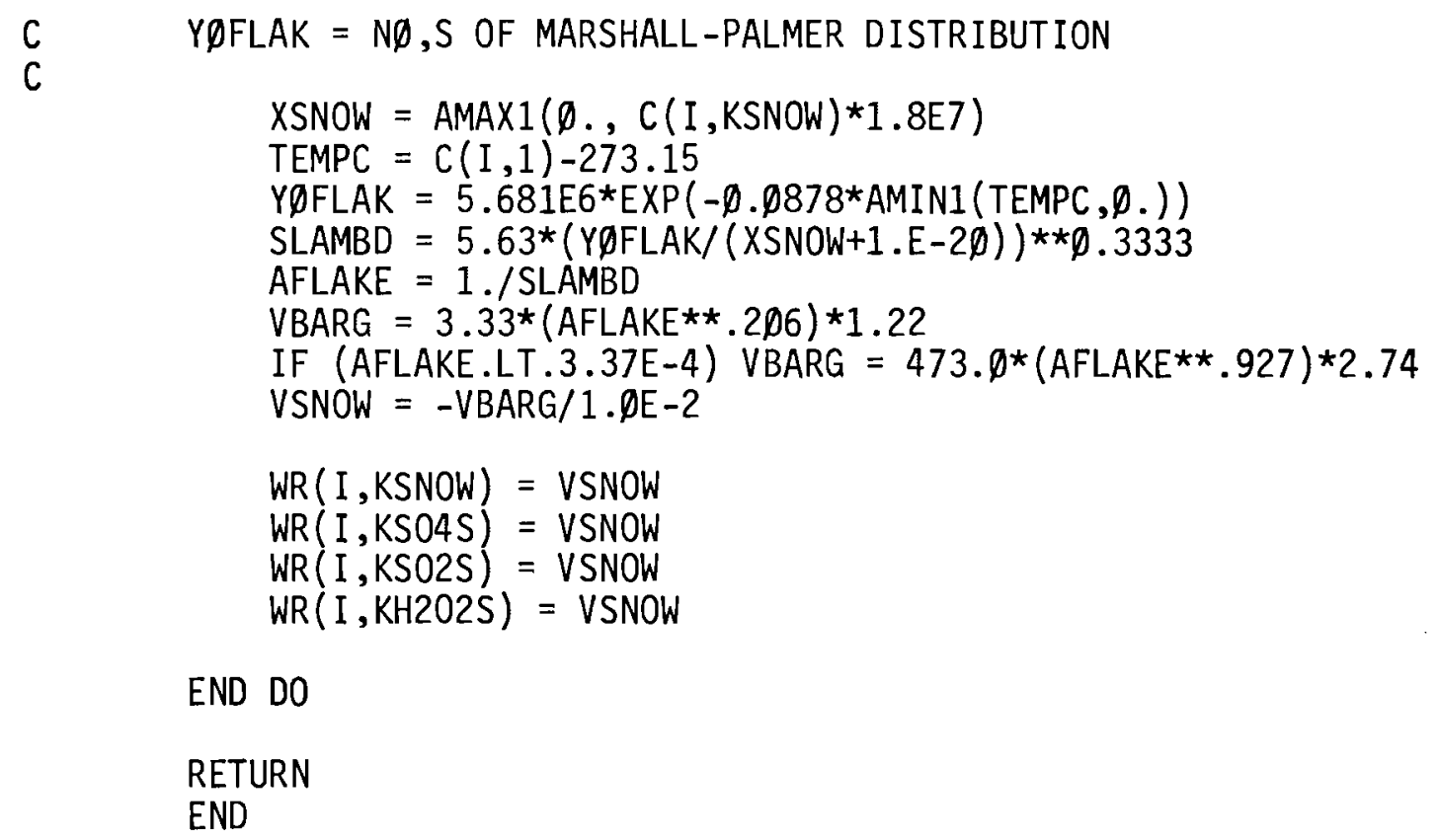


TABLE 5-10. Listing of Subroutine TIMESP for Example Application 2

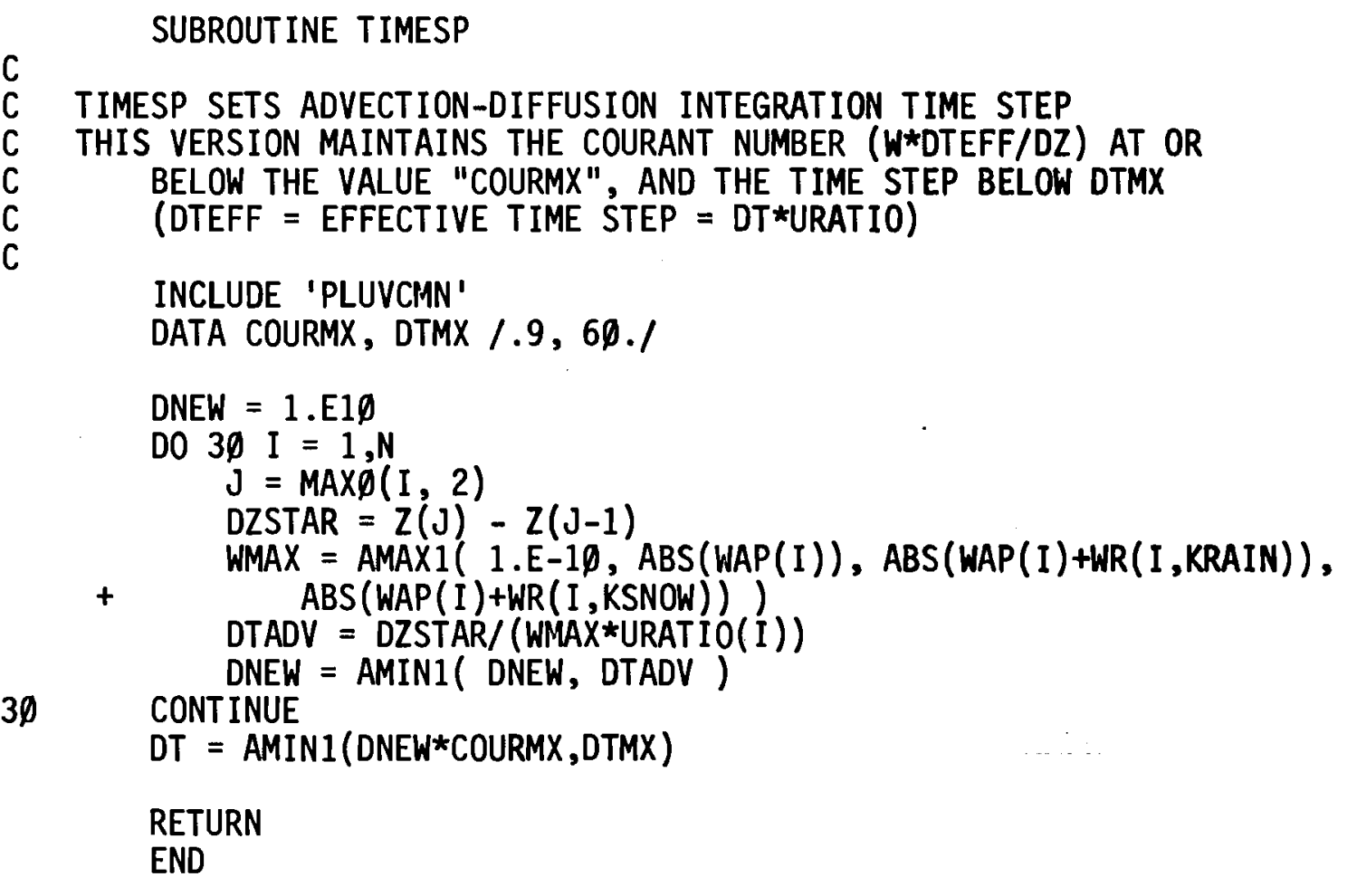


TABLE 5-11. Listing of Subroutine USHEAR for Example Application 2

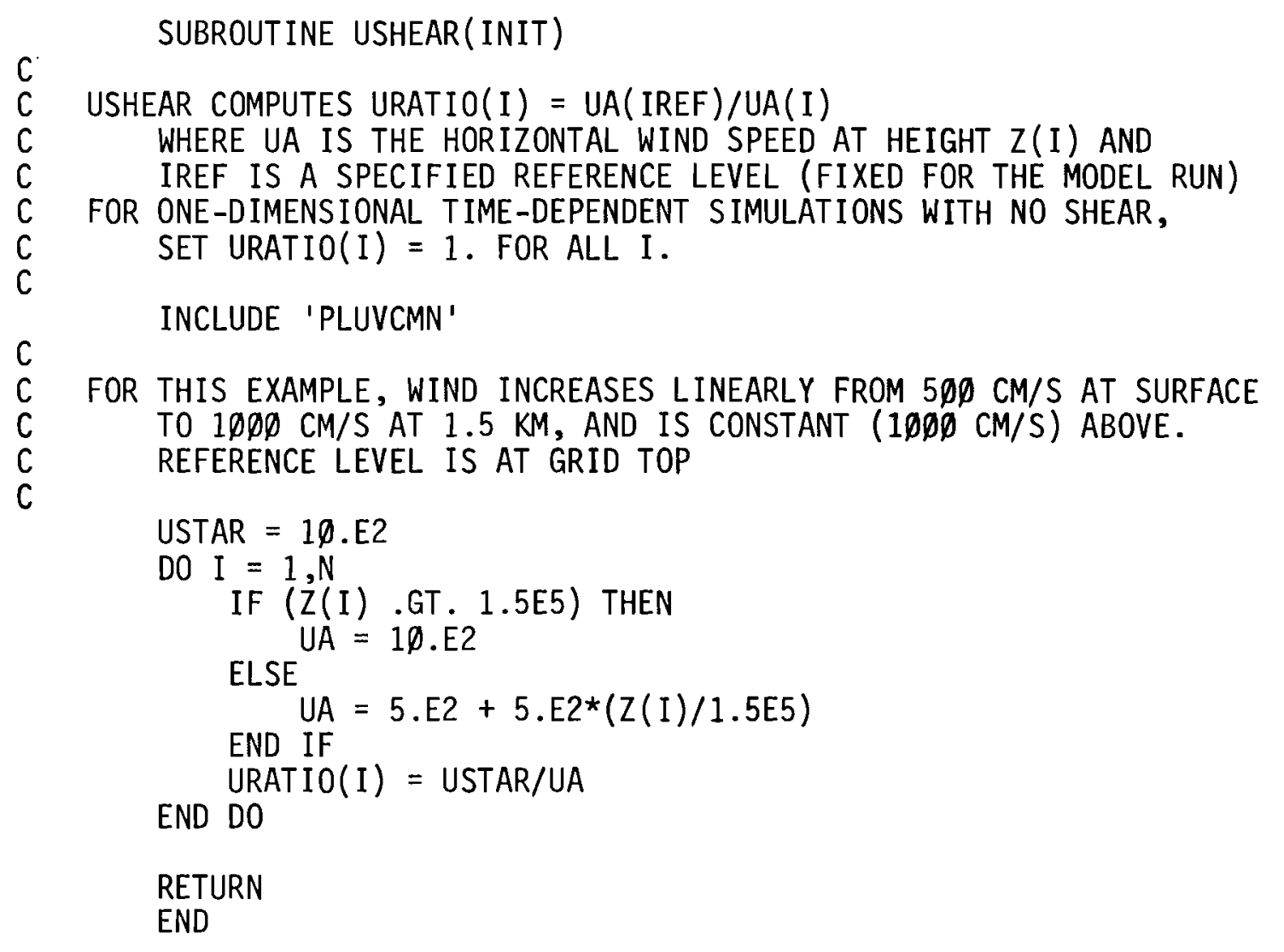


SUBROUTINE VERT (Table 5-12)

VERT establishes the two components of the air vertical velocity as given in Equation (11). For this example, the component relative to the grid, $w_{A} "$, has been arbitrarily specified as zero. The other component, the grid vertical velocity, is determined by the shape of the hypothetical orographic barrier shown in Figure 5-1. At the bottom grid level, this velocity is given by

$$
w_{A 0}=u_{A} \frac{d z_{G}}{d x}
$$

where $z_{G}$ is the height of the barrier. The time and distance coordinates are related by $x=u^{\star} t *$, so that

$$
w_{A 0}=\frac{u_{A}}{u^{\star}} \frac{d z_{G}}{d t^{\star}}
$$

The ground profile and the resulting $\mathrm{dz}_{G} / \mathrm{dt}$, is the arbitrarily chosen mathematical function shown in Figure 5-1. As noted in the USHEAR discussion of Chapter 3, the PLUVIUS array WAGRID is defined by

$$
\begin{aligned}
\operatorname{WAGRID}(1) & \equiv w_{A O} \\
\text { and } \operatorname{WAGRID}(I) & \equiv w_{A O}\left(u_{A} / u_{A O}\right)=\operatorname{WAGRID}(1) \star \operatorname{URATIO}(1) / \operatorname{URATIO}(\mathrm{I}) .
\end{aligned}
$$

\section{E. CLASS III SUBROUTINE DESCRIPTIONS}

Two Class III subroutines are used in this example. Both are called by subroutine GEN.

Subroutine HENRY (Table 5-13) computes the effective solubility parameter for $\mathrm{SO}_{2}$, as described in Equations $(68)-(71)$. The subroutine was borrowed directly from a previous code (Drewes and Hales, 1977).

FUNCTION SSAT (Table 5-14) computes the saturation vapor density with respect to ice, and is needed to calculate the depositional growth rate for snow. 
TABLE 5-12. Listing of Subroutine VERT for Example Application 2

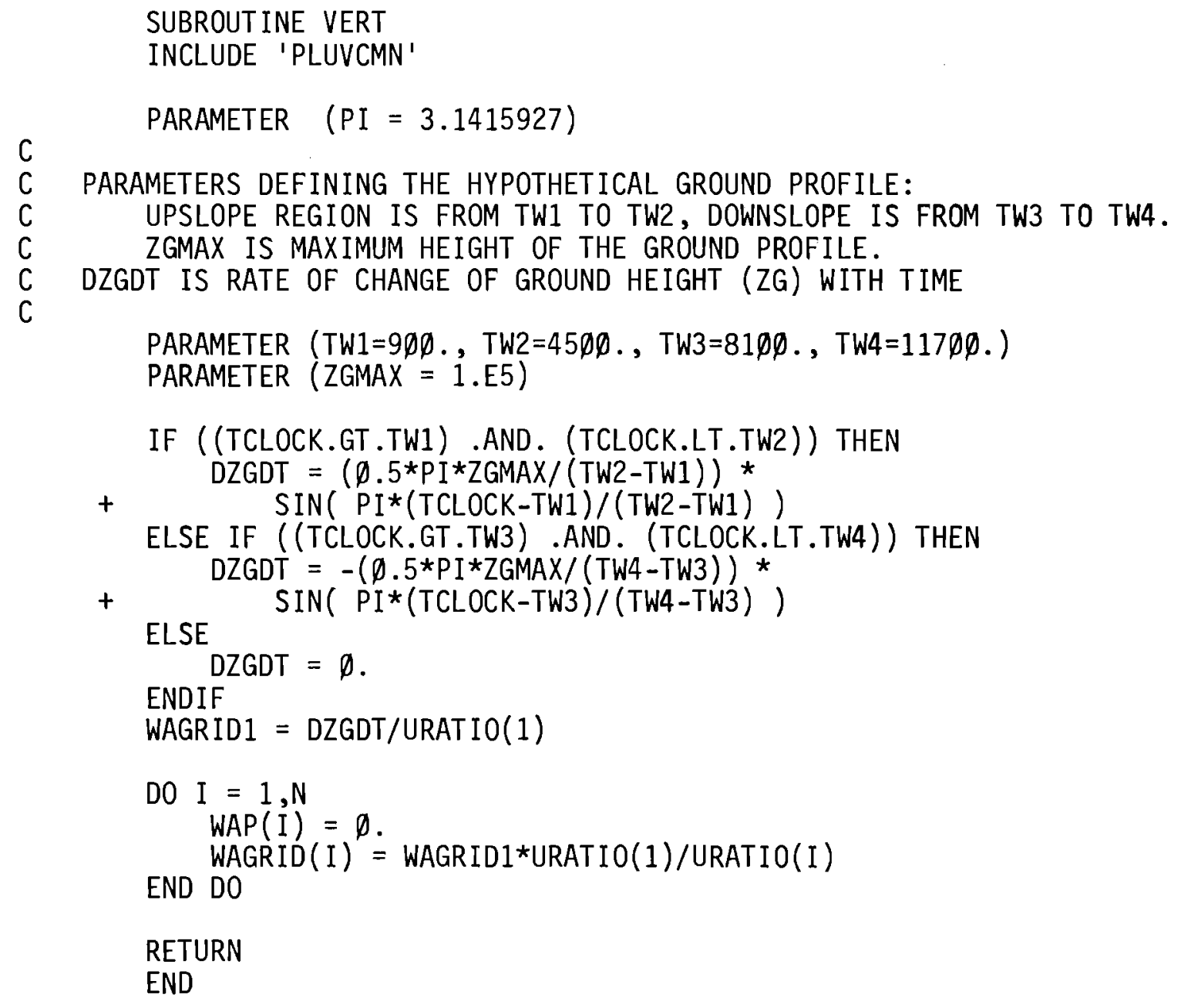


TABLE 5-13. Listing of Subroutine HENRY for Example Application 2

SUBROUT INE HENRY ( HPRIME, C, HEX, T, P, LGOPT )

C

C SUBROUTINE FOR CALCULATING APPARENT HENRY'S LAW CONSTANT

C ON THE BASIS OF JOHNSTONE-LEPPLA PARAMETERS

C HPRIME IS THE APPARENT HENRY'S LAW CONSTANT, DEFINED BY:

C HPRIME $=$ SO2 + GAS / SO2 $+A Q$, WHERE:

C SO2 $+A Q=$ CONCENTRATION OF SULFUR-IV IN AQUEOUS PHASE (MOLES/CM**3 WATER)

SO2+GAS = CONCENTRATION OF GAS PHASE S02 (MOLE FRACTION)

C IS EITHER

SO2 $+A Q$ WHEN LGOPT $=1$ (MOLES/CM**3 WATER)

SO2+GAS WHEN LGOPT $=\emptyset$ (MOLE FRACTION)

HEX IS THE AQUEOUS PHASE HYDROGEN ION CONCENTRATION FROM SPECIES

OTHER THAN SULFUR-IV (MOLAR)

$T$ IS TEMPERATURE (DEGREES $K$ )

C P IS ATMOSPHERIC PRESSURE (ATMOSPHERES)

C LGOPT IS A FLAG EXPLAINED ABOVE

C

IF ((LGOPT.NE. $\emptyset)$.AND. (LGOPT.NE.1)) STOP 7777

HANK $=\operatorname{EXP}(10.21-3112 . / T) / P$

EQCON $=\operatorname{EXP}(-1 \emptyset .96+197 \emptyset . / T)$

$B=E Q C O N+H E X$

$\mathrm{C}$

C LGOPT $=1-\rightarrow C$ IS THE AQUEOUS CONCENTRATION

IF (LGOPT .NE. 1) GOTO $2 \emptyset$

CDUM $=$ EQCON* $1 \emptyset \emptyset \emptyset .{ }^{*} \mathrm{C}$

TEST1 $=4 . * \operatorname{CDUM} /(B * B)$

IF (TEST1 .GT. .ØØ1) GOTO $1 \emptyset$

C........... LOW CONCENTRATIONS - USE ASYMPTOTIC EXPRESSION $H P R I M E=H A N K *(1 .-E Q C O N / B)$

GOTO $4 \emptyset$

C..........SOLVE TOTAL SOLUBILITY EQUATION

$10 \quad$ HPRIME $=\operatorname{HANK}^{\star}\left(1 .+\left(\mathrm{B}-\mathrm{SQRT}\left(\mathrm{B}{ }^{\star} \mathrm{B}+4 .{ }^{\star} \mathrm{CDUM}\right)\right) /\left(200 \emptyset .{ }^{\star} \mathrm{C}\right)\right)$

GOTO $4 \varnothing$

C

C LGOPT $=\emptyset-\rightarrow C$ IS THE GAS PHASE CONCENTRATION

C

$2 \emptyset$ TEST $1=4 .{ }^{\star}{ }^{*} Q C O N{ }^{*} C /\left(H E X * H E X{ }^{*} H A N K\right)$

IF (TEST1 .GT. . $\emptyset \emptyset 1$ ) GOTO $3 \emptyset$

C..........LOW CONCENTRAT IONS - USE ASYMPTOT IC EXPRESSION HPRIME = HANK $\star H E X / B$

GOTO $4 \emptyset$ 
TABLE 5-13 Continued

C............. SOLVE TOTAL SOLUBILITY EQUATION

$3 \emptyset$ HPRIME $=\mathrm{C} /\left(\mathrm{C} / \mathrm{HANK}-\left(\mathrm{HEX}-\mathrm{SQRT}\left(\mathrm{HEX} * \mathrm{HEX}+4 .{ }^{*} \mathrm{C} \star \mathrm{EQCON} / \mathrm{HANK}\right)\right) / 2.\right)$

$4 \emptyset \quad$ HPRIME $=$ HPRIME* $1 \emptyset \emptyset \emptyset$.

RETURN

END 
TABLE 5-14. Listing of Function SSAT for Example Application 2

\section{FUNCTION SSAT ( TEMPK)}

- $\quad$ C SSAT = THE SATURATION CONCENTRATION OF WATER VAPOR (GRAM MOLES/CC) OVER ICE AT TEMPK DEGREES KELVIN

(ESAT IS SATURATION VAPOR PRESSURE IN MB)

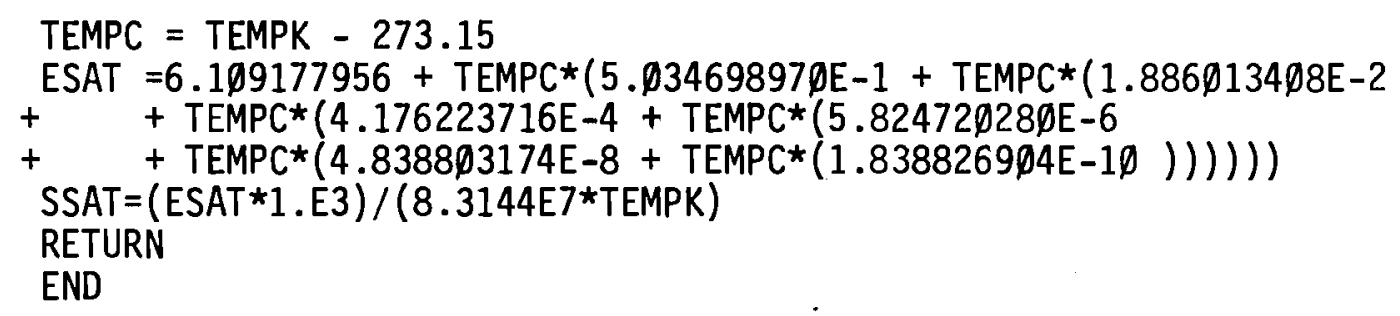


F. MODEL OUTPUT

Printed output from Example Application 2 is reproduced in the tables of Appendix D. Some of the more interesting features of the simulation are shown in Figures 5-4 through 5-6.

Figure 5-4 shows the time-height distributions of cloud water, rain, and snow (which were shown schematically in Figure 5-1). These should be viewed as two-dimensional, $x-z$ distributions. A cloud forms on the upwind side of the orographic barrier, then dissipates on the downwind side. Initially, snow growth is most rapid at higher elevations because of the temperature dependence of deposition growth. The highest snow concentrations are at lower elevations, however, because the "concentration" represents the cumulative growth as snow particles descend. The melting level at about $2.5 \mathrm{~km}$ is quite apparent. Note that rain concentrations beneath the melting level are lower than the snow concentration above it, because rain has a higher fallspeed than snow and it is the precipitation flux that is conserved across the layer.

Figure 5-5 shows time-height distributions for $\mathrm{SO}_{2}$, sulfate, and $\mathrm{H}_{2} \mathrm{O}_{2}$. Note that the total concentration (i.e., the sum of gaseous/aerosol, cloud water, rain, and snow phases) of each species is shown. Ozone is only slightly depleted by scavenging so has not been shown. The $\mathrm{H}_{2} \mathrm{O}_{2}$ distribution is the easiest to interpret: essentially all $\mathrm{H}_{2} \mathrm{O}_{2}$ is destroyed by the aqueous reaction with $\mathrm{SO}_{2}$ shortly after the cloud forms. The $\mathrm{SO}_{2}$ distribution shows the effects of moderate depletion by aqueous reaction and non-reactive scavenging, and a broadening of the initial sharp vertical concentration gradient by diffusion. The $\mathrm{H}_{2} \mathrm{O}_{2}$ reaction accounts for a $10 \% \mathrm{SO}_{2}$ loss. (Initial $\mathrm{H}_{2} \mathrm{O}_{2} / \mathrm{SO}_{2}$ ratio is 0.1.$)$ The total $\mathrm{SO}_{2}$ loss is somewhat greater than $20 \%$ at higher elevations (initial $2 \mathrm{ppb}$, final $<1.6 \mathrm{ppb}$ ), and somewhere between 10 and $20 \%$ at lower elevations. This is explained by the inverse dependences of both the $\mathrm{SO}_{2}$-ozone reaction and $\mathrm{SO}_{2}$ solubility on $\mathrm{H}^{+}$concentration. The $\mathrm{H}^{+}$concentration is highest at low elevations where there is more sulfate. The sulfate distribution is interesting in that it shows the competing effects of production (by aqueous reaction of $\mathrm{SO}_{2}$ ) and loss (by precipitation scavenging). This results in a peak concentration of $2 \mathrm{ppb}$ at about 1 hour into the 

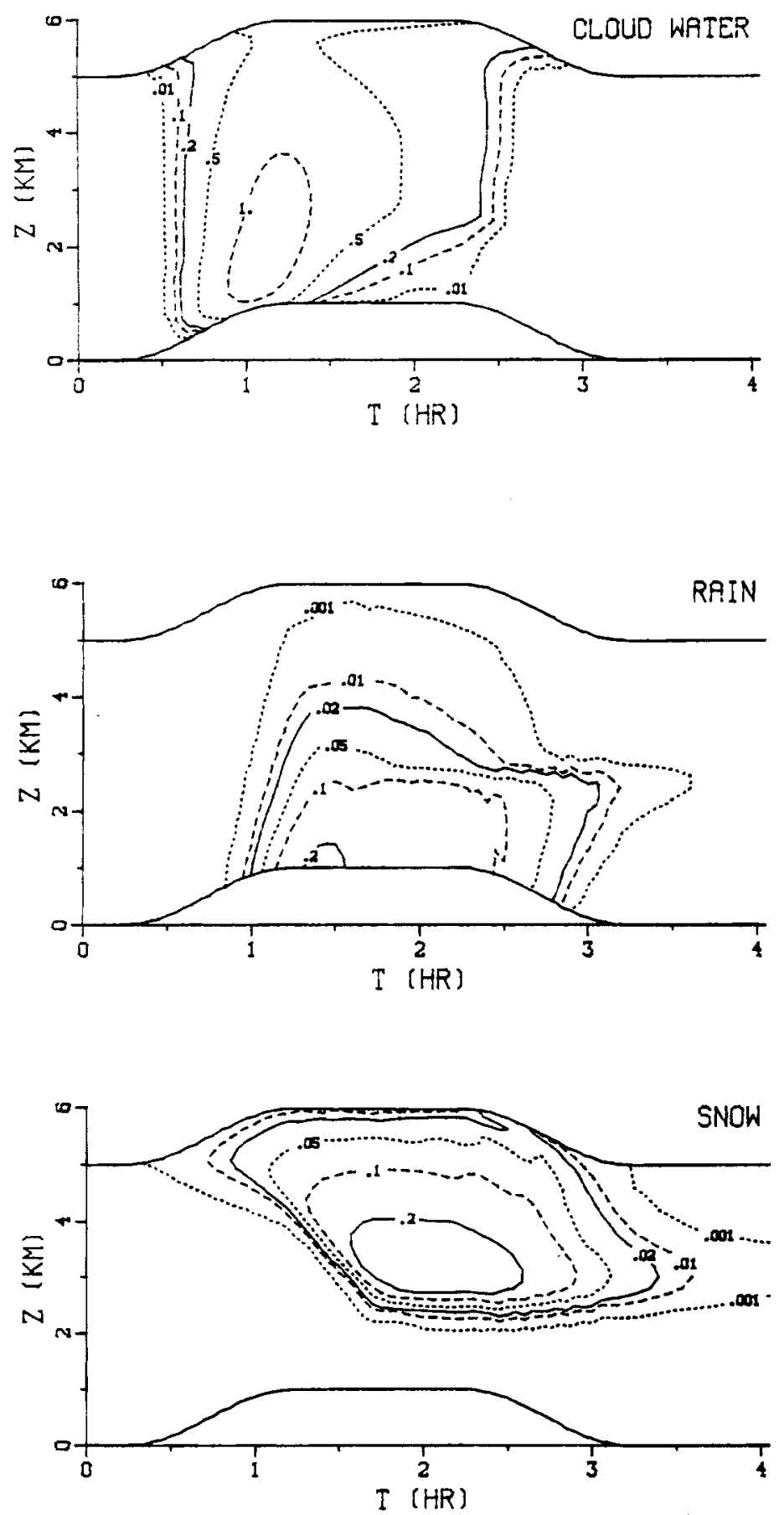

FIGURE 5-4. Distributions of Cloud Waţer, Rain, and Snow in Example Application 2. Contour units are $\mathrm{gm} / \mathrm{m}^{3}$. A time of 1 hour corresponds to a horizontal distance of $36 \mathrm{~km}$. 

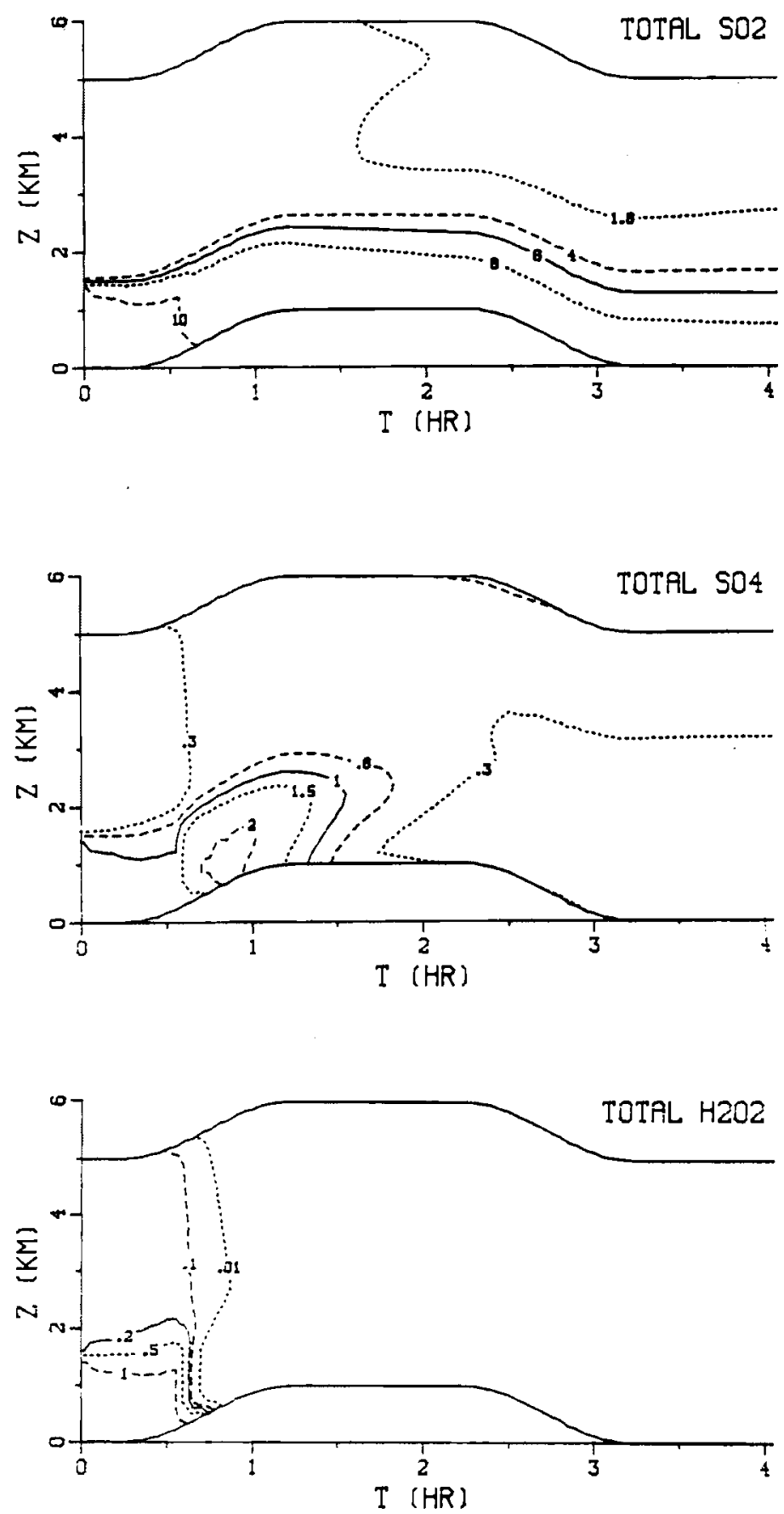

FIGURE 5-5. Distributions of Total $\mathrm{SO}_{2}$, Total $\mathrm{SO}_{4}$, and Total $\mathrm{H}_{2} \mathrm{O}_{2}$ Mixing Ratios in Example Application 2. The "total" is the sum of the species in gas/aerosol, cloud, rain, and snow forms. Contour units are ppb. A time of 1 hour corresponds to a horizontal distance of $36 \mathrm{~km}$. 

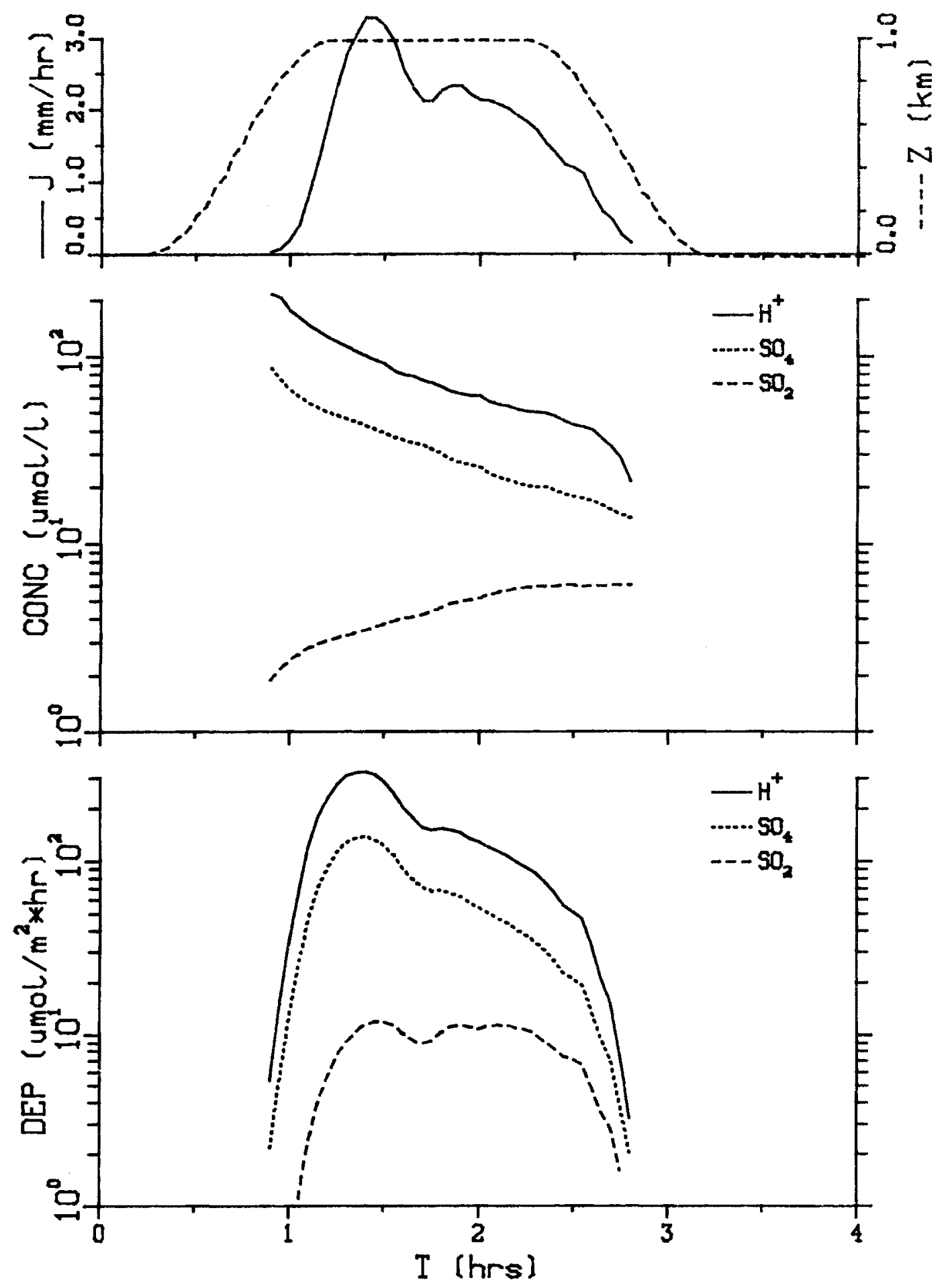

FIGURE 5-6. Rain Rate (J), Concentrations of Rainborne Pollutant (CONC), and Deposition Rates of Rainborne Pollutant (DEP) at the Surface (i.e., the bottom grid element) in Example Application 2. Dotted line in top subplot is the height of the orographic barrier. A time of 1 hour corresponds to a horizontal distance of $36 \mathrm{~km}$. 
simulation. At higher elevations, the final concentration is greater than the initial concentration, indicating that the production is greater than the loss in this region.

Figure 5-6 shows the surface rainfall rate, rainborne pollutant concentrations, and rainborne pollutant deposition rates. The rainfall rate shows an initial peak corresponding to the one in Figure 5-4, then a secondary peak about a half-hour later. Fluctuations like this are a result of the nonlinear nature of the precipitation growth and fallspeed parameterizations. The sulfate concentration decreases monotonically-- showing the gradual depletion of primary and secondary sulfate by scavenging. The $\mathrm{H}^{+}$ concentration follows the sulfate concentration, as constrained by Equation (72). The $\mathrm{SO}_{2}$ concentration increases with time, because of the inverse relation between its solubility and $\mathrm{H}^{+}$concentration. The relative contributions of primary (aerosol) sulfate and secondary sulfate to the surface deposition cannot be ascertained from this single simulation. However, one could simply run a second simulation in which the initial $\mathrm{SO}_{2}$ concentration is everywhere zero to obtain the primary sulfate deposition. 
6. PROBLEMS WITH PLUVIUS:

SOME PRACTICAL DIFFICULTIES AND SUGGESTIONS FOR THEIR RESOLUTION

Aside from the inherent one-dimensionality of PLUVIUS, there are a number of practical difficulties which can emerge with the model to produce malfunctions or inappropriate results, and several actions can be taken to minimize these effects. The first and most important of these is simply the problem of formulating a conceptual model and implementing it on PLUVIUS in a correct and expedient fashion. There is no easy solution to this; but our experience has shown that significant shakedown and backtracking time can be eliminated via systematic use of a formal implementation procedure. The procedure is as follows:

- Create interaction diagrams (e.g., Figures 5-2 and 5-3) to define all pathways and dependent variables.

- Create a species-definition table (eg. Table 5-1) to define specifically the interactive species within the computation.

- Create a table of initial conditions.

- Determine the number of diffusion regimes.

- Adjust the code's dimensioning to be sufficiently large to accommodate these parameters.

- Ensure that the water-related variables (if employed) are named in a manner that is consistent with usage in the main program (cf. Section 3A).

- Define al1 required boundary conditions.

- Define grid height and temporal and spatial spacing.

- Define vertical movement of grid and relative vertical flows $\left(w_{A}^{\prime}\right)$.

- Define fall-velocity features.

- Define diffusional behavior. 
the Class I subroutines to conform with the above specifis. A check-off list for this purpose is as follows:

IDJUST

BOUND

DIFF

GEN

GRDSET

SETTL

SETUP

TIMESP

USHEAR

VERT

onsolidate the above subroutines with PLUVIUS and the Class II jubroutines.

Add any required Class III subroutines.

Create an input data set as described in Section $3 \mathrm{C}$ (e.g., Table $5-2)$.

Execute the program.

second problem with PLUVIUS, which may arise to plague the user, is in the ordinary differential equation integration routine ODEINT. outine was chosen for present purposes because of its low start-up leads" and its generally efficient integration of stiff sets of ions. It is potentially susceptible to problems in two areas, however:

1. Integration of locally nonlinear systems: In general ODEINT requires rather small step sizes to integrate equations of the form

$$
\frac{\mathrm{d} A}{\mathrm{~d}} \frac{\mathrm{t}}{\mathrm{t}}=-\mathrm{kA} A^{\alpha} \quad \alpha \neq 1
$$

This is not a major problem, except that it sometimes detracts rather substantially from the code's efficiency. Most chemical- 
kinetics equations do not follow the above form. However, several cloud-physics parameterizations do involve nonlinear expressions of this type and thus tend to slow the code's execution rate.

2. Integration of some interactive systems: Typically ODEINT performs well in integrating complex multicomponent systems, such as air-chemistry schemes. There are, however, some exceptions which arise whenever specific reaction patterns occur; for example, the scheme

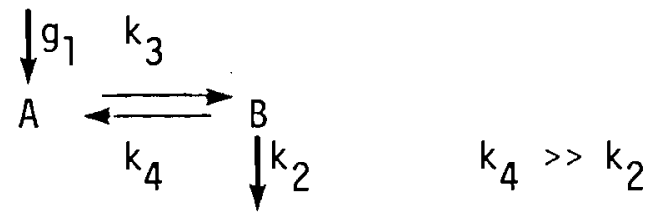

often can be integrated incorrectly by ODEINT, simply because some relatively significant terms can be overshadowed by others. Because of this, the user is well-advised to test ODEINT performance against more conventional simulations of his system (at only a single grid point), before embarking on extensive production runs. The user can, of course, replace ODEINT with a more trustworthy integration scheme, such as a Gear-based algorithm (Gear, 1971). Typically, however, such schemes demand large amounts of computer time for start-up overheads, thus reducing their appeal rather substantially.

Returning to the question of one-dimensionality, it should be noted that although this is a major shortcoming of PLUVIUS, its effects can be minimized by appropriate applications within the code. Three-dimensional plumes, for example, may be simulated by diluting the air parcel to account for cross-plume mixing by providing time-dependent dilution factors within subroutine GEN. Three-dimensional flow fields can be approximated in a 
similar manner, with judicious choice of the vertical-velocity component $w_{A}^{\prime} \cdot(a)$

In a final analysis, it is once again noted that PLUVIUS embodies a somewhat gross approximation to the real world, and constitutes a rather imperfect "lens" through which to observe atmospheric behavior. With this qualification, however, it is expected that prudent application of the code can lead to a number of revealing and scientifically rewarding insights. It is with this intent that PLUVIUS is submitted to the user community.

(a) It should be noted that the problem of one-dimensionality has been solved with the newer "PLUVIUS II" code, which allows computations in 1, 2, or 3 spatial dimensions at the option of the user. Currently operational, it is expected that PLUVIUS II will be documented in a future user's manual. 


\section{REFERENCES}

Bennetts, D. A. and F. Rawlins. 1981. "Parameterization of the Ice-Phase in a Model of Mid-Latitude Cumulonimbus Convection and Its Influence on the Simulation of Cloud Development." Quart. J.R. Met. Soc. 477-502.

Berry, E. X. and R. L. Reinherdt. 1974. "An Analysis of Cloud Drop Growth by Collection." J. of Atmos. Sci. 31:2118-2126.

Bird, R. B., W. E. Stewart and E. N. Lightfoot. 1960. Transport Phenomena, Wiley, New York.

Drewes, D. R. and J. M. Hales. 1977. SMICK - A Scavenging Modeling Incorporating Chemical Kinetics. Final Report on Project RP-858. Electric Power Research Institute, Palo Al to, Cal ifornia.

Gear, C.W. 1971. "The Automatic Integration of Ordinary Differential Equations." Comm. ACM 14:176-190.

Hales, J. M. and S. L. Sutter. 1973. "Solubility of Sulfur Dioxide in Water at Low Concentrations." Atmos. Envi. 7:997-1001.

Hales, J.M. 1981. PLUVIUS - A Generalized One-Dimensional Model of Reactive Pollutant Behavior, Including Dry Deposition, Precipitation Formation and Wet Removal. PNL-4046, Pacific Northwest Laboratory, Richland, Washington.

Heines, T. S. and L. K. Peters. 1973. "The Effect of a Horizontal Impervious Layer Caused by a Temperature Inversion Aloft on the Dispersion of Pollutants in the Atmosphere." Atmos. Envi. 7:39-48.

Houze, R. A. Jr., P. V. Hobbs, P. Hilterzegh and D. B. Parsons. 1979. "Size Distribution of Precipitation Particles in Frontal Clouds." J. of Atmos. Sci. 36:156-162.

Kessler, E. 1969. "On the Distribution and Continuity of Water Substance in Atmospheric Circulation." Meteorological Monographs No. 52.

Kirk, R. E. and D. F. Othmer. 1947. Encyclopedia of Chemical Technology. Interscience Encyclopedia, New York.

Levine, S. Z. and S. E. Schwartz. 1982. "In-Cloud and Below-Cloud Scavenging of Nitric Acid Vapor." Atmos. Envi. 16:1725-1734.

Lin, Y., R. D. Farley and H. D. Orville. 1983. "Bulk Parameterization of the Snow Field in a Cloud." J. of Atmos. Sci. 1065-1092.

MAP3S/RAINE. 1982. "The MAP3S/RAINE Precipitation Chemistry Network:

Statistical Overview for the Period 1976-1980." Atmos. Envi. 16:1603-1632. 
Martin, L. R. and D. E. Damshen. 1981. "Aqueous Oxidation of Sulfur Dioxide by Hydrogen Peroxide at Low pH." Atmos. Envi. 15:1615-1621.

Omstedt, G. and H. Rodhe. 1978. "Transformation and Removal Processes for Sulfur Compounds as Described by a One-Dimensional, Time-Dependent

Diffusion Model." Atm. Envi. 17:503-509.

Penkett, S. A., B. M. R. Jones, K. A. Bruce and A. E. J. Eggleton. 1979. "The Importance of Atmospheric Ozone and Hydrogen Peroxide in 0xidising Sulphur Dioxide in Cloud and Rainwater." Atmo. Envi. 13:123-137.

Pruppacher, H. R. and J. D. Klett. 1978. Microphysics of Clouds and Precipitation. Reidel, Boston, MA.

Schumb, W. C., C. N. Sutterfield and R. C. Wentworth. 1955. Hydrogen Peroxide. ACS Monograph Series, Reinhold, New York.

Scott, B. C. 1976. "A Theoretical Study of the Evolution of Mixed Phase Cumulus Clouds." Ph.D. Dissertation, University of Washington, Seattle, Washington.

Scott, B. C. 1982a. "Predictions of In-Cloud Conversion Rates of $\mathrm{SO}_{2}$ to SO Based Upon a Simple Kinetic and Kinematic Storm Model." Atmos. Ehvi. $16 ? 1735-1752$.

Scott, B. C. 1982b. "Theoretical Estimates of the Scavenging Coefficient for Soluble Aerosol as a Function of Precipitation Type, Rates and Altitude." Atmos. Envi. 16:1753-1762. 
APPENDIX A

\section{FINITE UIFFEREIICE APPROXIMATION FOR TRANSPORT TERIAS}

In this appendix, the finite differencing procedure employed in PLUVIUS Mod 5 to integrate the transport terms (advection and diffusion) of the mass- and energy-balance equations is described. The method uses Crank-Nicholson time-differencing and a combination of spatial-differencing techniques. Centered differencing for the diffusion terms and "compact" spatial-differencing for the advection terms (Adams, 1975 and 1977). This combination was adopted because the compact differencing method for both the advection and diffusion terms showed poor performance on some test problems (e.g., a single grid point "inversion," where the eddy diffusivity was set to zero). The method adopted is unconditionally stable (for linear problems). The time-differencing and centered spatial-differencing have second-order truncation errors, and the compact spatial-differencing has a fourth-order truncation error (for uniform grids).

The numerical problem is the integration of Equations (42) and (44) (or the corresponding two-dimensional, steady-state equations) over a time step $\Delta t$ from time $t_{j}$ to $t_{j+1}$, where the values of $c$ are known only at the discrete grid points $z_{1}, z_{2}, \ldots, z_{n}$. In general, the various coefficients in the equations $\left(w_{r}, w_{A}^{\prime}, D, c^{*}\right.$, etc.) will be functions of time and space. They may also be functions of $c$, the dependent variable, thus making the equations nonlinear. In the development here, the dependence of these coefficients on time and on the dependent variable $c$ is assumed negligible over the time step $\Delta t$ and is ignored.

In the following development, $c_{i}^{j}$ will be used to denote $c$ at time $t_{j}$ and vertical position $z_{j}$, and similarly for other variables. The superscript $j$ will be dropped on terms where the variation over $\Delta t$ is ignored (e.g., $\left.w_{A}, c^{*}, D\right)$, as it will always be $j$ and not $j+1$ in these cases. Time derivatives are indicated by the subscript $t\left(c_{t}=\hat{D} c / \hat{D} t\right.$ or $\left.D^{*} C / D t^{*}\right)$ and spatial derivatives by the subscript $z$ or $\xi\left(c_{z} \equiv \partial c / \partial z\right)$. 
The differencing procedure will be developed for the mass-balance equation for the two-dimensional, steady-state case:

$$
\begin{aligned}
\frac{D^{\star} C}{D t^{\star}} & =\mu\left\{-\frac{\partial}{\partial z}\left[\left(w_{r}+w_{A}^{\prime \prime}\right) C\right]+\frac{\partial}{\partial z}\left[c^{\star} D_{m} \frac{\partial}{\partial z}\left(c / c^{\star}\right)\right]\right. \\
& \left.+c \frac{\partial w_{A}^{\prime \prime}}{\partial z}+c \frac{w_{A}}{c^{\star}} \frac{\partial c^{\star}}{\partial z}+D 1\right\}
\end{aligned}
$$

where $\mu=u^{\star} / u_{A} *$. The term DI has been added in anticipation of the energy-balance equation; in the mass-balance equation $D 1 \equiv 0$. The mass-balance equation for the one-dimensional time-dependent case is handled identically, but with $\mu \equiv 1$. The energy-balance equation involves some modifications which are discussed at the end of this appendix.

Crank-Nicholson time-differencing approximates the time derivative in Equation (Al) as follows:

$$
\begin{aligned}
\left(c_{t}\right)_{i}^{j+1 / 2} & \simeq \frac{c_{i}^{j+1}-c_{i}^{j}}{\Delta t} \\
& =\frac{1}{2}\left\{[\text { right-hand side of }(A 1)]_{i}^{j+1}\right. \\
& +[\text { right-hand side of }(A 1)] \underset{i}{j}\}
\end{aligned}
$$

Before developing the "right-hand side of (AI)," which involves spatial differencing in several terms, we introduce a vertical coordinate transformation which will allow both uniform and non-uniform grid spacing to be treated alike. The new vertical coordinate, $\xi$, is just the vertical grid index

$$
\xi \equiv \mathbf{i} \text { at } z=z_{i}
$$

Vertical derivatives are transformed as: 


$$
\frac{\partial C}{\partial Z}=\frac{\partial \xi}{\partial Z} \quad \frac{\partial C}{\partial \xi}=\frac{1}{\Delta Z} \quad \frac{\partial C}{\partial \xi}
$$

where

$$
\Delta z \equiv \frac{\partial z}{\partial \xi}
$$

At interior grid points, $\Delta z$ is approximated using

$$
\Delta z_{i}=\frac{1}{2}\left(z_{i+1}-z_{i-1}\right),
$$

and at the grid boundaries,

$$
\begin{aligned}
& \Delta z_{n}=z_{n}-z_{n-1} \\
& \Delta z_{1}=z_{2}-z_{1} .
\end{aligned}
$$

Note that for uniform grids, these relations are exact.

To develop the advection term in Equation ( $A 1)$, we define:

$$
\begin{aligned}
& w_{v}=w_{r}+w_{A}^{\prime \prime} \\
& R=\frac{\partial}{\partial \xi}\left(w_{v} c\right) .
\end{aligned}
$$

The advection term is then

$$
\frac{\partial}{\partial z}\left[\left(w_{r}+w_{A}^{\prime \prime}\right) c\right]=\frac{R}{\Delta z} .
$$

Evaluation of $R$ involves a spatial derivative which is approximated using the compact differencing method (Adams, 1975 and 1977). At interior grids ( $i=2,3, \ldots, n-1)$, the method yields:

$$
R_{j-1}^{j}+4 R_{j}^{j}+R_{j+1}^{j}+3\left(w_{v} c\right)_{j-1}^{j}-3\left(w_{v} c\right)_{j+1}^{j}=0 .
$$

At the grid boundaries, the following relations hold: 


$$
\begin{aligned}
& R_{1}^{j}+R_{2}^{j}+2\left(w_{v} c\right)_{1}^{j}-2\left(w_{v} c\right)_{2}^{j}=0 \\
& R_{n-1}^{j}+R_{n}^{j}+2\left(w_{v} c\right)_{n-1}^{j}-2\left(w_{v} c\right)_{n}^{j}=0 .
\end{aligned}
$$

Identical equations hold at $t_{j+1}$. At time $t_{j}$, Equations (A4)-(A6) form a set of $n$ linear equations with $n$ unknowns $\left(R_{j}^{j}, i=1,2, \ldots, n\right)$, since $w_{v}$ and $c$ are known. The equations are tri-diagonal in nature and can be solved using Thomas's algorithm. In the PLUVIUS code, this computation is performed in subroutines FIRSTD and TRIDAG.

The diffusion term in Equation (Al) is developed as follows. Define

$$
Q_{i}^{j}=\left[D_{m} c^{\star} \frac{\partial}{\partial z}\left(\frac{c}{c^{\star}}\right)\right]_{i}^{j}
$$

Here the spatial derivative is approximated by a simple centered difference, and the Q's are evaluated "between grid points", so that

$$
Q_{i+1 / 2}^{j}=\frac{\left(D_{m} c^{\star}\right)_{i+1 / 2}}{\Delta z_{i+1 / 2}}\left[\left(\frac{c}{c^{\star}}\right)_{i+1}^{j}-\left(\frac{c}{c^{\star}}\right)_{i}^{j}\right]
$$

where $\Delta z_{i+1 / 2}=z_{i+1}-z_{i}$. The diffusion term is then

$$
\begin{aligned}
& \frac{\partial}{\partial z}\left[c^{\star} D_{m} \frac{\partial}{\partial z}\left(c / c^{\star}\right)\right]_{i}^{j}=\frac{1}{\Delta z_{i}}\left(Q_{j+1 / 2}^{j}-Q_{j-1 / 2}^{j}\right) \\
& =\operatorname{ADIFF}_{i} c_{j-1}^{j}+\text { BDIFF }_{i} c_{i}^{j}+\operatorname{CDIFF}_{i} c_{j+1}^{j}
\end{aligned}
$$

where

$$
\begin{aligned}
& \operatorname{ADIFF}_{i}=\frac{1}{\Delta z_{i} C^{\star}{ }_{i-1}}\left(\frac{D_{m^{c^{*}}}}{\Delta z}\right)_{i-1 / 2} \\
& \text { BDIFF }_{i}=-\frac{1}{\Delta z_{j} c^{\star}}\left[\left(\frac{D_{m} c^{\star}}{\Delta z}\right)_{j+1 / 2}+\left(\frac{D_{m} c^{\star}}{\Delta z}\right)_{i-1 / 2}\right]
\end{aligned}
$$




$$
\operatorname{CDIFF}_{i}=\frac{1}{\Delta z_{i}{ }^{*}{ }_{i+1}}\left(\frac{D_{m} c^{*}}{\Delta z}\right)_{i+1 / 2}
$$

The air density, $c^{*}$, is evaluated at $i+1 / 2$ by simply averaging the values at adjacent grid points. The eddy diffusivity, $D_{m}$, is defined between the grid points, at $z_{i+1 / 2}$, rather than at the grid points, $z_{i}$. The convention used is

$$
D(I, L) \equiv\left(D_{m}\right)_{i+1 / 2}
$$

where $D(I, L)$ is the two-dimensional array that holds the eddy diffusivities in PLUVIUS. (L specifies the diffusion regime, see Section 3.)

The third and fourth terms on the right-hand side of Equation (AI) involve spatial derivatives of $w_{A}^{\prime \prime}$ and $c^{*}$. We define

$$
\begin{aligned}
c_{i} & =\left(w_{A z}^{\prime \prime}+\frac{w_{A}}{c^{*}} c_{Z}^{*}\right)_{i} \\
& =\left[\frac{1}{\Delta z}\left(w_{A \xi}^{\prime \prime}+\frac{w_{A}}{c^{\star}} c_{\xi}^{\star}\right)\right] i
\end{aligned}
$$

The derivatives $w_{A \xi}^{\prime \prime}$ and $c_{\xi}^{*}$ are evaluated using the compact differencing technique, similar to the evaluation of $R$. For example, at interior grids, we have

$$
c_{\xi i-1}^{\star}+4 c_{\xi i}^{\star}+c_{\xi i+1}^{\star}+3 c_{i-1}^{\star}-3 c_{i+1}^{\star}=0
$$

In the PLUVIUS code, $\mathrm{Cl}$ is evaluated in subroutine DERIV, which makes calls to subroutine FIRSTD to evaluate the derivatives.

Equation (A2) can now be rewritten, at interior grid points, using Equations $(A 3),(A 9)$, and $(A 10)$, as 
where

$$
\begin{aligned}
& c_{i}^{j+1}-c_{i}^{j}=-\frac{\varepsilon}{\Delta z_{i}}\left(R_{i}^{j+1}+R_{i}^{j}\right)+\varepsilon\left[A D I F F_{i}\left(c_{i-1}^{j+1}+c_{i-1}^{j}\right)\right. \\
& \left.+ \text { BDIFF }_{i}\left(c_{i}^{j+1}+c_{i}^{j}\right)+\operatorname{CDIFF}_{i}\left(c_{i+1}^{j+1}+c_{i+1}^{j}\right)\right] \\
& +\varepsilon C l_{i}\left(c_{i}^{j+1}+c_{i}^{j}\right)+2 \varepsilon D 1_{i}
\end{aligned}
$$

$$
\varepsilon=\frac{1}{2} \mu \Delta t
$$

Equations (A4) and (A11) may be combined to form

$$
A M_{i} X V_{i-1}^{j+1}+B M_{i} X V_{i}^{j+1}+C M_{i} X V_{i+1}^{j+1}=D V_{i}
$$

Here $X V_{i}^{j}$ represents a two-element vector,

$$
X V_{i}^{j}=\left[\begin{array}{l}
c_{i}^{j} \\
R_{i}^{j}
\end{array}\right],
$$

The AM, BM, and CM are each $2 \times 2$ matrices, and DV is a two-element vector:

$$
\begin{aligned}
& A M_{i}=\left[\begin{array}{cc}
-\varepsilon A^{-} \text {IFF }_{i} & 0 \\
3 w_{v i-1} & 1
\end{array}\right] \\
& B M_{i}=\left[\begin{array}{cc}
1-\varepsilon B D I F F_{i}-\varepsilon C l_{i} & \frac{\varepsilon}{\Delta z_{i}} \\
0 & 4
\end{array}\right] \\
& \mathrm{CM}_{i}=\left[\begin{array}{cc}
-\varepsilon \mathrm{CDIFF}_{i} & 0 \\
-3 w_{v i+1} & 1
\end{array}\right]
\end{aligned}
$$




$$
D V_{i}=\left[\begin{array}{c}
c_{i}^{j}+\varepsilon\left(A D I F F_{i} c_{i-1}^{j}+\operatorname{BDIFF}_{\mathbf{j}} c_{i}^{j}+\operatorname{CDIFF}_{\mathbf{i}} c_{\mathbf{i}+1}^{j}\right. \\
\left.+C 1_{i} c_{i}^{j}+2 D 1_{i}-\frac{R_{i}^{j}}{\Delta z_{i}}\right) \\
0
\end{array}\right]
$$

Equation (A12) can be applied at all grid points. Equations (A13)-(A16) hold only at interior grid points. Different expressions for AM, BM, CM, and DV must be formulated at the grid boundaries for each set of boundary conditions [Equations (15)-(18) and (38)-(41)].

Concentration boundary conditions are the simplest to treat. At the top boundary, a concentration boundary condition gives

$$
\begin{aligned}
& A M_{n}=\left[\begin{array}{cc}
0 & 0 \\
2 w_{v n-1} & 1
\end{array}\right] \\
& B M_{n}=\left[\begin{array}{cc}
1 & 0 \\
-2 w_{v n} & 1
\end{array}\right] \\
& D v_{n}=\left[\begin{array}{c}
\hat{c}_{T}^{j+1} \\
0
\end{array}\right]
\end{aligned}
$$

At the bottom boundary, a concentration boundary condition yields:

$$
B M_{1}=\left[\begin{array}{cc}
1 & 0 \\
2 w_{v 1} & 1
\end{array}\right]
$$




$$
\begin{aligned}
& \mathrm{CM}_{1}=\left[\begin{array}{cc}
0 & 0 \\
-2 w_{v 2} & 1
\end{array}\right] \\
& D V_{1}=\left[\begin{array}{l}
c_{B}^{j+1} \\
0
\end{array}\right]
\end{aligned}
$$

Note that $\mathrm{CM}_{n}$ and $\mathrm{AM}_{1}$ are "irrelevant" (since $X V_{0}$ and $X V_{n+1}$ do not exist). Also, the bottom row elements in Equations (A17)-(A22) result from Equations (A5) and (A6).

The flux-specified boundary condition is more involved. Note that Equation (A11) could be applied at the grid-boundaries were it not for the diffusion term; thus an alternate treatment of this term is required at the boundaries. At the bottom boundary, the diffusion term is approximated by

$$
\frac{\partial}{\partial z}\left[c^{\star} D_{m} \frac{\partial}{\partial z}\left(c / c^{\star}\right)\right]_{1}^{j}=\frac{1}{\left(\frac{\Delta z}{2}\right)}\left(Q_{3 / 2}^{j}-Q_{1}^{j}\right)
$$

The term $Q_{3 / 2}^{j}$ is evaluated as in Equation (A8). For $Q_{1}^{j}$, we can use the flux boundary condition [Equation (18)] to write

$$
Q_{1}^{j}=\left(w_{r} c\right)_{1}^{j}-\hat{f}_{B}^{j}
$$

Thus the diffusion term can be written as

$$
\operatorname{BDIFF}_{1} c_{1}^{j}+\operatorname{CDIFF}_{1} c_{2}^{j}-\frac{2}{\Delta z_{1}}\left(w_{r} c\right)_{1}^{j}+\frac{2}{\Delta z_{1}} \hat{f}_{B}^{j}
$$

where

$$
\mathrm{BDIFF}_{1}=-\frac{2}{\Delta \mathrm{z}_{1} \mathrm{C}_{1}}\left(\frac{\mathrm{D}_{\mathrm{m}} \mathrm{c}^{\star}}{\Delta \mathrm{z}}\right)_{3 / 2}
$$




$$
\operatorname{CDIFF}_{1}=\frac{2}{\Delta \mathrm{z}_{1} \mathrm{C}_{2}}\left(\frac{\mathrm{D}_{\mathrm{m}} \mathrm{C}^{\star}}{\Delta \mathrm{z}}\right)_{3 / 2}
$$

This form may be used in Equation (A11), which results in

$$
\begin{aligned}
& \mathrm{BM}_{1}=\left[\begin{array}{cc}
1-\varepsilon \mathrm{BDIFF}_{1}-\varepsilon \mathrm{Cl}_{1}+\frac{2 w_{r 1}}{\Delta z_{1}} & \frac{\varepsilon}{\Delta z_{1}} \\
2 w_{v 1} & 1
\end{array}\right] \\
& \mathrm{CM}_{1}=\left[\begin{array}{cc}
-\varepsilon \mathrm{CDIFF}_{1} & 0 \\
-2 w_{v 2} & 1
\end{array}\right] \\
& D V_{1}=\left[\begin{array}{c}
c_{1}^{j}+\varepsilon\left(B D I F F_{1} c_{1}^{j}+C D I F F_{1} c_{2}^{j}+C_{1} c_{1}^{j}+2 D 1_{1}\right. \\
-\frac{2 w_{r 1}}{\Delta z_{1}} c_{1}^{j}-\frac{R_{1}^{j}}{\Delta z_{1}}+\frac{2}{\Delta z_{1}}\left(\hat{f}_{B}^{j}+\hat{f}_{B}^{j+1}\right) \\
0
\end{array}\right]
\end{aligned}
$$

The derivation for a flux boundary condition at the top grid point is similar. The diffusion term is developed as

$$
\begin{aligned}
& \frac{\partial}{\partial z}\left[c^{\star} D_{m} \frac{\partial}{\partial z}\left(c / c^{*}\right)\right]_{n}^{j}=\operatorname{ADIFF}_{n} c_{n-1}^{j}+\operatorname{BDIFF}_{n} c_{n}^{j} \\
& +\frac{2}{\Delta z_{n}}\left(w_{r} c\right)_{n}^{j}-\frac{2}{\Delta z_{n}} \hat{f}_{T}^{j}
\end{aligned}
$$

where 


$$
\begin{aligned}
& \operatorname{ADIFF}_{n}=\frac{2}{\Delta z{ }_{n}{ }^{\star} n-1}\left(\frac{D_{m} c^{\star}}{\Delta z}\right)_{n-1 / 2} \\
& \text { BDIFF }_{n}=-\frac{2}{\Delta z{ }_{n}{ }^{*}{ }_{n}}\left(\frac{D_{m} c^{\star}}{\Delta z}\right)_{n-1 / 2}
\end{aligned}
$$

The resulting forms for AM, BM and DV are

$$
\begin{aligned}
& A M_{n}=\left[\begin{array}{cr}
-\varepsilon A D I F F_{n} & 0 \\
2 w_{v n-1} & 1
\end{array}\right] \\
& B M_{n}=\left[\begin{array}{cc}
1-\varepsilon B D I F F_{n}-\varepsilon c 1_{n}-\frac{2 \varepsilon w_{r n}}{\Delta z_{n}} & \frac{\varepsilon}{\Delta z_{n}} \\
2 w_{v n} & 1
\end{array}\right] \\
& D v_{n}=\left[\begin{array}{c}
c_{n}^{j}+\varepsilon\left(A D I F F_{n} c_{n-1}^{j}+B D I F F_{n} c_{n}^{j}+c 1_{n} c_{n}^{j}\right. \\
+2 D 1_{n}+\frac{2 w_{r n}}{\Delta z_{n}} c_{n}^{j}-\frac{R_{n}^{j}}{\Delta z_{n}}-\frac{2}{\Delta z_{n}}\left(\hat{f}_{T}^{j}+\hat{f}_{T}^{j+1}\right)
\end{array}\right]
\end{aligned}
$$

For the case of the outflow condition at the bottom boundary, we use a modified form of Equation (A11) obtained by evaluating the diffusion term one grid-point "upstream" (at $i=2)$ and one step back in time. This yields 


$$
\begin{aligned}
& c_{1}^{j+1}-c_{1}^{j}=-\frac{2}{\Delta z_{1}}\left(R_{1}^{j+1}+R_{1}^{j}\right)+c\left[A D I F F_{2}\left(c_{1}^{j}+c_{1}^{j-1}\right)\right. \\
& \left.+B D I F F_{2}\left(c_{2}^{j}+c_{2}^{j-1}\right)+C D I F F_{2}\left(c_{3}^{j}+c_{3}^{j-1}\right)\right] \\
& +c C_{1}\left(c_{1}^{j+1}+c_{1}^{j}\right)+2 \varepsilon D 1_{1}^{j}
\end{aligned}
$$

With this we obtain the following forms for BM, CM and DV:

$$
\begin{aligned}
& \mathrm{BM}_{1}=\left[\begin{array}{cc}
1-\varepsilon \mathrm{Cl}_{1} & \frac{\varepsilon}{2 \Delta z_{1}} \\
2 w_{v 1} & 1
\end{array}\right] \\
& C_{1}=\left[\begin{array}{cc}
0 & 0 \\
-2 w_{v 2} & 1
\end{array}\right] \\
& D v_{1}=\left[\begin{array}{cc}
c_{1}^{j}+\varepsilon\left(C 1_{1} c_{1}^{j}+2 D 1_{1}-\frac{R_{1}^{j}}{\Delta z_{1}}+\text { OUTDIF }\right) \\
0
\end{array}\right]
\end{aligned}
$$

where

$$
\begin{aligned}
& \text { OUTDIF }=\operatorname{ADIFF}_{2}\left(c_{1}^{j}+c_{1}^{j+1}\right)+\operatorname{BDIFF}_{2}\left(c_{2}^{j}+c_{2}^{j-1}\right) \\
& +\operatorname{CDIFF}_{2}\left(c_{3}^{j}+c_{3}^{j-1}\right)
\end{aligned}
$$

The integration procedure over a single time step can be outlined as follows. At time $t_{j}$, the $c_{j}^{j}$ are known and $w_{r}, w_{A}^{\prime \prime}, D_{m}, c^{\star}$, etc. are evaluated by various Class I subroutines. The $R_{\dot{j}}^{J}$ are evaluated by solving equations $(A 4)-(A G)$. The derivatives $W_{A \xi}^{\prime \prime}$ and $c_{\xi}^{*}$ are evaluated similarly, to give the $\mathrm{Cl}_{i}$. Now the AM, BM, CM, and DV may be calculated. 
Finally, Equation (A11) are solved to obtain $c_{j}^{j+1}$ and $R_{j}^{j+1}$. This involves solving a set of paired simultaneous linear equations with a tridiagonal coefficient matrix, and a matrix form of the Thomas algorithm provides an efficient solution technique (Adams, 1975).

The treatment of the energy balance involves only minor modifications. The advection term is treated just as for the mass-balance equations, with the simplification that $w_{r} \equiv 0$ in this case. The diffusion term for the energy-balance equation can be treated as in the mass-balance equation, but the ADIFF, BDIFF, and CDIFF are somewhat different in form. The interested reader can find their definitions in the PLUVIUS subroutine TEMPF where they are computed. The $\mathrm{Cl}$ only uses the left term in Equation (A10). The D1 term is given by

$$
D 1=w_{A} \Gamma-\frac{1}{c^{\star} \chi} \frac{\partial}{\partial Z}\left(c^{*} \chi D_{H} \Gamma\right)
$$

The derivative here is evaluated by

$$
\begin{aligned}
& {\left[\frac{\partial}{\partial z}\left(c^{\star} \times D_{H} \Gamma\right]_{j}=\frac{1}{\Delta z_{i}}\left[\left(c^{\star} \times \Gamma\right)_{j+1 / 2} D_{H_{i+1 / 2}}\right.\right.} \\
& \left.-\left(c^{\star} \times \Gamma\right)_{i-1 / 2} D_{H_{i-1 / 2}}\right]
\end{aligned}
$$

and $\left(c^{\star} \times \Gamma\right)$ is evaluated at $i \pm 1 / 2$ by averaging its values at adjacent grid points.

One problem with this integration technique is the generation of high-wave number computational noise near steep gradient regions of the solution. Indeed, nearly all second-order and higher accuracy methods have this problem when the mass balance equation is dominated by the advection terms. In some cases, the noise may only by cosmetically undesirable, as when it generates small negative concentration values. In cases where the basic equation is nonlinear, the noise may grow unstably and completely contaminate the solution. This problem has arisen in our experience when 
working with precipitation species: a nonlinearity arises because the settling velocity is dependent on the precipitation concentration.

To reduce this problem, a filtering step has been added to the code and is exercised after each advection-diffusion integration step. The nonlinear filtering method devised by Forrester (1977) is used, with values for the filter parameters as suggested by McRae et al. (1982). Our experience suggests that the filtering is necessary for species with significant vertical velocities $\left(w_{r}\right.$ or $\left.w_{a}{ }^{\prime}\right)$, but is not always required for species with small vertical velocities (if the eddy diffusivity is sufficiently large). In situations where it is desirable to maintain a very sharp gradient (e.g., across a cloud base) and noise is not a problem, it is preferable not to filter the solution for particular species. Thus, a filtering coefficient FILFAC has been included as an input parameter for each species. Specifying a zero value for this coefficient effectively turns off the filter for a species. For any particular application, the need for filtering is best determined by experimentation. 


\section{REFERENCES}

Adams, Y. 1975. "A Hermitian Finite Difference Method for the Solution of Parabolic Equations." Comp. \& Maths. with Appls. 1:393-406.

Adams, Y. 1977. "Highly Accurate Compact Implicit Methods and Boundary Conditions." J. Comp. Physics. 24:10-22.

Forrester, C. K. 1977. "Higher Order Monotonic Convective Difference Schemes." J. Comp. Physics. 23:1-22.

McRae, G.J., W. R. Goodin and J.H. Seinfeld. 1982. "Numerical Solution of the Atmospheric Diffusion Equation for Chemically Reacting Flows." Comp. Physics. 45:1-42. 


\section{APPENDIX B}

TECHNIQUE FOR APPROXIMATION TO SOLUTIONS OF

ORDINARY DIFFERENTIAL EQUATIONS

The integration of the generation components of the mass and energy-balance equations [Equations (43) and (45)] involves the solution of NCOMP simultaneous, ordinary differential equations over a specified time interval at each of the vertical grid points. For many atmospheric chemistry - problems, these equations are highly-coupled and strongly nonlinear, and thus require specially designed algorithms for their efficient solution. In

- PLUVIUS MOD 5.0, this task is performed by subroutine ODEINT. (a)

Subroutine ODEINT is essentially a predictor-corrector code for approxi- mating the solutions of simultaneous, ordinary differential equations of the form

$$
\begin{aligned}
& \frac{d c_{k}}{d t}=g_{k}-\xi_{k} c_{k} ; \\
& k=1,2, \ldots, N C O M P ;
\end{aligned}
$$

where

$c_{k}$ is the concentration of species $k$ at time $t$,

$g_{k}$ is the generation rate of species $k$, and

$\xi_{k}$ is a pseudo first-order rate coefficient describing the decay of species $k$.

- At any given time step the code segregates the members of equation set $(B 1)$ on the basis of the magnitudes of $\xi k$. If $\varepsilon_{{ }^{\prime} k}$ exceeds a set value - $[\operatorname{RATESF}(K)]$, then Equation (BI) is considered to be stiff. Under these circumstances, an asymptotic or an exponentially-assisted integration technique is applied, at the discretion of the user. If the equation is not (a) Table $\mathrm{C}-7$ contains a listing of ODEINT. 
considered stiff, then a conventional predictor-corrector algorithm is used. Values of RATESF $(K)$ are set by the user in a DATA statement.

ODEINT will provide approximations to any form of Equation (B1), regardless of the set values of $\operatorname{RATESF}(K)$. Appropriate choice of these values is reflected primarily in the efficiency of the resulting calculation. If RATESF $(K)$ is set too high, then conventional calculations will be applied preferentially, forcing an inordinately fine integration time step to be used. If RATESF $(K)$ is set too low, then the stiff algorithms will be invoked preferentially with some loss of computational efficiency. Optimum efficiency will be attained with appropriate intermediate values of RATESF $(K)$. These values are somewhat problem dependent; in a practical sense the user is best advised to initially set RATESF(K) conservatively low, (a) assessing the impact . of increases in this parameter on subsequent test runs.

The argument list for the subroutine is as follows:

ODEINT ( I, TSTRTO, DTTOT, DTSUG, DTMAX)

I = vertical position index (ODEINT solves Equation (BI) at the single grid point specified by $I$, and thus is called repeatedly with $I$ varying from 1 to $\mathrm{N}$;

TSTRTO = value of the independent variable (time) at the start of the integration;

DTTOT = integration span of independent variable;

DTSUG = "suggested value" of initial time step. If DTSUG is set positive in the subroutine call, then this value will be the one utilized. If DTSUG is set negative, ODEINT will compute its own starting step size;

DTMAX = maximum allowable step size, which must be set prior to interrogating ODEINT.

Additional essential variables are supplied to ODEINT via COMMON statements. These variables include:

(a) A recommended starting point for atmospheric chemistry simulations is $\operatorname{RATESF}(K)=0.1 \mathrm{sec}^{-1}$. 


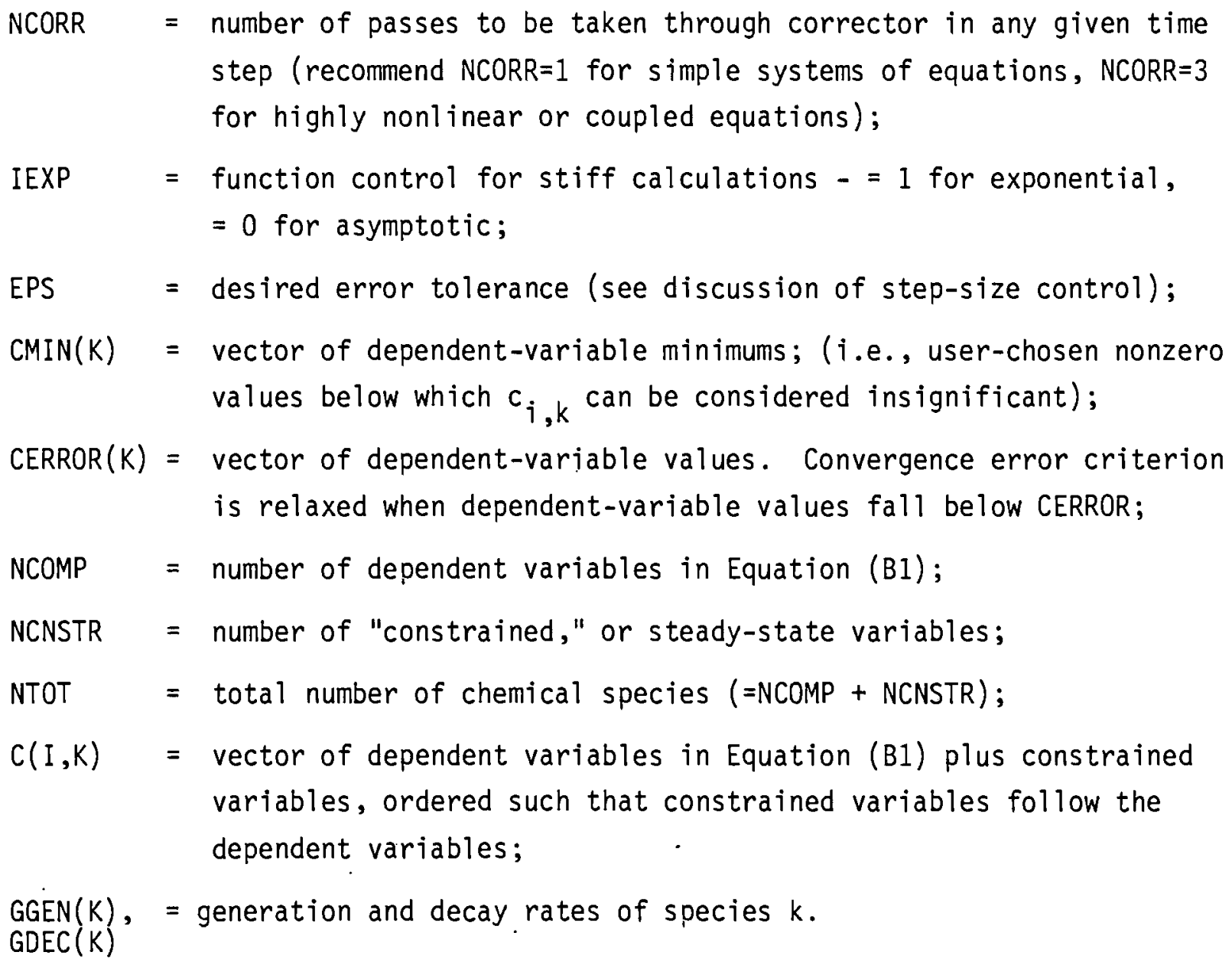
step (recommend NCORR=1 for simple systems of equations, NCORR=3 for highly nonlinear or coupled equations);

IEXP = function control for stiff calculations - = 1 for exponential, $=0$ for asymptotic;

EPS $=$ desired error tolerance (see discussion of step-size control);

$\operatorname{CMIN}(K)=$ vector of dependent-variable minimums; (i.e., user-chosen nonzero values below which $c_{i, k}$ can be considered insignificant);

$\operatorname{CERROR}(K)=$ vector of dependent-varjable values. Convergence error criterion is relaxed when dependent-variable values fall below CERROR;

NCOMP $=$ number of dependent variables in Equation (B1);

NCNSTR = number of "constrained," or steady-state variables;

NTOT = total number of chemical species (=NCOMP + NCNSTR);

$C(I, K)=$ vector of dependent variables in Equation (B1) plus constrained variables, ordered such that constrained variables follow the dependent variables;

$\operatorname{GGEN}(K), \quad=$ generation and decay rates of species $k$. $\operatorname{GDEC}(K)$

The $C(I, K)$ array represents the initial conditions, which must be supplied prior to any interrogation of ODEINT. Upon entry to ODEINT, concentrations at position $I$ are transferred from the $C(I, K)$ to a one-dimensional working array, $\operatorname{CNN}(K)$. At successful completion of the integration, the final concentration values are transferred back into the $C(I, K)$ array.

The arrays GGEN(K) and GDEC(K) are defined in terms of Equation (BI) as follows:

$$
\begin{aligned}
\operatorname{GGEN}(K) & \equiv g_{k} \\
\operatorname{GDEC}(K) & \equiv \xi_{k} c_{k} .
\end{aligned}
$$


Updated values of these variables are computed via interrogation of the subroutine

$$
\text { GEN ( I , IGCALC, TGEN, DTAU, JPASSO) , }
$$

where $I$ is the usual vertical-position index. IGCALC is a mode-control variable, defined as follows:

IGCALC $\leq 0:$ Only concentrations of constrained species (CNN (NCOMP +1$)$, ... CNN(NTOT) are computed.

IGCALC >0: Both constrained species and generation and decay rates are computed.

TGEN is the value of the independent variable (time).

DTAU is the current integration time-step within ODEINT.

JPASSO specifies whether GEN is being called from the predictor section $(=1)$ or the corrector section $(=2,3, \ldots$, on first, second, $\ldots$, corrector pass) of ODEINT.

Subroutine GEN must be supplied in appropriate form by the user prior to executing ODEINT. Units for GGEN and GDEC are moles/ $\mathrm{cm}^{3} \mathrm{sec}$, consistent with the code's standard usage. Note that GEN works with concentrations in the $\mathrm{CNN}(\mathrm{K})$ array, rather than the $\mathrm{C}(I, K)$ array.

Primary output from the subroutine is also conveyed via COMMON statements. In addition to the $C(I, K)$ solution array, this includes the array DTSAVE(I), which is the most recent independent-variable increment. It is often convenient to use DTSAVE(I) as an initial increment on subsequent calls to ODEINT.

ODEINT is based on some of the concepts utilized in the CHEMEQ code prepared by Young (1980). The conventional (non-stiff) predictor-corrector algorithm in ODEINT is similar to that in CHEMEQ. The asymptotic corrector equations are substantially different, however, and represent a marked improvement in the overall technique.

Conventional predictor-corrector equations used by ODEINT correspond to the so-called "improved Euler's method" [Carnahan, Luther and Wilkes (1969)]. These are: 
Predictor

$$
c_{t+\Delta t}^{1}=\left(g_{t}-\xi c_{t}\right) \Delta t+c_{t}
$$

\section{Corrector}

$$
c_{t+\Delta t}^{m+1}=\left[\bar{g}-\frac{\bar{\xi}}{2}\left(c_{t}+c_{t+\Delta t}^{m}\right)\right] \Delta t+c_{t} .
$$

Equations (B2) and (B3) may be obtained directly from Equation (B1), dropping the $k$ subscript for convenience. In these equations the superscript denotes the number of computational passes, and $\bar{g}$ and $\bar{\xi}$ pertain to simple averages over the interval $\Delta t$.

Exponential counterparts to Equations (B2) and (B3) can be derived by formally integrating Equation (BI) over the interval $\Delta t$, presuming that $g_{t}$ and $\xi_{t}$ are constant. The result is

$$
c_{t+\Delta t}^{1}=\frac{\left(g_{t}-\xi_{t} c_{t}\right)\left[\exp \left(\xi_{t} \Delta t\right)-1\right]}{\xi_{t} \exp \left(\xi_{t} \Delta t\right)}+c_{t}
$$

which can be modified to a corrector form

$$
c_{t+\Delta t}^{m+1}=\frac{\left(\bar{g}-\xi c_{t}\right)[\exp (\bar{\xi} \Delta t)-1]}{\bar{\xi} \exp (\bar{\xi} \Delta t)}+c_{t}
$$

One should note at this point, however, that in contrast to Equation (B3), concentration-averaging has not been performed to obtain Equation (B5). In this sense Equation (B5) should be considered more as an "improved predictor" than an actual corrector counterpart to Equation (B3).

Asymptotic approximations to Equations (B4) and (B5) can be derived by approximating $\exp (\xi \Delta t)$ in a Taylor's series:

$$
\exp (\xi \Delta t)=1+\xi \Delta t+\frac{\xi^{2}(\Delta t)^{2}}{2 !}+\ldots
$$


Truncation of Equation (B6) after the second and third terms leads respectively to the following asymptotic counterparts to Equations (B4) and (B5):

\section{Predictor:}

$$
c_{t+\Delta t}^{1}=\frac{\left(g_{t}-c_{t} \xi_{t}\right) \Delta t}{1+\xi_{t} \Delta t}+c_{t} ;
$$

Corrector:

$$
c_{t+t}^{m+1}=\frac{\left(\bar{g}-c_{t} \bar{\xi}\right) \Delta t\left(1+\frac{\xi \Delta t}{2}\right)}{1+\xi \Delta t\left(1+\frac{\xi \Delta t}{2}\right)}+c_{t} ;
$$

The additional Taylor's-series term has been included in Equation (B8) as a practical method of establishing conservative step-size control in the associated numerical algorithm.

Choice between exponentially-assisted or asymptotic calculations (IEXP=1 or 0 , respectiveiy) is at the user's discretion. The asymptotic forms Equations (B7) and (B8) pose the computational advantage of not requiring transcendental functions; the exponential counterparts, on the other hand, may be considered as somewhat more accurate (for any given step size), especially for reactions exhibiting a true first-order decay.

Choice of the appropriate number of corrector passes (NCORR) is also up to the user's discretion, and depends primarily upon system complexity. Simple noninteractive systems should be treated with a single corrector pass, while for highly interactive systems triple corrector passes may be advantageous. Multiple corrector passes provide the opportunity for enhanced dialogue between equations in the family at the expense of increased computation time Equation (B1). In general, an odd number of corrector passes will provide superior computational performance; using NCORR $>3$ is not recommended for any practical application.

Step-size control in ODEINT is determined primarily by the disagreement in values of the dependent variable(s) arising from the predictor and corrector 
operations of the previous time step. Since the error associated with Equations (B2) and (B3) is of the order of $(\Delta t)^{2}$ :

$$
\text { ERROR } \cong(\Delta t)^{2} ; \alpha=\text { some constant. }
$$

If $\varepsilon_{\text {old }}$ is the error associated with the previous time step, and EPS is the desired error tolerance, then

$$
\varepsilon_{\text {old }} \cong \alpha\left(\Delta t_{o l d}\right)^{2}
$$

and

$$
\text { EPS } \cong \alpha\left(\Delta t_{\text {new }}\right)^{2} \text {; }
$$

thus

$$
\Delta t_{\text {new }}=\Delta t_{\text {old }} \sqrt{\frac{\text { EPS }}{\varepsilon_{\text {old }}}} .
$$

Equation ( $B 9$ ), modified by a 0.9 conservativism factor, is used as a primary means of step-size control in ODEINT.

Under conditions where a given predictor-corrector cycle fails to achieve convergence, a penalty factor, PFACT $=0.5$ is imposed on the system. This reduces the subsequent grid step to one half of its naturally-computed value. In succeeding, successful cycles PFACT gradually approaches 1.0 , thus effecting a gradual relaxation of the penalty.

Under conditions where conventional predictor-corrector solution becomes negative for any dependent variable, the complete set of calculations for that time step is abandoned, and calculations are restarted for one-half the unsuccessful grid size. (The exponential and asymptotic approximations are always non-negative).

Error-relaxation is applied within the algorithm under circumstances when relative errors are insignificant. Four different situations where such relaxation occurs are:

- whenever concentrations approach negligible values (less than (ERROR), 
- whenever the starting concentration $\left(c_{t}\right)$ is negligibly small (near (MIN),

- whenever the projected concentration increase is so great as to make the current value and its relative error small by comparison, and

- whenever the projected concentration decrease is extremely rapid and a negligible concentration (near CMIN) will be reached shortly.

Error relaxation in this manner increases computational speed significantly. The user should review these adjustments in light of his individual needs however, and should modify the subroutine's relaxation block to fit his own particular requirements. 


\section{REFERENCES}

Carnahan, B., H. A. Luther and J. 0. Wilkes. 1969. Applied Numerical Methods. John Wiley, New York.

Young, T. R. 1980. CHEMEQ - A Subroutine for Solving Stiff Ordinary Differential Equations. NRL Memorandum Report 4091, Naval Research Laboratory, Washington, D.C. 


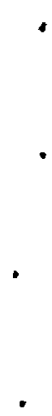


APPENDIX C

PLUVIUS MAIN PROGRAM AND

CLASS II SUBROUTINE LISTINGS

This appendix contains listings of the PLUVIUS main program and the 17 Class II subroutines. Note that most of these program units reference an INCLUDE file like that in Table 3-2 or Table 5-4. Table C-19 contains a description of variables and parameters that appear in the code. 
TABLE C-1. Listing of PLUVIUS Main Program Unit

PLUVIUS MOD 5

VERSION 1 - RELEASED AUG 1984

FOR DOCUMENTATION SEE:

J.M. HALES AND R.C. EASTER. PLUVIUS MOD 5 USER'S MANUAL.

PACIFIC NORTHWEST LABORATORIES REPORT TO U.S. EPA,

AUGUST, 1984 (**DRAFT**)

FOR INFORMATION, CONTACT :

J.M. HALES OR R.C. EASTER

GEOSCIENCES RESEARCH AND ENGINEERING DEPT.

BATTELLE PACIFIC NORTHWEST LABORATORIES

P.0. BOX 999

RICHLAND, WA. 99352

LANGUAGE: FORTRAN-77.

THIS CODE WAS DEVELOPED ON A VAX 11-78ఐ USING THE VMS OPERATING

SYSTEM. THE PROGRAM USES NO OPERATING SYSTEM FACILITIES.

THE ONLY CHANGES NEEDED TO RUN IT ON ANOTHER SYSTEM ARE THE

FOLLOWING NON-STANDARD LANGUAGE USAGES (FROM DEC VAX FORTRAN-77):

1. THE "INCLUDE" STATEMENT, FOUND AT THE START OF EACH PROGRAM UNIT

PROGRAM PLUVIUS

INCLUDE 'PLUVCMN'

COMMON/FILTERCMN/NF ILTR, FILFAC (NCMAX), MAXITA, MAXITB, NFSRCH, NFSET

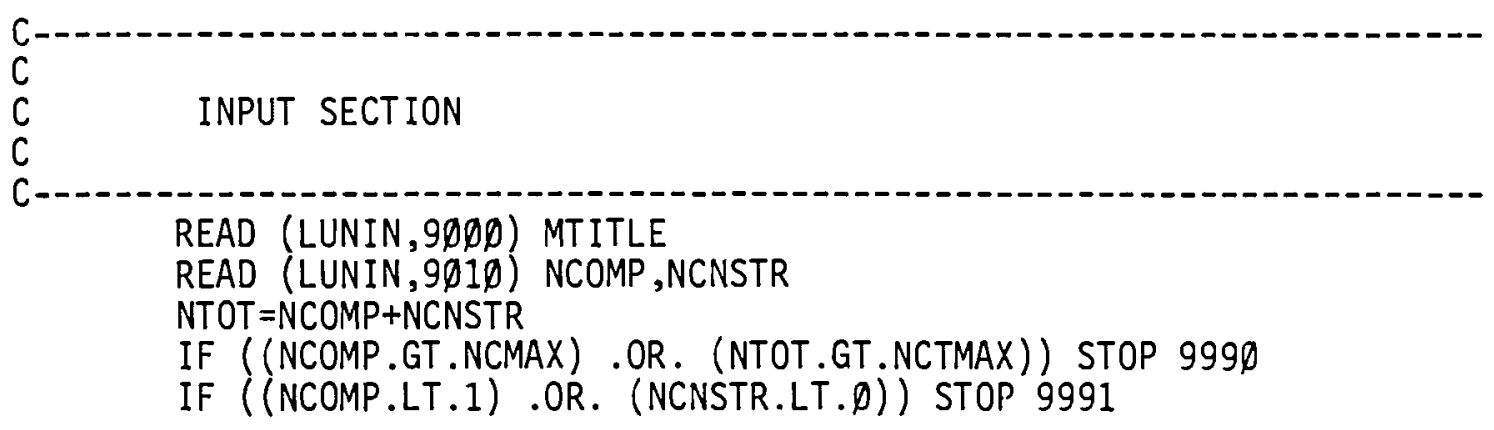




\section{TABLE C-1 Continued}

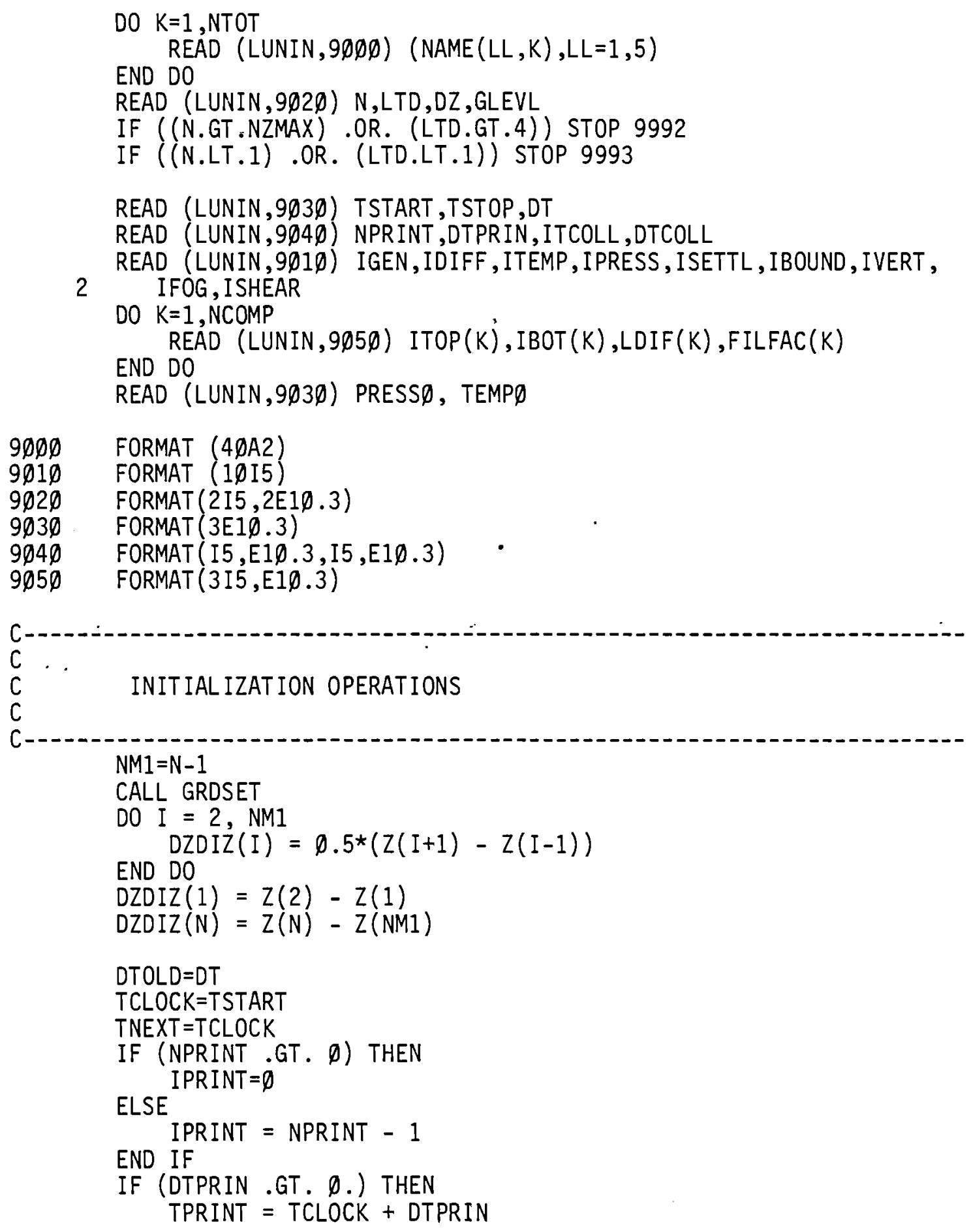


TABLE C-1 Continued

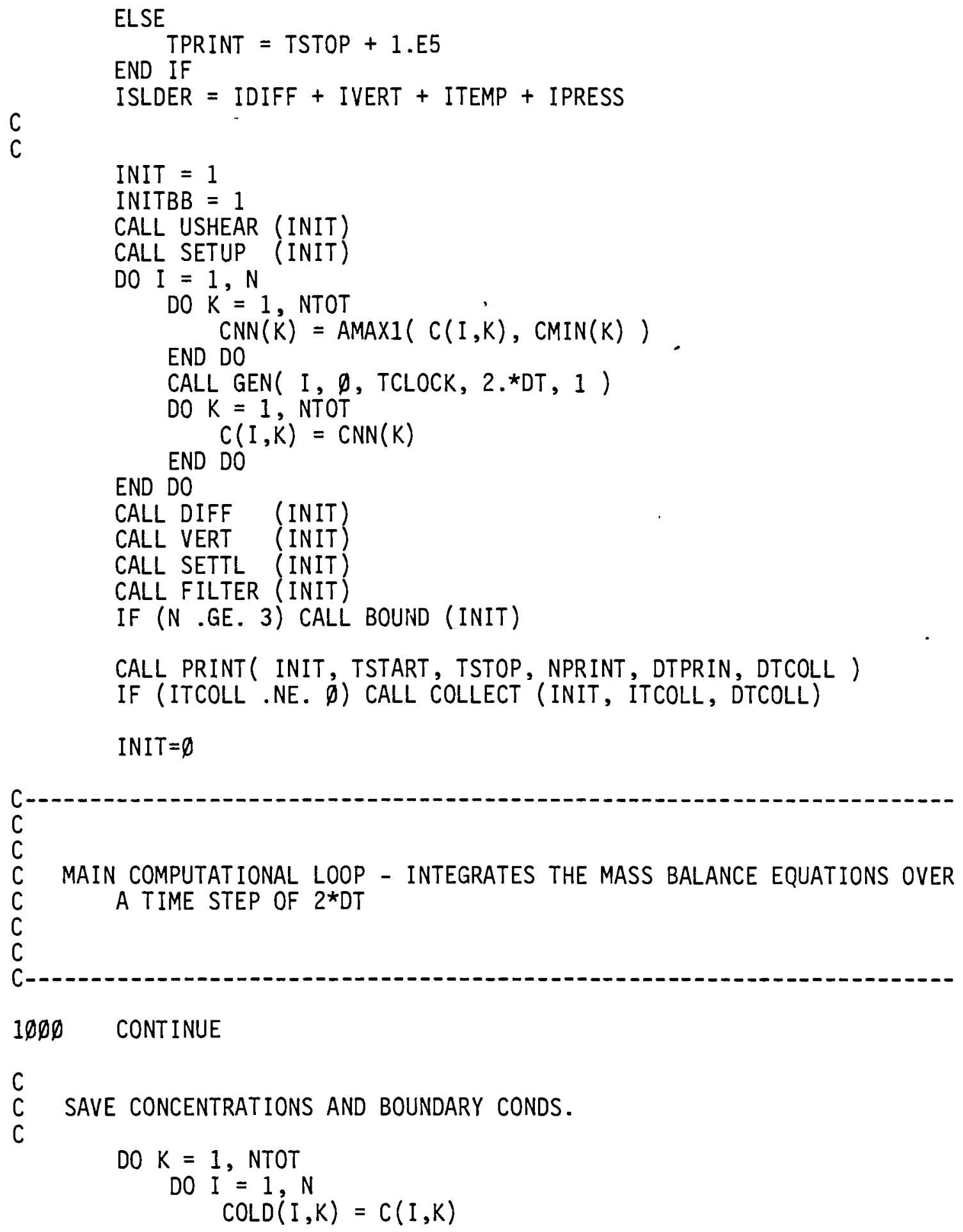


END DO

END DO

DO $K=1$, NCOMP

$\operatorname{FBOLD}(K)=F B(K)$

END DO

$\operatorname{FTOLD}(K)=F T(K)$

$\mathrm{C}$

C DO ADVECTION-DIFFUSION INTEGRATION FOR TIME STEP DT

C

IF (ISHEAR .NE. $\emptyset$ ) CALL USHEAR( INIT)

IF (IDIFF .NE. $\emptyset$ ) CALL DIFF (INIT)

IF (IVERT .NE. $\emptyset$ ) CALL VERT( INIT )

IF (ISETTL .NE. $\emptyset$ ) CALL SETTL( INIT)

DTOLD = DT

CALL TIMESP

TNEXT = TCLOCK + DT

CALL ADVINT( INIT, INITBB, ISLDER )

CALL ADJUST

TCMID = TNEXT

C

C DO CHEMICAL REACTION / MASS TRANSFER INTEGRATION FOR TIME STEP 2 ¿DT

C

IF (IGEN .NE. $\emptyset$ ) CALL CHMINT( INIT, INITBB )

C

C SAVE CONCENTRATIONS AND BOUNDARY CONDS. AGAIN

C

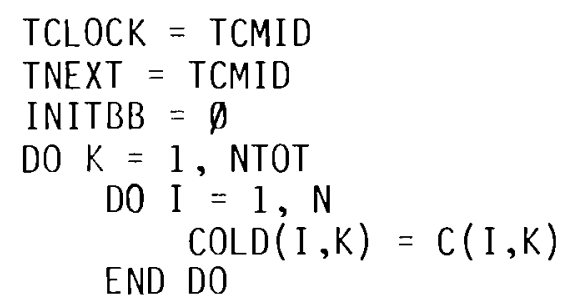

END DO

DO $K=1, N C O M P$
FBOLD $(K)=F B(K)$
FTOLD $(K)=F T(K)$
END DO
C
C
C DO ADVECTION-DIFFUSION INTEGRATION FOR TIME STEP DT AGAIN

$$
C-5
$$




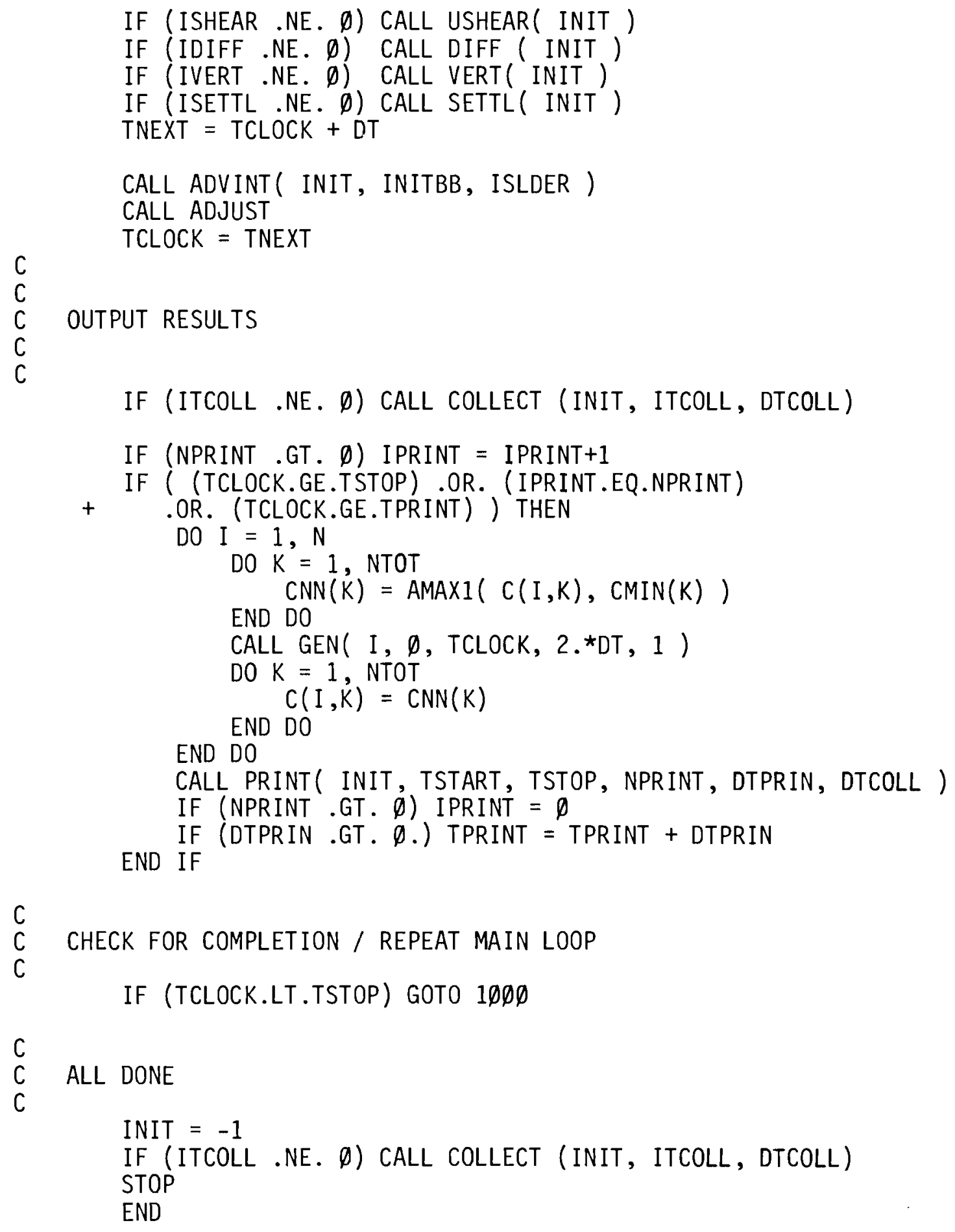


TABLE C-2. Listing of Subroutine ADVINT

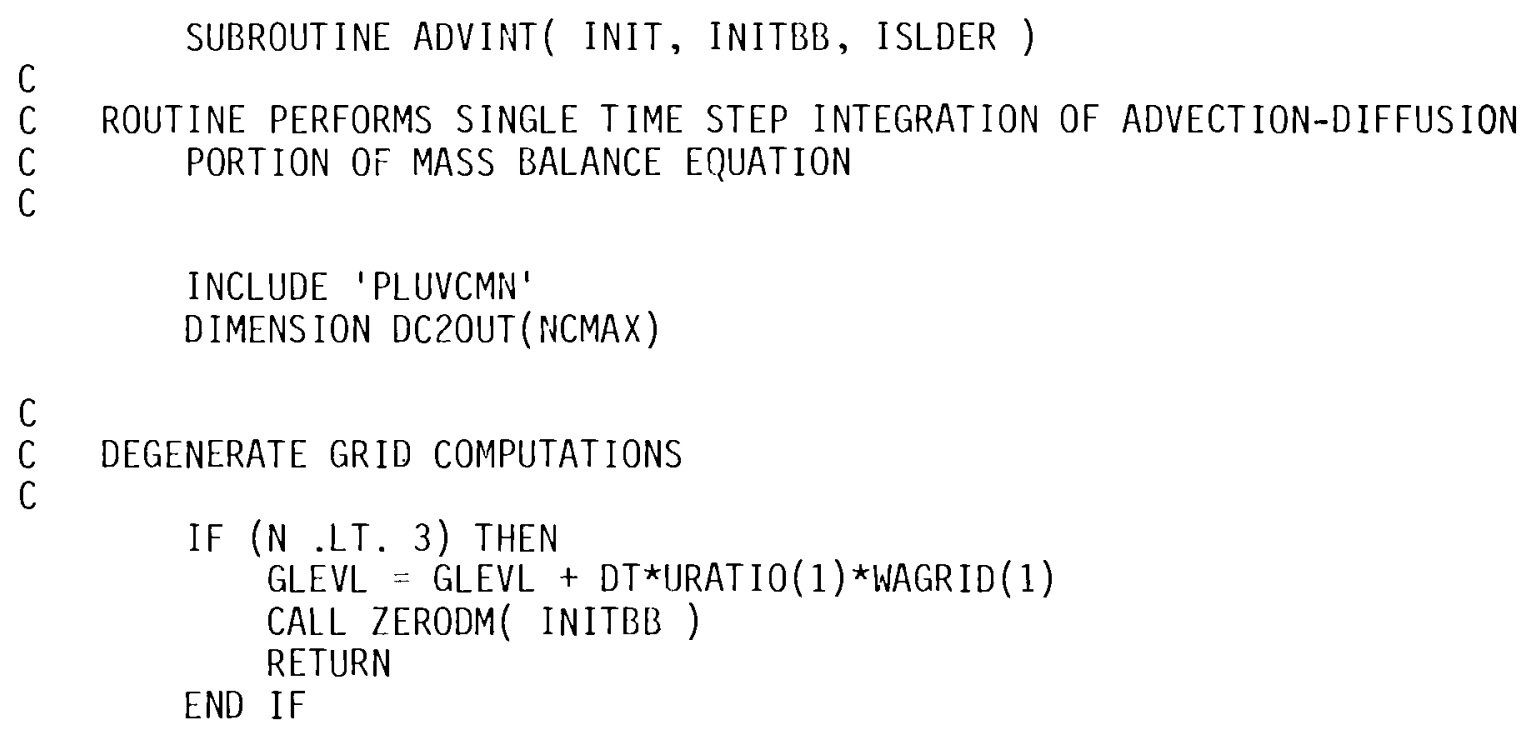

C

C DEGENERATE GRID COMPUTATIONS

C SET BOUNDARY CONDITIONS

IF (IBOUND .NE. $\emptyset$ ) CALL BOUND( INIT )

IF (ISLDER+INITBB .NE. $\emptyset$ ) CALL DERIV( INITBB )

C
C
C
C

LOOP FOR EACH COMPUTED SPECIES

DO $4 \emptyset \emptyset \emptyset \mathrm{K}=1$, NCOMP

$L=\operatorname{LDIF}(K)$

C

$C$
$C$ CALCULATE FIRST DERIVATIVE OF $C^{\star}(W R+$ WAP $)$

DO $\mathrm{I}=1, \mathrm{~N}$ $W V A R(I)=W R(I, K)+W A P(I)$

$\operatorname{DWVCDI}(\mathrm{I})=\operatorname{WVAR}(\mathrm{I}) * \operatorname{COLD}(\mathrm{I}, \mathrm{K})$

END DO

CALL FIRSTD（DWVCDI, DWVCDI )

C

C GET DIFF. EQUATION AND BOUNDARY RELATION COEFFICIENTS

IF (K.EQ.KTEMP) THEN

IF (ITEMP .EQ. $\emptyset$ ) GOTO $4 \emptyset \emptyset \emptyset$

CALL TEMPF( FXBTC1, FXBTD1, FXTPC1, FXTPD1) 


\section{TABLE C-2 Continued}

ELSE

END IF

CALL SETVEC( K, FXBTC1, FXBTD1, FXTPC1, FXTPD1 )

$\mathrm{C}$

C SET UP INTERIOR TRI-DIAGONAL COEFFICIENTS

DO I $=2, N M 1$

DTHFUR $=.5 *$ DT*URATIO (I)

$\operatorname{AMAT}(2,1, I)=3 . * \operatorname{WAR}(I-1)$

$\operatorname{AMAT}(2,2, \mathrm{I})=1$.

$\operatorname{AMAT}(1,1, \mathrm{I})=-\operatorname{DTHFUR}{ }^{\star} \operatorname{ADIFFU}(\mathrm{I}, \mathrm{L})$

$\operatorname{AMAT}(1,2, I)=\emptyset$.

$\operatorname{BMAT}(2,1, I)=\emptyset$.

$\operatorname{BMAT}(2,2, I)=4$.

$\operatorname{BMAT}(1,1, I)=1 . \emptyset-\operatorname{DTHFUR}{ }^{*} \mathrm{C} 1(\mathrm{I})-\operatorname{DTHFUR} * \operatorname{BDIFFU}(I, L)$

$\operatorname{BMAT}(1,2, \mathrm{I})=\operatorname{DTHFUR} / D Z D I Z(I)$

$\operatorname{CMAT}(2,1, I)=-3 . * W V A R(I+1)$

$\operatorname{CMAT}(2,2, \mathrm{I})=1$.

$\operatorname{CMAT}(1,1, I)=-\operatorname{DTHFUR} * \operatorname{CDIFFU}(I, L)$

$\operatorname{CMAT}(1,2, I)=\emptyset . \emptyset$

$\operatorname{DVEC}(2, I)=\emptyset$

$\operatorname{DVEC}(1, \mathrm{I})=\operatorname{COLD}(\mathrm{I}, \mathrm{K})+\operatorname{DTHFUR} *(-\operatorname{DWVCDI}(\mathrm{I}) / \operatorname{DZDIZ}(\mathrm{I})+$ 2. ${ }^{\circ} \operatorname{DIADV}(\mathrm{I})+(\mathrm{CI}(\mathrm{I})+\operatorname{BDIFFU}(\mathrm{I}, \mathrm{L})) * \operatorname{COLD}(\mathrm{I}, \mathrm{K})+$

$+$ END DO $\operatorname{ADIFFU}(I, L) * \operatorname{COLD}(I-1, K)+\operatorname{CDIFFU}(I, L) * \operatorname{COLD}(I+1, K))$

C

C SET UP TRI-DIAGONAL COEFFICIENTS TOP BOUNDARY

c

SECOND COMPONENT OF THE COEFFICIENTS

$\operatorname{AMAT}(2,1, N)=2 . * \operatorname{WVAR}(\mathrm{NM} 1)$

$\operatorname{AMAT}(2,2, N)=1$.

$\operatorname{BMAT}(2,1, N)=-2 . * \operatorname{WVAR}(N)$

$\operatorname{BMAT}(2,2, N)=1$.

$\operatorname{DVEC}(2, N)=\emptyset$.

C 
TABLE C-2 Continued

C FIRST COMPONENT - INFLOW OR "CONCENTRATION" BOUNDARY CONDITION IF (ITOP(K) .LE. Ø) THEN

$\operatorname{AMAT}(1,1, N)=\emptyset$.

$\operatorname{AMAT}(1,2, N)=\emptyset$.

$\operatorname{BMAT}(1,1, N)=1$.

$\operatorname{BMAT}(1,2, N)=\emptyset$.

$\operatorname{DVEC}(1, N)=\operatorname{CT}(K)$

C

C FIRST COMPONENT - FLUX BOUNDARY CONDITION

ELSE

DTHFUR $=.5 * D T * U R A T I O(N)$

$\operatorname{AMAT}(1,1, N)=-\operatorname{DTHFUR} \star \operatorname{ADIFFU}(N, L)$

$\operatorname{AMAT}(1,2, N)=\emptyset$.

$\operatorname{BMAT}(1,1, N)=1.0-\operatorname{DTHFUR} *(\mathrm{Cl}(\mathrm{N})+\operatorname{BDIFFU}(N, L)+\operatorname{FXTPC1})$

$\operatorname{BMAT}(1,2, N)=\operatorname{DTHFUR} / \operatorname{DZDIZ}(\mathrm{N})$

$\operatorname{DVEC}(1, N)=\operatorname{COLD}(N, K)+\operatorname{DTHFUR} *(-(\operatorname{DWVCDI}(N) / \operatorname{DZDIZ}(\mathrm{N}))$

$+\quad+\operatorname{COLD}(N, K) *(\mathrm{CI}(N)+\operatorname{BDIFFU}(N, L)+F X T P C 1)$

$\left.+\quad+\operatorname{COLD}(N M 1, K) * \operatorname{ADIFFU}(N, L)+2 . D^{*}(\operatorname{DIADV}(N)+\operatorname{FXTPD1})\right)$

END IF

C

C SET UP TRI-DIAGONAL COEFFICIENTS AT BOTTOM BOUNDARY

C

C

C SECOND COMPONENT OF THE COEFFICIENTS

$\operatorname{BMAT}(2,1,1)=2 . \star W V A R(1)$

$\operatorname{BMAT}(2,2,1)=1$.

$\operatorname{CMAT}(2,1,1)=-2 . \star W V A R(2)$

$\operatorname{CMAT}(2,2,1)=1$.

$\operatorname{DVEC}(2,1)=\emptyset$.

$c$

C FIRST COMPONENT - INFLOW OR "CONCENTRATION" BOUNDARY CONDITION IF (IBOT(K) .EQ. $\emptyset)$ THEN

$\operatorname{BMAT}(1,1,1)=1$.

$\operatorname{BMAT}(1,2,1)=\emptyset$.

$\operatorname{CMAT}(1,1,1)=\emptyset$.

$\operatorname{CMAT}(1,2,1)=\emptyset$.

$\operatorname{DVEC}(1,1)=C B(K)$

C

C FIRST COMPONENT - OUTFLOW BOUNDARY CONDITION

ELSE IF (IBOT(K) .LT. $\emptyset)$ THEN 
TABLE C-2 Continued

$$
\begin{aligned}
& \text { DTHFUR }=.5 * D T * U R A T I O(1) \\
& \operatorname{DC2OUX}=\operatorname{ADIFFU}(2, \mathrm{~L}) * \operatorname{COLD}(1, \mathrm{~K})+\operatorname{BDIFFU}(2, \mathrm{~L}) * \operatorname{COLD}(2, \mathrm{~K})+ \\
& +\quad \operatorname{CDIFFU}(2, L) * \operatorname{COLD}(3, K) \\
& \text { IF (INITBB .NE. } \emptyset \text { ) DC2OUT(K) }=\text { DC2OUX } \\
& \operatorname{CMAT}(1,2,1)=\emptyset \text {. }
\end{aligned}
$$

$\mathrm{C}$

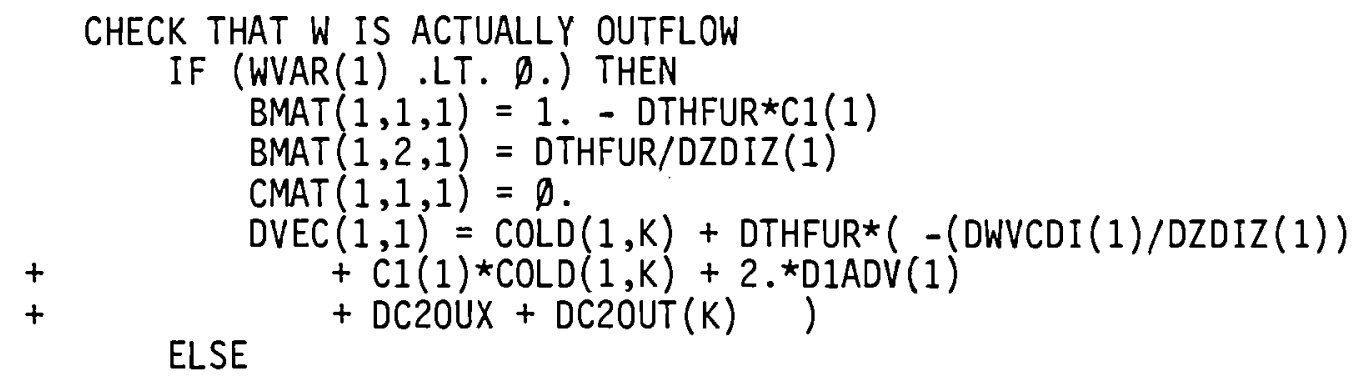

C

HAVE INFLOW, USE DC/DZ $=\emptyset$ AS THE B.C. $(C(2)=C(1))$

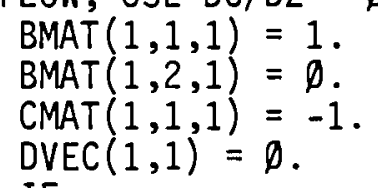

C

C FIRST COMPONENT, FLUX BOUNDARY CONDITION

ELSE

$$
\begin{aligned}
& \text { DTHFUR }=.5 * \text { DT*URATIO(1) } \\
& \operatorname{BMAT}(1,1,1)=1 . \emptyset-\operatorname{DTHFUR} *(\operatorname{C} 1(1)+\operatorname{BDIFFU}(1, L)+\operatorname{FXBTC1}) \\
& \operatorname{BMAT}(1,2,1)=\operatorname{DTHFUR} / \text { DZDIZ }(1) \\
& \operatorname{CMAT}(1,1,1)=-\operatorname{DTHFUR} * \operatorname{CDIFFU}(1, L) \\
& \operatorname{CMAT}(1,2,1)=\emptyset \text {. } \\
& \operatorname{DVEC}(1,1)=\operatorname{COLD}(1, K)+\operatorname{DTHFUR} *(-(\operatorname{DWVCDI}(1) / \operatorname{DZDIZ}(1)) \\
& +\quad+\operatorname{COLD}(1, K) *(\operatorname{C1}(1)+\operatorname{BDIFFU}(1, L)+\operatorname{FXBTC1}) \\
& \left.+\quad+\operatorname{COLD}(2, K) \star \operatorname{CDIFFU}(1, L)+2{ }^{*}(\operatorname{DIADV}(1)+\operatorname{FXBTD} 1)\right)
\end{aligned}
$$

END IF

$\stackrel{c}{C}$

SOLVE TRI-DIAGONAL SYSTEM FOR NEW C'S AND DCDZ'S

CALL TRIDG2( $1, N$, AMAT, BMAT, CMAT, DVEC, UVEC )

DO I $=1, N$

END DO

$$
C(I, K)=\operatorname{UVEC}(1, I)
$$


TABLE C-2 Continued

\section{$4 \emptyset \emptyset \emptyset \quad$ CONTINUE}

C

C APPLY FILTER TO SOLUTION VARIABLES

C

CALL FILTER( INIT )

- $\quad$ C CALC NEW SURface leVEl AND PRESSURE

GLEVL $=$ GLEVL + DT*URATIO(1)*WAGRID (1)

IF (IPRESS .NE. Ø) CALL PRESSF( INIT)

RETURN

END 
TABLE C-3. Listing of Subroutine CHMINT

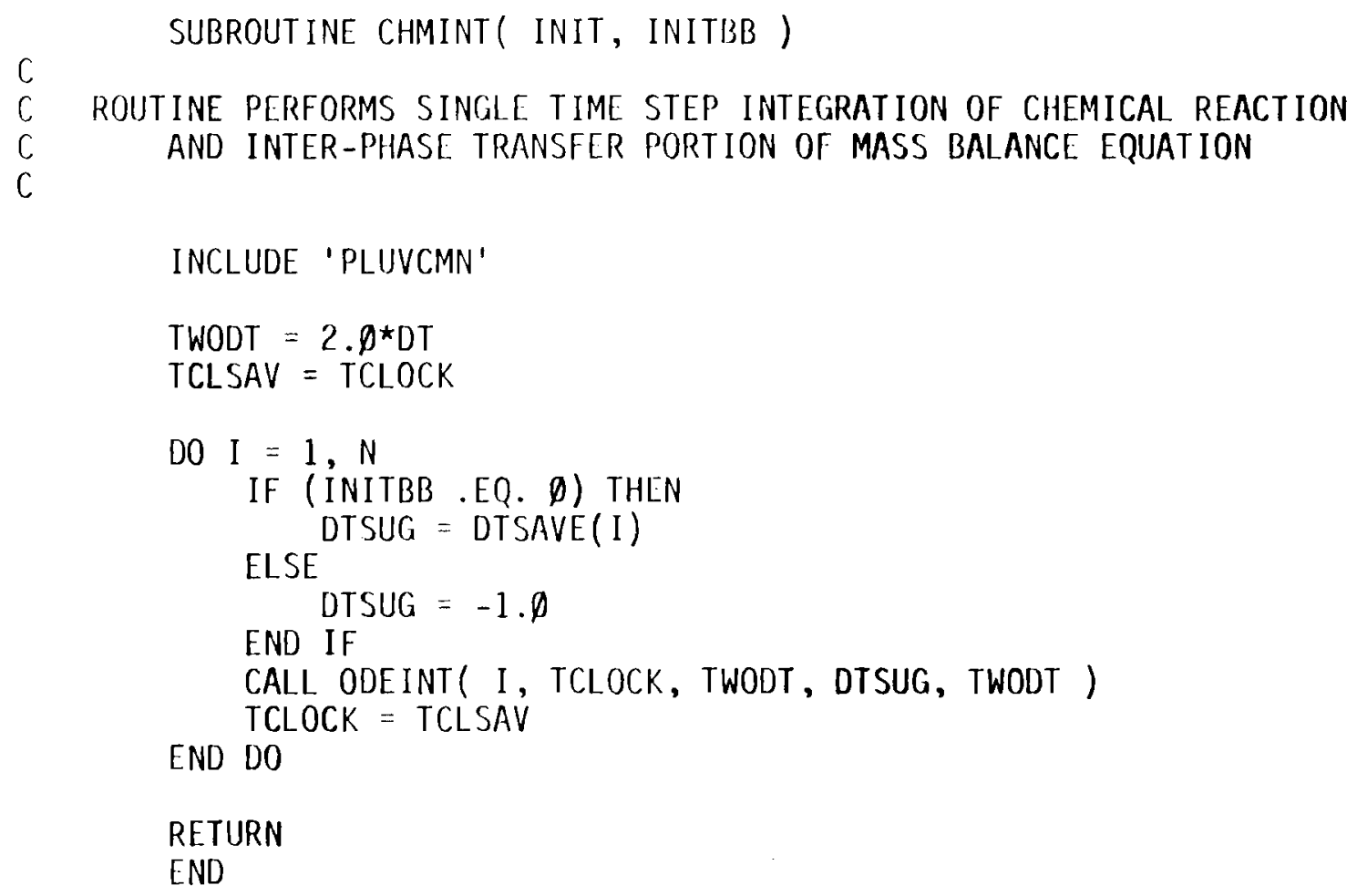


TABLE C-4 Continued

$$
\begin{aligned}
& \operatorname{ADIFFU}(I, L)=\operatorname{DHATIM}(1+\operatorname{CS}(\mathrm{I}) / \mathrm{CS}(\operatorname{IMI})) / \mathrm{TWODH} \\
& \operatorname{CDIFFU}(I, L)=\operatorname{DHATIP} *(1+\operatorname{CS}(\mathrm{I}) / \operatorname{CS}(\mathrm{IP} 1)) / \mathrm{TWODH} \\
& +\quad \operatorname{BDIFFU}(I, L)=-\frac{\operatorname{DHATIM} *(1 .+\operatorname{CS}(\operatorname{IM} 1) / \mathrm{CS}(\mathrm{II})))+}{\operatorname{DHATIP} *(1 .+\operatorname{CS}(\operatorname{IPI} 1) / \mathrm{CS}(\mathrm{I}))) / \text { TWODH }}
\end{aligned}
$$

END DO

$$
\begin{aligned}
& \operatorname{CDIFFU}(N, L)=\emptyset . \\
& \operatorname{BDIFFU}(N, L)=-\operatorname{DHATIP} *(1 .+\operatorname{CS}(N M I) / \operatorname{CS}(N)) /(\operatorname{DZDIZ}(N)) \\
& \operatorname{ADIFFU}(N, L)=\operatorname{DHATIP} *(1 .+\operatorname{CS}(N) / \operatorname{CS}(N M 1)) /(\operatorname{DZDIZ}(N))
\end{aligned}
$$

END DO

$C$
$C$
$C$
$C$
$C$
$C$
$C$
$C$

COMPUTE :

C1DWAP $=D($ WAP $) / D Z=(1 . / D Z D I Z) * D($ WAP $) / D I Z$

CIDLCS $=($ WA $/ C S) * D(C S) / D Z$

$=(($ WAGRID+WAP $) / C S / D Z D I Z) * D(C S) / D I Z$

CALL FIRSTD( WAP, C1DWAP )

CALL FIRSTD( CS, CIDLCS )

DO I $=1, N$ $\operatorname{CIDWAP}(\mathrm{I})=\operatorname{CIDWAP}(\mathrm{I}) / \operatorname{DZDIZ}(\mathrm{I})$

$\operatorname{CIDLCS}(I)=(\operatorname{WAGRID}(\mathrm{I})+\operatorname{WAP}(\mathrm{I})) * \operatorname{C1DLCS}(\mathrm{I}) /(\operatorname{CS}(\mathrm{I}) * \operatorname{DZDIZ}(\mathrm{I}))$

END DO

RETURN

END 
TABLE C-5. Listing of Subroutine FILTER

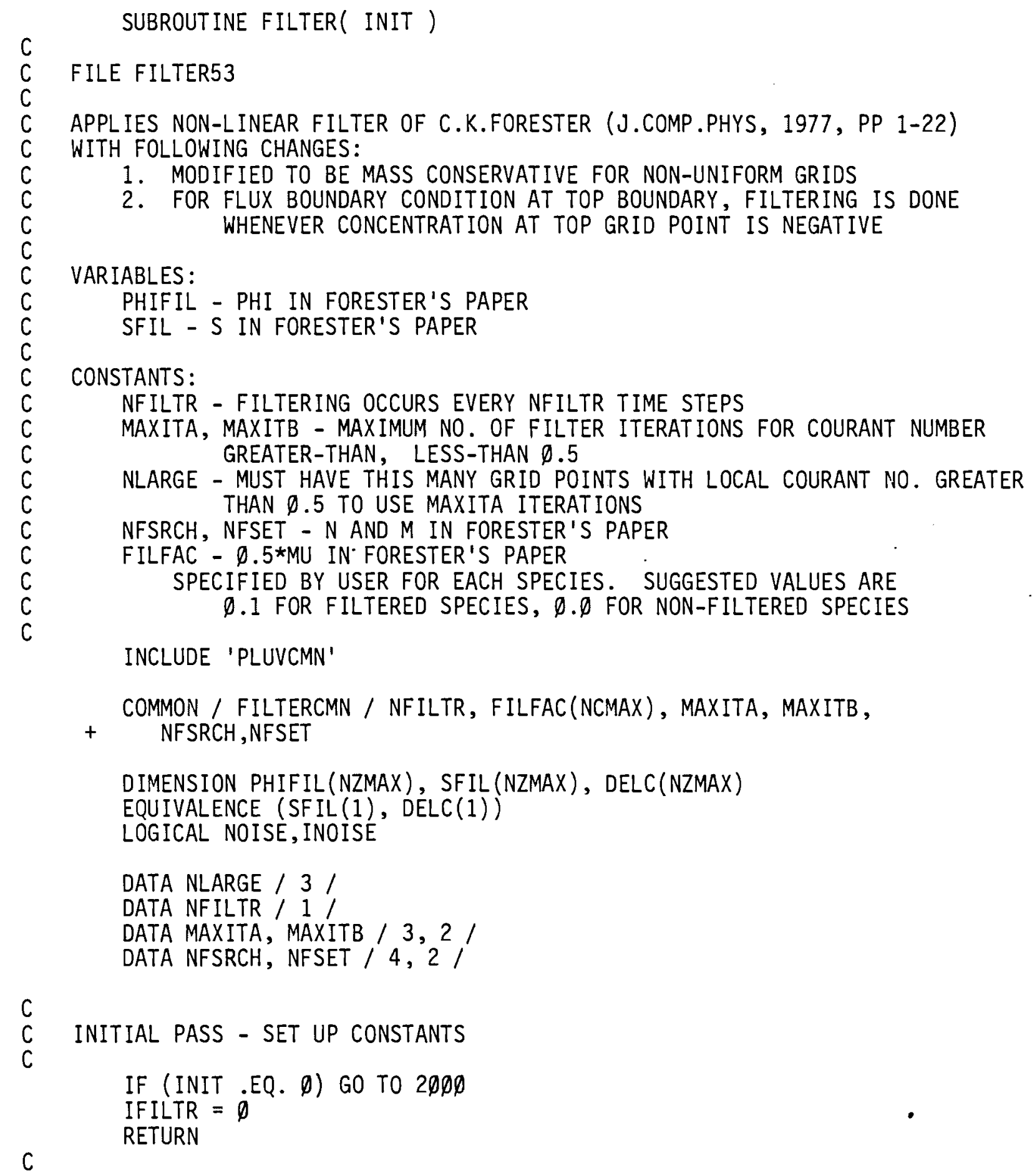




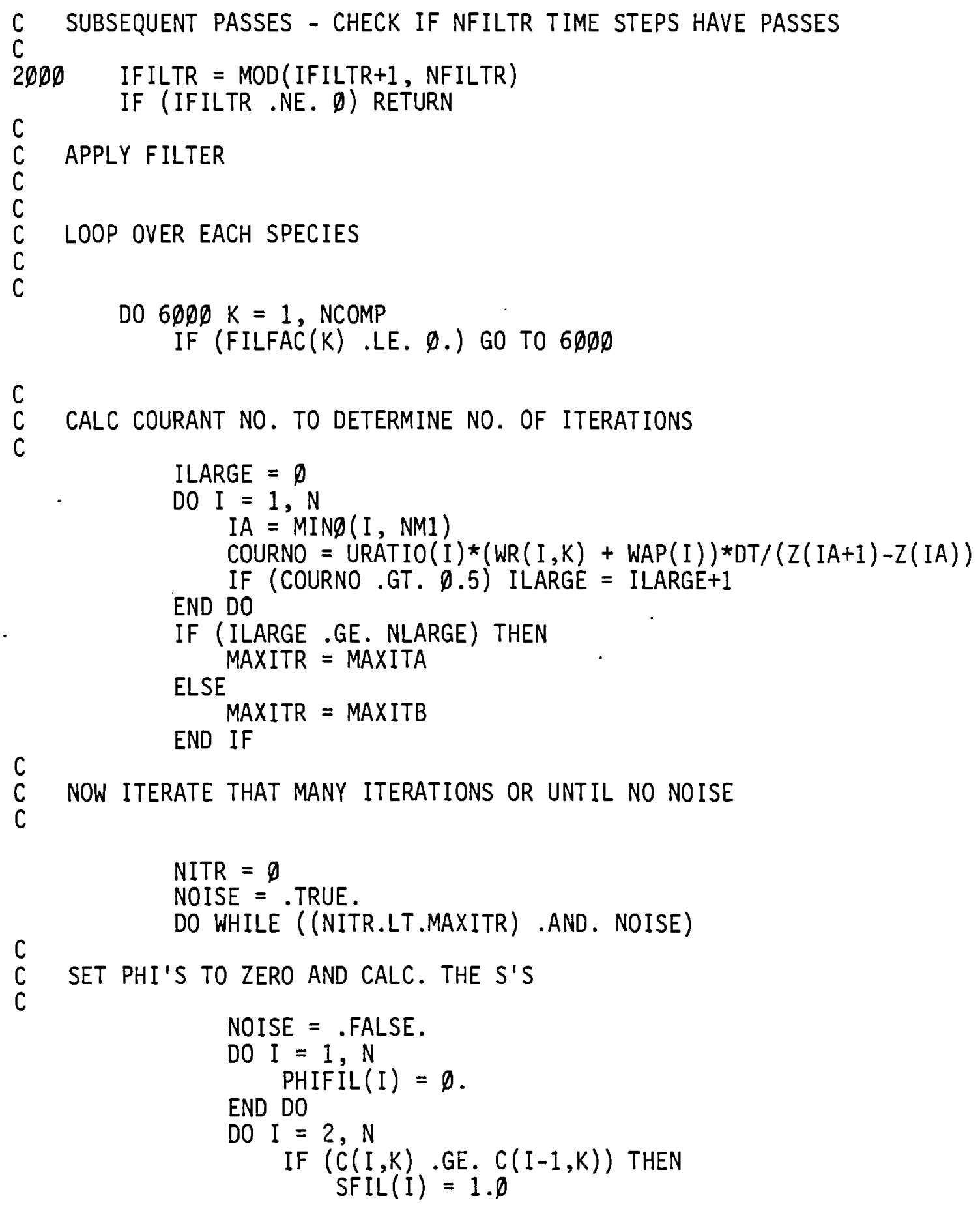


TABLE C-5 Continued

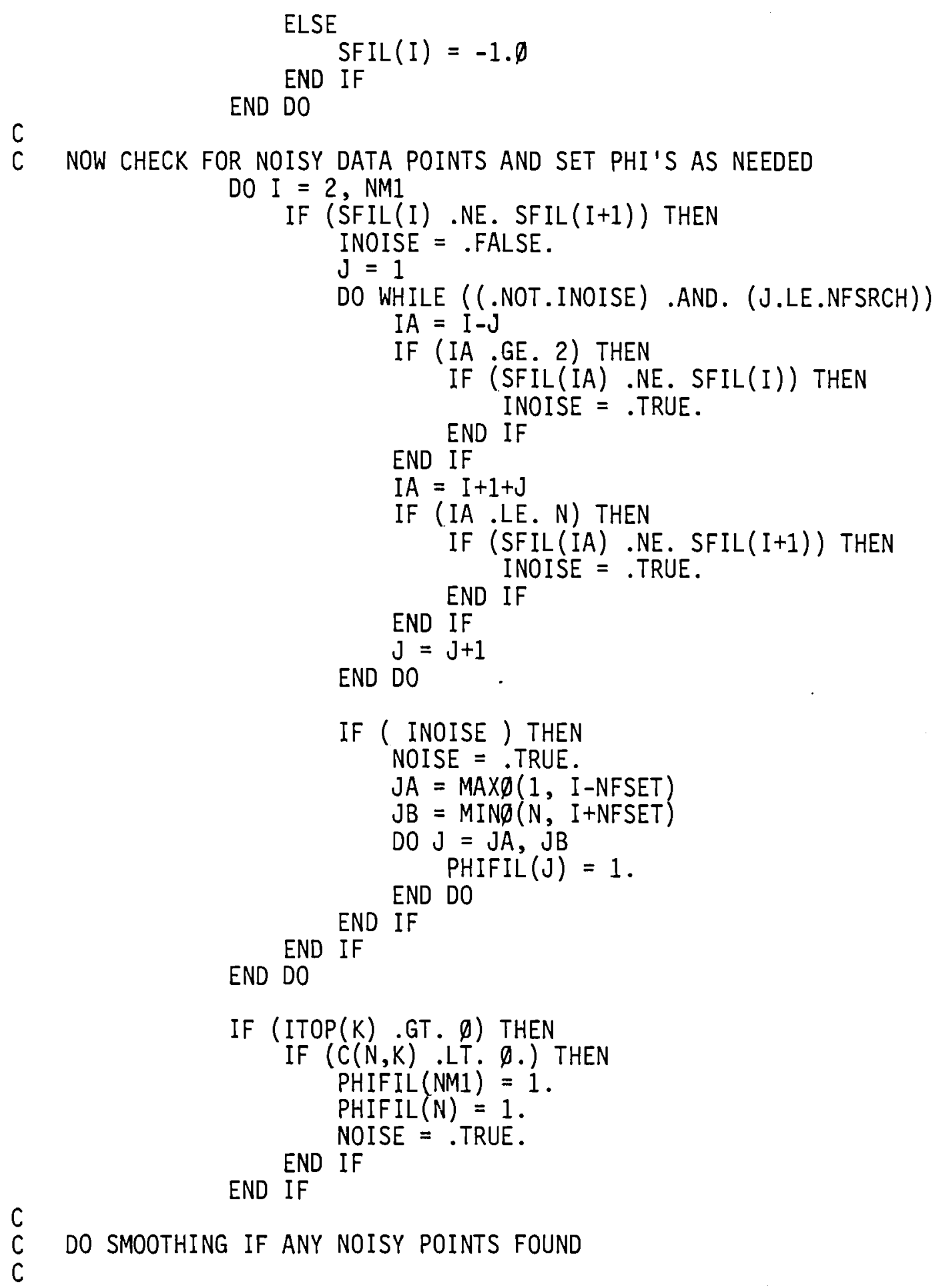

C

C DO SMOOTHING IF ANY NOISY POINTS FOUND 


\section{TABLE C -5 Continued}

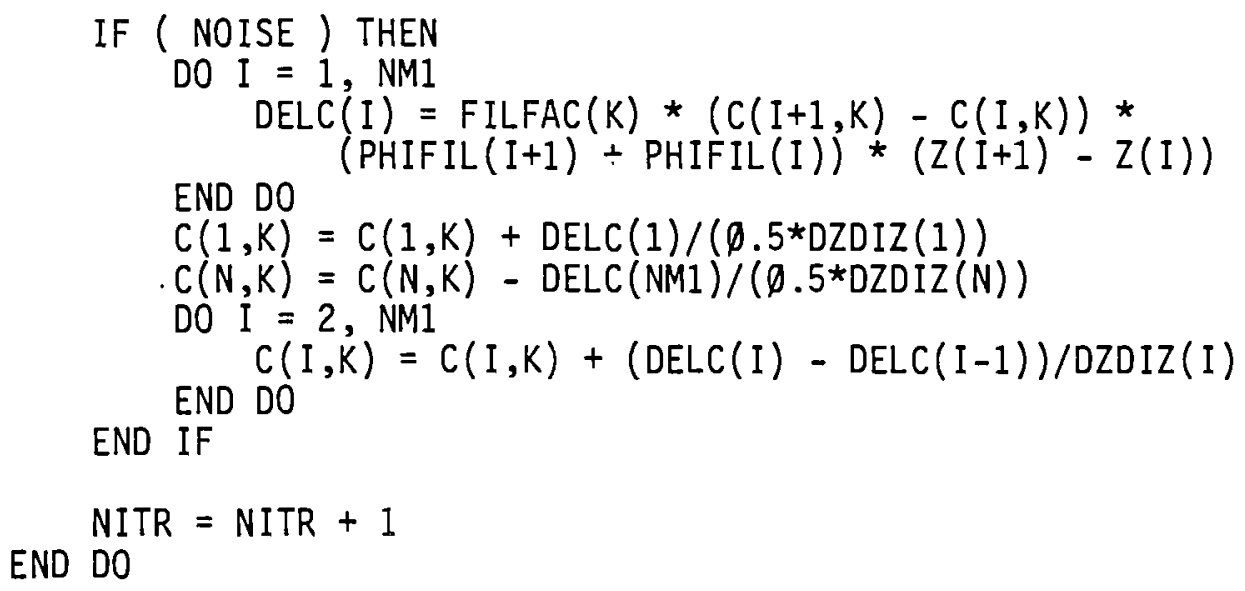

6000 END DO

RETURN

END 
TABLE C-6. Listing of Subroutine FIRSTD

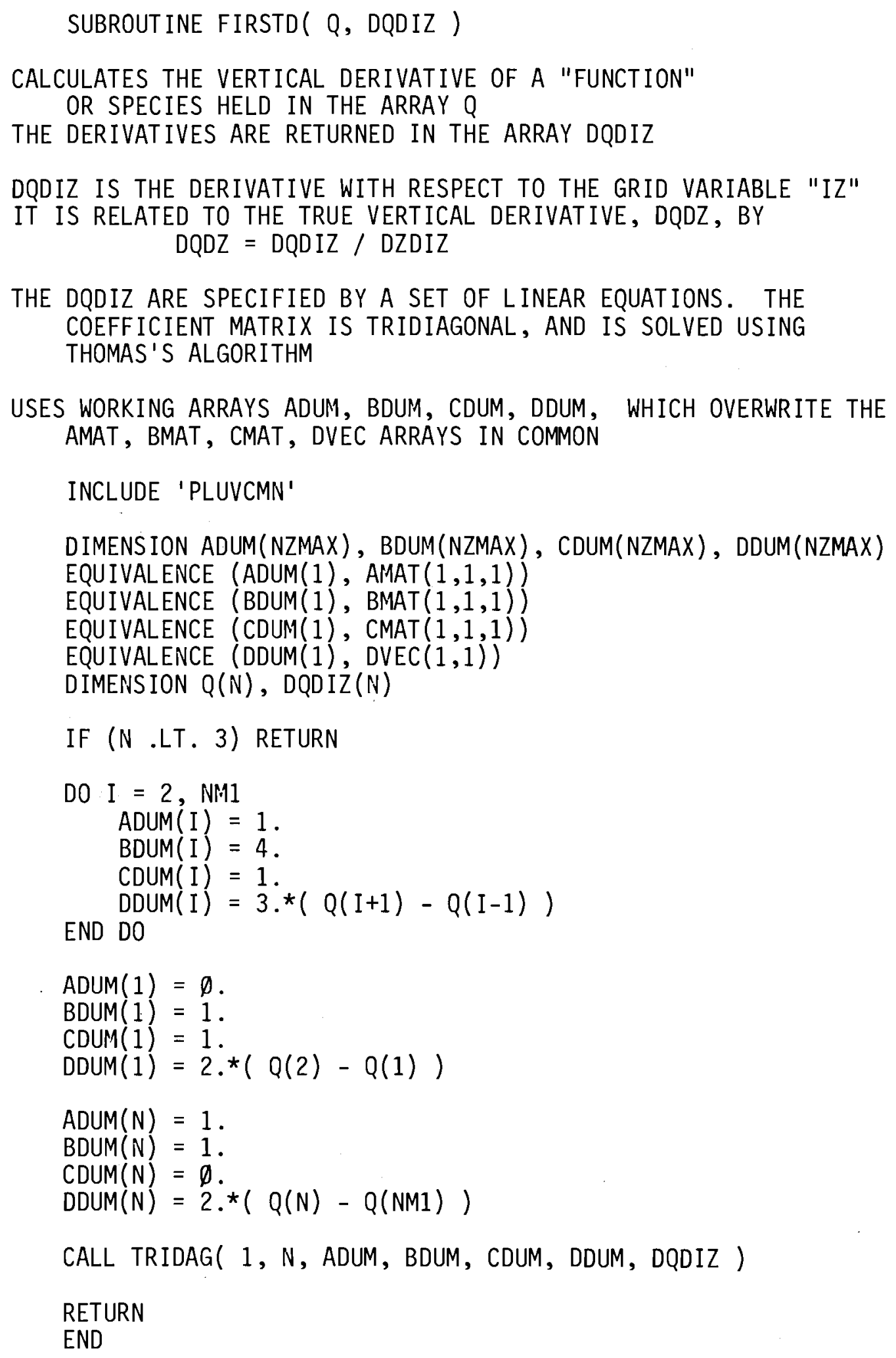

CALL TRIDAG( $1, N$, ADUM, BDUM, CDUM, DDUM, DQDIZ )

RETURN

END 
TABLE C-7. Listing of Subroutine ODEINT

SUBROUTINE ODEINT(I, TSTRTO, DTTOT, DTSUG, DTMAX )

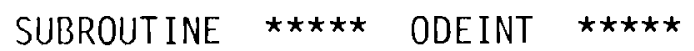

Performs numerical integrations of the system of equations

$D(C(I, K)) / D T=\operatorname{GGEN}(K)-\operatorname{GDEC}(K)$

Where:

$T$ is the independent variable

$C(I, K)$ is the vector of dependent variables ( $I$ is fixed during each call to ODEINT)

$G G E N(K)$ is the vector of species generation rates

$\operatorname{GDEC}(K)$ is the vector of species destruction rates. (GDEC(K) is expressed internally as a psuedo first-order relation $\operatorname{GDEC}(K)=X I(K) \star C(K)$, where $X I(K)$ is the vector of psuedo first-order rate coefficients.

Both GGEN(K) and GDEC(K) are determined by interrogating a user-supplied subroutine, named GEN

TSTRTO is the model time at the begining of the call to odeint

DTTOT is the time interval over which the equations are integrated

DTMAX is the (user specified) maximum allowable

time step

DTSUG is the "suggested" initial time step for the integration. If this is set negative by the calling program, then ODEINT will determine its own step size.

(After a successful integration, the final step size is

passed back in DTSAVE(I). It should be used to establish

DTSUG on repeated calls.)

The following parameters affect the mechanics of the numerical integration. They are held in common blocks, and should be initialized in the SETUP subroutine. 


\section{TABLE C-7 Continued}

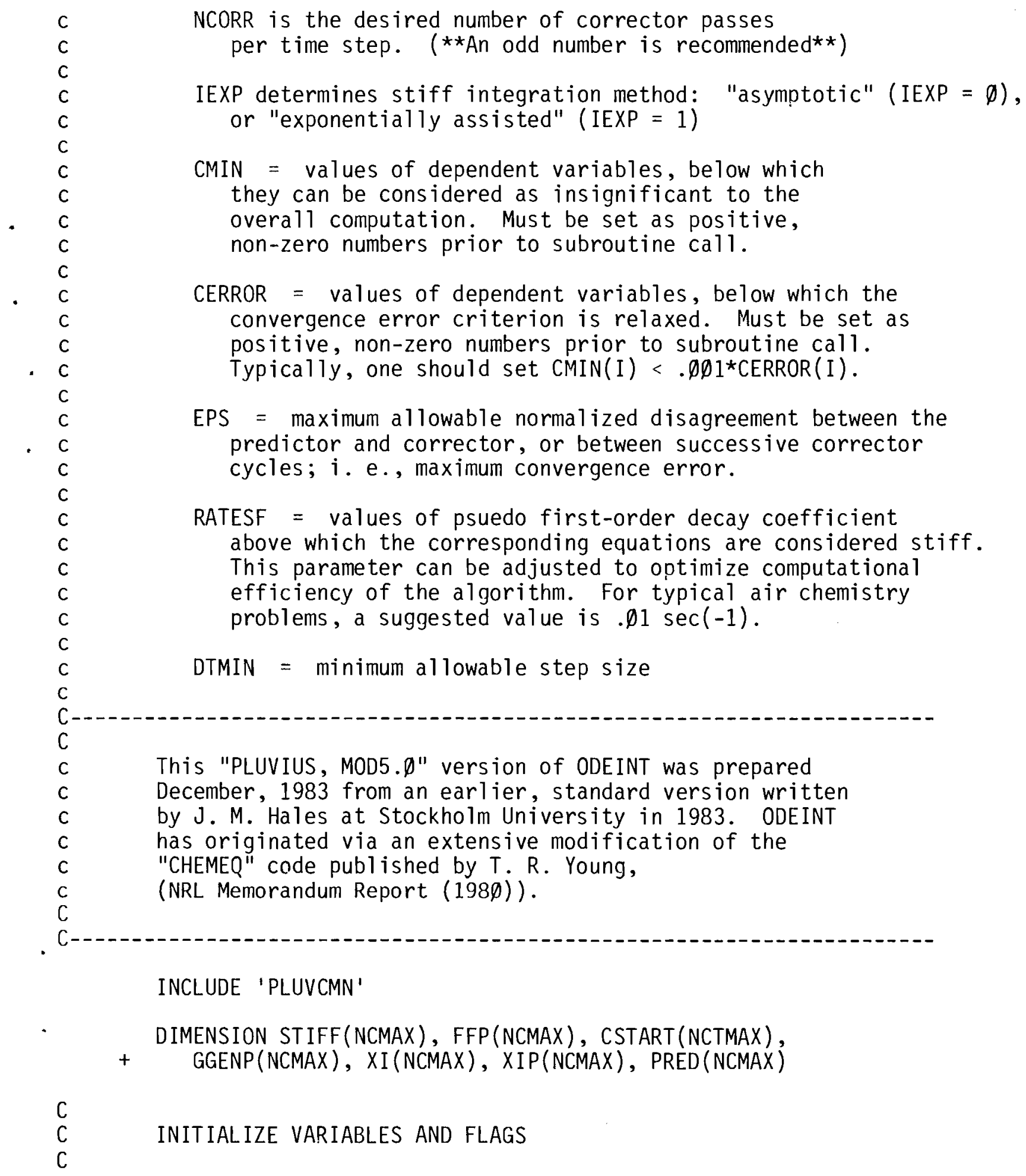




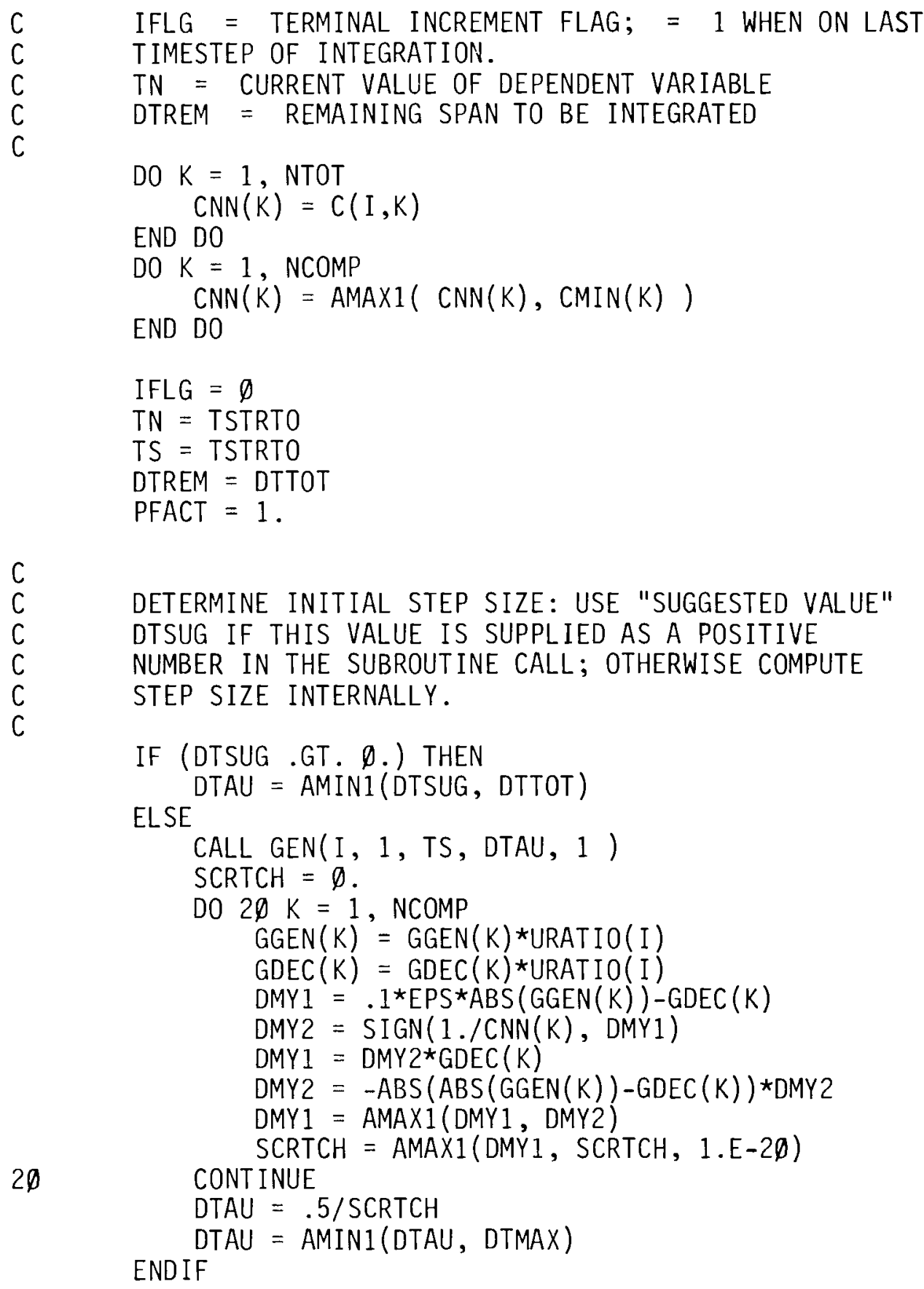


TABLE C-7 Continued

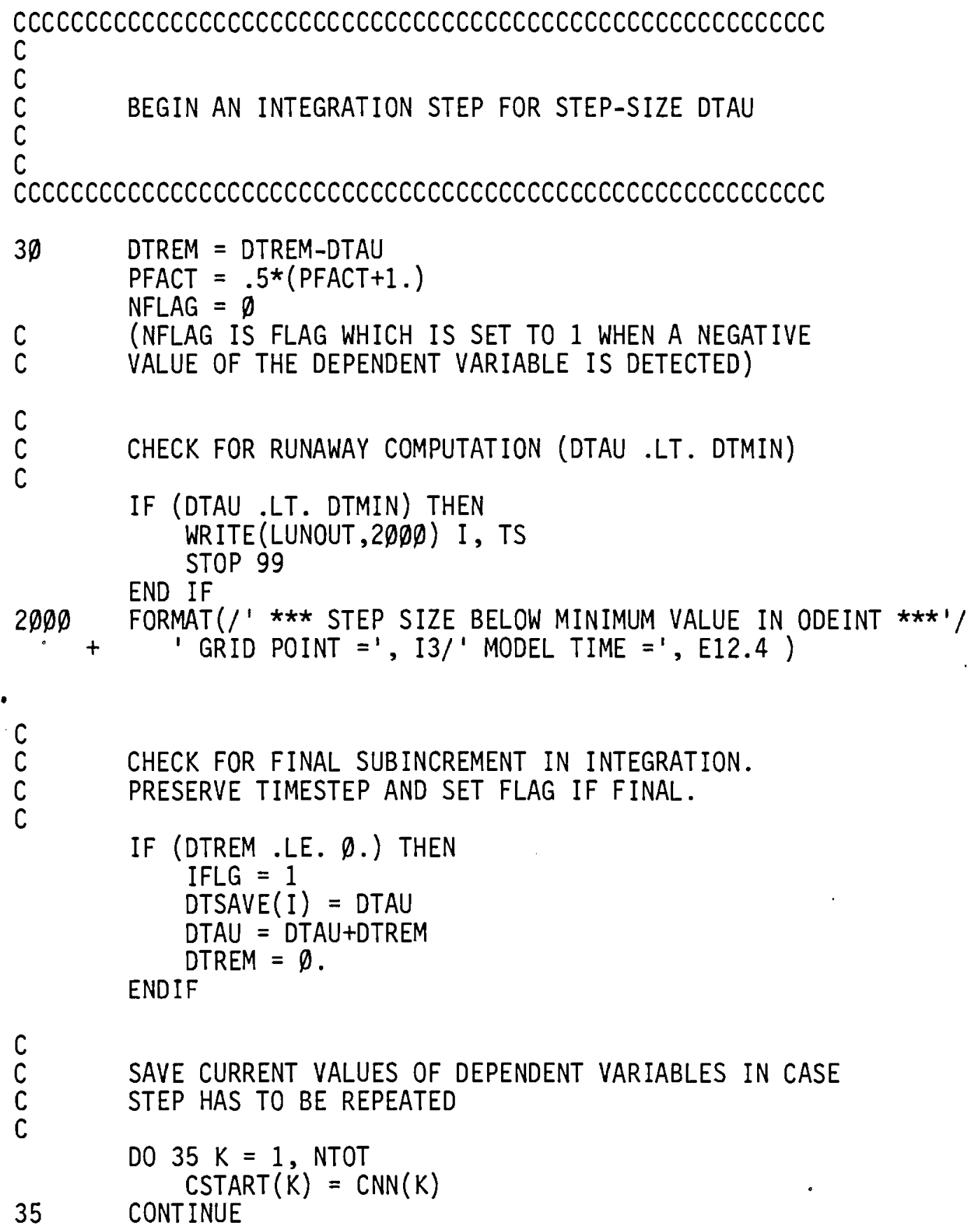

SAVE CURRENT VALUES OF DEPENDENT VARIABLES IN CASE STEP HAS TO BE REPEATED

DO $35 K=1$, NTOT CONTINUE$$
\operatorname{CSTART}(K)=\operatorname{CNN}(K)
$$ 
TABLE C-7 Continued

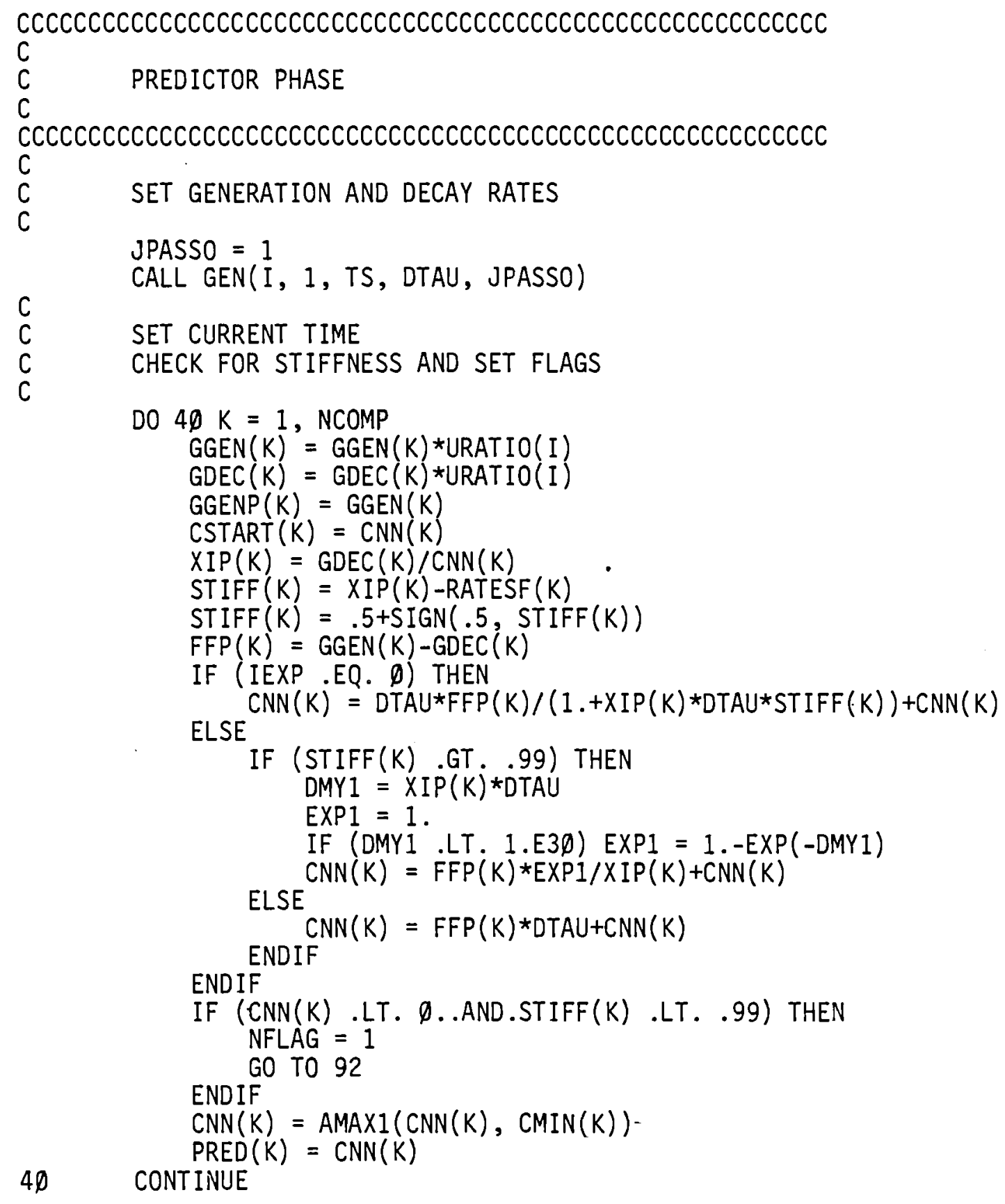


TABLE $\mathrm{C}-7$ Continued

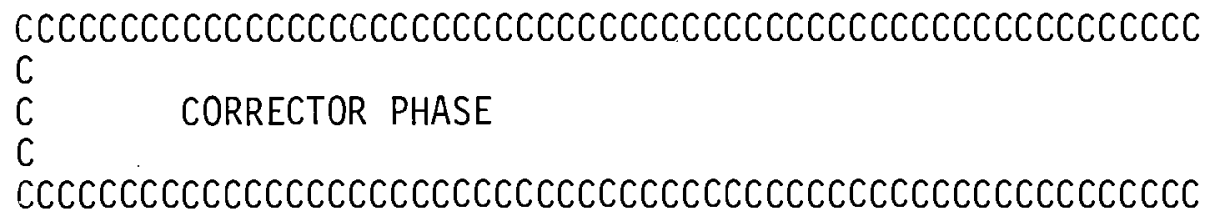


TABLE C-7 Continued

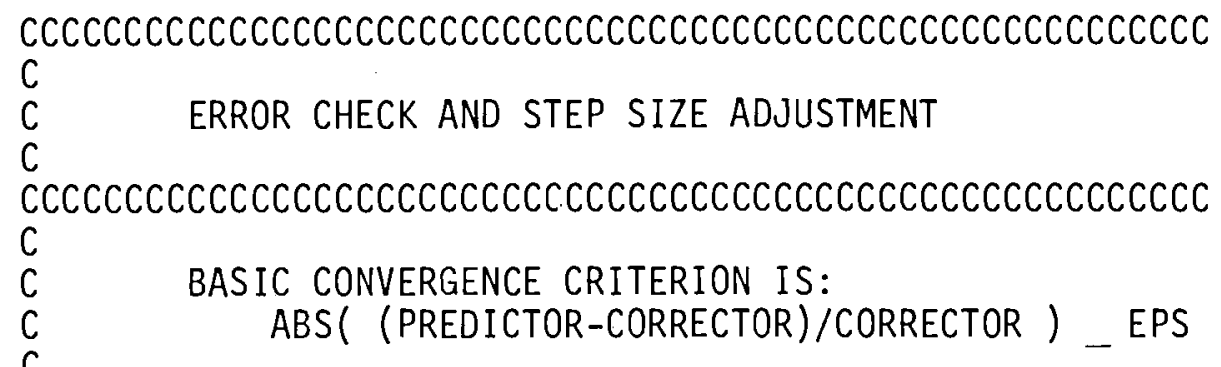

THE CONVERGENCE CRITERION IS RELAXED UNDER A NUMBER OF CIRCUMSTANCES. THIS ERROR RELAXATION SHOULD BE CONSIDERED "APPLICATION-DEPENDENT", AND THE USER MAY WISH TO MODIFY IT AS REQUIRED. IN THE AIR-CHEMISTRY APPLICATIONS OF THE PLUVIUS MOD 5 USERS' MANUAL, ERRORS ARE RELAXED WHENEVER:

1) CONCENTRATIONS APPROACH NEGL IGIBLE VALUES (RLOCON)

2) THE STARTING CONCENTRATION IS NEGL IGIBLY SMALL (RZROST)

3) THE PROJECTED INCREASE IS SO LARGE AS TO MAKE THE CURRENT VALUE AND ITS RELATIVE ERROR SMALL BY COMPARISON (RFASTI)

4) THE PROJECTED DECREASE IS RAPID (RFASTD)

$80 \quad$ ERRMX $=1 . E-6$

C SETTING ERRMX TO 1.E-6 LIMITS STEP SIZE INCREASE TO SQRT(1.E6*EPS)

DO $9 \emptyset \mathrm{K}=1$, NCOMP

RLOCON $=\emptyset .5^{*}(\operatorname{CSTART}(K)+\operatorname{CNN}(K)) / \operatorname{CERROR}(K)$

RZROST $=$ ABS ( CSTART $(K) / \operatorname{CMIN}(K)-1$.

PROJTN $=$ CSTART $(K)+D T R E M * F F P(K) /(1 .+X I P(K) \star D T R E M \star S T I F F(K))$

IF (PROJTN .GT. Ø.) THEN RFASTI $=$ CNN $(K) /$ PROJTN

ELSE

RFASTD $=$ PROJTN $/$ CMIN $(K)$

END IF

RFASTI $=1$.

RFASTD $=\emptyset$.

REDFTR = AMIN1 $(1 .$, RLOCON, RFASTD, RFASTI, RZROST)

$\operatorname{ERR}=(\operatorname{CNN}(K)-\operatorname{PRED}(K)) / \operatorname{AMAXI}(\mathrm{CNN}(K), \operatorname{PRED}(K))$

ERELAX $=$ ABS (ERR) *REDFTR

ERRMX = AMAXI (ERELAX, ERRMX)

$9 \emptyset$ CONTINUE

$\mathrm{C}$
$\mathrm{C}$
$\mathrm{C}$
$\mathrm{C}$
$\mathrm{C}$

ERROR EXCEEDS TOLERANCE. SET PENALTY FACTOR AND SET UP DATA FOR RESTART IF NEGATIVE VALUES WERE EXPERIENCED (NFLAG=1), HALVE THE STEPSIZE. OTHERWISE, COMPUTE NEW STEP SIZE BASED ON SIZE OF ERROR

IF (ERRMX .LT. EPS) GO TO 94 


\section{TABLE C-7 Continued}

92

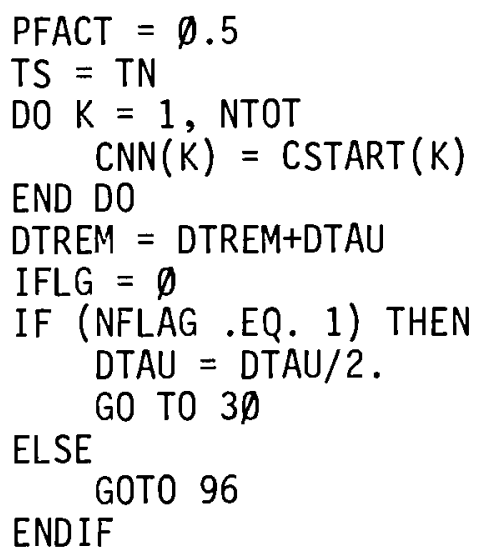

C

C

$96 \quad$ EPSRTO $=$ EPS/ERRMX

C

C USE NEWTON'S METHOD TO ESTIMATE SQRT(EPSRTO)

SQRTO $=.5^{*}($ EPSRTO +1.$)$

DO IDUM $=1,2$

SQRTO $=.5 *($ SQRTO + EPSRTO $/$ SQRTO $)$

END DO

DTAU $=$ DTAU*SQRTO*.9*PFACT

DTAU = AMIN1 (DTAU, DTMAX)

$\mathrm{C}$
$\mathrm{C}$
$\mathrm{C}$
$\mathrm{C}$
$\mathrm{C}$

RECYCLE FOR REDUCED STEP SIZE IF ERROR IS TOO HIGH

OTHERWISE, ADVANCE INDEPENDENT VARIABLE AND CYCLE TO PREDICTOR PHASE

IF (ERRMX .LE. EPS) $T N=T S$

GO TO $3 \emptyset$

END 
TABLE C-8. Listing of Subroutine SETVEC

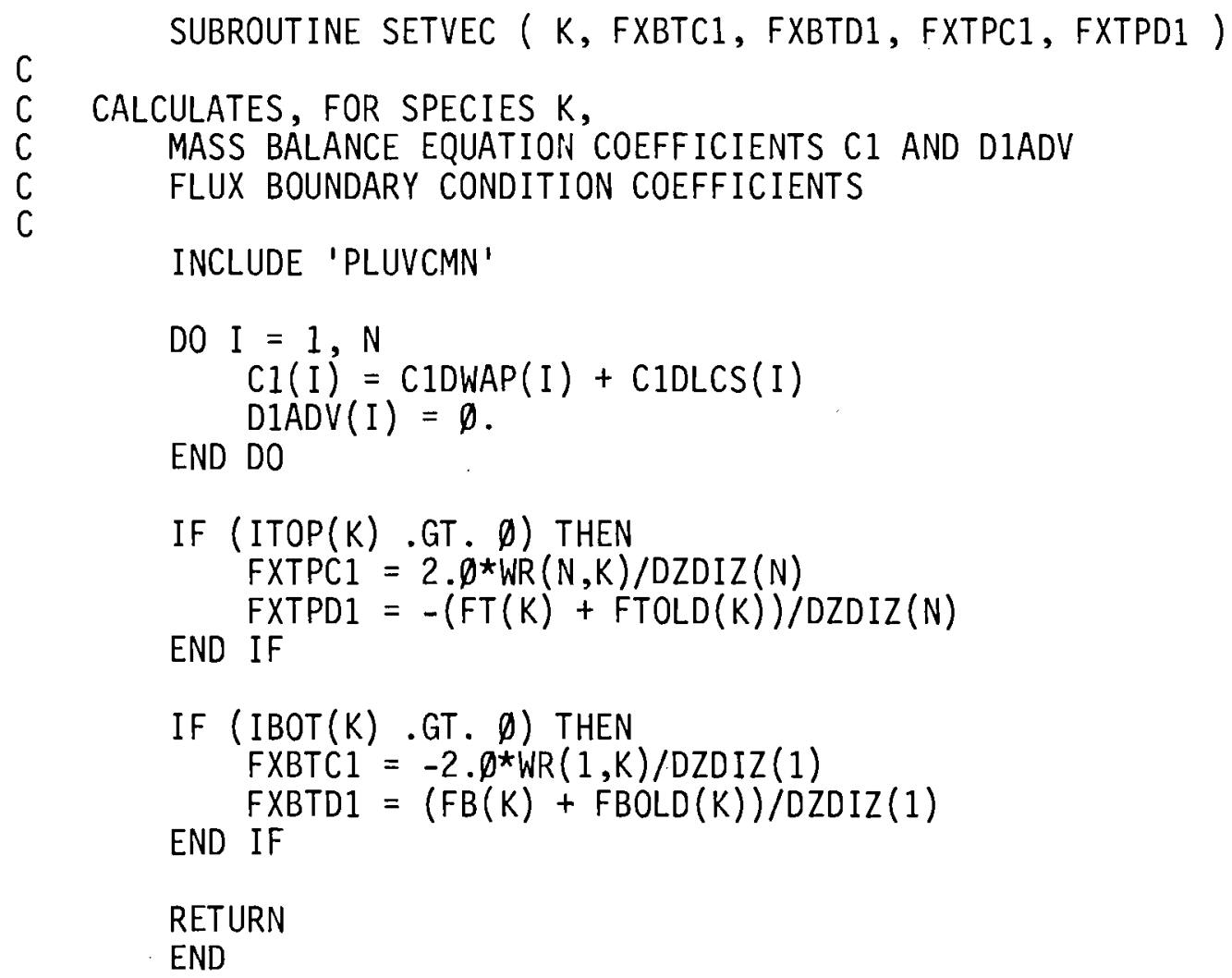


TABLE C-9. Listing of Subroutine TEMPF

SUBROUTINE TEMPF( FXBTC1, FXBTD1, FXTPC1, FXTPD1 )

C

C

THIS SUBROUTINE SHOULD NOT BE USED TO SET INITIAL TEMPERATURE

AND DENSITY VALUES. THEY SHOULD BE INITIALLY SET IN

EITHER 'PRESSF' OR 'SETUP'

THE 'GEN' SUBROUTINE SHOULD SET

GGEN (KTEMP) $=$ HDOTL $/$ CPCSPS (I)

HDOTL IS A LATENT HEATING TERM, AND IS DEFINED IN THE PLUVIUS MOD-5

USER'S MANUAL. ITS DIMENSIONS ARE (ERG/CM**3/SEC)

INCLUDE 'PLUVCMN'

DIMENSION GAMMAW(NZMAX), PSI1(NZMAX), GCPSI (NZMAX)

EQUIVALENCE (GAMMAW $(1), \operatorname{AMAT}(1,1,1)$ )

EQUIVALENCE (PSI1(1), $\operatorname{BMAT}(1,1,1)$ )

EQUIVALENCE $(\operatorname{GCPSI}(1), \operatorname{CMAT}(1,1,1))$

DATA GAMMAD/-9.76E-5/ ! DRY ADIABATIC LAPSE RATE (DEG K/CM)

DATA CP/2.91E8/

DATA R/8.314E7/

! AIR HEAT CAPACITY, CONSTANT PRESSURE (ERG/MOLE/DEG K)

DATA HLC/4.5E11/

! GAS CONSTANT (ERG/MOLE/DEG K)

! LATENT HEAT OF CONDENSATION (ERG/MOLE WATER)

DATA CPCSPS/ NZMAX*1.2E4 / ! TO AVOID DIVIDE BY ZERO IN GEN

DETERMINE SATURATION, AND COMPUTE GAMMAW AND PSI1

$L=\operatorname{LDIF}(K T E M P)$

DO I $=1, N$

TEMPK $=\operatorname{COLD}(\mathrm{I}, \mathrm{KTEMP})$

CS(I) $=$ RHOAIR( PRESS(I), TEMPK ) 


$$
\begin{aligned}
& \operatorname{ISSAT}(\mathrm{I})=\emptyset \\
& \operatorname{CPCSPS}(\mathrm{I})=\operatorname{CP} \operatorname{CS}(\mathrm{I})
\end{aligned}
$$

C

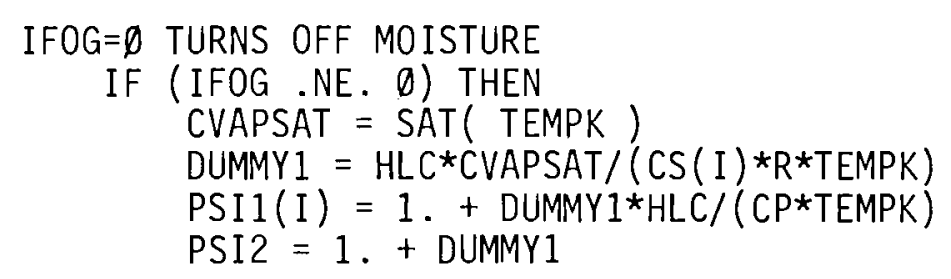

C

GAMMAW IS MOIST ADIABATIC LAPSE RATE

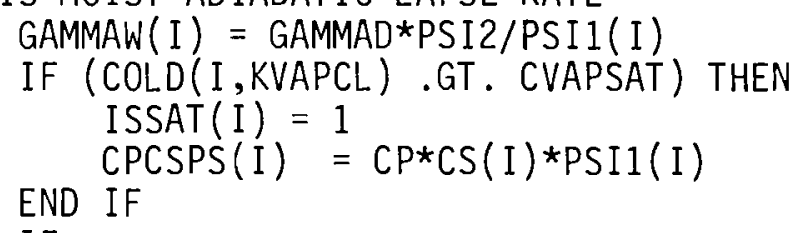

END DO

$c$
$c$
$c$

FOR DEgENERATE GRID CASE, EXIT hERE

IF (N .LE. 3) RETURN

$c$
$C$
$C$

CAlCulate Ci and DIADV

DO $I=1, N$

$\mathrm{CI}(\mathrm{I})=\operatorname{CIDWAP}(\mathrm{I})$

IF (ISSAT(I) . EQ. Ø) THEN

$\operatorname{GCPSI}(\mathrm{I})=\operatorname{CPCSPS}(\mathrm{I}) * \operatorname{GAMMAD}$

ELSE

$\operatorname{DIADV}(I)=($ WAGRID $(I)+\operatorname{WAP}(I)) *$ GAMMAD

$\operatorname{GCPSI}(\mathrm{I})=\operatorname{CPCSPS}(\mathrm{I}) * \operatorname{GAMMAW}(\mathrm{I})$

END IF

$\operatorname{DIADV}(I)=($ WAGRID $(I)+W A P(I)) * \operatorname{GAMMAW}(\mathrm{I})$

END DO

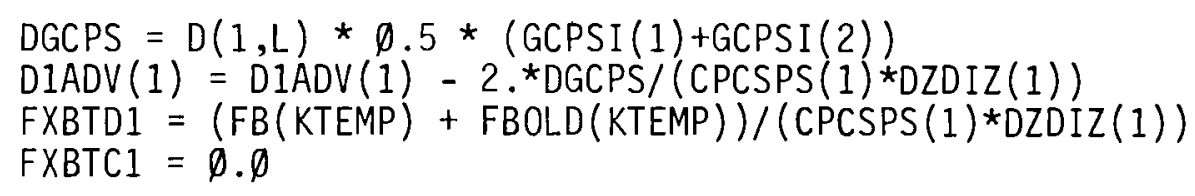




\section{TABLE C-9 Continued}

$\mathrm{DO} I=2, \mathrm{NM} 1$

DGCPSO = DGCPS

$\mathrm{DGCPS}=\mathrm{D}(\mathrm{I}, \mathrm{L}) * \emptyset .5 *(\mathrm{GCPSI}(\mathrm{I})+\mathrm{GCPSI}(\mathrm{I}+1))$

END DO

$\operatorname{DIADV}(\mathrm{I})=\operatorname{D1ADV}(\mathrm{I})-(\mathrm{DGCPS}-\operatorname{DGCPSO}) /(\operatorname{CPCSPS}(\mathrm{I}) \star \operatorname{DZDIZ}(\mathrm{I}))$

$\operatorname{D1ADV}(N)=\operatorname{D1ADV}(N)+2 . \star \operatorname{DGCPS} /(\operatorname{CPCSPS}(N) \star \operatorname{DZDIZ}(N))$

FXTPD1 $=-($ FT $($ KTEMP $)+F T O L D(K T E M P)) /(\operatorname{CPCSPS}(N) \star D Z D I Z(N))$

FXTPC1 $=\emptyset . \emptyset$

CALCULATE ADIFFU, BDIFFU, AND CDIFFU (SIMILAR TO CODE IN DERIV)

DUMOLD $=\emptyset$.

DO I $=1, \mathrm{NM} 1$

$\operatorname{CSPSDZ}=\operatorname{CPCSPS}(\mathrm{I}) * \operatorname{DZDIZ}(\mathrm{I})$

DUM $=D(I, L) * \emptyset .5 *(\operatorname{CPCSPS}(I+1)+\operatorname{CPCSPS}(I)) /(Z(I+1)-Z(I))$

$\operatorname{ADIFFU}(I, L)=$ DUMOLD $/ C S P S D Z$

$\operatorname{CDIFFU}(\mathrm{I}, \mathrm{L})=\operatorname{DUM} / \mathrm{CSPSDZ}$

$\operatorname{BDIFFU}(I, L)=-(\operatorname{ADIFFU}(I, L)+\operatorname{CDIFFU}(I, L))$

DUMOLD = DUM

END DO

$\operatorname{ADIFFU}(N, L)=2 \cdot{ }^{\circ} \operatorname{DUMOLD} /(\operatorname{CPCSPS}(N) \star \operatorname{DZDIZ}(N))$

$\operatorname{BDIFFU}(N, L)=-\operatorname{ADIFFU}(N, L)$

$\operatorname{CDIFFU}(N, L)=\emptyset$.

$\operatorname{CDIFFU}(1, L)=2 . \star \operatorname{CDIFFU}(1, L)$

$\operatorname{BDIFFU}(1, L)=-\operatorname{CDIfFU}(1, \mathrm{~L})$

RETURN

END 
TABLE C-10. Listing of Subroutine TRIDG2

SUBROUTINE TRIDG2（JLO, JHI, AMAT, BMAT, CMAT, DVEC, UVEC )

ROUT INE FOR SOLVING A SYSTEM OF PAIRED SIMULTANEOUS LINEAR EQUATIONS WITH A TRIDIAGONAL COEFFICIENT MATRIX USING THOMAS'S ALGORITHM

IN THIS CASE, EACH UNKNOWN IS A 2 ELEMENT VECTOR, AND EACH ELEMENT OF COEFF ICIENT MATRIX IS ITSELF A 2 BY 2 MATRIX

INPUTS :

AMAT - AMAT(I) IS THE SUB-DIAGONAL ELEMENT OF ROW I OF THE COEFFICIENT MATRIX

BMAT - BMAT(I) IS THE DIAGONAL ELEMENT OF ROW I OF THE COEFFICIENT MATRIX

CMAT - CMAT(I) IS THE SUPER-DIAGONAL ELEMENT OF ROW I OF THE COEFFICIENT MATRIX

DVEC - DVEC(I) IS THE RIGHT-HAND SIDE ELEMENT OF THE I-TH EQUATION

JLO, JHI - ONLY THE EQUATIONS NUMBERED JLO THRU JHI INCLUSIVE ARE SOLVED (I.E., ROWS JLO THRU JHI OF THE MATRIX)

OUTPUT:

UVEC - UVEC(I) IS THE I-TH ELEMENT OF THE SOLUTION VECTOR

ROUTINE DOES NOT CHECK THAT SYSTEM IS NON-SINGULAR, SO WILL FAIL (DIVIDE BY ZERO) IF IT IS

DIMENSION AMAT $(2,2, \mathrm{JHI}), \operatorname{BMAT}(2,2, \mathrm{JHI}), \operatorname{CMAT}(2,2, \mathrm{JHI})$

DIMENSION DVEC $(2, \mathrm{JHI}), \operatorname{UVEC}(2, \mathrm{JHI})$

DIMENSION XMAT $(2,2), \operatorname{YMAT}(2,2), \operatorname{ZMAT}(2,2), \operatorname{XVEC}(2), \operatorname{VVEC}(2)$

$C$
$C$
$C$
$C$
$C$
$C$
$C$
$C$
$C$
$C$
$C$

FORWARD PASS - REDUCE THE SYSTEM BY ELIMINATING THE SUB-DIAGONAL ELEMENTS. IN THE REDUCED SYSTEM, THE NEW DIAGONAL ELEMENTS ARE UNITY

THE NEW SUPER-DIAGONAL ELEMENTS ARE IN AMAT (WHOSE CONTENTS ARE THUS DESTROYED)

THE NEW RIGHT-HAND SIDE IS IN DVEC (THUS DESTROYED ALSO)

IF IT IS DESIRED NOT TO DESTROY THE AMAT AND DVEC ELEMENTS, THE ROUTINE CAN BE WRITTEN USING TWO ADDITIONAL WORKING

ARRAYS: $\operatorname{EMAT}(2,2, \mathrm{JHI})$ AND $\operatorname{FVEC}(2, \mathrm{JHI})$

DO $\mathrm{J}=\mathrm{JLO}, \mathrm{JHI}$

$\mathrm{JM}=\mathrm{J}-1$

IF (J.EQ.JLO) THEN

$\operatorname{XMAT}(1,1)=\emptyset$.

$\operatorname{XMAT}(1,2)=\emptyset$.

$\operatorname{XMAT}(2,1)=\emptyset$.

$\operatorname{XMAT}(2,2)=\emptyset$.

$\operatorname{XVEC}(1)=\emptyset$.

$\operatorname{XVEC}(2)=\emptyset$. 


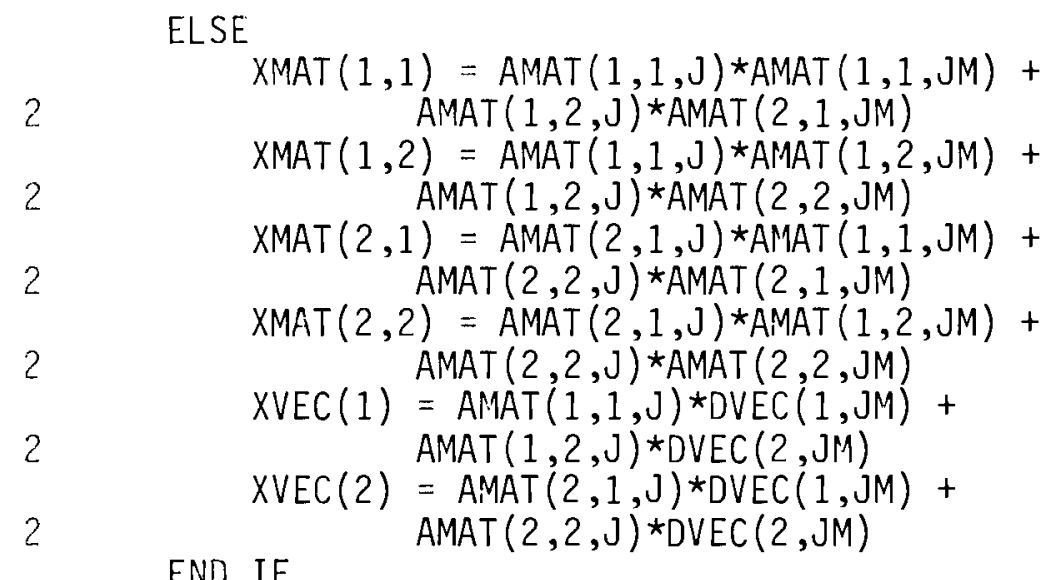

END IF

$$
\begin{aligned}
& \operatorname{YMAT}(1,1)=\operatorname{BMAT}(1,1, \mathrm{~J})-\mathrm{XMAT}(1,1) \\
& \operatorname{YMAT}(1,2)=\operatorname{BMAT}(1,2, \mathrm{~J})-X \operatorname{XMAT}(1,2) \\
& \operatorname{YMAT}(2,1)=\operatorname{BMAT}(2,1, \mathrm{~J})-\operatorname{XMAT}(2,1) \\
& \operatorname{YMAT}(2,2)=\operatorname{BMAT}(2,2, \mathrm{~J})-\operatorname{XMAT}(2,2) \\
& \text { DET }=\operatorname{YMAT}(1,1) * Y M A T(2,2)-\operatorname{YMAT}(1,2) * Y M A T(2,1) \\
& \operatorname{ZMAT}(1,1)=\operatorname{YMAT}(2,2) / \text { DET } \\
& \operatorname{ZMAT}(1,2)=-Y M A T(1,2) / D E T \\
& \operatorname{ZMAT}(2,1)=-\operatorname{YMAT}(2,1) / D E T \\
& \operatorname{ZMAT}(2,2)=\operatorname{YMAT}(1,1) / D E T
\end{aligned}
$$

$$
\begin{aligned}
& \operatorname{AMAT}(1,1, \mathrm{~J})=\operatorname{ZMAT}(1,1) * \operatorname{CMAT}(1,1, \mathrm{~J})+Z \mathrm{ZMAT}(1,2) * \operatorname{CMAT}(2,1, \mathrm{~J}) \\
& \operatorname{AMAT}(1,2, \mathrm{~J})=\mathrm{ZMAT}(1,1) * \operatorname{CMAT}(1,2, \mathrm{~J})+\operatorname{ZMAT}(1,2) * \operatorname{CMAT}(2,2, \mathrm{~J}) \\
& \operatorname{AMAT}(2,1, \mathrm{~J})=\mathrm{ZMAT}(2,1) * \operatorname{CMAT}(1,1, \mathrm{~J})+\mathrm{ZMAT}(2,2) * \operatorname{CMAT}(2,1, \mathrm{~J}) \\
& \operatorname{AMAT}(2,2, \mathrm{~J})=\operatorname{ZMAT}(2,1) * \operatorname{CMAT}(1,2, \mathrm{~J})+\operatorname{ZMAT}(2,2) * \operatorname{CMAT}(2,2, \mathrm{~J}) \\
& \operatorname{VVEC}(1)=\operatorname{DVEC}(1, \mathrm{~J})-\operatorname{XVEC}(1) \\
& \operatorname{VVEC}(2)=\operatorname{DVEC}(2, \mathrm{~J})-\operatorname{XVEC}(2) \\
& \text { END DO } \\
& \operatorname{DVEC}(1, \mathrm{~J})=\operatorname{ZMAT}(1,1) * \operatorname{VVEC}(1)+\operatorname{ZMAT}(1,2) * \operatorname{VVEC}(2) \\
& \operatorname{DVEC}(2, \mathrm{~J})=\operatorname{ZMAT}(2,1) * Y \operatorname{VEC}(1)+\operatorname{ZMAT}(2,2) * \operatorname{YVEC}(2)
\end{aligned}
$$

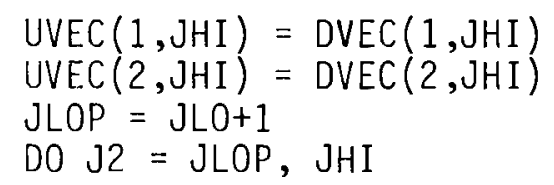


IABLE C-11. Listing of Subroutine TRIDAG

SUBROUTINE TRIDAG ( JLO, JHI, AA, BB, CC, DD, VV )

ROUTINE FOR SOLVING A SYSTEM OF SIMULTANEOUS LINEAR EQUATIONS WITH

A TRIDIAGONAL COEFFICIENT MATRIX USING THOMAS'S ALGORITHM

INPUTS:

AA - AA(I) IS THE SUB-DIAGONAL ELEMENT OF ROW I OF THE COEFFICIENT MATPIX

$B B$ - BB(I) IS THE DIAGONAL ELEMENT OF ROW I OF THE COEFFICIENT MATRIX

CC - CC(I) IS THE SUPER-DIAGONAL ELEMENT OF ROW I OF THE COEFFICIENT MATRIX

DD - DD(I) IS THE RIGHT-HAND SIDE ELEMENT OF THE I-TH EQUATION

JLO, JHI - ONLY THE EQUATIONS NUMBERED JLO THRU JHI INCLUSIVE ARE SOLVED (I.E., ROWS JLO THRU JHI OF THE MATRIX)

OUTPUT:

VV - VV(I) IS THE I-TH ELEMENT OF THE SOLUTION VECTOR

ROUTINE DOES NOT CHECK THAT SYSTEM IS NON-SINGULAR, SO WILL FAIL (DIVIDE BY ZERO) IF IT IS

RIGHT-HAND-SIDE VECTOR ( DD ) IS DESTROYED

DIMENSION AA(JHI), BB(JHI), CC(JHI), DD(JHI), VV(JHI)

FORWARD PASS - ELIMINATE SUB-DIAGONAL ELEMENTS AND NORMALIZE DIAGONAL ELEMENTS

NEW SUPER-DIAGONAL ELEMENTS HELD IN VV

NEW RIGHT-HAND-SIDE ELEMENTS HELD IN DD

$\mathrm{DD}(\mathrm{JLO})=\mathrm{DD}(\mathrm{JLO}) / \mathrm{BB}(\mathrm{JLO})$

$B E T A=B B(J L O)$

$\mathrm{JLOP1}=\mathrm{JLO}+1$

DO I = JLOP1, JHI

$V V(I-1)=C C(I-1) / B E T A$

$B E T A=B B(I)-A A(I) * V V(I-1)$

END DO

$D D(I)=(D D(I)-A A(I) * D D(I-1)) / B E T A$

${ }_{C}^{C}$

BACKWARD PASS - SOLVE BY REVERSE SUBSTITUTION

$\mathrm{VV}(\mathrm{JHI})=\mathrm{DD}(\mathrm{JHI})$

DO IDUM $=$ JLOP1, JHI

$\mathrm{I}=\mathrm{JHI}+\mathrm{JLO}-\mathrm{IDUM}$

END DO

$V W(I)=D D(I)-V V(I) * V V(I+I)$

RETURN

END 


\section{TABLE C-19 Continued}

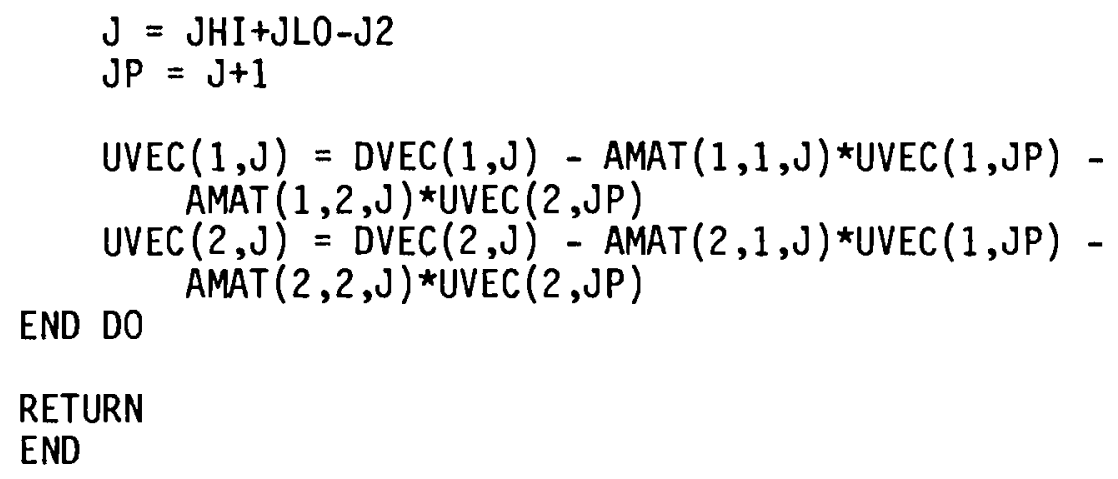

RETURN

END 
TABLE C-12. Listing of Subroutine ZERODM

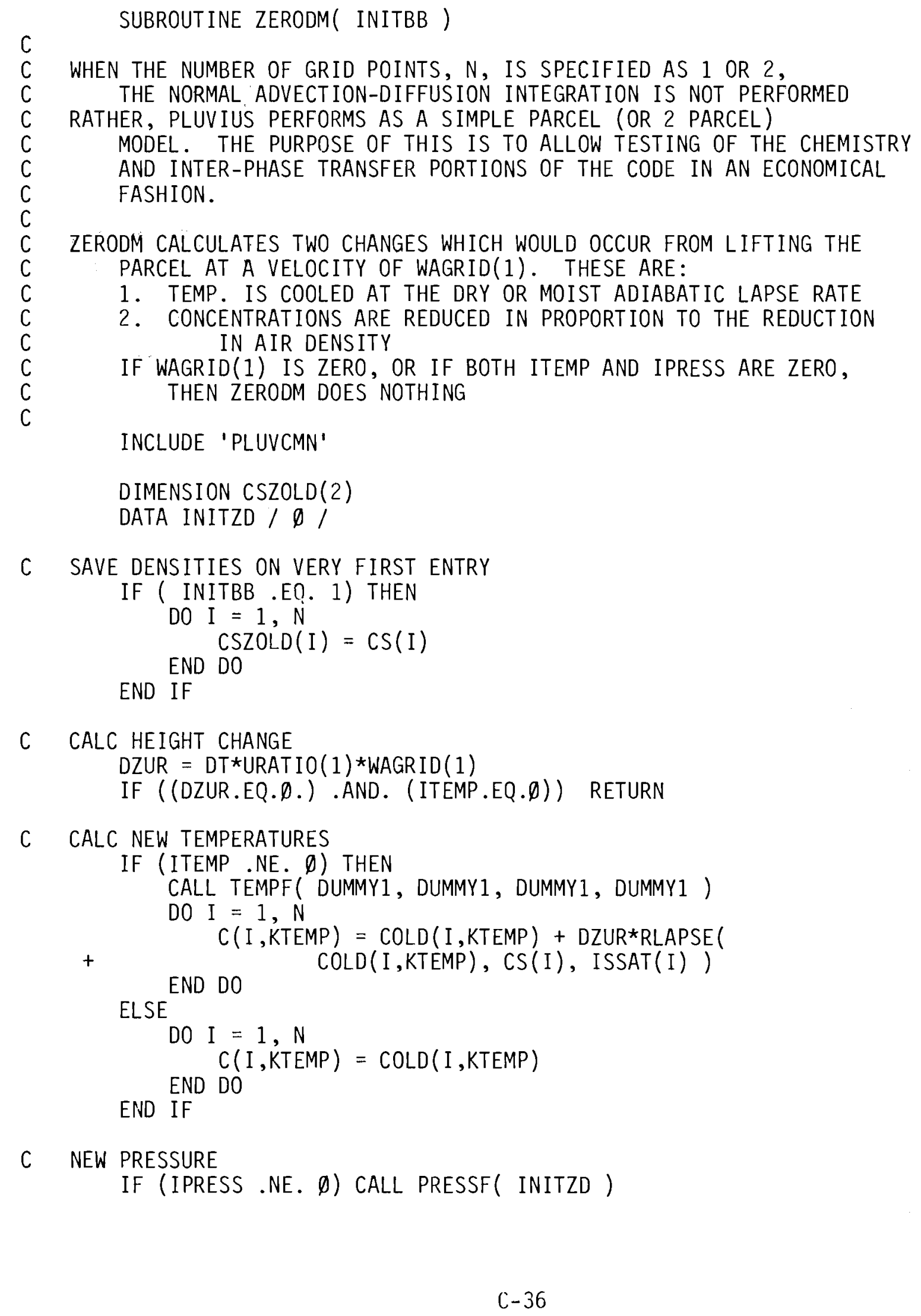




\section{TABLE C-12 Continued}

C NEW DENSITIES, AND CHANGES TO SPECIES CONCENTRATIONS

DO $\mathrm{I}=1, \mathrm{~N}$

$\mathrm{CS}(\mathrm{I})=$ RHOAIR( PRESS(I), C(I, KTEMP ) $)$

RATIOCS $=$ CS $(I) / C S Z O L D(I)$

DO $K=1$, NCOMP

END DO

IF (K .NE. KTEMP) $C(I, K)=\operatorname{RATIOCS} * \operatorname{COLD}(I, K)$

END DO

$\operatorname{CSZOLD}(I)=\operatorname{CS}(I)$

RETURN

END 
TABLE C-13. Listing of Subroutine PRESSF

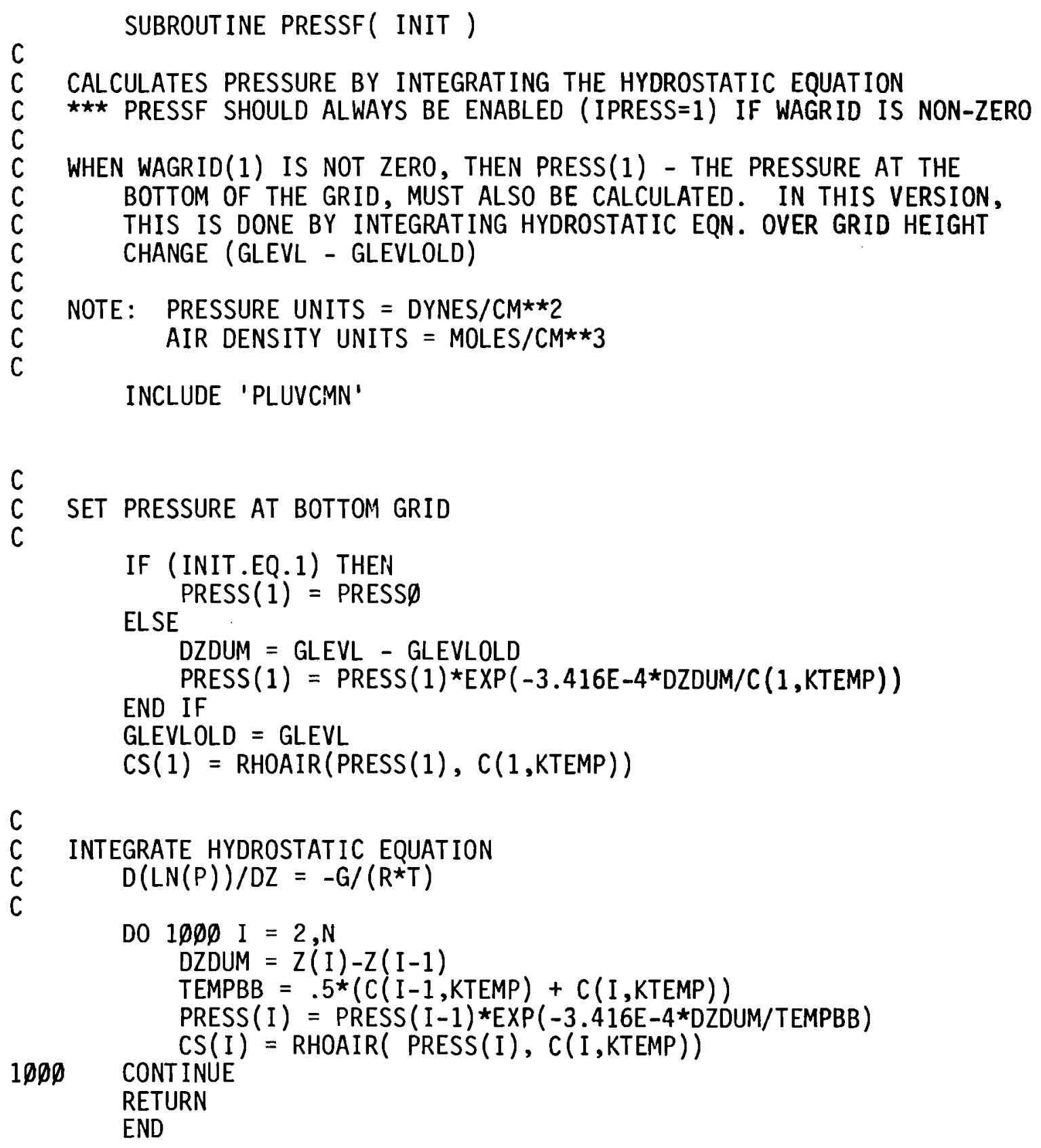


TABLE C-14. Listing of Function RHOAIR

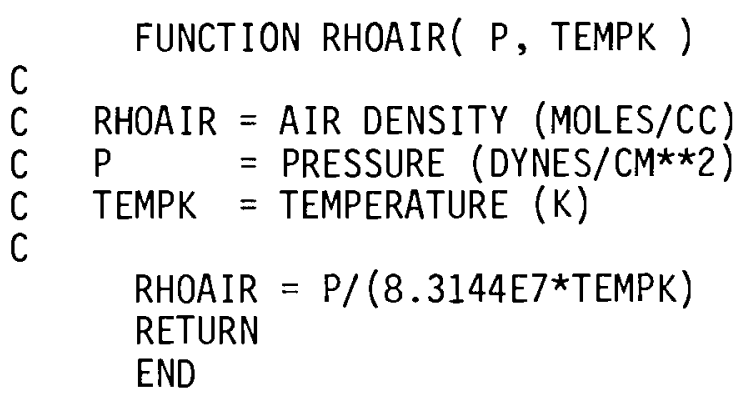

TABLE C-15. Listing of Function RLAPSE

$c$
$c$
$c$
$c$
$c$
$c$
$c$
$c$
$c$
$c$

FUNCTION RLAPSE ( TEMPK, RHOA, JFOG )

RLAPSE = LAPSE RATE $(1 /$ CM $)$

ADIABAT IC IF JFOG $=\emptyset$

PSEUDOADIABAT IC OTHERWISE

TEMPK $=$ TEMP $(K)$

RHOA = AIR DENSITY (MOLES/CC)

THERMODYNAMIC UNITS ARE CGS (CONSTANTS USE MOLES)

THE SAT FUNCTION MUST RETURN THE SATURATION VAPOR

DENSITY (MOLES/CC) AT TEMP TEMPK

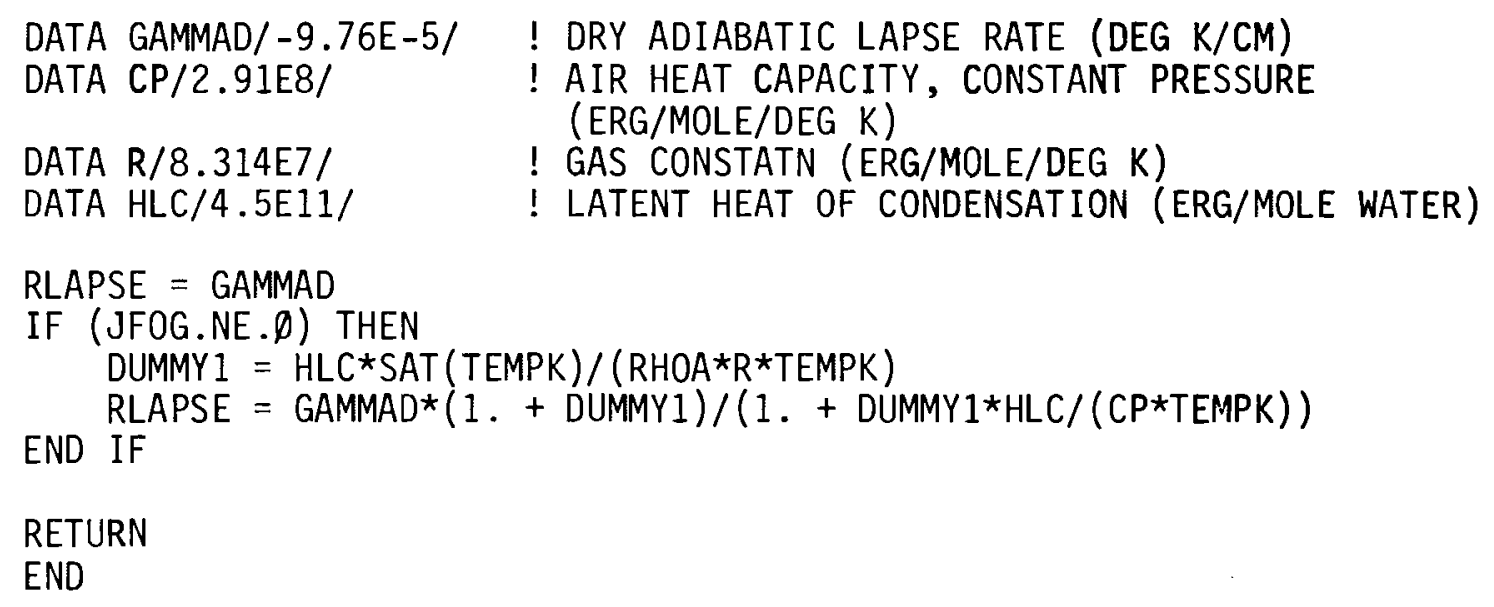




\section{TABLE C-16. Listing of Function SAT}

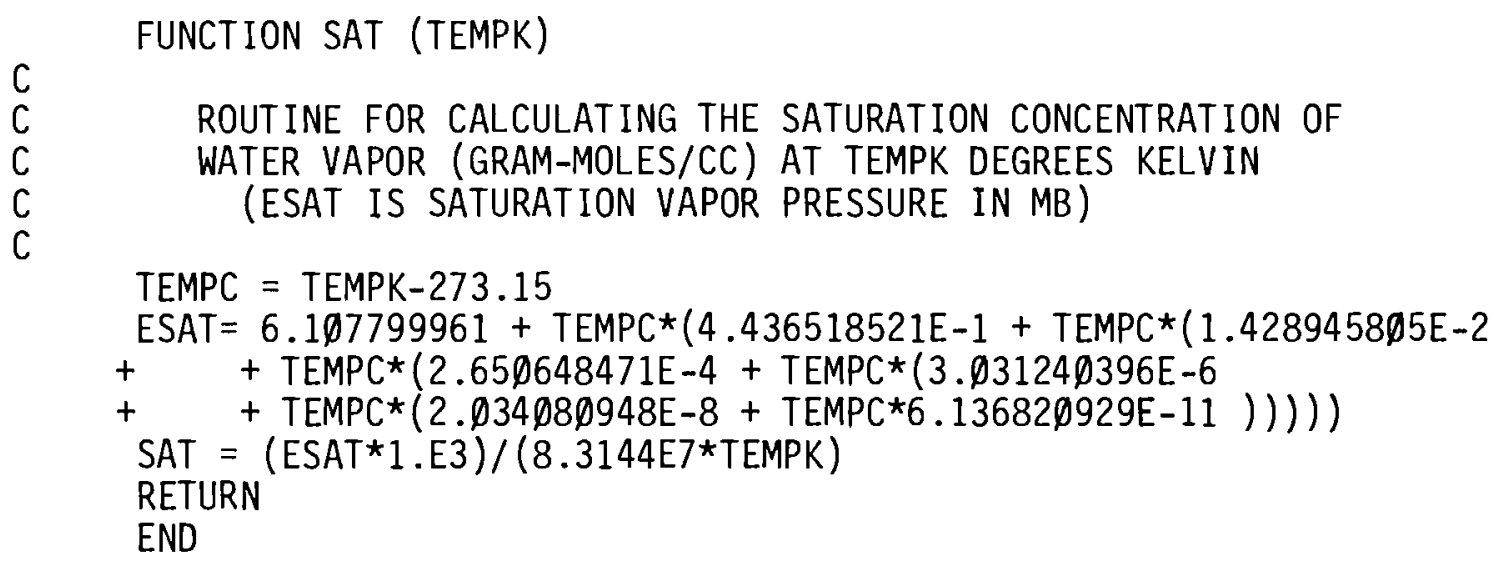




\section{TABLE C-17. Listing of Subroutine COLLECT}

SUBROUTINE COLLECT ( INIT, ITCOLL, DTCOLL )

ROUTINE DOES OUTPUT TO DISK FILE FOR POST-PROCESSING

PARAMETERS ARE OUTPUT AT TIME INTERVALS $=$ DTCOLL

ITCOLL $>\emptyset$ - MODEL OUTPUT IS TIME AVERAGED OVER THE INTERVAL

ITCOLL $<\emptyset$ - NO AVERAGING

FOR ITCOLL $>\emptyset$, INITIAL CONCENTRATION FIELD IS OUTPUT, THEN

FIRST SMOOTHED OUTPUT IS FROM (TSTART $+.5 *$ DTCOLL) TO

$($ TSTART $+1.5 *$ DTCOLL $)$

ROUTINE WILL NOT FUNCTION UNLESS DTCOLL > $1 . E-5$

INCLUDE 'PLUVCMN'

PARAMETER (LUNCOL $=8$ )

PARAMETER (NCSUMMX $=$ NZMAX ${ }^{*}$ NCTMAX)

DIMENSION CSUM(NZMAX, NCTMAX)

DATA DTSUM, IEND / $\emptyset ., \emptyset$ /

DATA CSUM / NCSUMMX $\bullet$. /

IF (DTCOLL.LE.1.E-5) RETURN

$c$

INITIAL ENTRY - WRITE "HEADING" INFO. TO FILE

IF (INIT .EQ. 1) THEN

WRITE(LUNCOL) N, NTOT+2, DTCOLL

WRITE (LUNCOL) ( $(\mathrm{I}), \mathrm{I}=1, \mathrm{~N})$

WRITE (LUNCOL) MTITLE

WRITE (LUNCOL) ( $(\operatorname{NAME}(I, K), I=1,5), K=1, N T O T+2)$

WRITE(LUNCOL) TCLOCK, ( $(\mathrm{I}(\mathrm{I}, \mathrm{K}), \mathrm{I}=1, \mathrm{~N}), \mathrm{K}=1, \mathrm{NTOT})$,

$+\quad(\operatorname{PRESS}(\mathrm{I}), I=1, N),(\mathrm{CS}(\mathrm{I}), I=1, N), \mathrm{GLEVL}$

IF (ITCOLL .GT. $\emptyset$ ) THEN

TAVEAA $=$ TCLOCK $+.5 *$ DTCOLL

TAVEZZ = TAVEAA + DTCOLL

TCONTZ = TAVEAA

ELSE

END IF

TAVEZZ = DTCOLL - .๑1*DT

END IF

RETURN
IF

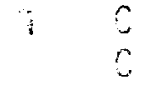

NORMAL ENTRY - NO AVERAGING 
c

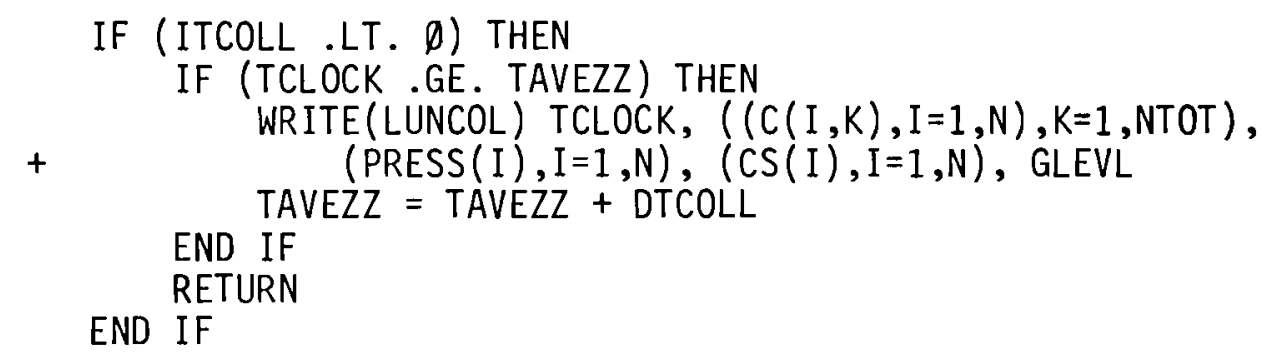

C

C ADD CONTRIBUTION OF CURRENT VALUES TO "RUNNING SUM" IN CSUM

C

IF (TCLKAA .GT. TAVEAA) THEN TCONTA = TCLKAA

ELSE

TCONTA $=$ TAVEAA

END IF

IF (TCLKZZ .LT. TAVEZZ) THEN

ELSE

TCONTZ $=$ TCLKZZ

END IF

TCONTZ $=$ TAVEZZ

DTCONT $=$ TCONTZ - TCONTA

DTSUM $=$ DTSUM + DTCONT

DO $K=1$, NTOT

DO I $=1, N$ END DO

$\operatorname{CSUM}(\mathrm{I}, \mathrm{K})=\operatorname{CSUM}(\mathrm{I}, \mathrm{K})+\operatorname{DTCONT}{ }^{*} \mathrm{C}(\mathrm{I}, \mathrm{K})$

END DO

C CHECK IF AVERAGING COMPLETE OVER PRESENT INTERVAL (TAVEAA TO TAVEZZ)

C IF NOT, RETURN. OTHERWISE, OUTPUT AVERAGED VALUES 


\section{TABLE C-17 Continued}

C

IF (TCLKZZ .LT. TAVEZZ) RETURN

$4 \emptyset \emptyset \emptyset$ IF (DTSUM .LE. 1.E-5) RETURN

DO $\mathrm{K}=1$, NTOT

DO $\mathrm{I}=1, \mathrm{~N}$

$\operatorname{CSUM}(I, K)=\operatorname{CSUM}(I, K) / D T S U M$

END DO

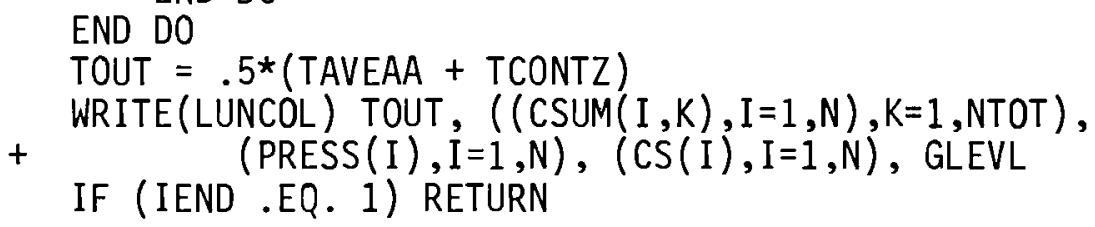

- $\mathrm{C}$

C NOW PREPARE FOR NEW AVERAGING INTERVAL

C

TAVEAA $=$ TAVEZZ

TAVEZZ = TAVEZZ + DTCOLL

TCONTZ = TAVEAA

DTSUM $=\emptyset$.

DO $K=1$, NTOT

DO $\mathrm{I}=1, \mathrm{~N}$

END DO

$\operatorname{CSUM}(I, K)=\emptyset$.

END DO

GO TO 1000

END 
TABLE C-18. Listing of Subroutine PRINT

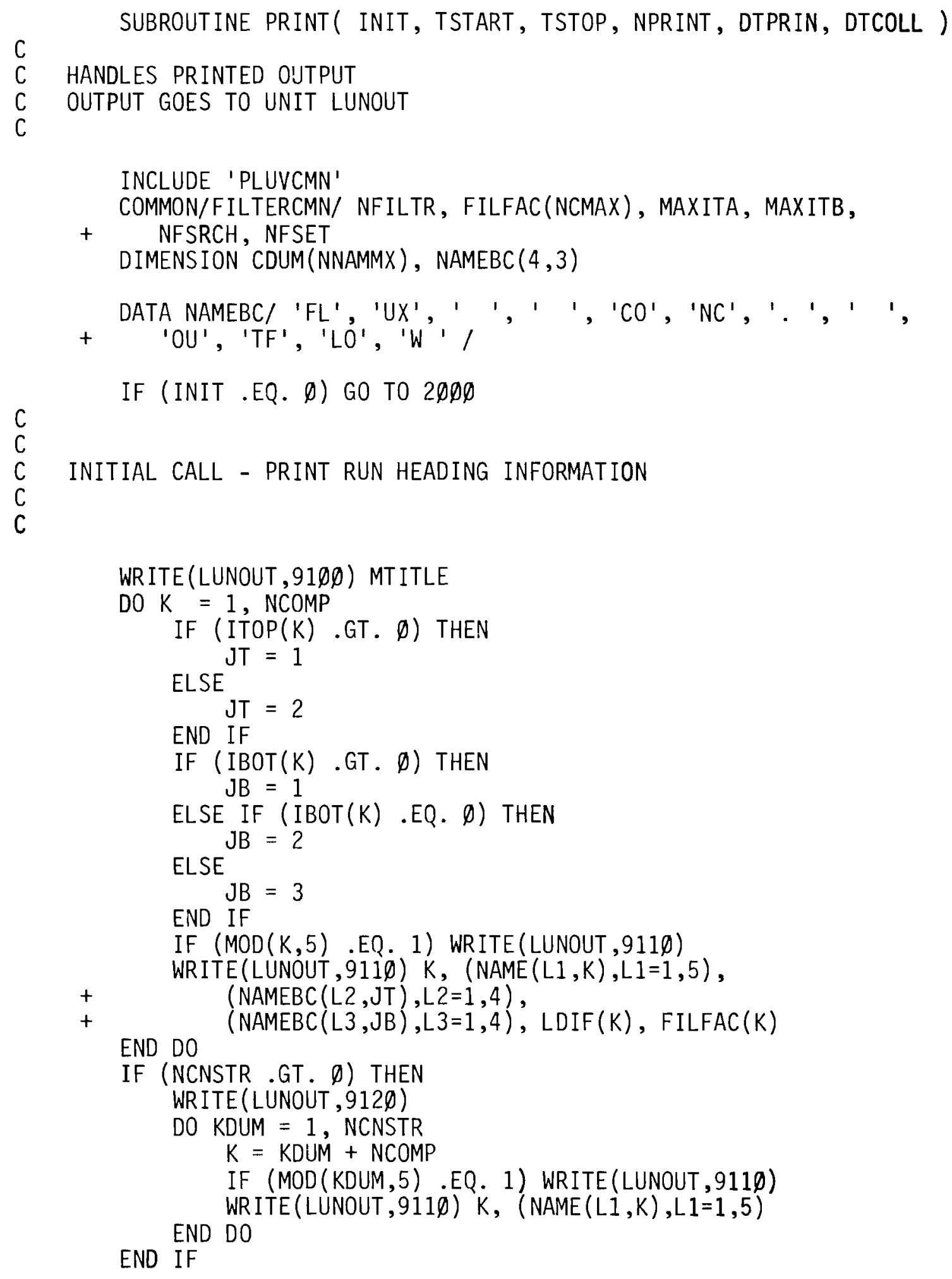




\section{TABLE C-18 Continued}

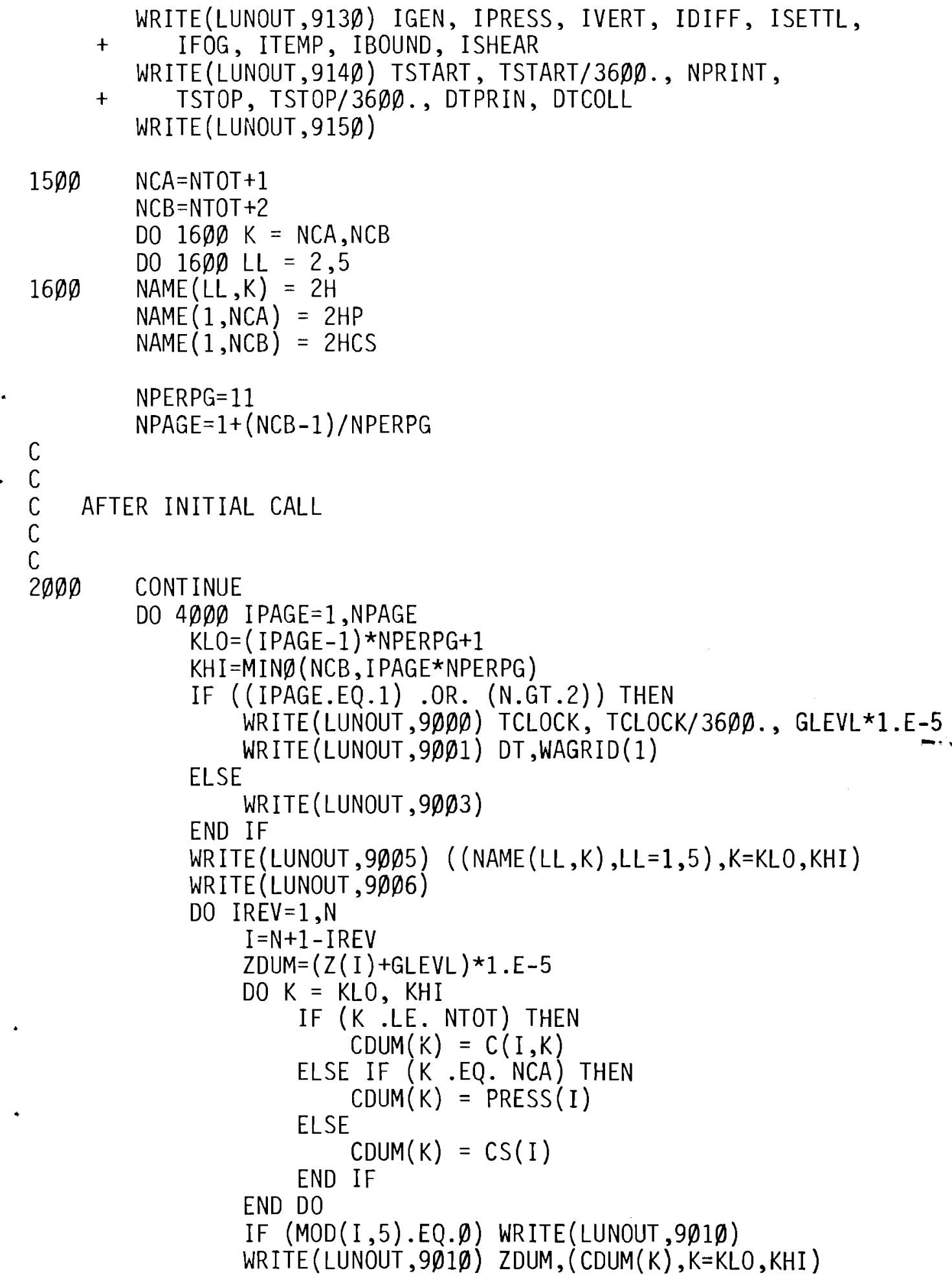




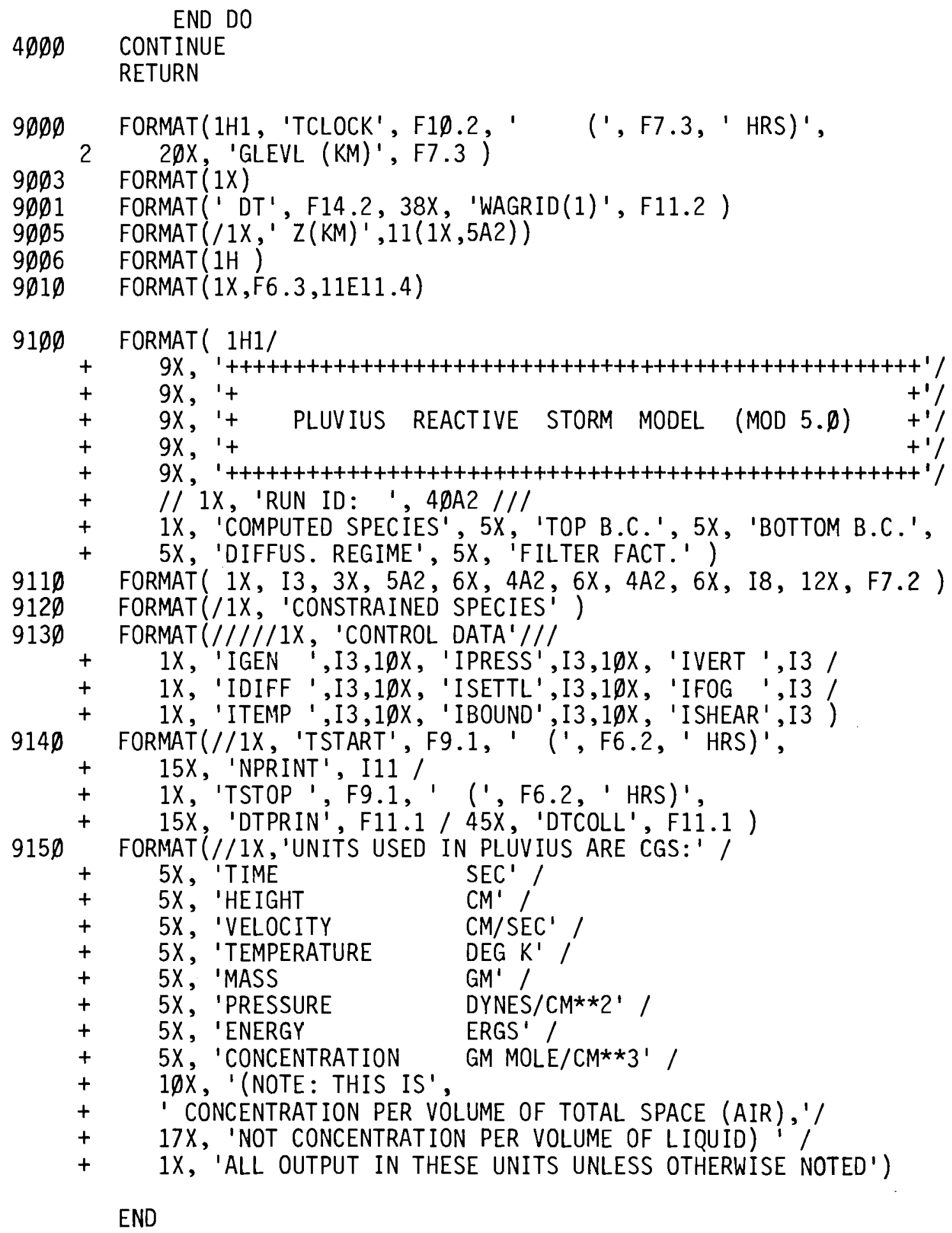


Table C-19 provides a description of PLUVIUS variables and parameters which the user may have occasion to use, and all global variables (regardless of utility). This table does not include all of the internal variables used in the code, nor does it include variables from the Class I subroutines of Examples 1 and 2. These variables are either self-documented within the code iistings or described in Sections 4 and 5 , respectively.

Arrays are shown in the table with appropriate index variables. The index variable $I$ refers to vertical grid position; $K$ refers to species number; and L refers to diffusion regime. $\mathrm{Jl}$ and $\mathrm{J} 2$ refer to "other" indices; most arrays shown with these indices are used in the solution of the advection-diffusion component and should not be of interest to the user. Where appropriate, physical units for variables are shown in brackets [ ].

TABLE C-19. Description of PLUVIUS Variables and Parameters

Variable

$\operatorname{ADIFFU}(\mathrm{I}, \mathrm{L})$

AMAT $(\mathrm{Jl}, \mathrm{J} 2, \mathrm{I})$

$\operatorname{BDIFFU}(\mathrm{I}, \mathrm{L})$

BMAT ( J1, J2, L)

C $(I, K)$

$C B(K)$

CDIFFU (, L $)$

CERROR (K)
Description

ADIFF in Eq. (A9). $\left[\mathrm{sec}^{-1}\right]$

$A M$ in Eqs. (Al2) and (A13).

BDIFF in Eq. (A9). $\left[\mathrm{sec}^{-1}\right]$

$B M$ in Eqs. (A12) and (A14).

Dependent variable values (i.e., temperature or species concentration). [K or mole/cc]

Dependent variable value at bottom boundary; $C_{B}$ in Eq. (16) or $T_{B}$ in Eq. (41).

CDIFF in Eq. (A9). $\left[\mathrm{sec}^{-1}\right]$

Values of dependent variables, below which the convergence error criterion is relaxed during integration of the generation components (see Appendix B). [mole/ $\mathrm{Cc}$ or $\mathrm{K}$ ] 
TABLE C-19 Continued

Variable

CMAT $(\mathrm{J} 1, \mathrm{~J} 2, \mathrm{I})$

CMIN (K)

CNN (K)

$\operatorname{COLD}(I, K)$

CPCSPS (I)

CS (I)

CT (K)

C1 (I)

CIDLCS (I)

CIDWAP (I)

$D(I, L)$

DT

DTAU

DTCOLL

DTMAX

\section{Description}

$C M$ in Eqs. (A12) and (A15).

Values of dependent variables, below which they can be considered as insignificant to the overall computation (see Appendix B). [mole/CC or $K$ ]

Working array to hold $C(I, K)$ values at a particular grid I during integration of generation component of mass-balance equations (used in subroutines ODEINT and GEN). [mole/CC or K]

Working array to hold previous $C(I, K)$ values during advection-diffusion integration. [K or mole/cc]

$\left(c^{\star}{ }_{X} C_{p}\right)$ in Eqs. $(34)-(36)$. [erg/cc.K]

Air density. [mole/cc]

Dependent variable value at top boundary; $\hat{\mathrm{C}}_{\mathrm{T}}$ in Eq. (15) or $\hat{\mathrm{T}}_{\mathrm{T}}$ in Eq. (40). [mole/cc or K]

Cl in Eq. $(A 10) \cdot\left[\mathrm{sec}^{-1}\right]$

Second term in right-hand side of Eq. (A10).
$\left[\mathrm{sec}^{-1}\right]$

First term in right-hand side of Eq. (A10). $\left[\mathrm{sec}^{-1}\right]$

Eddy diffusivity. $\left[\mathrm{cm}^{2} / \mathrm{sec}\right]$

Current time-step for advection-diffusion integration. [sec]

Current integration time-step in subroutine ODEINT. Passed as parameter to subroutine GEN. [sec]

Time interval for output of model results to mass storage. [sec]

Parameter passed to subroutine ODEINT, specifying maximum time-step for integration of generation components. [sec] 
- 


\section{TABLE C-19 Continued}

Variable

FT (K)

FTOLD (K)

FXBTC1

FXBTDI

FXTPC1

FXTPD1

$\operatorname{GDEC}(K)$

GGEN ( $K)$

GLEVL

I

IBOT $(K)$

IBOUND

\section{Description}

Vertical flux at top boundasy; $\hat{f}_{\mathrm{T}}$ in Eq. (177) or $\hat{q}_{\top}$ in Eq. (38). [mole/ $/ \mathrm{cm}^{2} \mathrm{sec}^{\mathrm{T}}$ or $\left.\mathrm{erg} / \mathrm{cm}^{2} \mathrm{sec}\right]$

Previous value of $F T(K)$. During an advectiondiffusion integration step, FT refers to time TNEXT and FTOLD refers to time TCLOCK.

The term $\frac{-2 w_{r 1}}{\Delta z_{1}}$ in Eq. (A28), or similar term for temperature case.

The term $\frac{1}{\Delta z_{1}}\left(\hat{f}_{B}^{j}+\hat{f}_{B}^{j+1}\right)$ in Eq. $(A 30)$, or similar term for temperature case.

The term $\frac{2 w_{r n}}{\Delta z_{n}}$ in Eq. (A35), or similar term for temperature case.

The term $-\frac{1}{\Delta z}\left(\hat{f}_{T}^{j}+\hat{f}_{T}^{j+1}\right)$ in Eq. (A36), or similar term for temperature case.

Decay rates [loss or sink terms in right-hand side of Eq. (43) or (45)]. [mole/cc. sec or $\mathrm{K} / \mathrm{sec}]$

Generation rates [source terms in right-hand side of Eq. (43) or (45)]. [mole/cc.sec or $\mathrm{K} / \mathrm{sec}]$

Changing component of grid height. Total grid height $=Z(I)+$ GLEVL. $[\mathrm{cm}]$

Index variable used to specify vertical grid number.

Bottom boundary condition designator for computed species: positive $\rightarrow$ flux specified, zero $\rightarrow$ concentration specified, negative $\rightarrow$ outflow specified.

Bypass control variable for boundary conditions (see Section 3). 
TABLE C-19 Continued

Variable

IDIFF

IEXP

IFOG

IGCALC

IGEN

INIT

IN ITBB

IPRESS

ISETTL

ISHEAR

ISLDER

ISSAT (I)
Description

Bypass control variable for eddy diffusivity (see Section 3).

Flag specifying stiff integration method in subroutine ODEINT (see Appendix B).

Bypass control variable for water condensation (see Section 3).

Parameter passed to subroutine GEN, specifying either that only constrained variables need be calculated (IGCALC $=0$ ), or that GGEN and GDEC are also required $($ IGCALC $=1)$.

Bypass control variable for physico-chemical transformation (see Section 3).

Initialization flag. INIT $=1$ during initialization. INIT $=0$ once integration of equations has begun.

Secondary initialization flag. INITBB is initially 1 and is set to 0 after first calls of ADVINT and CHMINT.

Bypass control variable for pressure (see Section 3).

Bypass control variable for settling velocity (see Section 3).

Bypass control variable for horizontal wind shear (see Section 3).

Parameter passed to subroutine ADVINT. Acts as a bypass variable for subroutine DERIV. DERIV is bypassed when IDIFF, IVERT, ITEMP, and IPRESS are all zero.

Flag specifying whether advection-diffusion component of energy-balance equation is being treated as unsaturated (ISSAT $=0$ ) or saturated $($ ISSAT $=1)$ during current major computation loop. 
TABLE C-19 Continued

Variable

ITCOLL

ITEMP

$\operatorname{ITOP}(K)$

IVERT

JPASSO

K

KTEMP

KVAPCL

$\mathrm{L}$

$\operatorname{LDIF}(K)$

LTD

LUNCOL

LUNIN

LUNOUT

\section{Description}

Specifies output mode to mass storage:

zero $\rightarrow$ no output, negative $\rightarrow$ unaveraged output

every DTCOLL secs, positive $\rightarrow$ averaged output

every DTCOLL Secs.

Bypass control variable for temperature (energy balance equation) (See Section 3 ).

Top boundary condition designator for comruted species: positive $\rightarrow$ flux specified, zero or negative $\rightarrow$ concentration specified.

Bypass control variable for vertical air velocity (see Section 3 ).

Parameter passed to subroutine GEN. When GEN is called from ODEINT, JPASSO $=1$ during the predictor pass and JPASSO $=2,3, \ldots$, on successive corrector passes. When GEN is called from PLUVIUS (before printed outout). JPASSO $=1$.

Index variable used to specify species number.

Species location variable for temperature.

Always required.

Species location variable for water-vapor + cloud water variable. Required when IFOG $=1$ (see Section 3).

Index variable used to specify "diffusion regime."

Diffusion regime of each species.

Total number of "diffusion regimes" for a run.

Parameter specifying logical unit number for output to mass storage (from subroutine COLLECT).

Parameter specifying logical unit number for input.

Parameter specifying logical unit number for printed output (from subroutine PRINT). 
TABLE C-19 Cont inued

Variable

MAXITA

MAXITB

MT ITLE

N

NAMES $(\mathrm{J} 1, \mathrm{~K})$

NCMAX

NCNSTR

NCOMP

NCORR

NCTMAX

NFILTR

NFSET

NFSRCH
Description

Affects filtering. See discussion at end of Appendix $A$ and comments in listing of subroutine FILTER.

Affects filtering. See discussion at end of Appendix $A$ and comments in listing of subroutine FILTER.

Run title which appears on model output (up to 80 characters).

Number of vertical grid points.

Species name which appears on model output (up to 10 characters).

Parameter for dimensioning arrays. Specifies maximum number of computed species.

Number of "constrained species", which are computed by methods that do not involve the mass- or energy-balance equations.

Number of "computed species", which are modeled via the finite-difference approximations to the mass-balance or energy-balance equations.

Number of corrector passes used in subroutine ODEINT (see Appendix B).

Parameter for dimensioning arrays. Specifies maximum number of computed and constrained species.

Specifies how often filtering is applied to solution to advection-diffusion component. Filtering occurs every NFILTR steps. (Suggested value=1)

Affects filtering. See discussion at end of Appendix $A$ and comments in listing of subroutine FILTER.

Affects filtering. See discussion at end of Appendix $A$ and comments in listing of subroutine FILTER. 
TABLE C-19 Continued

Variable

NM1

NNAMMX

NPRINT

NTOT

NZMAX

PRESS ( I)

PRESS $\emptyset$

RATESF ( $K)$

TCLOCK

TEMP $\emptyset$

TGEN

TNEXT
Description

$N-1$.

Parameter for dimensioning NAMES array NNAMMX = NCTMAX+2.

Specifies frequency of printed output when output is desired after a fixed number of major computation loops.

Total number of species, NCOMP+NCNSTR.

Parameter for dimensioning arrays. Specifies maximum number of vertical grid points.

Air pressure. [dyne $\left./ \mathrm{cm}^{2}\right]$

Pressure at bottom of grid at start of computation. [dyne $\left./ \mathrm{cm}^{2}\right]$

Values of pseudo first-order decay coefficient above which a species is considered to have stiff behavior (see Appendix B).

Current model time. Because of the splitting of the advection-diffusion and generation components of the equations, model time is somewhat i1l-defined during a major computation step. TCLOCK holds the model time at the start and end of each major integration step, at the start of each advection-diffusion integration step, and at the start of each generation integration step. During the integration of the generation component, model time varies from TCLOCK to TCLOCK+2.DT as the integration progresses, and is held by the variables TS and TN in subroutine ODEINT and TGEN in subroutine GEN. [sec]

Temperature of bottom of grid at start of computation. [K]

Parameter passed to subroutine GEN specifying current model time. [sec]

Model time at end of current advection-

diffusion integration step. [sec] 
TABLE C-19 Continued

Variable

TPRINT

TSTART

TSTOP

TSTRTO

URATIO (I)

$\operatorname{UVEC}(\mathrm{J} 1, \mathrm{I})$

WAGRID (I)

WAP (I)

WR $(I, K)$

WVAR (I)

$Z$ (I)

\section{Description}

Holds the time at which printed output will next occur, when output is requested at fixed time intervals. [sec]

Model time at beginning of computation. [sec]

Model time at which computation terminates. [sec]

Parameter passed to subroutine ODEINT, specifying the model time at the start of the integration time interval. [sec]

$u^{*} / u_{A}$ of Eq. (13).

$X V$ in $\mathrm{Eq} .(\mathrm{Al2})$.

Grid vertical velocity. $w_{A}$ in $\mathrm{Eq}$. (8) or ${ }^{w_{A O}}\left(u_{A} / u_{A O}\right)$ in Eq. (1i). [ $\left[\mathrm{Cm}_{\mathrm{Asec}}\right]$

Component of vertical air velocity relative to grid. $W_{A}^{\prime}$ in Eq. (8) or $w_{A} "$ in Eq. (11).

Settling velocity. $[\mathrm{cm} / \mathrm{sec}$, signed negative]

Working array, holds WR(I,K)+WAP(I) for species currently being treated in subroutine ADVINT. $[\mathrm{cm} / \mathrm{sec}]$

Relative height of each grid position. Total height $=Z$ (I) + GLEVL. $Z$ (I) is constant in time, while GLEVL can change. [cm] 


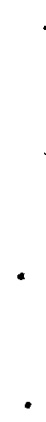




\section{APPENDIX D}

\section{EXAMPLE APPLICATION 2 MODEL OUTPUT LISTINGS}

This appendix contains the printed model output for Example Application 2. Table $D-1$ is the output heading page. Tables D-2 through D-6 contain output at model times of $0,1,2,3$, and 4 hours. 
TABLE D-1. Output Heading Page From Example Application 2

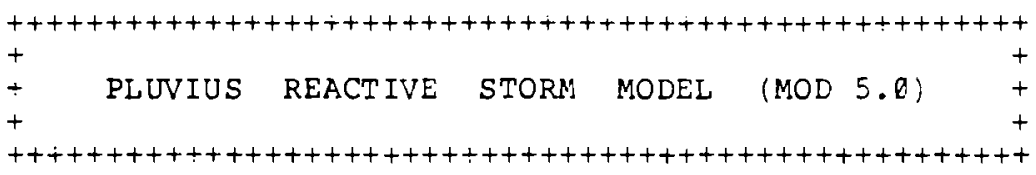

RUN ID: EXAMPLE RUN 2 - PLUVIUS MOD 5.0 USER MANUAL

$\begin{array}{cl}\text { COMPUTED SPECI } \\ 1 & \text { TEMP } \\ 2 & \text { VAPCL } \\ 3 & \text { RAIN } \\ 4 & \text { SNOW } \\ 5 & \text { SO2-GC } \\ & \\ 6 & \text { SO2-R } \\ 7 & \text { SO2-S } \\ 8 & \text { SO4-A } \\ 9 & \text { SO4-C } \\ 10 & \text { SO4-R } \\ & \\ 11 & \text { SO4-S } \\ 12 & \text { H2O2-GC } \\ 13 & \text { H2O2-R } \\ 14 & \text { H2O2-S } \\ 15 & \text { O3-G } \\ & \\ \text { CONSTRAINED S } & \\ 16 & \text { CLOUD } \\ 17 & \text { HION-C } \\ 18 & \text { HION-R } \\ 19 & \text { SO2-G } \\ 20 & \text { SO2-C } \\ 21 & \text { H2O2-G } \\ 22 & \text { H2O2-C } \\ & \\ & \end{array}$

CONTROL DATA

$\begin{array}{ll}\text { TOP B.C. } & \text { BOTTOM B.C } \\ \text { FLUX } & \text { FLUX } \\ \text { FLUX } & \text { FLUX } \\ \text { FLUX } & \text { OUTFLOW } \\ \text { FLUX } & \text { OUTFLOW } \\ \text { FLUX } & \text { FLUX } \\ \text { FLUX } & \\ \text { FLUX } & \text { OUTFLOW } \\ \text { FLUX } & \text { OUTFLOW } \\ \text { FLUX } & \text { FLUX } \\ \text { FLUX } & \text { FLUX } \\ \text { FLUX } & \text { OUTFLOW } \\ \text { FLUX } & \\ \text { FLUX } & \text { OUTFLOW } \\ \text { FLUX } & \text { FLUX } \\ \text { FLUX } & \text { OUTFLOW } \\ & \text { OUTFLOW }\end{array}$

DIFFUS . REGIME

1
2
3
4
2
3
4
2
2
3
4
2
3
4
2
FILTER FACT.

$$
\begin{aligned}
& 0.00 \\
& 0.00 \\
& 0.10 \\
& 0.10 \\
& 0.00 \\
& 0.10 \\
& 0.10 \\
& 0.00 \\
& 0.00 \\
& 0.10 \\
& 0.10 \\
& 0.00 \\
& 0.10 \\
& 0.10 \\
& 0.00
\end{aligned}
$$

\section{SPECIES}


TABLE D-2. Example Application 2 Model Output at TCLOCK $=0$ Hours

$\begin{array}{lrll}\text { TCLOCK } & 0.00 & (0.000 \text { HRS } & \text { GLEVL (KM) } 0.000 \\ \text { DT } & 60.00 & & \text { WAGRID(1) }\end{array}$
$\mathrm{Z}$ (KM) TEMP
VAPCL RAIN
SNOW
$\mathrm{SO} 2-\mathrm{GC}$
$\mathrm{SO} 2-\mathrm{R}$
SO 2-S
SO4-
SO4-C
SO4-R
SO4-S

$5.000 \quad 0.2597 \mathrm{E}+03 \quad 0.9064 \mathrm{E}-07 \quad 0.1000 \mathrm{E}-16 \quad 0.1000 \mathrm{E}-16 \quad 0.4973 \mathrm{E}-13 \quad 0.1000 \mathrm{E}-23 \quad 0.1000 \mathrm{E}-23 \quad 0.4973 \mathrm{E}-14 \quad 0.1000 \mathrm{E}-23 \quad 0.1000 \mathrm{E}-23 \quad 0.1000 \mathrm{E}-23$

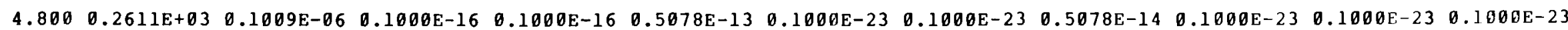

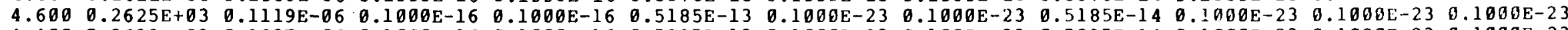

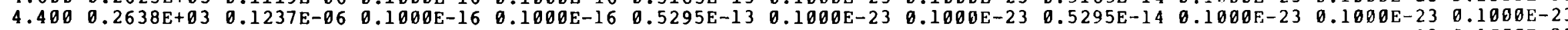

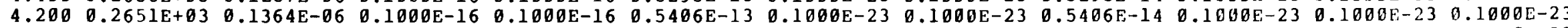

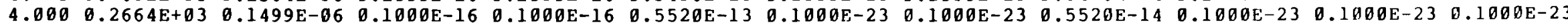

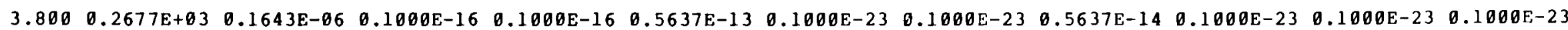

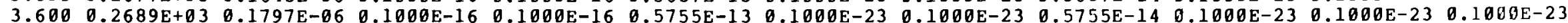

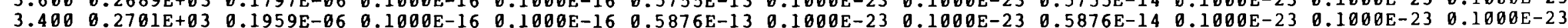

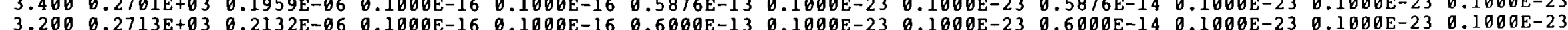

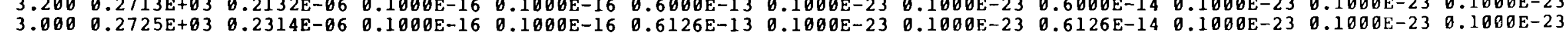

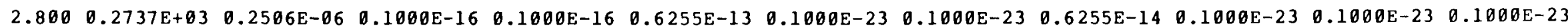

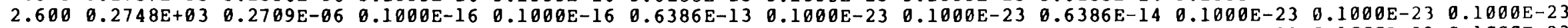

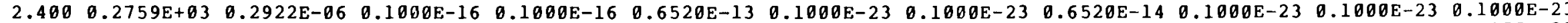

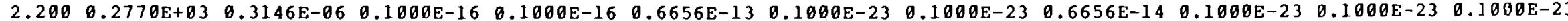

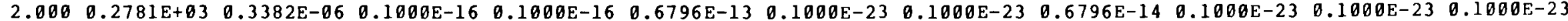

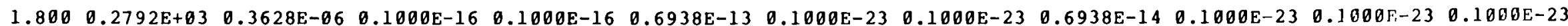

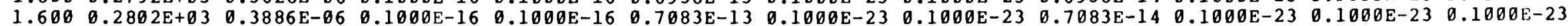

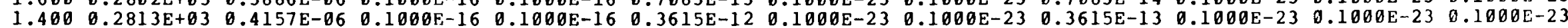
$1.2000 .2823 \mathrm{E}+030.4439 \mathrm{E}-960.1000 \mathrm{E}-160.1000 \mathrm{E}-160.3690 \mathrm{E}-120.1090 \mathrm{E}-230.1000 \mathrm{E}-230.3690 \mathrm{E}-130.1000 \mathrm{E}-230.1000 \mathrm{E}-230.1000 \mathrm{E}-23$

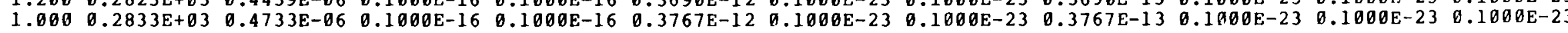

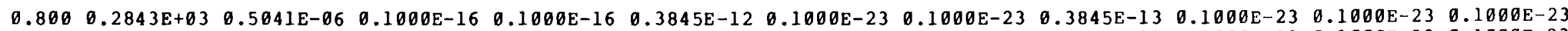

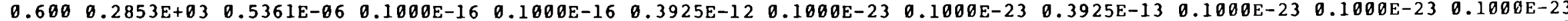
$0.4000 .2862 \mathrm{E}+03 \quad 0.5694 \mathrm{E}-06 \quad 0.1000 \mathrm{E}-16 \quad 0.1000 \mathrm{E}-16 \quad 0.4007 \mathrm{E}-12 \quad 0.1000 \mathrm{E}-23 \quad 0.1000 \mathrm{E}-23 \quad 0.4007 \mathrm{E}-13 \quad 0.1000 \mathrm{E}-23 \quad 0.1000 \mathrm{E}-23 \quad 0.1000 \mathrm{E}-23$ $9.200 .2872 \mathrm{E}+30.6941 \mathrm{E}-960.1090 \mathrm{E}-160.1000 \mathrm{E}-160.4089 \mathrm{E}-120.1000 \mathrm{E}-230.1000 \mathrm{E}-230.4089 \mathrm{E}-130.1000 \mathrm{E}-230.1000 \mathrm{E}-230.1000 \mathrm{E}-23$

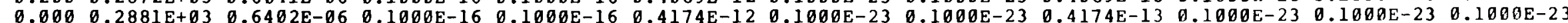




\begin{tabular}{|c|c|c|c|c|c|c|c|c|c|c|c|}
\hline $\begin{array}{l}\text { TCLOCR } \\
\text { DT }\end{array}$ & $\begin{array}{r}0.00 \\
60.00\end{array}$ & 1 & (0 HRS) & & $\begin{array}{l}\text { GI,E } \\
\text { WAG }\end{array}$ & $\begin{array}{l}\text { KM) } \\
\text { 1) }\end{array}$ & & & & & \\
\hline $\mathrm{Z}(\mathrm{KM})$ & $\mathrm{H} 2 \mathrm{O} 2-\mathrm{GC}$ & $\mathrm{H} 2 \mathrm{O} 2-\mathrm{R}$ & $\mathrm{H} 2 \mathrm{O} 2-\mathrm{S}$ & O3-G & CLOUD & $\mathrm{HION}-\mathrm{C}$ & HION-R & $\mathrm{SO} 2-\mathrm{G}$ & $\mathrm{SO} 2-\mathrm{C}$ & $\mathrm{H} 2 \mathrm{O} 2-\mathrm{G}$ & $\mathrm{H} 2 \mathrm{O} 2-\mathrm{C}$ \\
\hline
\end{tabular}

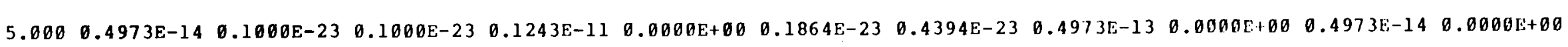

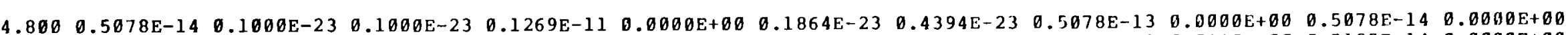

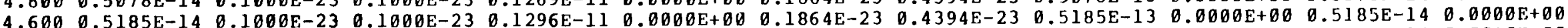

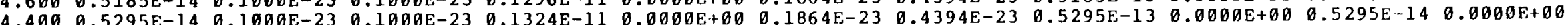

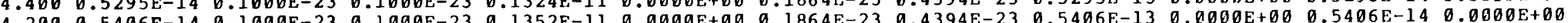

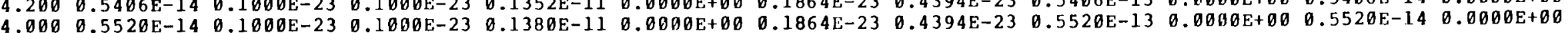

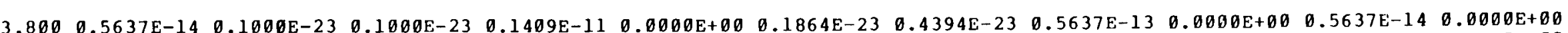

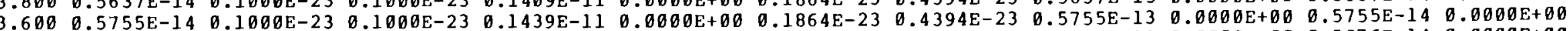

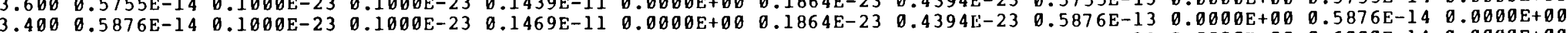

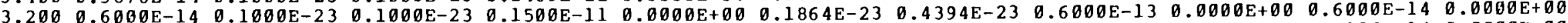
$3.000 \quad 0.6126 \mathrm{E}-140.1000 \mathrm{E}-23 \quad 0.1000 \mathrm{E}-230.1532 \mathrm{E}-110.0000 \mathrm{E}+00 \quad 0.1864 \mathrm{E}-23 \quad 0.4394 \mathrm{E}-23 \quad 0.6126 \mathrm{E}-13 \quad 0.0000 \mathrm{E}+00 \quad 0.6126 \mathrm{E}-14 \quad 0.0000 \mathrm{E}+00$

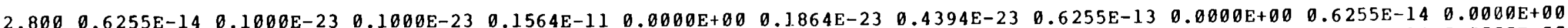

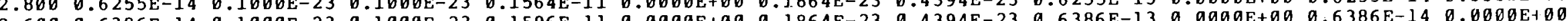

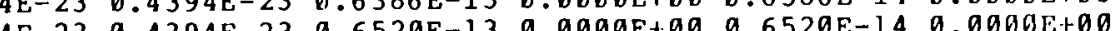

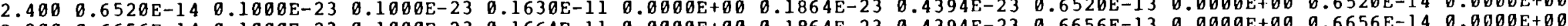

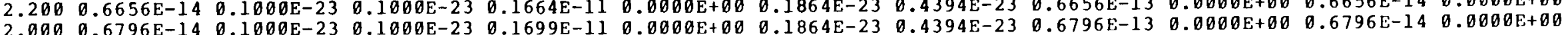

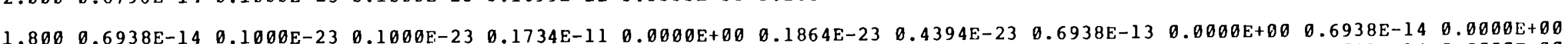

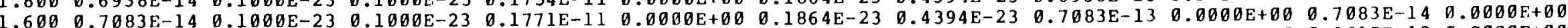

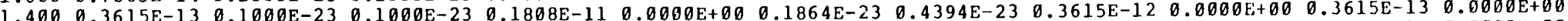

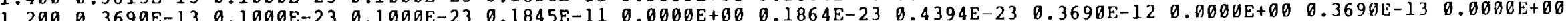

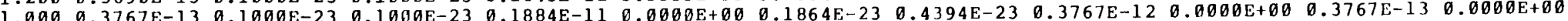

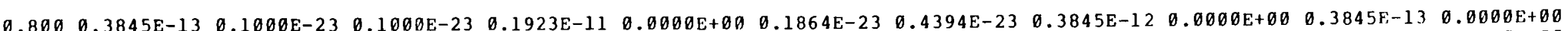

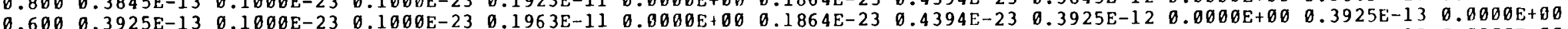

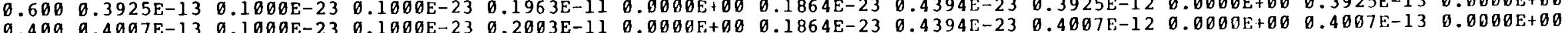

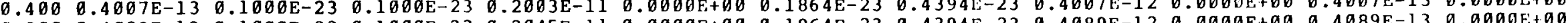

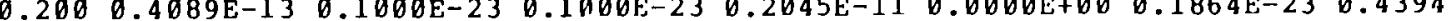

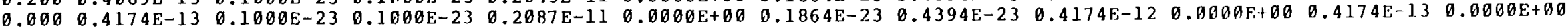


TABLE D-2 Continued

\begin{tabular}{|c|c|c|}
\hline 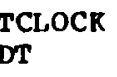 & $\begin{array}{r}0.00 \\
60.00\end{array}$ & 0.000 \\
\hline$Z(K M)$ & $\mathbf{P}$ & cs \\
\hline 5.000 & $0.5369 E+\theta 6$ & $0.2486 \mathrm{E}-04$ \\
\hline $\begin{array}{l}4.800 \\
4.600 \\
.400 \\
4.200 \\
090\end{array}$ & $\begin{array}{l}0.5512 \mathrm{E}+06 \\
0.5658 \mathrm{E}+06 \\
0.5806 \mathrm{E}+06 \\
0.5958 \mathrm{E}+06 \\
0.6114 \mathrm{E}+06\end{array}$ & $\begin{array}{l}0.2539 \mathrm{E}-04 \\
0.2593 \mathrm{E}-04 \\
0.2647 \mathrm{E}-04 \\
0.2703 \mathrm{E}-04 \\
0.2760 \mathrm{E}-04\end{array}$ \\
\hline $\begin{array}{l}3.800 \\
3.600 \\
3.400 \\
3.200\end{array}$ & $\begin{array}{l}0.627 \\
0.643 \\
0.659 \\
0.676 \\
0.694\end{array}$ & $\begin{array}{l}0.2818 E-04 \\
0.2878 E-04 \\
0.2938 E-04 \\
0.3006 E-04 \\
0.3063 E-04\end{array}$ \\
\hline $\begin{array}{l}2.800 \\
2.600 \\
2.400 \\
2.200\end{array}$ & $\begin{array}{l}0.7116 E+06 \\
0.7295 E+06 \\
0.7478 E+06 \\
0.7666 E+06 \\
0.7857 E+06\end{array}$ & $\begin{array}{l}0.3127 E-04 \\
0.3193 E-04 \\
0.3260 E-04 \\
0.3328 E-04 \\
0.3398 E-04\end{array}$ \\
\hline $\begin{array}{l}.800 \\
.600 \\
.400 \\
.200 \\
.600\end{array}$ & $\begin{array}{l}0.8052 \mathrm{E}+ \\
0.8251 \mathrm{E}+ \\
0.8454 \mathrm{E}+ \\
0.8661 \mathrm{E}+ \\
0.8873 \mathrm{E}+\end{array}$ & $\begin{array}{l}0.34 \\
0.35 \\
0.36 \\
0.36 \\
0.37\end{array}$ \\
\hline $\begin{array}{l}0.800 \\
0.600 \\
0.400 \\
0.200\end{array}$ & $\begin{array}{l}0.9089 E+B 6 \\
0.9310 E+B 6 \\
0.9535 E+B 6 \\
0.9765 E+86 \\
0.1006 E+07\end{array}$ & $\begin{array}{l}0.3925 E-04 \\
0.4607 E-04 \\
0.4689 E-04 \\
0.4174 E-04\end{array}$ \\
\hline
\end{tabular}

GI.EVL (KM) WAGR I D (1)

0.000

B. 00 
TABLE D-3. Example Application 2 Model Output at TCLOCK $=1$ Hours

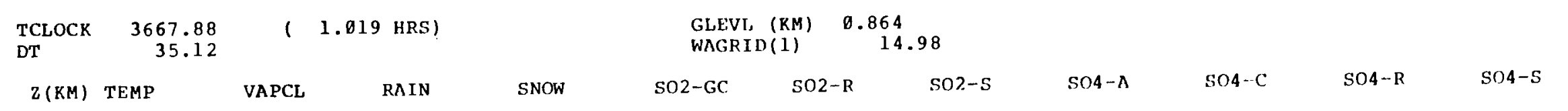

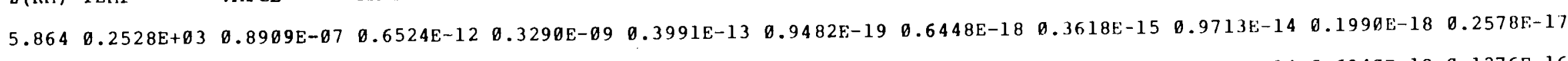

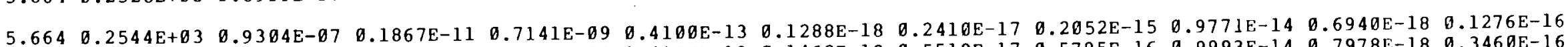

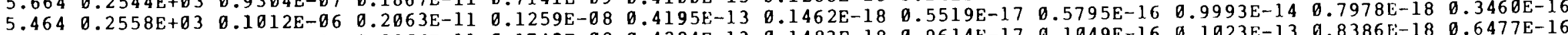

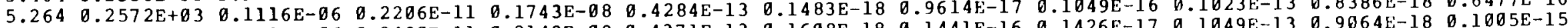

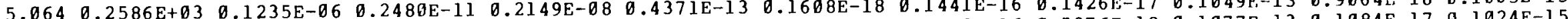
$4.8640 .2600 \mathrm{E}+03 \quad 0.1364 \mathrm{E}-06 \quad 0.3121 \mathrm{E}-11 \quad 0.2086 \mathrm{E}-08 \quad 0.4461 \mathrm{E}-13 \quad 0.1852 \mathrm{E}-18 \quad 0.1478 \mathrm{E}-16 \quad 0.5976 \mathrm{E}-18 \quad 0.1077 \mathrm{E}-13 \quad 0.1084 \mathrm{E}-17 \quad 0.1024 \mathrm{E}-15$

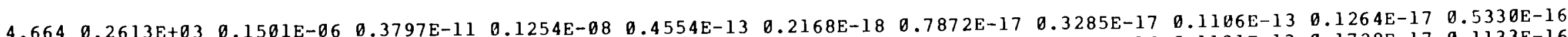

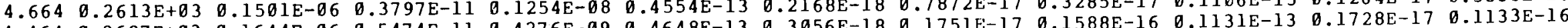

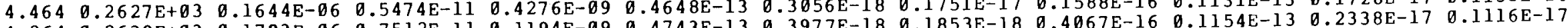

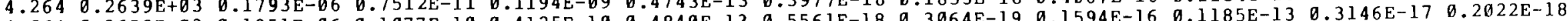

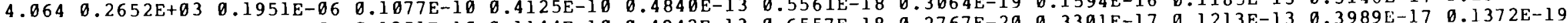

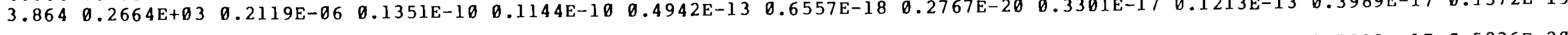

$\begin{array}{lllllllllllll}3.664 & 0.2676 \mathrm{E}+03 & 0.2295 \mathrm{E}-06 & 0.2158 \mathrm{E}-10 & 0.2825 \mathrm{E}-11 & 0.5046 \mathrm{E}-13 & 0.1023 \mathrm{E}-17 & 0.7049 \mathrm{E}-21 & 0.4623 \mathrm{E}-18 & 0.1239 \mathrm{E}-13 & 0.5992 \mathrm{E}-17 & 0.5236 \mathrm{E}-20\end{array}$

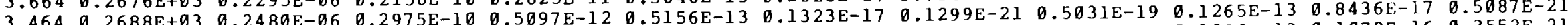

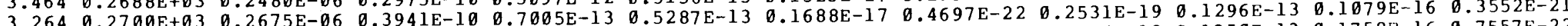

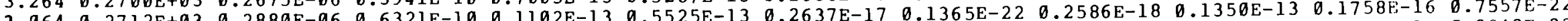

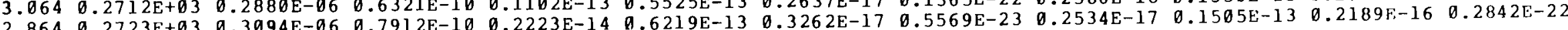

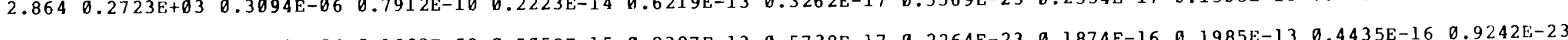

$2.664 \quad 0.2735 \mathrm{E}+03 \quad 0.3319 \mathrm{E}-06 \quad 0.1283 \mathrm{E}-09 \quad 0.5059 \mathrm{E}-15 \quad 0.8387 \mathrm{E}-13 \quad 0.5738 \mathrm{E}-17 \quad 0.2264 \mathrm{E}-23 \quad 0.1874 \mathrm{E}-16 \quad 0.1985 \mathrm{E}-13 \quad 0.4435 \mathrm{E}-16 \quad 0.9242 \mathrm{E}-23$

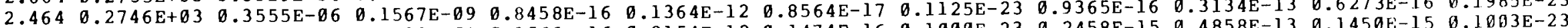

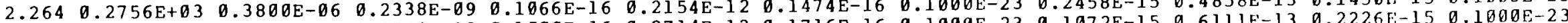

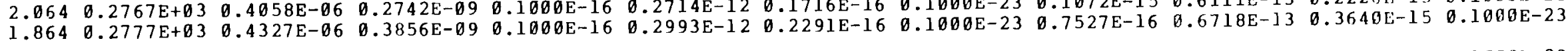

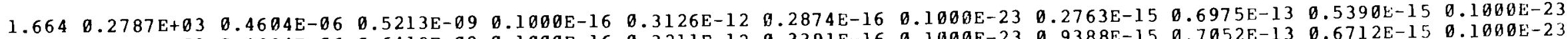

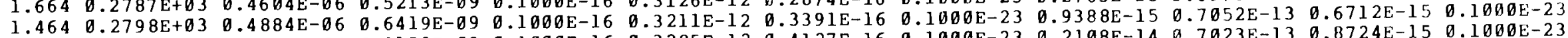

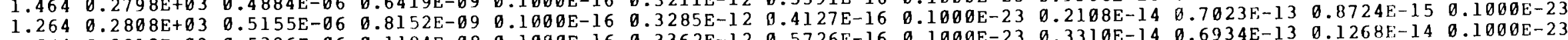
$1.0640 .2818 \mathrm{E}+03 \quad 0.5386 \mathrm{E}-06 \quad 0.1184 \mathrm{E}-08 \quad 0.1000 \mathrm{E}-16 \quad 0.3362 \mathrm{E}-12 \quad 0.5726 \mathrm{E}-16 \quad 0.1900 \mathrm{E}-23 \quad 0.2623 \mathrm{E}-14 \quad 0.7021 \mathrm{E}-13 \quad \emptyset .1784 \mathrm{E}-14 \quad 0.1990 \mathrm{E}-23$

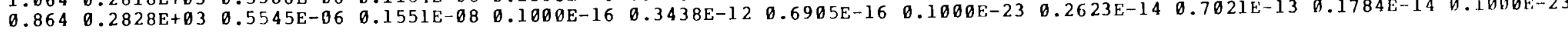


$\underline{\text { TABLE } D-3}$ Continued

\begin{tabular}{|c|c|c|c|}
\hline $\begin{array}{l}\text { TCI,OCK } \\
\text { DT }\end{array}$ & $\begin{array}{r}3667.88 \\
35.12\end{array}$ & ( $1.019 \mathrm{HRS})$ & $\begin{array}{l}\text { GLEVL (KM) } \\
\text { WAGRID (1) }\end{array}$ \\
\hline
\end{tabular}

$\mathrm{Z}(\mathrm{KM}) \mathrm{H} 2 \mathrm{O} 2-\mathrm{GC}$ H2O2-R H2O2-S O3-G CLOUD HION-C HION-R SO2-G

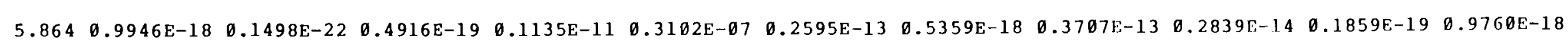

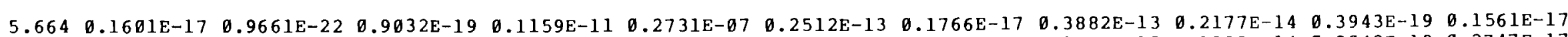

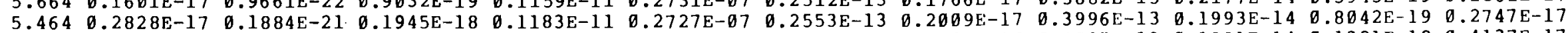

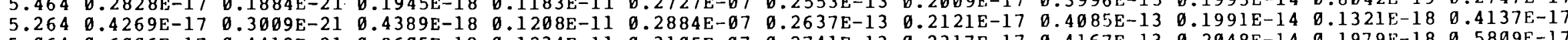

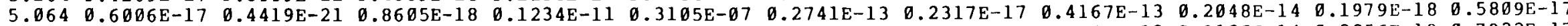

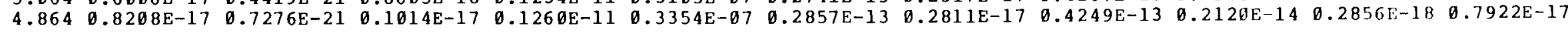

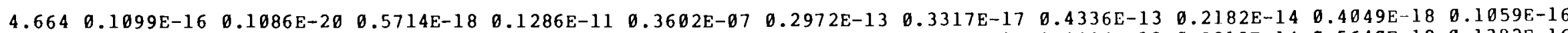

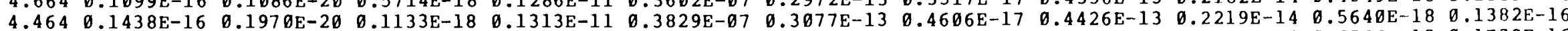
$4.2640 .1814 \mathrm{E}-16 \quad 0.3093 \mathrm{E}-200.8272 \mathrm{E}-20 \quad 0.1340 \mathrm{E}-110.4048 \mathrm{E}-070.3176 \mathrm{E}-13 \quad 0.6259 \mathrm{E}-17 \quad 0.4518 \mathrm{E}-13 \quad 0.2247 \mathrm{E}-14 \quad 0.7576 \mathrm{E}-18 \quad 0.1738 \mathrm{E}-16$

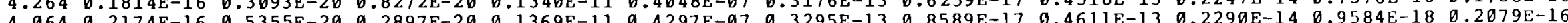

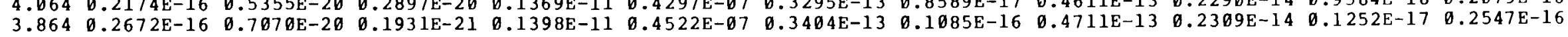

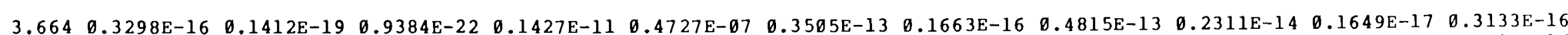

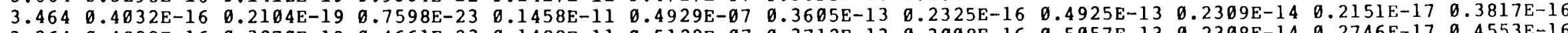

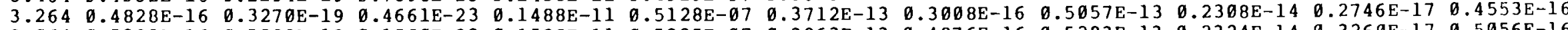

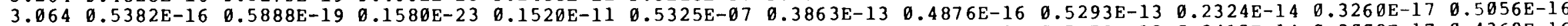

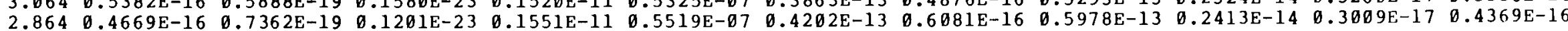

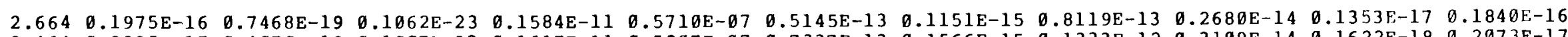

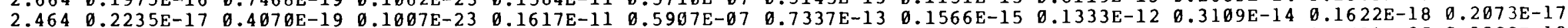

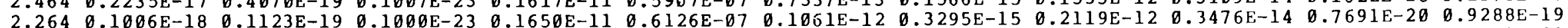

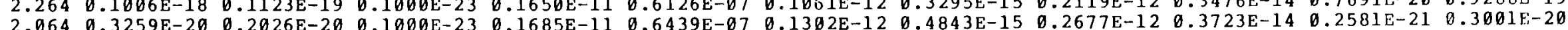

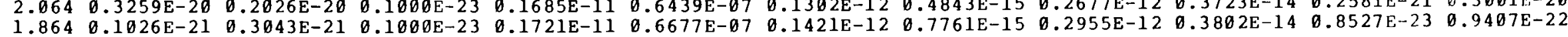

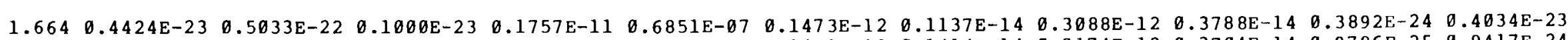

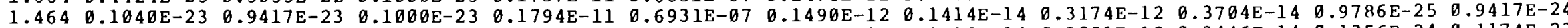

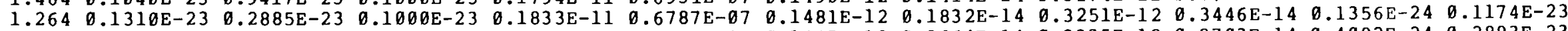

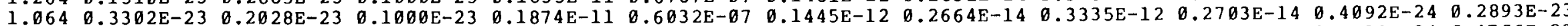

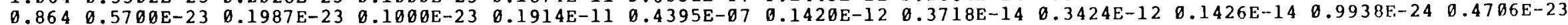


TABLE D-3 Continued

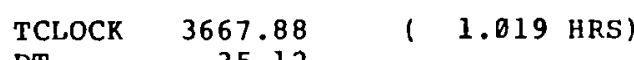 \\ DT \\ $\mathrm{Z}(\mathrm{KM}) \quad \mathrm{P}$ \\ CS \\ $5.864 \quad 0.4775 E+06 \quad 0.2271 E-04$ \\ $5.664 \quad 0.4905 \mathrm{E}+06 \quad 0.2319 \mathrm{E}-04$ \\ $5.464 \quad 0.5038 \mathrm{E}+06 \quad 0.2369 \mathrm{E}-04$ \\ $5.2640 .5174 \mathrm{E}+06 \quad 0.2419 \mathrm{E}-04$ \\ $5.064 \quad 0.5313 E+06 \quad 0.2471 E-04$ \\ $4.864 \quad 0.5455 E+06 \quad 0.2523 E-04$ \\ $4.664 \quad 0.5600 \mathrm{E}+06 \quad 0.2577 \mathrm{E}-04$ \\ $4.464 \quad 0.5748 \mathrm{E}+06 \quad 0.2632 \mathrm{E}-04$ \\ $4.2640 .5899 \mathrm{E}+06 \quad 0.2688 \mathrm{E}-04$ \\ $4.064 \quad 0.6653 \mathrm{E}+06 \quad 0.2745 \mathrm{E}-04$ \\ $3.864 \quad 0.6211 \mathrm{E}+06 \quad 0.2804 \mathrm{E}-04$ \\ $3.6640 .6372 \mathrm{E}+06 \quad 0.2863 \mathrm{E}-04$ \\ $3.464 \quad 0.6536 \mathrm{E}+06 \quad 0.2924 \mathrm{E}-04$ \\ $3.264 \quad 0.6704 \mathrm{E}+06 \quad 0.2986 \mathrm{E}-04$ \\ $3.0640 .6875 \mathrm{E}+06 \quad 0.3049 \mathrm{E}-04$ \\ $\begin{array}{lll}3.064 & 0.6875 E+06 & 0.3049 E-04 \\ 2.864 & 0.7050 \mathrm{E}+06 & 0.3114 \mathrm{E}-04\end{array}$ \\ $2.664 \quad 0.7229 \mathrm{E}+06 \quad 0.3179 \mathrm{E}-04$ \\ $2.464 \quad 0.7412 \mathrm{E}+06 \quad 0.3247 \mathrm{E}-04$ \\ $2.264 \quad 0.7598 \mathrm{E}+06 \quad 0.3315 \mathrm{E}-04$ \\ $2.064 \quad 0.7788 \mathrm{E}+06 \quad 0.3386 \mathrm{E}-04$ \\ $1.864 \quad 0.7983 \mathrm{E}+66 \quad 0.3457 \mathrm{E}-04$ \\ $1.664 \quad 0.8181 \mathrm{E}+66 \quad 0.3530 \mathrm{E}-04$ \\ $1.4640 .8384 \mathrm{E}+060.3604 \mathrm{E}-04$ \\ $1.4640 .8591 \mathrm{~B}+060.3680 \mathrm{~B}-04$ \\ $1.2640 .8591 \mathrm{~B}+060.3680 \mathrm{E}-04$ \\ $0.8640 .9017 \mathrm{E}+06 \quad 0.3835 \mathrm{E}-04$
}

GLEVL (KM) $\oslash .864$

WAGRID(1) $\quad 14.98$ 
TABLE D-4. Example Application 2 Model Output at TCLOCK $=2$ Hours

\begin{tabular}{|c|c|c|c|c|c|c|c|c|c|c|c|}
\hline $\begin{array}{l}\text { TCLOCR } \\
\text { DT }\end{array}$ & $\begin{array}{r}7225.84 \\
23.53\end{array}$ & 2.007 & 7 HRS) & & $\begin{array}{l}\text { GLFVL, } \\
\text { WAGR I D }\end{array}$ & $\begin{array}{r}0.994 \\
0.0\end{array}$ & & & & & \\
\hline $\mathrm{Z}(\mathrm{KM})$ & TEMP & VAPCL & $\mathrm{R} \Lambda \mathrm{IN}$ & SNOW & $\mathrm{SO} 2-\mathrm{GC}$ & $\mathbf{S O 2 - R}$ & so2-s & SO4 $-\Lambda$ & so4-C & $\mathrm{SO} 4-\mathrm{R}$ & SO4-S \\
\hline 5.994 & $0.2518 \mathrm{E}+03$ & $0.8468 \mathrm{E}-07$ & $0.2748 \mathrm{E}-11$ & $0.5527 \mathrm{E}-09$ & $0.3554 \mathrm{E}-13$ & $0.6007 \mathrm{E}-18$ & D. $1276 \mathrm{E}-17$ & $0.2085 \mathrm{E}-15$ & $0.1313 E-13$ & $0.4933 \mathrm{E}-17$ & $0.2329 \mathrm{E}-1$ \\
\hline $\begin{array}{l}5.794 \\
5.594 \\
5.394 \\
5.194 \\
4.994\end{array}$ & $\begin{array}{l}0.2534 \mathrm{E}+03 \\
0.2549 \mathrm{E}+03 \\
0.2563 \mathrm{E}+03 \\
0.2578 \mathrm{E}+03 \\
0.2591 \mathrm{E}+03\end{array}$ & $\begin{array}{l}0.8601 \mathrm{E}-07 \\
0.9640 \mathrm{E}-07 \\
0.9725 \mathrm{E}-07 \\
0.1064 \mathrm{E}-06 \\
0.1168 \mathrm{E}-06\end{array}$ & $\begin{array}{l}0.2202 \mathrm{E}-10 \\
0.3217 \mathrm{E}-10 \\
0.5911 \mathrm{E}-10 \\
0.8038 \mathrm{E}-10 \\
0.1291 \mathrm{E}-09\end{array}$ & $\begin{array}{l}0.1190 \mathrm{E}-08 \\
0.1977 \mathrm{E}-08 \\
0.3041 \mathrm{E}-08 \\
0.3413 \mathrm{E}-08 \\
0.5126 \mathrm{E}-08\end{array}$ & $\begin{array}{l}0.3686 \mathrm{E}-13 \\
0.3816 \mathrm{E}-13 \\
0.3914 \mathrm{E}-13 \\
0.3990 \mathrm{E}-13 \\
0.4054 \mathrm{E}-13\end{array}$ & $\begin{array}{l}0.1233 \mathrm{E}-17 \\
0.2319 \mathrm{E}-17 \\
0.2833 \mathrm{E}-17 \\
0.4416 \mathrm{E}-17 \\
0.5535 \mathrm{E}-17\end{array}$ & $\begin{array}{l}0.7355 \mathrm{E}-17 \\
0.1051 \mathrm{E}-16 \\
0.2148 \mathrm{E}-16 \\
0.2678 \mathrm{E}-16 \\
0.4502 \mathrm{E}-16\end{array}$ & $\begin{array}{l}0.1707 \mathrm{E}-15 \\
0.9663 \mathrm{E}-16 \\
0.4052 \mathrm{E}-16 \\
0.1397 \mathrm{E}-16 \\
0.5957 \mathrm{E}-17\end{array}$ & $\begin{array}{l}0.1263 \mathrm{E}-13 \\
0.1203 \mathrm{E}-13 \\
0.1158 \mathrm{E}-13 \\
0.1133 \mathrm{E}-13 \\
0.1111 \mathrm{E}-13\end{array}$ & $\begin{array}{l}0.9627 \mathrm{E}-17 \\
0.1662 \mathrm{E}-16 \\
0.3092 \mathrm{E}-16 \\
0.3958 \mathrm{E}-16 \\
0.6957 \mathrm{E}-16\end{array}$ & $\begin{array}{l}0.5139 \mathrm{E}-16 \\
0.8819 \mathrm{E}-16 \\
0.1662 \mathrm{E}-15 \\
0.2463 \mathrm{E}-15 \\
0.4279 \mathrm{E}-15\end{array}$ \\
\hline
\end{tabular}

$4.7940 .2605 \mathrm{E}+030.1287 \mathrm{E}-06 \quad 0.1641 \mathrm{E}-99 \quad 0.5858 \mathrm{E}-98 \quad 0.4114 \mathrm{E}-13 \quad 0.7448 \mathrm{E}-17 \quad 0.5975 \mathrm{E}-16 \quad 0.6930 \mathrm{E}-17 \quad 0.1098 \mathrm{E}-13 \quad 0.7727 \mathrm{E}-16 \quad 0.5524 \mathrm{E}-15$

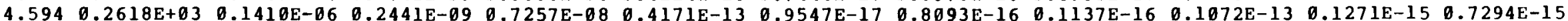

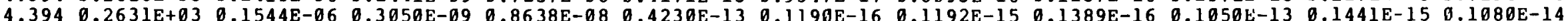

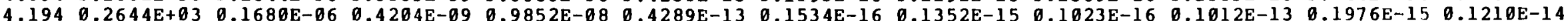

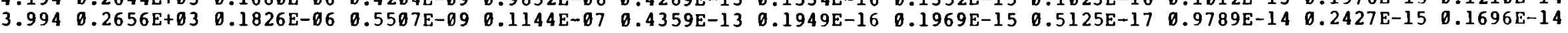

$3.794 \quad 0.2669 \mathrm{E}+03 \quad 0.1975 \mathrm{E}-06 \quad 0.7322 \mathrm{E}-09 \quad 0.1300 \mathrm{E}-07 \quad 0.4439 \mathrm{E}-13 \quad 0.2557 \mathrm{E}-16 \quad 0.2320 \mathrm{E}-15 \quad 0.1886 \mathrm{E}-17 \quad 0.9265 \mathrm{E}-14 \quad 0.3010 \mathrm{E}-15 \quad 0.1893 \mathrm{E}-14$

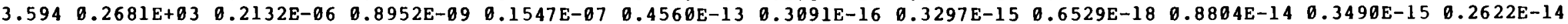

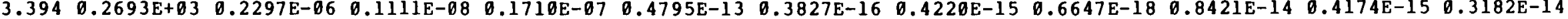

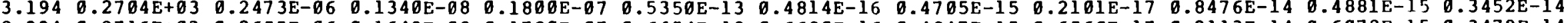

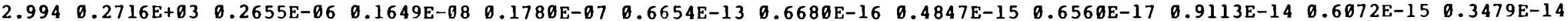

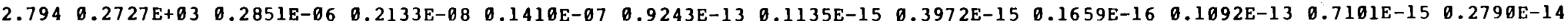

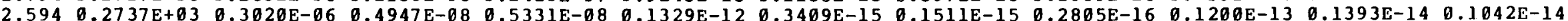

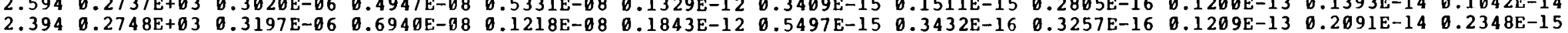

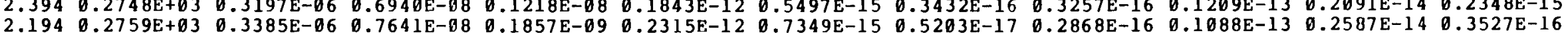

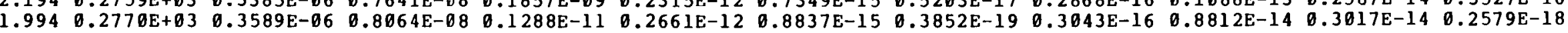

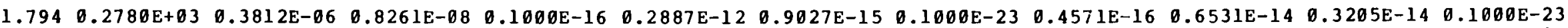
$1.5940 .2791 \mathrm{E}+03 \quad 0.4052 \mathrm{E}-06 \quad 0.8275 \mathrm{E}-080.1000 \mathrm{E}-16 \quad 0.3040 \mathrm{E}-120.8652 \mathrm{E}-150.1000 \mathrm{E}-230.1034 \mathrm{E}-150.4510 \mathrm{E}-140.3372 \mathrm{E}-140.1000 \mathrm{E}-23$ $1.3940 .2801 \mathrm{E}+030.4309 \mathrm{E}-06 \quad 0.8285 \mathrm{E}-080.1000 \mathrm{E}-16 \quad 0.3160 \mathrm{E}-120.8203 \mathrm{E}-15 \quad 0.1000 \mathrm{E}-23 \quad 0.4260 \mathrm{E}-150.3044 \mathrm{E}-140.3604 \mathrm{E}-140.1000 \mathrm{E}-23$ (194.

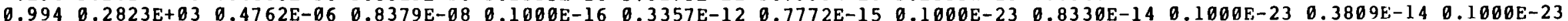




\section{TABLE D-4 Continued}

\begin{tabular}{|c|c|c|c|c|c|c|c|c|c|c|c|}
\hline $\begin{array}{l}\text { TCLOCK } \\
\text { DT }\end{array}$ & $\begin{array}{r}7225.84 \\
23.53\end{array}$ & 1 & 7 HRS) & & $\begin{array}{l}\text { GLE } \\
\text { WAG }\end{array}$ & $\begin{array}{l}\mathrm{KM}) \\
\text { 1) }\end{array}$ & & & & & \\
\hline $\mathrm{Z}(\mathrm{KM})$ & $\mathrm{H} 2 \mathrm{O} 2-\mathrm{GC}$ & H 2O2-R & $\mathrm{H} 2 \mathrm{O} 2-\mathrm{S}$ & $\mathrm{O} 3-\mathrm{G}$ & CLOUD & $\mathrm{HION}-\mathrm{C}$ & HION-R & $\mathrm{SO} 2-\mathrm{G}$ & $\mathrm{SO} 2-\mathrm{C}$ & $11202-G$ & $\mathrm{H} 202-\mathrm{C}$ \\
\hline
\end{tabular}

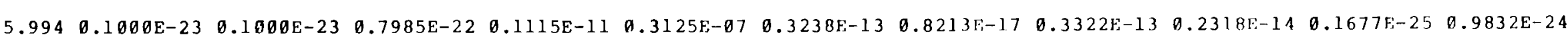

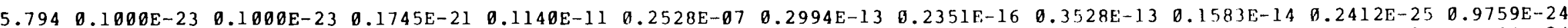
$\begin{array}{llllllllllll}5.594 & 0.1003 \mathrm{E}-23 & 0.1000 \mathrm{E}-23 & 0.2997 \mathrm{E}-21 & 0.1164 \mathrm{E}-11 & 0.2180 \mathrm{E}-07 & 0.2794 \mathrm{E}-13 & 0.3912 \mathrm{E}-16 & 0.3696 \mathrm{E}-13 & 0.1194 \mathrm{E}-14 & 0.3240 \mathrm{E}-25 & 0.9704 \mathrm{E}-24\end{array}$

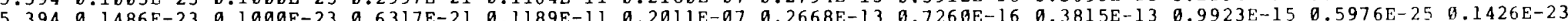
5.

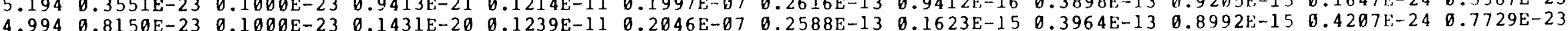

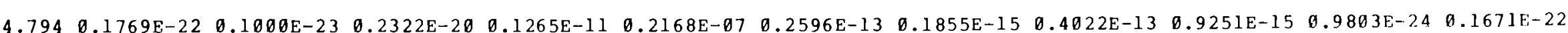

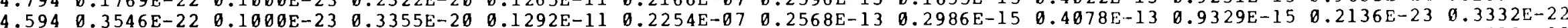

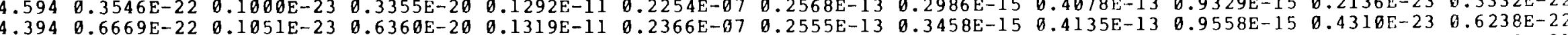

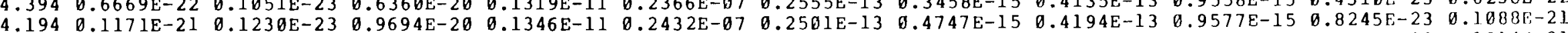
$3.994 \quad 0.1963 \mathrm{E}-21 \quad 0.1628 \mathrm{E}-23 \quad 0.1832 \mathrm{E}-19 \quad 0.1375 \mathrm{E}-11 \quad 0.2509 \mathrm{E}-07 \quad 0.2459 \mathrm{E}-13 \quad 0.5918 \mathrm{E}-15 \quad 0.4262 \mathrm{E}-13 \quad 0.9665 \mathrm{E}-15 \quad 0.1496 \mathrm{E}-22 \quad 0.1814 \mathrm{E}-21$

$3.7940 .3045 \mathrm{E}-210.2711 \mathrm{E}-230.2917 \mathrm{E}-190.1404 \mathrm{E}-110.2511 \mathrm{E}-07 \quad 0.2362 \mathrm{E}-13 \quad 0.7463 \mathrm{E}-15 \quad 0.4345 \mathrm{E}-13 \quad 0.9443 \mathrm{E}-15 \quad 0.2575 \mathrm{E}-22.0 .2788 \mathrm{E}-21$ . (1)

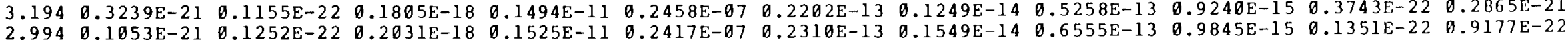

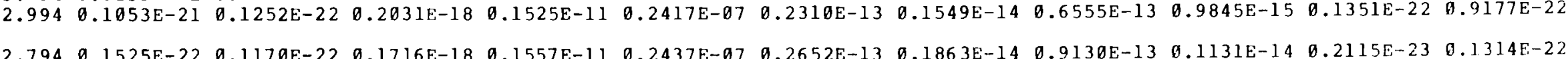

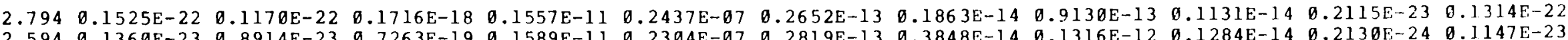

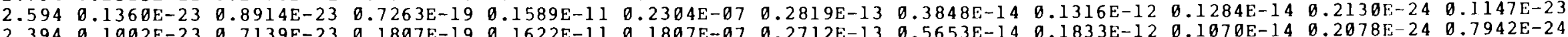

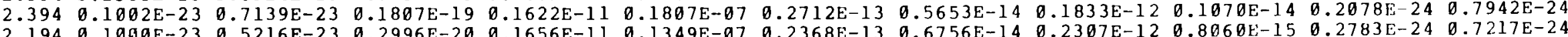
$\begin{array}{llll} & \end{array}$

$1.7940 .1000 \mathrm{E}-230.2186 \mathrm{E}-23 \quad 0.1000 \mathrm{E}-230.1727 \mathrm{E}-110.6969 \mathrm{E}-080.1394 \mathrm{E}-13 \quad 0.8064 \mathrm{E}-140.2883 \mathrm{E}-12 \quad 0.4927 \mathrm{E}-15 \quad 0.4719 \mathrm{E}-24 \quad 0.5281 \mathrm{E}-24$ $\begin{array}{llllll}1.59 & 0\end{array}$

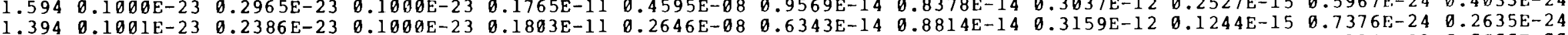

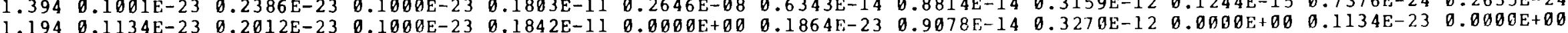

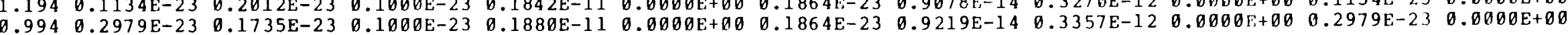


TABLE D-4 Continued

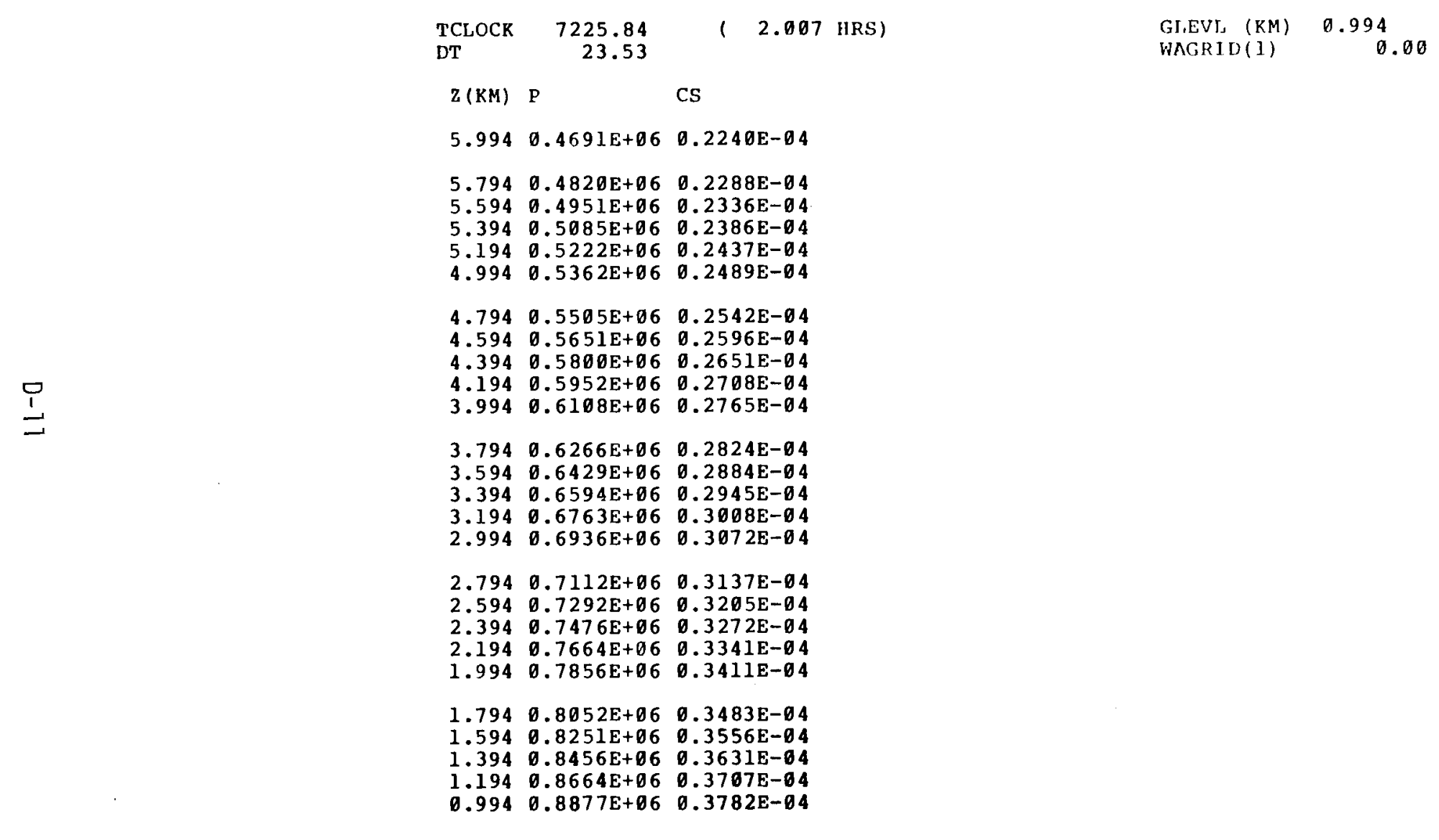




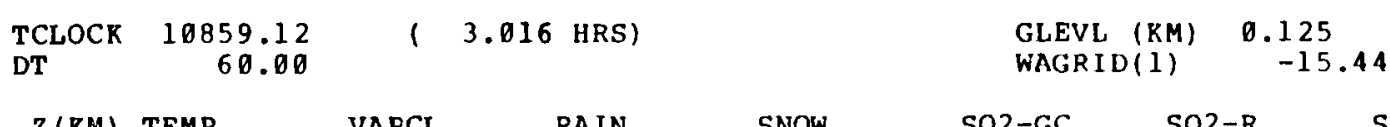

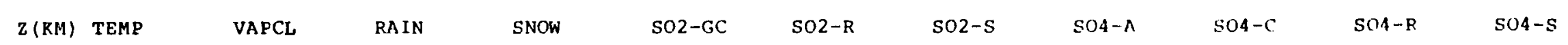

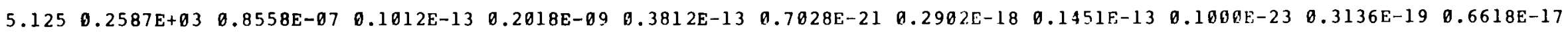

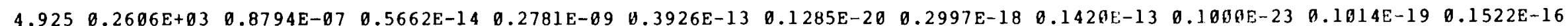

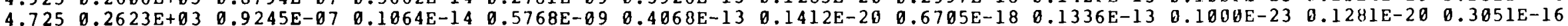

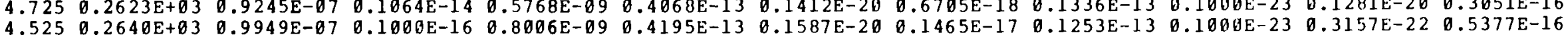

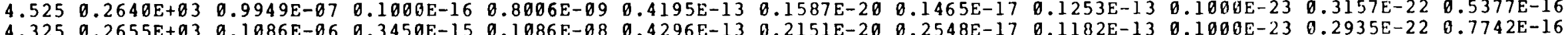

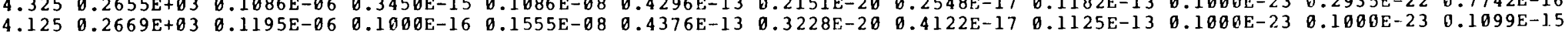

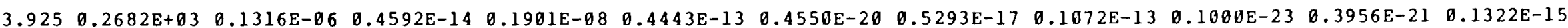

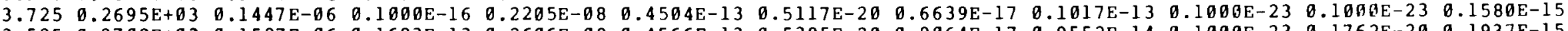

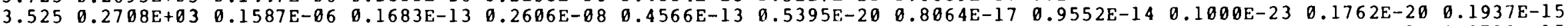

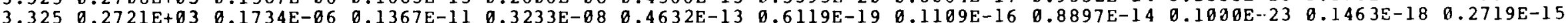

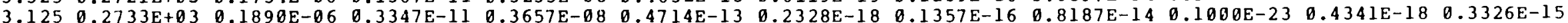

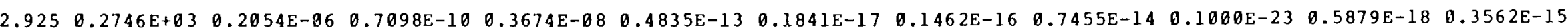

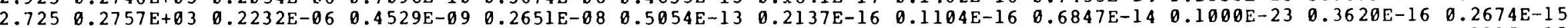

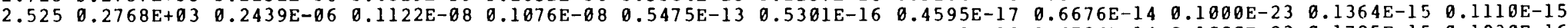

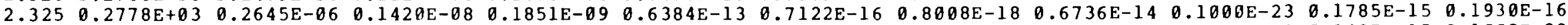

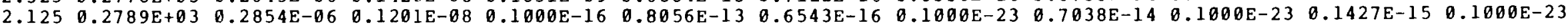

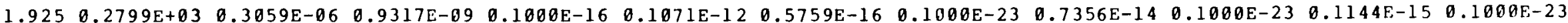

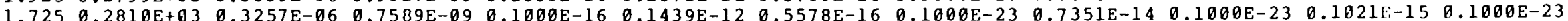

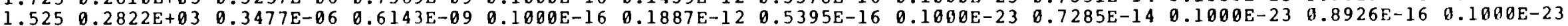

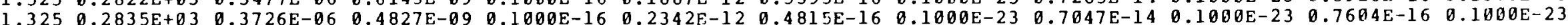

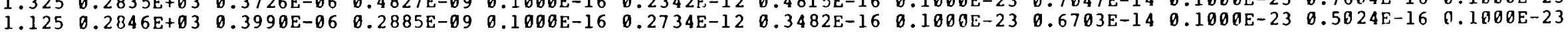

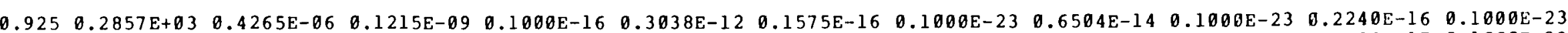

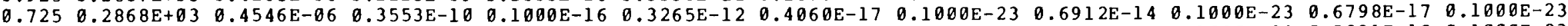

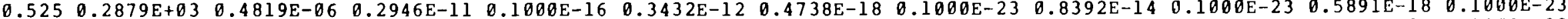

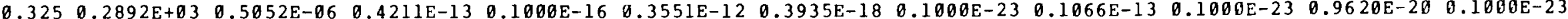

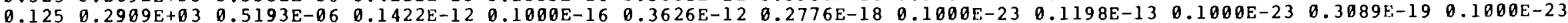




\section{TABLE D-5 Continued}
TCLOCK 10859.12
( $3.016 \mathrm{HRS}$ )
GI,EVL (KM)
0. 125
DT $\quad 60.00$
$\mathrm{H} 2 \mathrm{O} 2-\mathrm{R} \quad \mathrm{H} 2 \mathrm{O} 2-\mathrm{S}$
03-G
WAGRID (.1)
Z (KM) H2O2-GC
CLOUD
HION-C
HION-R
SO2-G
SO2-C
11202-G
$\mathrm{H} 2 \mathrm{O} 2-\mathrm{C}$

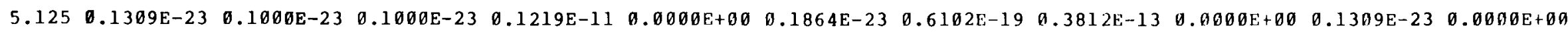

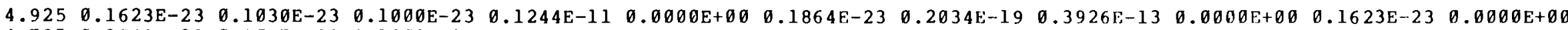

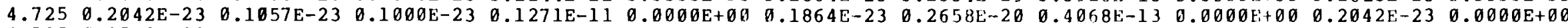

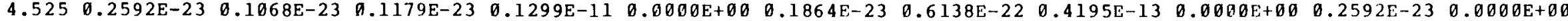

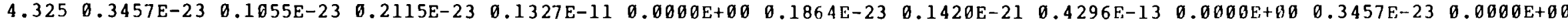

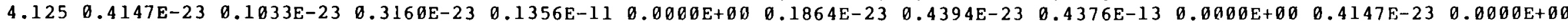

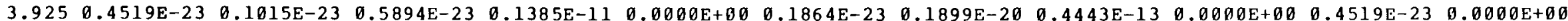

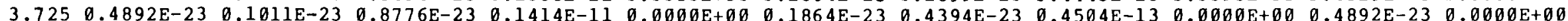

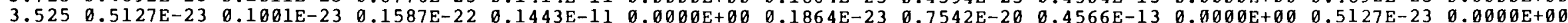

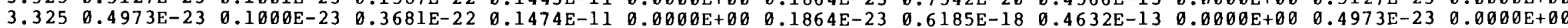

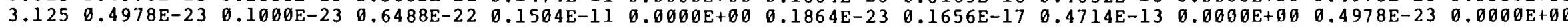

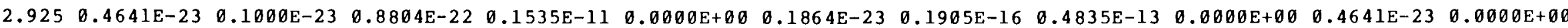

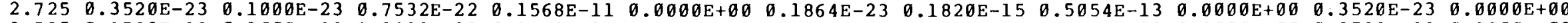

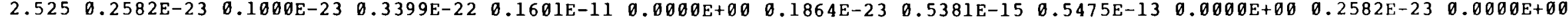

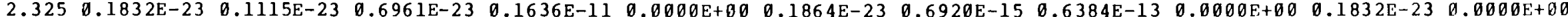

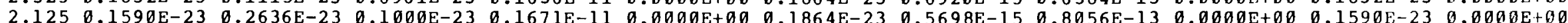

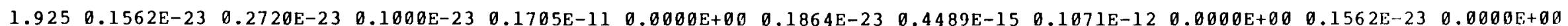

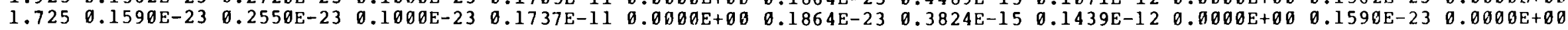

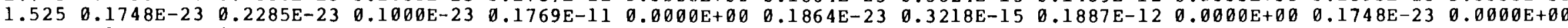

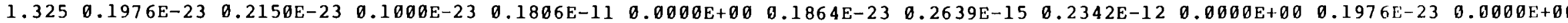

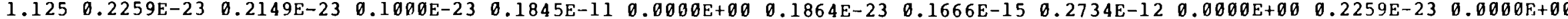

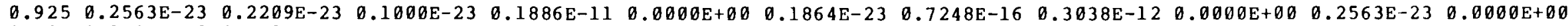

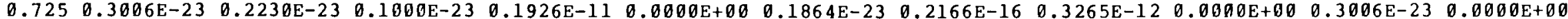

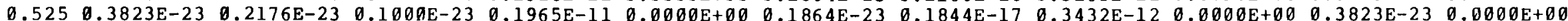

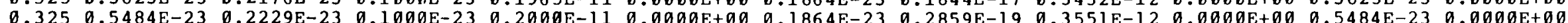

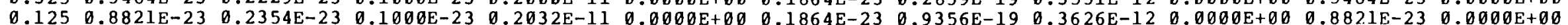


TABLE D-5 Continued

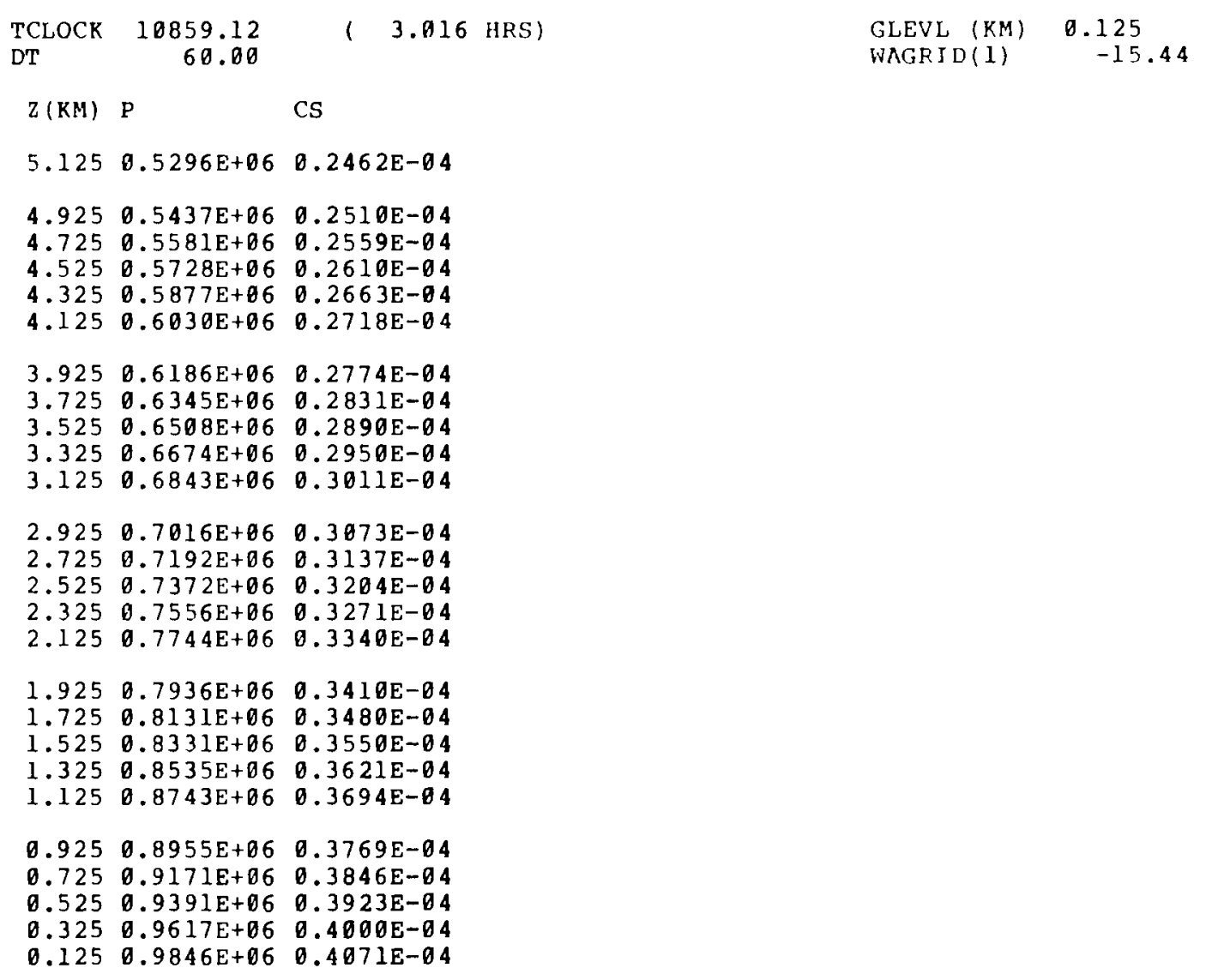


TABLE D-6. Example Application 2 Model Output at TCLOCK $=4$ Hours

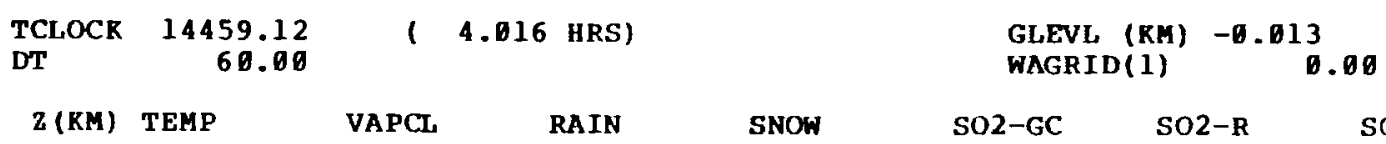

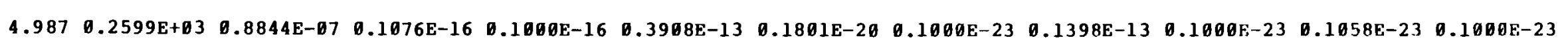

$4.787 \quad 0.2618 \mathrm{E}+03 \quad 0.9114 \mathrm{E}-07 \quad 0.1015 \mathrm{E}-16 \quad 0.1000 \mathrm{E}-16 \quad 0.4000 \mathrm{E}-13 \quad 0.2951 \mathrm{E}-20 \quad 0.1000 \mathrm{E}-23 \quad 0.1395 \mathrm{E}-13 \quad 0.1000 \mathrm{E}-23 \quad 0.1011 \mathrm{E}-23 \quad 0.1000 \mathrm{E}-23$ $4.587 \quad 0.2635 \mathrm{E}+03 \quad 0.9596 \mathrm{E}-07 \quad 0.1044 \mathrm{E}-16 \quad 0.1147 \mathrm{E}-14 \quad 0.4115 \mathrm{E}-13 \quad 0.4390 \mathrm{E}-20 \quad 0.4002 \mathrm{E}-23 \quad 0.1346 \mathrm{E}-13 \quad 0.1000 \mathrm{E}-23 \quad 0.1034 \mathrm{E}-23 \quad 0.7466 \mathrm{E}-22$ $4.3870 .2652 \mathrm{E}+03 \quad 0.1029 \mathrm{E}-06 \quad 0.1000 \mathrm{E}-16 \quad 0.4909 \mathrm{E}-14 \quad 0.4232 \mathrm{E}-13 \quad 0.6067 \mathrm{E}-20 \quad 0.1189 \mathrm{E}-22 \quad 0.1279 \mathrm{E}-13 \quad 0.1006 \mathrm{E}-23 \quad 0.1000 \mathrm{E}-23 \quad 0.4227 \mathrm{E}-21$ $4.187 \quad 0.2667 \mathrm{E}+03 \quad 0.1119 \mathrm{E}-06 \quad 0.1591 \mathrm{E}-16 \quad 0.4330 \mathrm{E}-12 \quad 0.4336 \mathrm{E}-13 \quad 0.7277 \mathrm{E}-20 \quad 0.9909 \mathrm{E}-21 \quad 0.1211 \mathrm{E}-13 \quad 0.1000 \mathrm{E}-23 \quad 0.1457 \mathrm{E}-23 \quad 0.3247 \mathrm{E}-19$

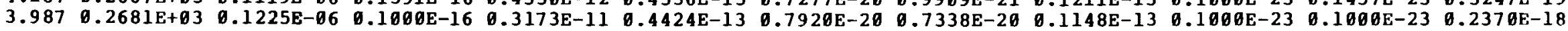

$3.787 \quad 0.2695 \mathrm{E}+03 \quad 0.1344 \mathrm{E}-06 \quad 0.9061 \mathrm{E}-16 \quad 0.1240 \mathrm{E}-10 \quad 0.4499 \mathrm{E}-13 \quad 0.8840 \mathrm{E}-20 \quad 0.2905 \mathrm{E}-19 \quad 0.1089 \mathrm{E}-13 \quad 0.1000 \mathrm{E}-23 \quad 0.7236 \mathrm{E}-23 \quad 0.8949 \mathrm{E}-18$ $3.5870 .2708 \mathrm{E}+03 \quad 0.1475 \mathrm{E}-06 \quad 0.1000 \mathrm{E}-16 \quad 0.6171 \mathrm{E}-10 \quad 0.4567 \mathrm{E}-13 \quad 0.9364 \mathrm{E}-20 \quad 0.1472 \mathrm{E}-18 \quad 0.1629 \mathrm{E}-13 \quad 0.1000 \mathrm{E}-23 \quad 0.1000 \mathrm{E}-23 \quad 0.4260 \mathrm{E}-17$

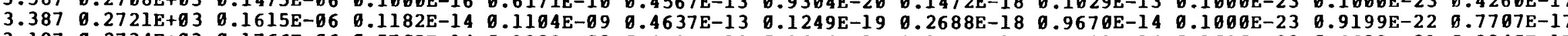

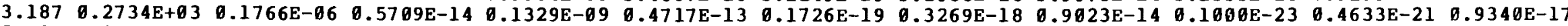
$2.9870 .2746 \mathrm{E}+030.1930 \mathrm{E}-66$ 0.1820E-12 0.1351E-69 0.4826E-13 0.3998E-19 0.3350E-18 0.8397E-14 0.1606E-23 $0.1420 \mathrm{E}-19$ 0.9542E-17

$2.7870 .2757 \mathrm{E}+03 \quad 0.2116 \mathrm{E}-06 \quad 0.1591 \mathrm{E}-11 \quad 0.9910 \mathrm{E}-10 \quad 0.5004 \mathrm{E}-13 \quad 0.1342 \mathrm{E}-18 \quad 0.2470 \mathrm{E}-18 \quad 0.7905 \mathrm{E}-14 \quad 0.1000 \mathrm{E}-23 \quad 0.1233 \mathrm{E}-18 \quad 0.7022 \mathrm{E}-17$

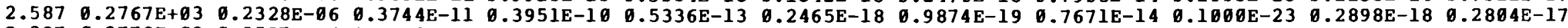

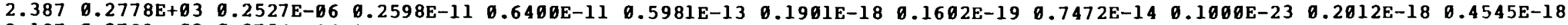
$2.1870 .2789 \mathrm{E}+030.2726 \mathrm{E}-66 \quad 0.7007 \mathrm{E}-120.1000 \mathrm{E}-160.7124 \mathrm{E}-13$ 0.1036E-18 $0.1000 \mathrm{E}-230.7433 \mathrm{E}-140.1000 \mathrm{E}-230.5384 \mathrm{E}-190.1000 \mathrm{E}-23$

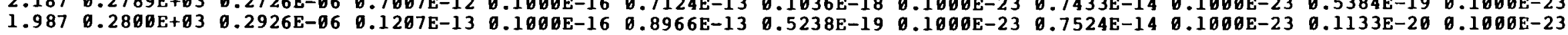

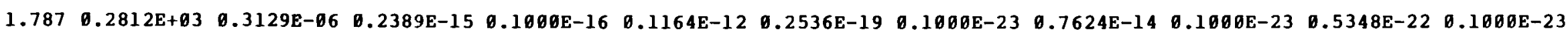

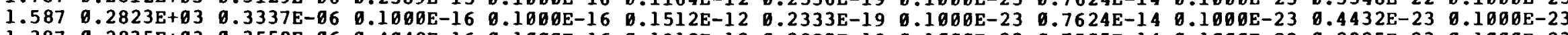

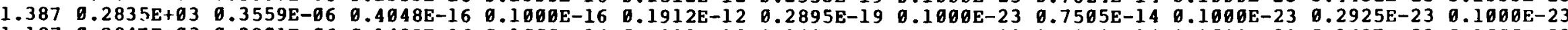

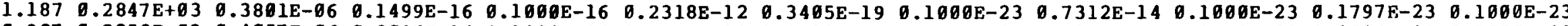

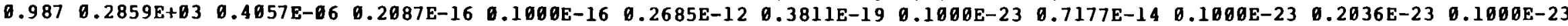

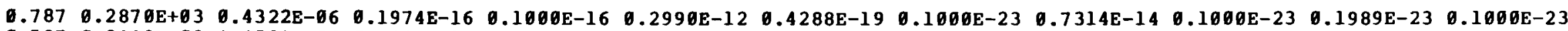

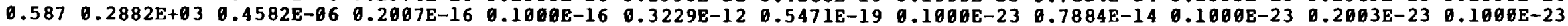

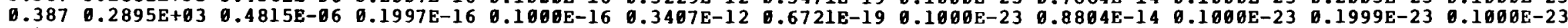

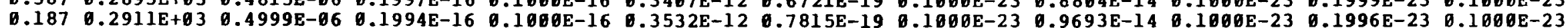

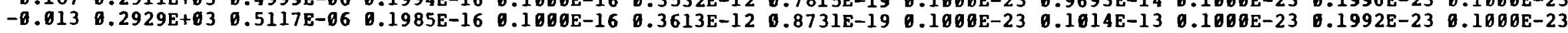




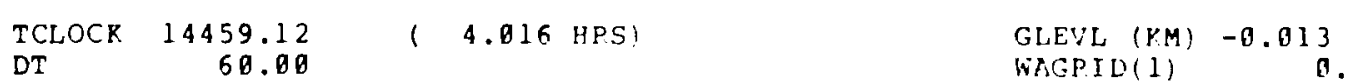

60.00

$\operatorname{MAGPID(1)} \quad-0.013$

$\mathrm{Z}(\mathrm{KH}) \mathrm{H2O2-GC}$ H2O2-R H2O2-S O3-G HOLD HIO:-C HION-R $\mathrm{R}$ SO2-G

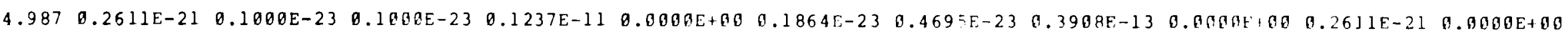

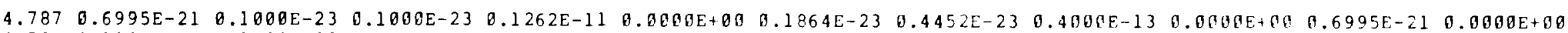

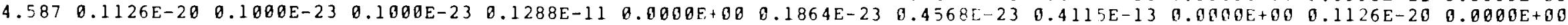

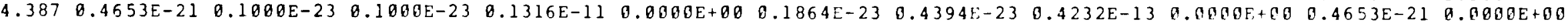

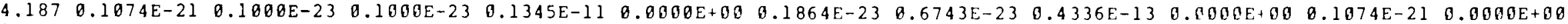

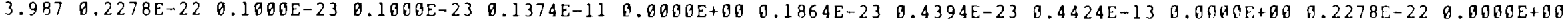

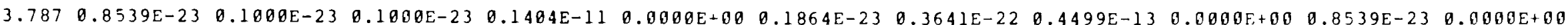

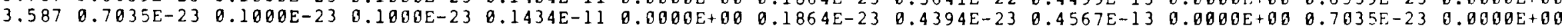

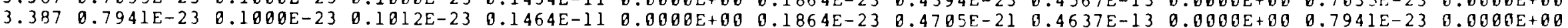

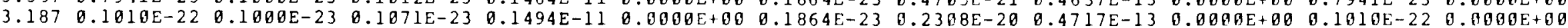

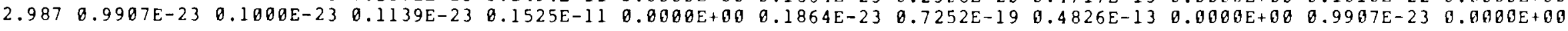

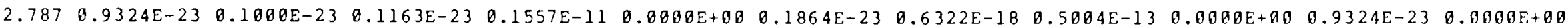

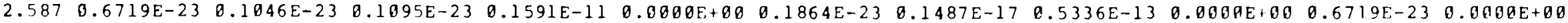

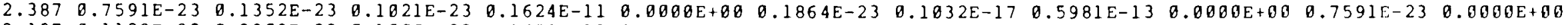

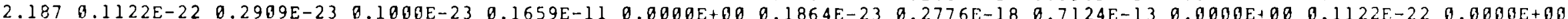

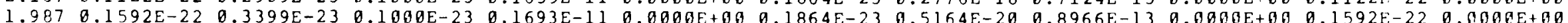

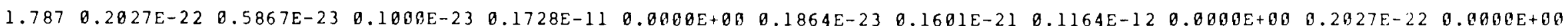

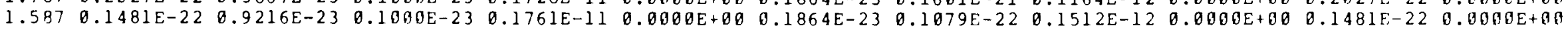

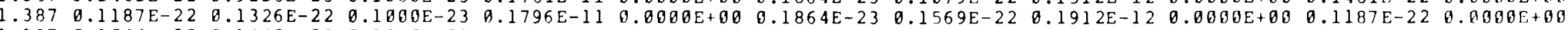

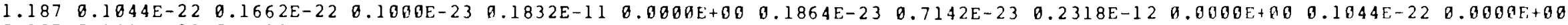

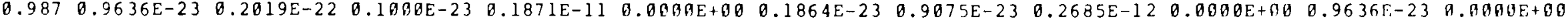

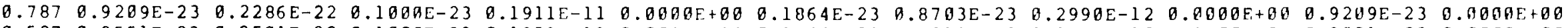

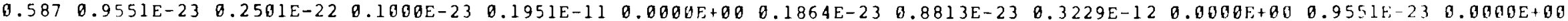

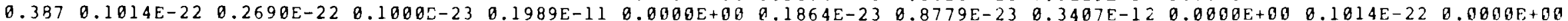

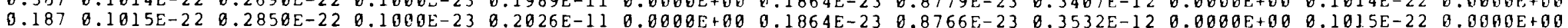

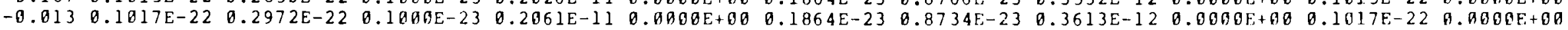




\section{TCLOCK 14459.12 \\ DT \\ 60.00 \\ Z (KM) P \\ CS \\ (4.016 HRS)}

$4.987 \quad 0.5397 \mathrm{E}+06 \quad 0.2498 \mathrm{E}-94$

$4.787 \quad 0.5540 \mathrm{E}+06 \quad 0.2545 \mathrm{E}-04$ $4.5870 .5686 \mathrm{E}+06 \quad 0.2595 \mathrm{E}-04$ $\begin{array}{lll}4.587 & 0.5686 \mathrm{E}+06 & 0.2595 \mathrm{E}-04 \\ 4.387 & 0.5835 \mathrm{E}+06 & 0.2647 \mathrm{E}-04\end{array}$ $4.1870 .5987 \mathrm{E}+06 \quad 0.2700 \mathrm{E}-04$ $\begin{array}{lll}4.187 & 0.5987 \mathrm{E}+06 & 0.2700 \mathrm{E}-04 \\ 3.987 & 0.6142 \mathrm{E}+06 & 0.2755 \mathrm{E}-04\end{array}$

$3.787 \quad 0.6300 \mathrm{E}+06 \quad 0.2812 \mathrm{E}-04$ $3.587 \quad 0.6462 \mathrm{E}+06 \quad 0.2869 \mathrm{E}-04$ $\begin{array}{lll}3.387 & 0.6626 \mathrm{E}+06 & 0.2929 \mathrm{E}-04\end{array}$ $3.187 \quad 0.6794 \mathrm{E}+06 \quad 0.2989 \mathrm{E}-04$ $2.987 \quad 0.6966 \mathrm{E}+06 \quad 0.3051 \mathrm{E}-04$

$2.787 \quad 0.7141 \mathrm{E}+06 \quad 0.3115 \mathrm{E}-04$ $2.587 \quad 0.7320 \mathrm{E}+06 \quad 0.3182 \mathrm{E}-04$ $2.3870 .7502 \mathrm{E}+060.3248 \mathrm{E}-04$ $\begin{array}{lll}2.387 & 0.7502 E+06 & 0.3248 \mathrm{E}-04 \\ 2.187 & 0.7689 \mathrm{E}+06 & 0.3315 \mathrm{E}-04\end{array}$ $\begin{array}{lll}2.187 & 0.7689 \mathrm{E}+06 & 0.3315 \mathrm{E}-04 \\ 1.987 & 0.7879 \mathrm{E}+06 & 0.3384 \mathrm{E}-04\end{array}$

$1.787 \emptyset .8073 \mathrm{E}+\emptyset 6 \quad 0.3453 \mathrm{E}-04$ $1.587 \quad 0.8271 \mathrm{E}+06 \quad 0.3524 \mathrm{E}-04$ $\begin{array}{lll}1.387 & 0.8474 \mathrm{E}+06 & 0.3595 \mathrm{E}-04\end{array}$ $1.187 \quad 0.8680 \mathrm{E}+06 \quad 0.3667 \mathrm{E}-04$ $0.987 \quad 0.8890 \mathrm{E}+\emptyset 6 \quad 0.3740 \mathrm{E}-04$

$0.787 \quad 0.9105 \mathrm{E}+06 \quad 0.3815 \mathrm{E}-04$ $0.587 \quad 0.9324 \mathrm{E}+\emptyset 6 \quad 0.3891 \mathrm{E}-04$ $0.387 \quad 0.9547 \mathrm{E}+06 \quad 0.3966 \mathrm{E}-04$ $0.187 \quad 0.9774 \mathrm{E}+06 \quad 0.4039 \mathrm{E}-04$ $\begin{array}{lll}0.013 & 0.1001 \mathrm{E}+07 & 0.4109 \mathrm{E}-04\end{array}$
GLEVL (KM) -0.013 WAGR I D ( 1 )

9.00 


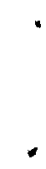

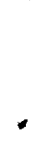

.

. 


\section{DISTRIBUTION}

No. of

Copies

\section{OFFSITE}

A. A. Churm

DOE Patent Division

9800 S. Cass Avenue

Argonne, IL 60439

27 DOE Technical Information Center

Dr. Elmar R. Al twicker

Dept. of Chem. Engr.

Rensselaer Polytechnic Inst.

Troy, NY 12181

Dr. David S. Ballantine

Physical \& Technological

Research Division ER-74

Office of Health and

Environmental Research

U.S. Department of Energy

Germantown

Washington, D.C. 20545

Dr. Leonard Barrie

Atmospheric Environment

Service

4905 Dufferin Street

Downsview, Ontario

Canada M3H 5T4

Dr. Jack Calvert

National Center for

Atmospheric Research

P.0. Box 3000

Boulder, CO 80302

Dr. Greg Carmichael

College of Engineering

125B Chemistry Building

University of Iowa

Iowa City, IA 52242
No. of

Copies

Dr. Julius Chang

National Center for

Atmospheric Research

P.0. Box 3000

Boulder, CO 80302

Dr. Robert Charlson

Dept. of Civil Engineering

University of Washington

Seattle, WA 98105

Dr. William R. Cotton

Atmospheric Sciences Dept.

Colorado State University

Fort Collins, CO 80523

10 Dr. Jack Durham

MD-57

Environmental Protection Agency/ESRL

Research Triangle Park NC 27711

Prof. James Galloway

Dept. of Environmental Sciences

Clark Hall

University of Virginia

Charlottesville, VA 22903

Donald Henderson

National Park Service

655 Parfet Street

P.0. Box 25287

Denver, CO 80225

Mr. Bruce Hicks, Director

Atmospheric Turbulence \&

Diffusion Laboratory

P.0. Box E

Oak Ridge, TN 37380

Dr. Glenn Hilst

Electric Power Research Inst.

P.0. Box 10412

Palo Alto, CA 94304 
ito. of

Copies

Dr. Larry Kleinman

Energy \& Environ. Bldg 051

Brookhaven National Laboratory

Upton, NY 11973

Dr. Dennis Lamb

Desert Research Institute

Sage Bldg. - Stead Campus

Reno, NV 89507

Dr. Al Lazrus

National Center for

Atmospheric Research

P.0. Box 3000

Boulder, CO 80302

Dr. Gene F. Likens, Director

Institute of Ecosysten Studies

New York Botanical Garden

Cary Arboretum

Box $A B$

Millbrook, NY 12545

Dr. Gregory J. McRae

Chenical Engineering

Carnegie-Mellon University

Schenley Park

Pittsburgh, PA 15213

Ur. Paul Michael

Energy \& Environment, B1dg. 051

Brookhaven National Laboratory

Uptori, NY 11973

Prof. Volker Mohrien

Atmospheric Sciences Research

Conter

SUNYY-ES-2A

1no() Washington Avemue

Mlbary, NY 17\%??

Irr. Peter Mueller

Plectric Power Research Inst.

P.o. Box 1041?

Palo Nito, CA 943014
No. of

Copies

Prof. Harry Orville

Institute of Atmosnheric Science

South Dakota School of Mines and Technology

Rapid City, SD 57701

Dr. Ari Patrinos

Energy \& Environment Bldg. 051

Brookhaven National Laboratory

Upton, NY 11973

Prof. Rosa dePena

Department of Meteorology

Pennsylvania State University

University Park, PA 16802

Dr. Len K. Peters

Dept. of Chemical Engineering

University of Kentucky

Lexington, KY 40506

Dr. Philip M. Roth

Creekside Center

7 Mount Lassen Drive

Suite 0126

San Rafael, CA 94903

Dr. Christian Segnieur

Systems Applications Inc.

950 Northqate Drive

San Rafael, CA 94903

Dr. John H. Seinfeld

Chemical Engineering

California Institute of

Technology

Pasadena, CA 91125

Dr. Richard i. Semonin

Illinois State Water Survey

P.0. Box 5050, Station $A$

Champaign, IL 618?0

Dr. Jack [0. Shannon

Argonne National Laboratory

9700 South Cass Bldg. 131

Argonne, IL 60439 
No. of

Copies

Mr. David H. Slade

Physical \& Technological

Research Division, ER-74

Office of Health and

Environmental Research

Department of Energy

Washington, DC 20545

\section{FOREIGN}

Willem Asman

Institute for Meteorology \& Oceanography

State U Utrecht

5 Princetonplein

3584 cc Utrecht

The Netherlands

Dr. Greg Ayers

CSIRO

Private Bag No. 1

Mordialloc, Vic 3195

Australia

Anton Eliassen

Norwegian Meteorological

Institute

P.0. Box 320

Blindern

Norway

Bernard Fisher

CEGB

Kelvin Avenue

Leatherhead, Surrey

England KT22 7SE

John Garland

AERE/Harwell

Oxfordshire

England OX11 ORA

Lennart Granat

Department of Meteorology

University of Stockholm

S-106 91 Stockholm

Sweden
No. of

Copies

Oystein Hov

Norwegian Institute for

Air Research

P. 0. Box 130

N-2001 Lillestrom

Elvegt. 52

Norway

Ivar Issacson

Oslo University

Os 10

Norway

Dr. Stuart Penkett

Environmental and Medical Sciences Division

AERE/Harwel 1

Oxfordshire

England 0X11 ORA

Dr. Lars Prahm

National Agency of Environmental

Protection

Air Pollution Laboratory

Ris $\varnothing$ National Laboratory

DK-4000 Roskilde

Denmark

Dr. Henning Rodhe

Stockholms Universitet

Arrheniuslaboratoriet

Meteorologiska institutionen

Fack

S-104 05 Stockholm

Sweden

Ruth Skarin

Stockholms Universitet

Arrhenius laboratoriet

Meteorologiska institutionen

Fack

S-104 05 Stockholm

Sweden 
No. of

Copies

Dr. Sjaak Slanina

ECN Netherlands Energy Research Foundation

P.0. Box 1

1755 2G Petten

The Netherlands

Dr. Hilding Sundquist

Stockholms Universitet

Arrheniuslaboratoriet

Meteorologiska institutionen

Fack

S-104 05 Stockholm

Sweden

\section{ONSITE}

DOE Richland Operations Office

H. E. Ransom

53 Pacific Northwest Laboratory
A. Alkezweeny
C. Berkowitz
E. Chapman
T. Dana
C. Doran
J. Droppo
R. Easter (15)
R. Hadlock
J. Hales (15)
T. Horst
N. Laulainen
C. Lindsey
D. Luken
W. Pennell
B. Scott
G. Slinn
L. Wendel1
D. Whi teman
Publishing Coordination (2)
Technical Information (5) 